\title{
Integrated approaches of social-ecological resilience assessment and urban resilience management
}

Resilience thinking, transformations and implications for sustainable city development in Lianyungang, China

Dissertation

zur Erlangung des mathematisch-naturwissenschaftlichen Doktorgrades

"Doctor rerum naturalium"

der Georg-August-Universität Göttingen

im Promotionsprogramm Geographie

der Georg-August University School of Science (GAUSS)

vorgelegt von

Yi Li

aus Changsha, China

Göttingen 


\section{Betreuungsausschuss:}

Prof. Dr. Martin Kappas: Abt. Kartografie, GIS und Fernerkundung, Institut für Geographie der Universität Göttingen

Prof. Dr. Heiko Faust: Abt. Humangeographie, Institut für Geographie der Universität Göttingen

\section{Mitglieder der Prüfungskommission}

Referent/in: Prof. Dr. Martin Kappas -- Abt. Kartografie, GIS und Fernerkundung, Institut für Geographie der Universität Göttingen

Korreferent/in: Prof. Dr. Heiko Faust -- Abteilung Humangeographie, Institut für Geographie der Universität Göttingen

Weitere Mitglieder der Prüfungskommission:

1. Prof. Dr. Daniela Sauer -- Abteilung Physische Geographie, Institut für Geographie der Universität Göttingen

2. Prof. Dr. Renate Bürger-Arndt -- Abteilung Naturschutz und Landschaftspflege, Burckhardt-Institut der Fakultät für Forstwissenschaften und Waldökologie der Universität Göttingen

3. Prof. Dr. Hans Ruppert -- Abteilung Sedimentologie \& Umweltgeologie, Geowissenschaftliches Zentrum der Universität Göttingen

4. Prof. Dr. Christoph Dittrich -- Abteilung Humangeographie, Institut für Geographie der Universität Göttingen

Tag der mündlichen Prüfung: 2016.02.03 


\section{Contents}

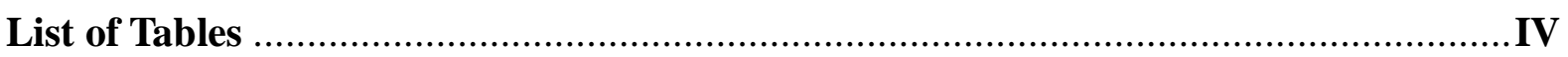

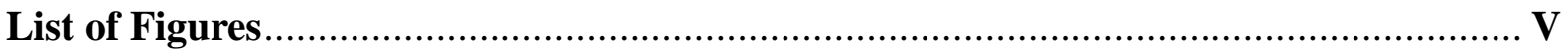

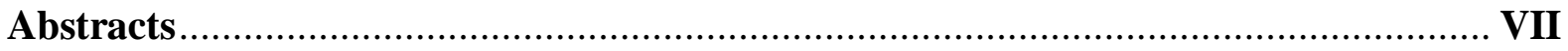

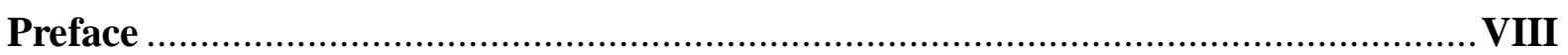

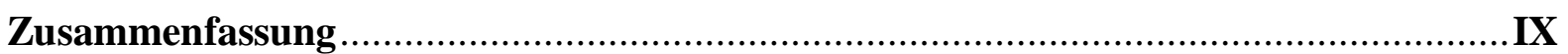

Acknowledgements....................................................................................................

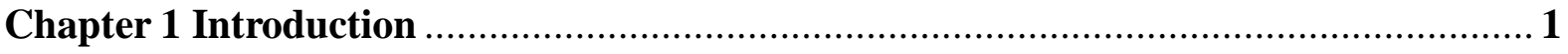

1.1 Essential Concepts of Resilience Theory …………………................................... 1

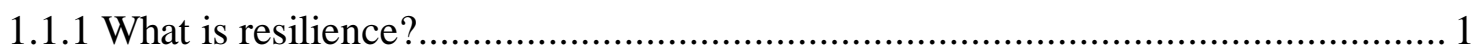

1.1.2 Resilience thinking ................................................................................ 2

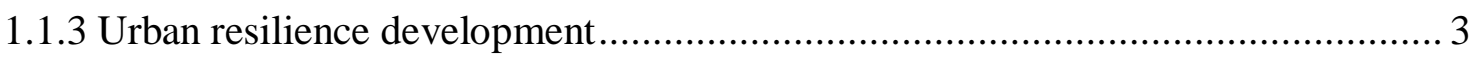

1.1.4 Thresholds \& Tipping point ......................................................................

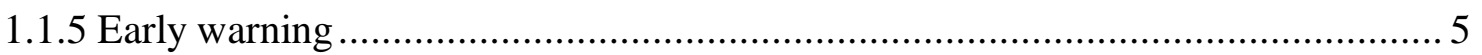

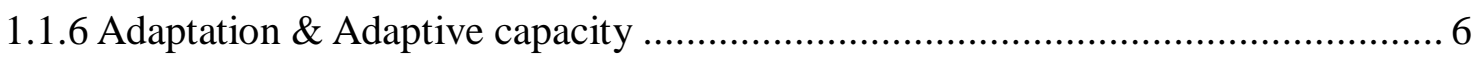

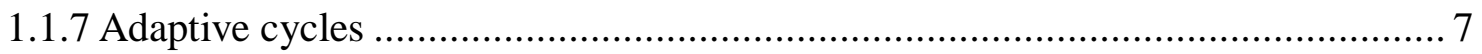

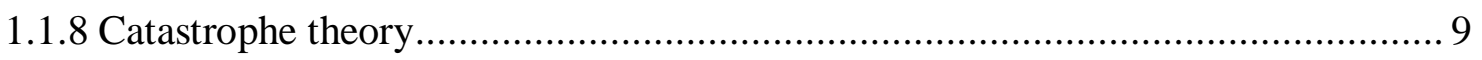

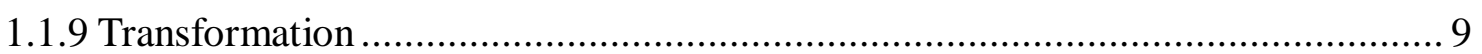

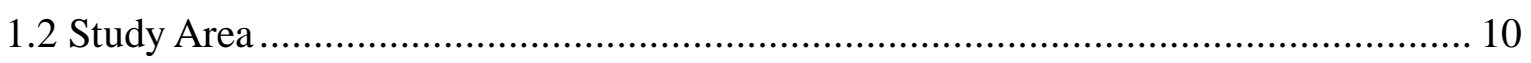

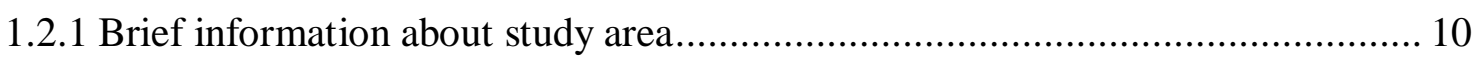

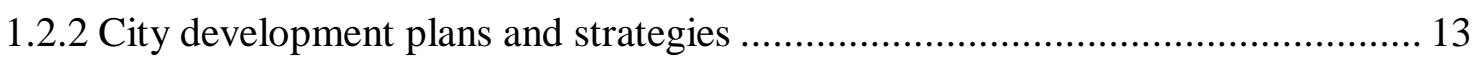

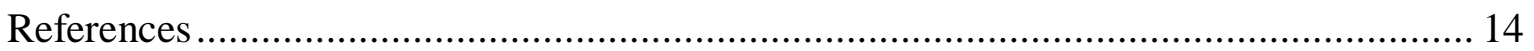

Chapter 2 Resilience Assessment of Human-Environment Systems .............................. 19

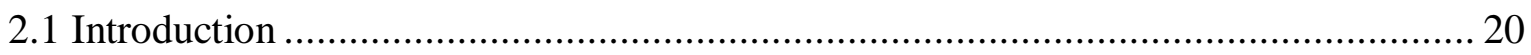

2.2 Methodological Framework for Deriving Resilience Assessments............................ 21

2.2.1 Available data and development of combined indices for Lianyungang area ...... 22

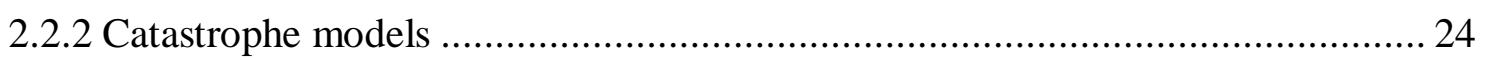

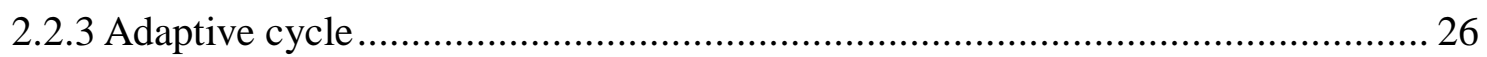

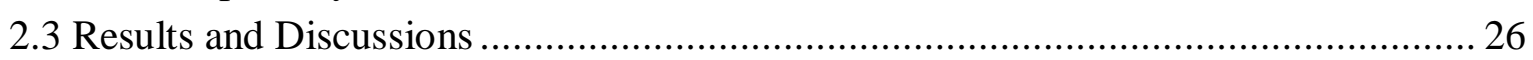

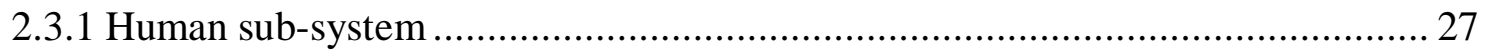

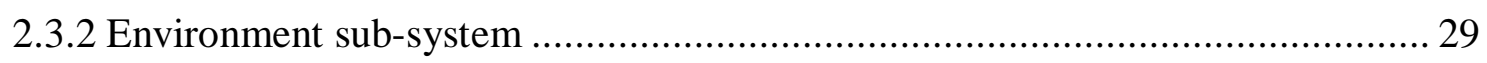

2.3.3 Social-ecological systems approach ................................................................ 30

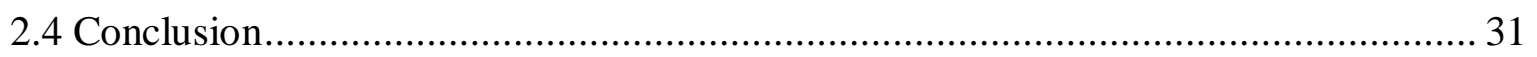

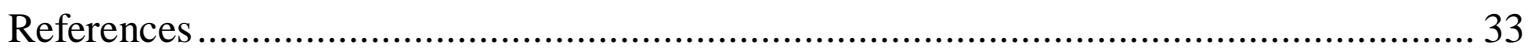

Chapter 3 Resilience Assessment of Social-Ecological Systems....................................... 35 


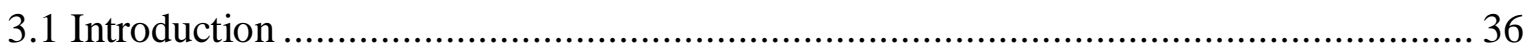

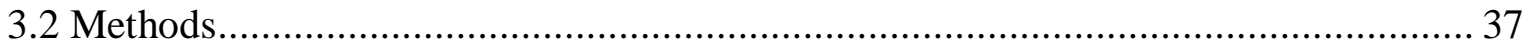

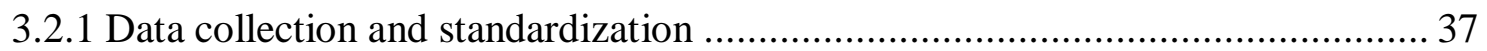

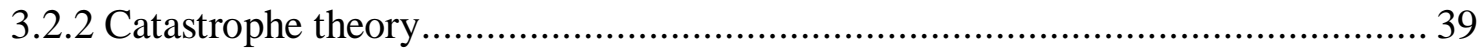

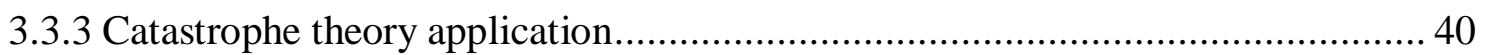

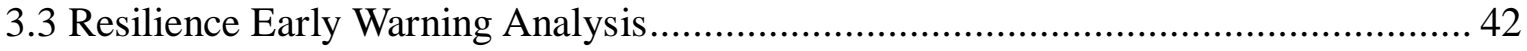

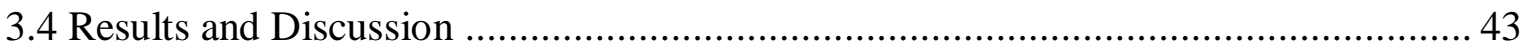

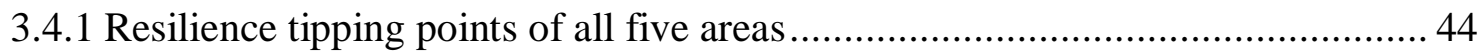

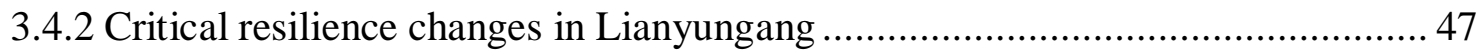

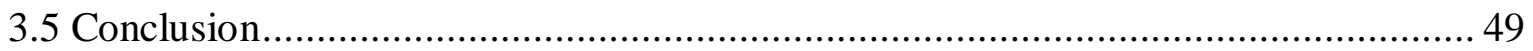

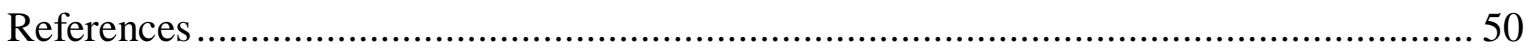

Chapter 4 Ecological Resilience Assessment ….......................................................... 53

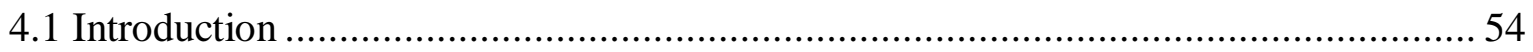

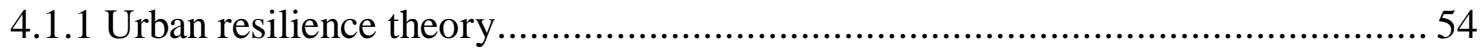

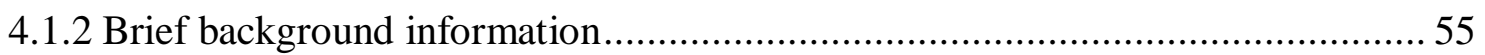

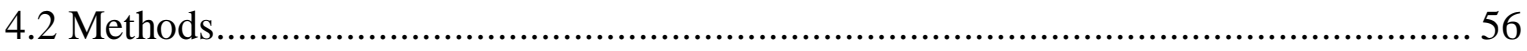

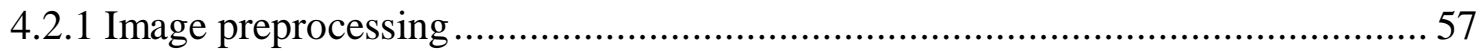

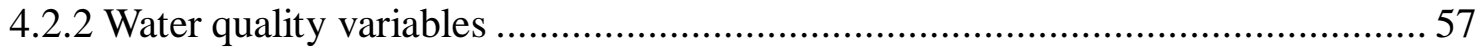

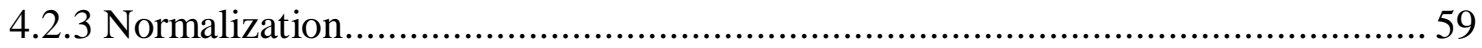

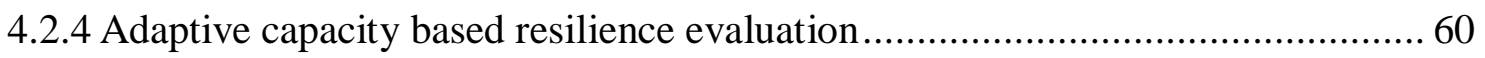

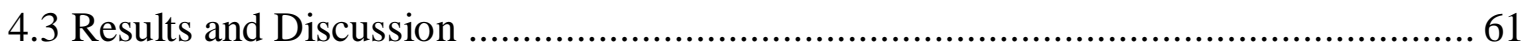

4.3.1 Water quality of different landscapes ........................................................ 61

4.3.2 Resilience results between different land use types and water quality variables.. 64

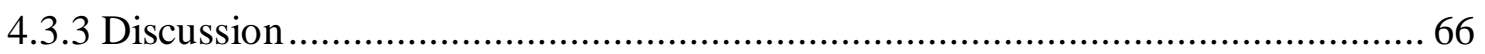

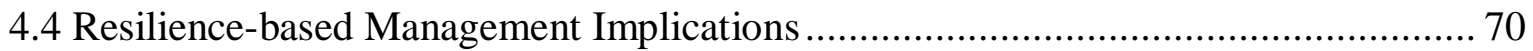

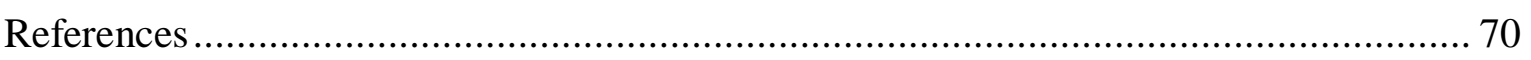

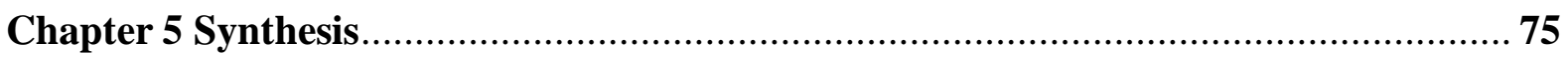

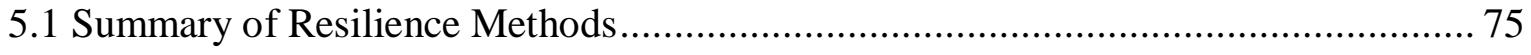

5.1.1 Catastrophe models \& Adaptive capacity model .............................................. 75

5.1.2 Early warning model \& Adaptive cycles .................................................... 77

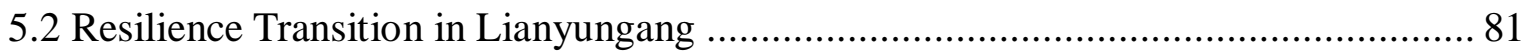

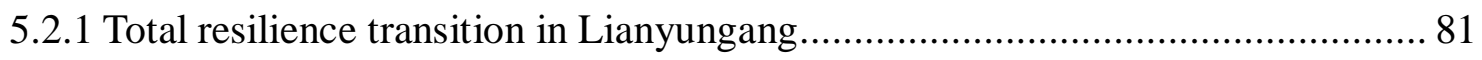

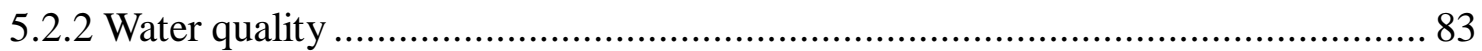

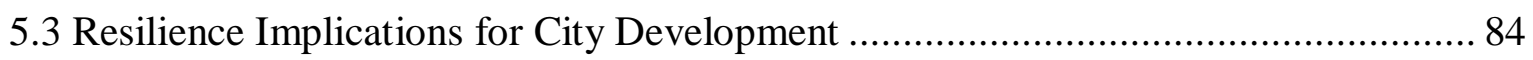

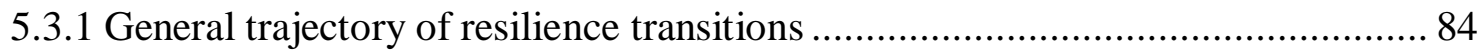

5.3.2 Decoupling resilience between urban development and environment quality ..... 86

5.3.3 Resilience-based management and policy intervention ................................ 87

5.3.4 Adaptive management-learning and creating opportunity................................ 90

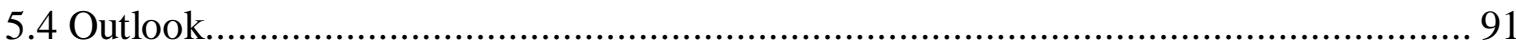

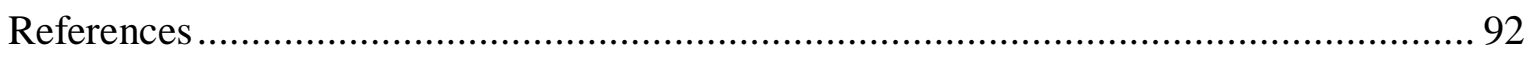

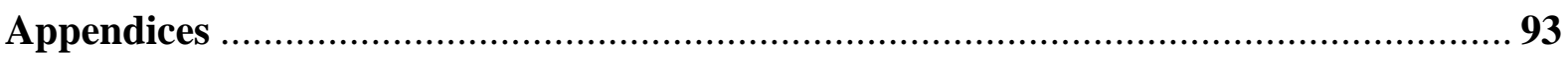




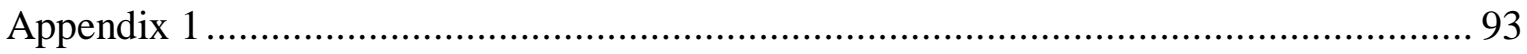

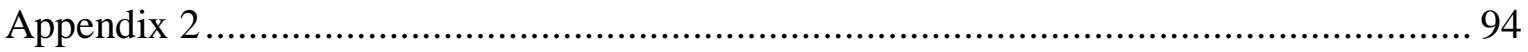

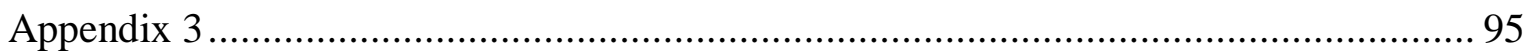

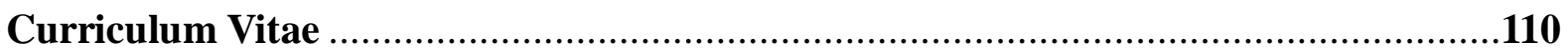




\section{List of Tables}

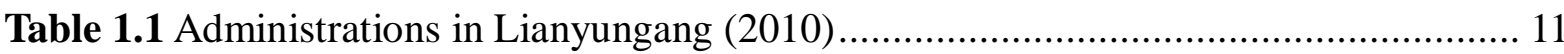

Table 2.1 Resilience sub-systems and indicators for Lianyungang ................................ 22

Table 2.2 Corresponding grade values of catastrophe models ...................................... 25

Table 3.1 Resilience sub-systems and indicators for Lianyungang ................................. 38

Table 3.2 Statistical data of Social-1 sub-system in central district (central, 2002) ............ 41

Table 4.1 Environmental Quality Standard value for Surface Water ................................ 59

Table 5.1 Comparison of catastrophe models and adaptive capacity ................................ 75

Table 5.2 Comparison of early warning model and adaptive cycles ................................ 78

Table S1 Pearson correlation coefficients between landscape metrics and water quality in the center, inner, and outer peri-urban layers for 2000 97

Table S2 Pearson correlation coefficients between landscape metrics and water quality in the center, inner, and outer peri-urban layers for 2004 98

Table S3 Pearson correlation coefficients between landscape metrics and water quality in the center, inner, and outer peri-urban layers for 2008 99

Table S4 Fitting Model and Threshold of PLAND and Water Quality Variables 104

Table S5 Fitting Model and Threshold of PD and Water Quality Variables 105

Table S6 Fitting Model and Threshold of ED and Water Quality Variables ...................... 106

Table S7 Fitting Model and Threshold of COHESION and Water Quality Variables ......... 107

Table S8 Fitting Model and Threshold of SHAPE_AM and Water Quality Variables........ 109 


\section{List of Figures}

Fig.1.1 Essential concepts of resilience theory …...................................................... 1

Fig.1.2 Four-stage development of urban resilience ....................................................... 4

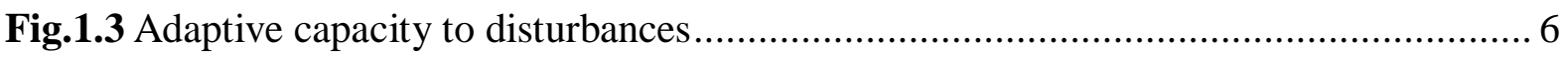

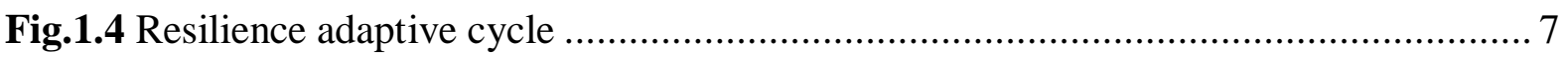

Fig.1.5 Representation of scales in Panarchy …...................................................... 8

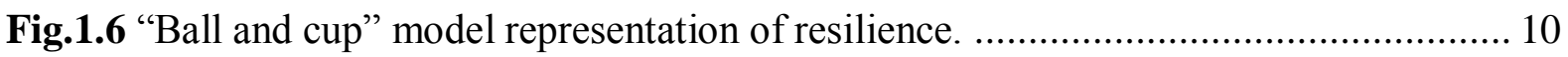

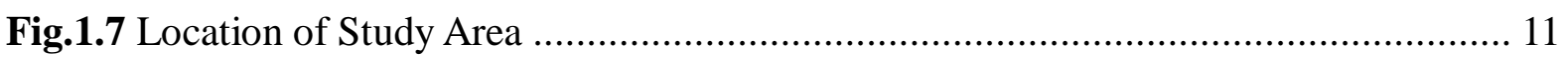

Fig.1.8 Rapid development in Lianyungang ........................................................... 12

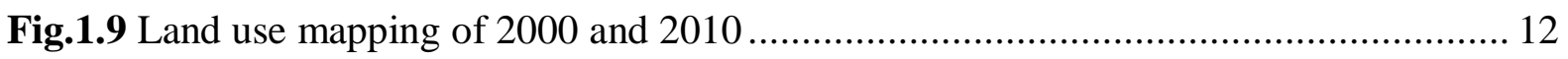

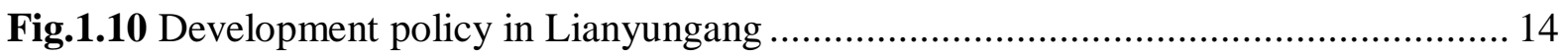

Fig.2.1 Analytical processes for human-environment resilience................................... 21

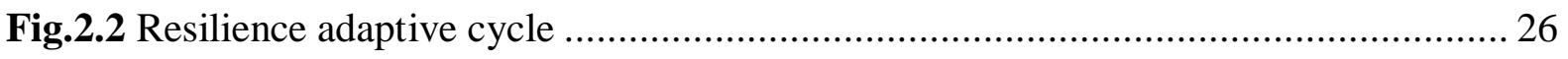

Fig.2.3 Resilience trends of the human-1 sub-system (2000-2010) ................................. 27

Fig.2.4 Resilience trends of the human-2 sub-system (2000-2010) ................................. 28

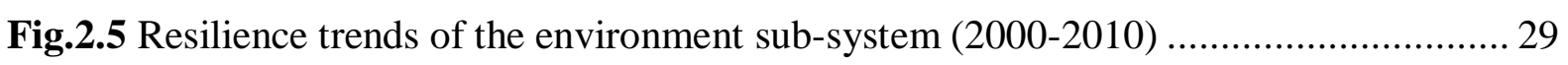

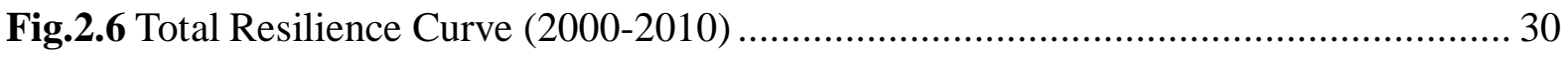

Fig.3.1 Flowchart of social-ecological resilience assessment model ................................. 37

Fig.3.2 Evaluating social-ecological resilience in probability distribution equilibria ........... 43

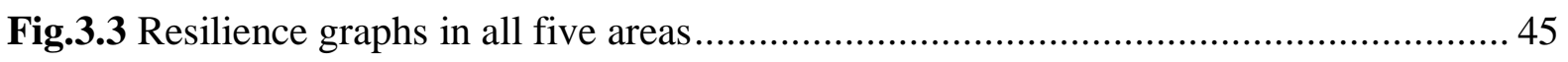

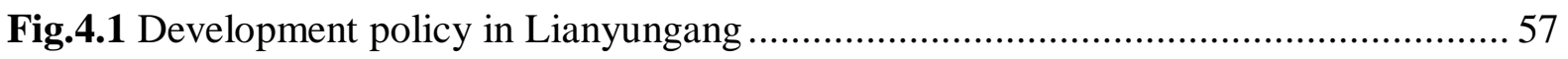

Fig.4.2 Typical resilience performance to disturbances and resilience measurement ............ 61

Fig.4.3 Spatial distribution of Water Comprehensive Pollution Index (2000 and 2010)....... 63

Fig.4.4 Resilience value of five significant water quality variables in built-up land from 2000 to 2010 64

Fig.4.5 Resilience value of five significant water quality variables in bare land from 2000 to 2010 65 
Fig.4.6 Resilience value of five significant water quality variables in agricultural land from 2000 to 2010 66

Fig.4.7 Resilience timeline with regional and national policies 69

Fig.5.1 Resilience transformation phases during 2000-2010 82

Fig.5.2 Landscape and water quality management with threshold models 87

Fig.5.3 Resilience-based management framework 89

Fig.S1 Catastrophe progression model for the Social-Ecological System. 93

Fig.S2 Resilience graphs in all five areas 94

Fig.S3 Mapping correlation analysis of landscape metrics and water quality parameters at the $0.01 \mathrm{p}$ level 96

Fig.S4 Change in water quality variables in 2000, 2004 and 2008 103

Fig.S5 Scatter plot and regression lines between CA and water quality variables 103 


\begin{abstract}
s
The urban system is a multi-interaction system, due to the rapid urbanization and intertwined vulnerability of the ecological system. It will be a challenge to maintain a sustainable development of the urban and urbanizing areas (peri-urban areas). Resilience provides an approach for understanding how urban social-ecological systems adapt to disturbances like water or air pollution. To cope with these disturbances, a resilience-based management can operationalize and promote guiding principles for city development. The purpose of this thesis is to combine different quantitative approaches to calculate and assess resilience in the city of Lianyungang. This research calculates resilience with the social and ecological indicators based on two different theories: catastrophe models and adaptive capacity. Based on the output of these two theories, transformation processes are then illustrated by using early warning and adaptive cycle models. Specifically, resilience transitions between different landscape patterns and water quality variables are illustrated and their trajectories in relation to urban development strategies are detected.

The results suggest a positive resilience trend and an adaptive development in Lianyungang during 2000-2010. However, the early warning model suggests a tipping point in 2009, where its signal hits a critical mark, which would imply a "Less Resistant" state. Furthermore, it reveals the decoupling of urban development and water quality. $\mathrm{NH}_{3}-\mathrm{N}$, Cadmium and Total Phosphorus experienced the most resilient shifts under rapid urbanization, which points out a direction for future water quality management. National and regional planning practices contribute to manage the ongoing shifts in different resilient transition states. This implication can help to develop and enhance further city plans. Ultimately, this thesis provides the political underpinnings for building and managing resilient urban system in a particular coastal urban setting.
\end{abstract}

Keywords: catastrophe model; early warning; tipping point/threshold; adaptive capacity; urban resilience; social-ecological resilience; water quality 


\section{Preface}

Resilience thinking arose in conjunction with ideas behind sustainability discourse, and it provides a lens to understand the adaptive capacity of a system to absorb perturbations. Resilience-based management is the key pathway to the sustainability in social-ecological systems. It focuses on exploring mechanisms and theories to navigate resilience changes, and those changes are integrated with continuously uncertainty. However, current approaches of resilience assessment focus on theory and knowledge, and have only started to explore potential methods in recent years. This study explores the resilience transformations in both social and ecological sub-systems, which includes resilience trajectory alterations and regime shifts. Resilience adjustment of institutional structures and management strategies are two focal aspects for future resilience management.

In this thesis, there are three steps taken to present a framework for resilience thinking and assessment in complex adaptive systems. Chapter 1 is the first step as a foundation for understanding the basic theories and critical concepts of resilience, which support resilience analysis through the whole study. The second step outlines the core of the approach with three manuscripts from Chapter 2 to Chapter 4. Chapter 2 and 3 analyze the social-ecological resilience transition through different approaches, and identify essential factors in relation to resilience changes. Chapter 4 investigates the specific ecological resilience between landscape patterns and water quality variables. This step demonstrates different perspectives of resilience in the linked systems of humans and nature. It develops a framework to illustrate how resilience thinking might be applied to address challenges in the integrated systems, and how the systems adapt to those challenges or transform within a safe operating space. Chapter 5 is the third step, discussing the highlights of different theories and methods used in this thesis; it addresses the resilience trajectory and transition based on key factors and city development plans. This chapter explains: How might a resilience approach be put into operation with uncertainty changes? What are the feedbacks and responses to resilience change while maintaining a system's function? What are the implications for management of urban social-ecological systems and development policy? 


\section{Zusammenfassung}

Im Zusammenhang des Diskurses der Nachhaltigkeit erwuchs der Ansatz des ResilienzDenkens, welches die Grundlage zum Verständnis von anpassungsfähigen Systemen bildet, die in der Lage sind Störungseinflüsse zu berücksichtigen.

Die Stabilität von sozial-ökologischen Systemen basiert auf dem Wege eines ResilienzManagements. Der Fokus dieses Managements befasst sich mit spezifischen Merkmalen bzw. mit Einflussgrößen eines komplexen sozial-ökologischen Systems, mit dem Ziel anwendbare Richtlinien zu schaffen und Vorhersagen zu potenziellen Gefahren und Schwachstellen urbaner Systeme treffen zu können. Jedoch befassen sich aktuelle Ansätze des Resilienz-Managements eher mit theoretischen Grundlagen und erst in den letzten Jahren wurde damit begonnen, potentielle Anwendungsmethoden zu erkunden. Ziel dieses Ansatzes ist die veränderbare Anpassungsfähigkeit und die Widerstandsfähigkeit von sozial-ökologischen Systemen. Im Rahmen dieser Doktorarbeit wurde die sozial-ökologische (bzw. Mensch-Umwelt) Dynamik unter Verwendung verschiedener Modelle für das Gebiet Lianyungang analysiert und quantifiziert. Die Arbeit befasst sich insbesondere mit dem Mechanismus und der Theorie steuerbarer Widerstandsfähigkeit welche Unsicherheiten und einem ständigen Wandel unterworfen sind. Resilienz in dieser Arbeit berücksichtigt das Konzept der sog. "adaptive capacity" um sowohl Störungseinflüsse zu berücksichtigen und Veränderungen zu integrieren, ohne dabei jedoch die Konfigurationen des ursprünglichen Systems zu verändern. Die vorliegende Studie befasst sich mit Transformationen der Widerstandsfähigkeit sowohl sozialer als auch ökologischer Sub-Systeme, welche eine Veränderung im Verlauf der Resilienz unter Beobachtung von Regimeveränderungen und deren Feedbacks berücksichtigt. Die Anpassung der Resilienz an institutionelle Strukturen und Management Strategien stellen zwei der Hauptaspekte für ein zukünftiges Resilienz-Management dar.

In dieser Arbeit werden drei Schritte des aktuellen Frameworks für Resilienz Konzepte berücksichtigt und im Rahmen eines komplexen adaptiven Systems bewertet. Im ersten Kapitel werden als erster Schritt das Verständnis zu den grundlegenden Theorien dargestellt, sowie die wichtigsten Konzepte der Resilienz erörtert. Der zweite Schritt umfasst den Kern der Arbeit mit drei Manuskripten in den Kapiteln zwei bis vier. In den Kapiteln zwei und drei werden Verschiebungen der sozial-ökologischen Widerstandsfähigkeit behandelt. Kapitel vier beschreibt die spezifischen ökologischen Zusammenhänge zwischen Landschaftsmustern und Variablen zur Wasserqualität. In diesem Schritt werden zudem unterschiedliche Perspektiven der Resilienz im Verbundsystem Mensch-Umwelt dargestellt. Der hierfür entwickelte Rahmen zeigt wie resilientes Denken für Herausforderungen in integrierten Systemen angewandt werden kann und wie sich diese Systeme an diese Veränderungen anpassen bzw. innerhalb sicherer Bereiche verschieben lassen. Der letzte Schritt, welcher die Aspekte unterschiedlicher Methoden und Theorien behandelt, die in dieser Arbeit zur Anwendungen kommen wird in Kapitel fünf diskutiert. Des Weiteren werden hier Entwicklungspfade und Verschiebungen auf Grund von Schlüsselfaktoren sowie Stadtentwicklungsplänen beschrieben. Dies zeigt: Inwieweit ein Resilienzansatz innerhalb von Unsicherheitsverschiebungen operational genutzt 
werden kann? Welche Reaktionen auf Veränderungen der Resilienz angemessen sind, ohne die Funktionen des Systems negativ zu beeinflussen? Welche Auswirkungen ergeben sich daraus für das Management urbaner sozial-ökologischer Systeme und Entwicklungspolitik? 


\section{Acknowledgements}

This thesis would not have been possible without the help of numerous people. First of all, I would like to thank my supervisor Professor Martin Kappas for his consistent support with both guidance and freedom to explore my topics. Even though my interesting topics are not what he works on, he still helped me to find some other researchers who could give suggestions. I would like to thank my master supervisor Dr. Yangfan Li at Xiamen University for his valuable feedbacks and inspirations to improve the direction of the study. He provided valuable comments on earlier versions of manuscripts as it began to take shape. Likewise, I would also like to thank Matthew Gaudreau at University of Waterloo. He was kind enough to provide very helpful comments and check language for the manuscripts, and paid great attention to detail. He also helped to find out the vital information from some Chinese documents. I am also indebted to the members of our department who have taken the time to listen to and comment on my topic at various stages. Dr. Jan Degener was always willing to help me, he gave me a lot of guidance since I started to write this thesis; He was also kind and patient to help me to solve all my problems, even for my stupid questions, he always explained them until I understand. I would also like to thank Alexander Winz for his help with GIS technical advices related to the manuscripts, helped me to save a lot time with those problems. Dr. Isabelle Matthias helped a lot since the very beginning of writing this thesis, she was always willing to help me with different questions and translated the Abstract of this thesis into German. Many thanks to others members in our department, they also helped me during my study here. Special thanks to Professor Salman Qureshi at Humboldt-Universität, Professor Klaus Hubacek at University of Maryland, Professor Wei Wu at University of Southern Mississippi, Dr. Peilei Fan at Michigan State University; they are co-authors of related papers and manuscripts, thanks for their contributions. Thanks to Svenja and Emmy for their professional suggestions for improving the statistical methods.

In addition, many thanks to my best friend Deng Chaolian for her support, care and readiness to help, I am extremely grateful. We have known each other since 2005, and no matter how busy she is, she talks to me every day just want to make sure everything is fine here. She is the first one I want to talk with whenever I have problem, even though she might not able to help me. Also many thanks to my best friends Xiang Wenhua and Lu Jia, they always support me and think for me, even we are far away from each other. As well as my friends in Goettingen, I would like to thank Qi Jing and Ariane for their help and supports, which was always appreciated. Our regular girls talking time together really helped me to relieve pressure. Thanks to my flat mates Svenja and Kyra, we had great time living together. Finally, I would like to thank my parents and my brother for their greatest love and moral support, I won't able to finish my study without them. As well as the support from my aunties and uncles are also very much appreciated.

Thanks to all! 


\section{Chapter 1 Introduction}

\subsection{Essential Concepts of Resilience Theory}

Resilience becomes an increasingly relevant scientific approach to deal with the interwoven and complex systems of humans and nature through several key concepts (Fig.1.1). This section introduces the key resilience concepts that are used in this thesis.

\subsubsection{What is resilience?}

"Resilience is the capacity of a system, be it an individual, a forest, a city or an economy, to deal with change and continue to develop. It is about the capacity to use shocks and disturbances like a financial crisis or climate change to spur renewal and innovative thinking." (Stockholm Resilience Centre 2014).

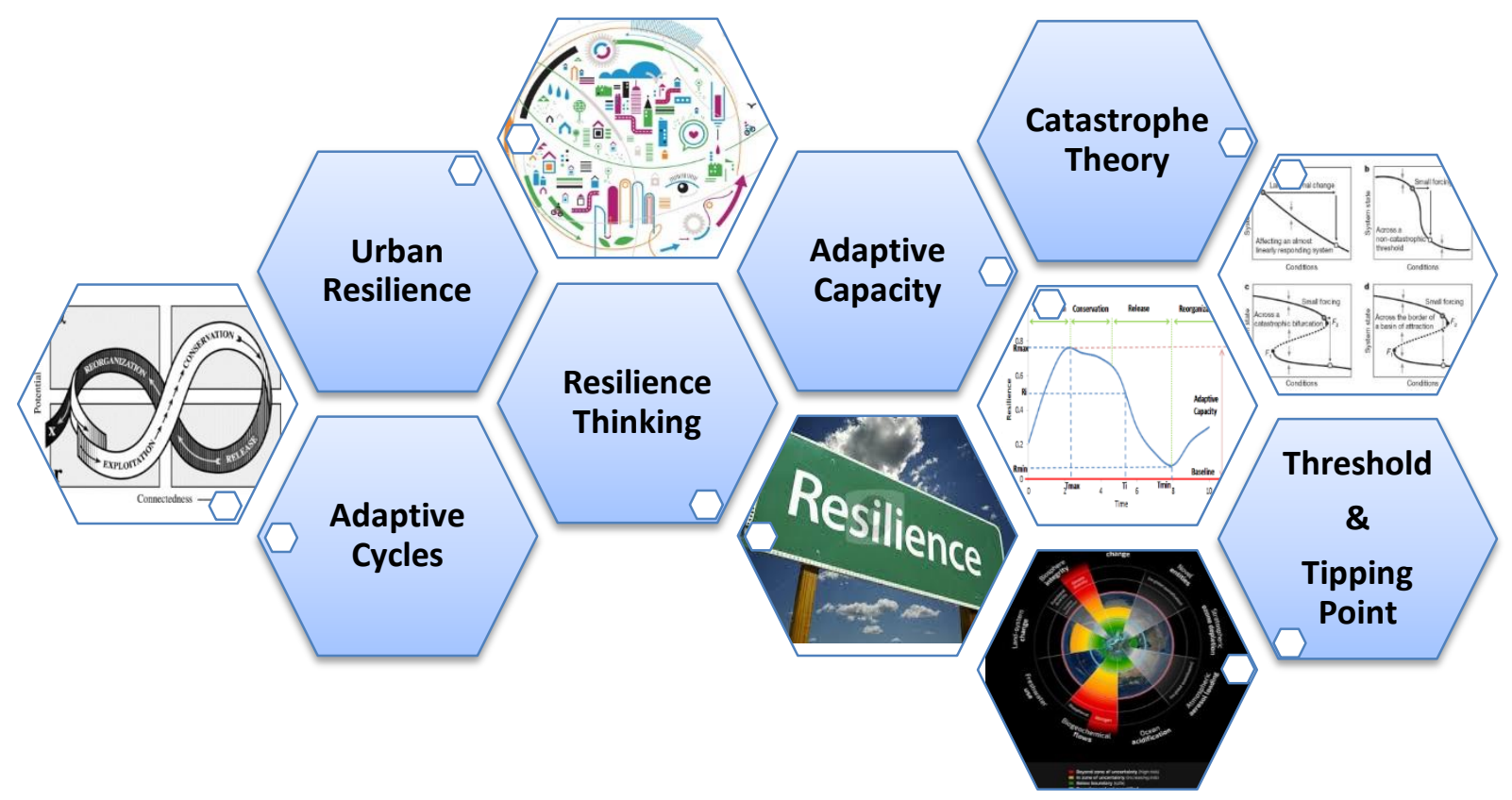

Fig.1.1 Essential concepts of resilience theory

Resilience is the capacity of a system to absorb disturbances and still retain its basic functions and structures (Walker and Salt 2006). Resilience offers mechanisms for navigating the transform of systems and adapting to a more stable and sustainable equilibrium (Scheffer et al. 2001, Folke 2006, Sellberg et al. 2015). It is a two-side theory, it contributes when the system is desired to maintain its current stable state; but it works against sustainability when a system faces threat or assets are being depleted, transformation is needed for sustainability (O'Connell et al. 2015). Loss of resilience can cause collapse of the system, and may even leads to abrupt and irreversible transitions of undesirable configurations. 
Specified resilience focus on whether there is a threshold and how far the current state is from its threshold. General resilience is a system's capacity to manage disturbances and navigate the state of the system. The concept of resilience is not only for understanding the multi-scale relationship of social-ecological systems (SESs), but also applies resilient development strategies in urban planning disciplines (Colding 2006, Resilience Alliance 2007, Wilkinson 2012, West and Schultz 2015, Rockefeller Foundation 2015).

Resilience represents an area of explorative research that helps to explain the system's dynamics relevant to transformation. A growing group of resilience scholars have been studying transformations toward improved ecosystem stewardship, and therefore provides the major policy implications for global sustainability development (Gunderson et al. 1995, Gunderson and Holling 2002, Olsson et al. 2006, Folke et al. 2010, Westley et al. 2011, Olsson et al. 2014). Also recent work discusses resilience in Earth system science and planetary boundaries, and about reciprocal interactions to avoid crossing critical thresholds/tipping (Rockström et al. 2009a, 2009b, Walker et al. 2009, Steffen et al. 2011, 2015b).

\subsubsection{Resilience thinking}

Resilience thinking embraces changes and diversity, it learns and gains experiences from them. It believes that humans and nature are strongly integrated with each other that they are conceived as one social-ecological system. Resilience thinking offers a sustainable way of understanding system changes and managing future development with constructive alternatives, which enables human to live in a safe operating space. By understanding how and why the system resilience changes, it opens a window to build a capacity to cope with the unexpected gradual and sudden crises, as opposed to waiting for the collapse (Walker and Salt 2006). It is about generating increased knowledge to strengthen its long-term capacity to withstand perturbations.

The Grate Acceleration (Steffen et al. 2004, Steffen et al. 2015a) is pushing the Earth dangerously close to its boundaries. It is approaching the magnitude of the great forces in nature, and it operates on much faster time scales than the rates of natural variability (Rockström et al. 2009, Steffen et al. 2015b). Furthermore, it leads human into the current geological period called Anthropocene-the age of Man. Resilience thinking provides a road map for sustainable development, it can help managers to navigate system's resilience transformation. It strives for building flexibility and adaptive capacity, rather than attempting to maintain its unchangeable stable state and short-term economic gains (Stockholm Resilience Centre 2014).

Key points for resilience thinking (Walker and Salt 2012):

- The basics concepts of resilience thinking involve: thresholds/tipping points, adaptive capacity, transitions/transformations and linked adaptive cycles.

- Resilience is a complicated and complex property of a system; it applies in different ways to different scales. Therefore, it requires a dynamic, integrated and adaptive approach to manage resilience changes.

- Resilience thinking addresses that the systems surround us are complicate adaptive systems, and all systems are self-organizing systems before crossing thresholds.

- Resilience thinking is about embracing system changes instead of avoiding it. Ignoring 
or preventing system changes will cause the increase of vulnerability and forego emerging opportunities.

- Resilience is an "active and passive" theory. Sometimes it is easy to predict how the system will respond to your actions, and sometimes feedbacks come as a complete surprise.

- It is about the balance among all the critical information and requisite simplicity. A good management brings together the insights of the key contextual elements or attractors in the system, understanding what is important in terms of operating in a safe space.

- Transformability depends on three main attributes: getting across the state of denial, creating possible pathway for transformation, and having the capacity for resilience shifts.

- Appropriate policies and strategies depend on the phase of the adaptive cycle of the focal scale and the relevant scales. When will be the best time for implementing interventions? How can adaptive management/governance be introduced?

\subsubsection{Urban resilience development}

Definitions of resilience have undergone a four-stage development (Fig.1.2) with disciplinary amendments. It integrates the social, economic, and ecological sciences, along with political planning in recent years (Gaudreau and Cao 2015). The initial definition of resilience came from ecological science by Holling (1973), conceptualizing resilience as the recovery and return time to an equilibrium following a perturbation (Pimm 1984, O'Neill et al. 1986). In the second stage, resilience became defined as "the capacity of the system to absorb disturbance", and the system's ability to self-organize in relation to social and economic development (Folke and Carpenter 2000, Gunderson 2000, Holling, 2001, Folke et al. 2002, Walker et al. 2004). The third stage represents the beginning of urban resilience. Considerable research defines urban resilience as the ability of a city to tolerate disturbances before reorganizing around a new set of structures and processes (Alberti et al. 2003, Colding 2006, Walker et al. 2006). At the fourth stage, scholars of urban management and planning highlight the characteristics of urban resilience. Urban resilience is a key concept in urban management and planning, appearing in urban development policy and guidelines. It operationalizes a city's sustainability and flexibility, and seeks to apply these principles for resilient cities (Colding 2006, Resilience Alliance 2007, Sellberg et al. 2015, West and Schultz 2015). However, resilience is rather a fuzzy concept in urban studies and quantitative assessment of urban resilience is still not well established. To our knowledge, few scientific analyses address resilience modeling, even fewer focusing on cities (Wang et al. 2012, Salvati et al. 2013, Asefa et al. 2014). 


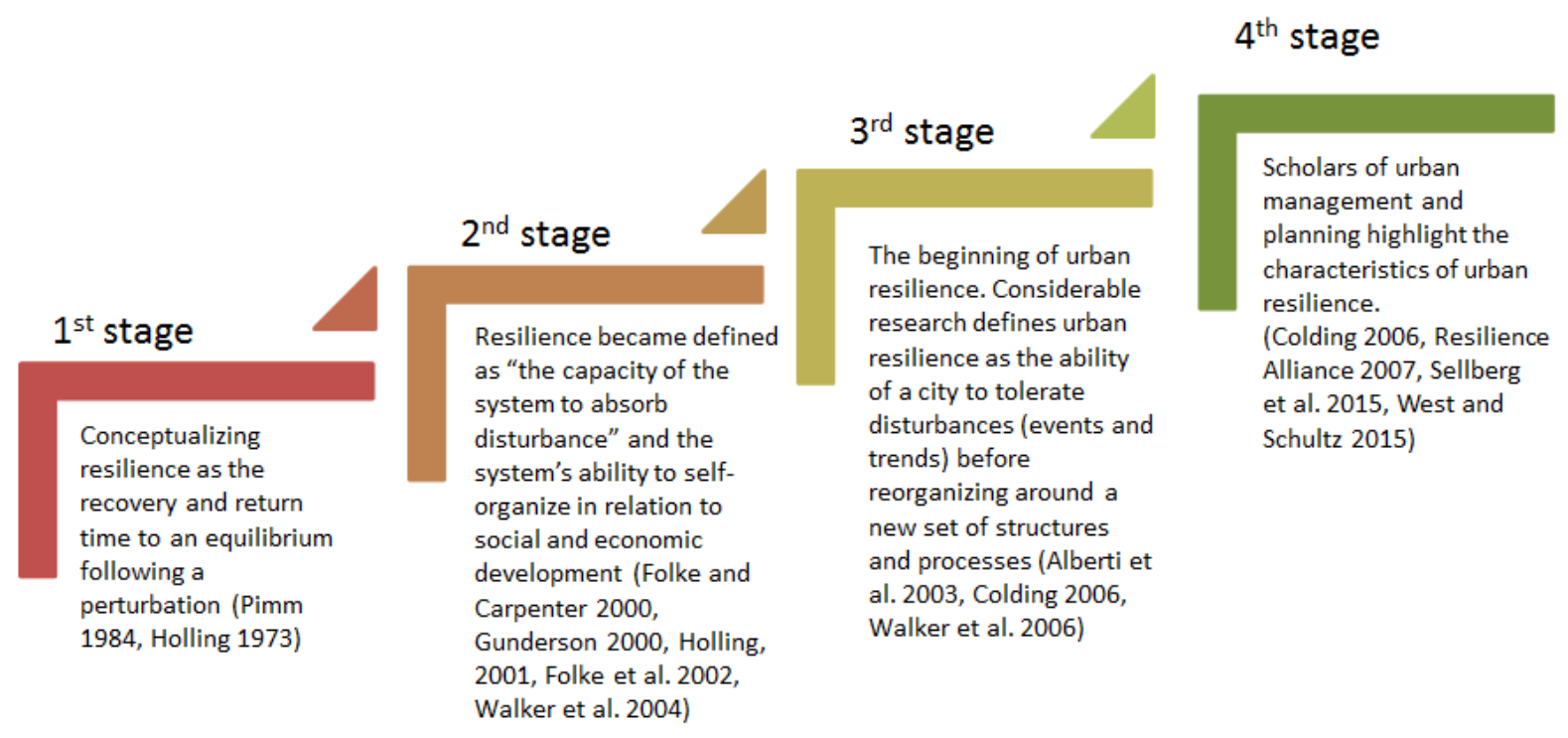

Fig.1.2 Four-stage development of urban resilience

The urban system is a multi-interaction system, due to the rapidly urbanizing landscape characterized by intense human pressures, which is intertwined with ecological system vulnerability. Globally, more people live in the urban areas than in the rural areas, urbanization represents a challenge of the urban social and ecological systems. Because $60 \%$ of urban areas projected into 2030 are yet to be built (Elmqvist 2012). And by 2050, 66\% of the world's population is projected to be urban (World Urbanization Prospects 2014). With the development of rapid urbanization, the future big problems will be the resilience of urbanizing regions (peri-urban areas), where are under rapid and massive expansion and sprawling (and often largely unplanned), especially over the developing world.

A resilient system has the transform capacity to withstand disturbances, or develops a different way of making a living. From the framework of 100 Resilient Cities (Rockefeller Foundation 2015), resilient cities demonstrate seven qualities:

- Reflectiveness: the ability of using the past experience to guide future decisions and to modify behaviors or plans;

- Resourcefulness: the ability of recognizing the alternative ways to use resources during the crisis, and keep the functions and configuration of such system;

- Robustness: the quality that helps to conceive and construct systems, it includes making provisions to detect the possible failure;

- Redundancy: the spare capacity to accommodate disruption, especially to the extreme crisis and external event;

- Flexibility: the willingness to adopt the alternative strategies in relation to changing circumstances and recognizing traditional practices;

- Inclusiveness: the property of good governance that can emphasize the need for broad consultation to build city resilience;

- Integration: the property of bring institutions together and catalyzing additional benefits to achieve a greater state. 


\subsubsection{Thresholds \& Tipping point}

Threshold is the limit that how much a self-organizing system can be changed and still recovers to maintain its configurations and functions. Threshold is needed in a self-organizing system, once the system goes beyond the breakpoint between two regimes of a system, and then all functions change differently. Because crossing the threshold can result in tremendous and irreversible consequences (Westley et al. 2002, Walker and Meyers 2004, Resilience Alliance 2007, Li et al. 2015).

The theory of threshold plays an important role in resilience practice-understanding, determining where it might occurs, and what might trigger this (Walker and Salt 2012). More and more research focus on dynamics of threshold that operate at regional and global scales. One key perspective of planetary boundary theories is how long a boundary can temporarily be transgressed before a threshold is crossed (Rockström et al. 2009b, Steffen et al. 2015). There is ample evidence that certain key control variables in ecosystems (e.g., ocean, forests, fresh water, etc.) changes gradually can trigger an abrupt and tremendous system state change when critical thresholds have been crossed (Carpenter et al. 2001, Hughes et al. 2007, Scheffer 2009, Rockström et al. 2009a). Managing resilience requires identifying the critical threshold and what are the key triggers that cause a system approaching threshold. More discussions about thresholds are in Chapter 4 and Appendix 3.

Another similar concept in resilience theory is tipping point. In principle, a tipping point can be used to describe a critical, dramatic and rapid transition with irreversible effects resulted in an alternative resilience state. More generally, it addresses intention of both government and researchers how to detect tipping points, and distinguish environmental fluctuations from the dynamic perturbations under anthropogenic forcing. Tipping points are often not easy to identify, some of variables in a system even don't them. For the other variables that have tipping points, it is necessary to know about them, because they can cause significant resilience shifts or lead to the collapse of the whole system. So the early warning signal of tipping point is important for maintaining a system's stability. Tipping point is discussed in Chapter 3.

\subsubsection{Early warning}

Urban resilience appears as a key concept in urban management and planning. It can detect early warning signals when systems approach tipping point to adapt to the shifts (Resilience Alliance 2007, Scheffer et al. 2009, Sellberg et al. 2015, West and Schultz 2015, Rockefeller Foundation 2015). In principle, a signal of early warning of systems can be represented by tipping point, at which the future state of the current resilience system is qualitatively altered (Lenton et al. 2008, Scheffer et al. 2009). Early warning signals can help to avoid the risks of unexpected resilience collapse in complex systems, or the critical slowing down of resilience. Moreover, the early warning signals can guide the design of resilient systems. However, there are so far no ways that can be used to measure how close a system is to a critical transition, it is an emerging field in relation to tipping points. The early warning theory is used for resilience analysis in Chapter 3. 


\subsubsection{Adaptation \& Adaptive capacity}

Adaptation is a change process that enables a system to achieve a desired stable equilibrium by reducing vulnerability to disturbances (Folke et al. 2005, O'Connell et al. 2015). As a capacity to manage resilience in relation to alternative regimes, adaptation can be able to avoid tuning into an undesirable system regime, or to succeed in shifting into a desirable and stable regime (Holling et al. 2002, Folke et al. 2002, Smit and Wandel 2006, Walker and Salt 2006). The loss of adaptive capacity is the loss of opportunity for resilience, and "gaining from the disturbances" became a new path of perceiving resilience. Recent studies identify adaptive capacity in resilience at different scales (Pelling and High 2005, Folke et al. 2005, Rockström et al. 2009b, Adger et al. 2011, Steffen et al. 2015b).

Adaptive capacity involves either or both of two abilities (Resilience Alliance 2007):

(1) The ability to determine the trajectory of system state - the position within its current basin of attraction;

(2) The ability to alter the shape of the basins, which moves the positions of thresholds or makes the system more or less resistant to perturbation.

As the most important property of a resilient system, the ability to self-organize is particularly important in adaptive capacity for dealing with disturbances. A city sustainability planning enhances a system's adaptive capacity. A higher adaptive capacity represents a higher resilience level (Fig.1.3), which means the system has a better chance to recover and maintain its structure after disturbances. This is the basic theory used for resilience analysis in Chapter 4.

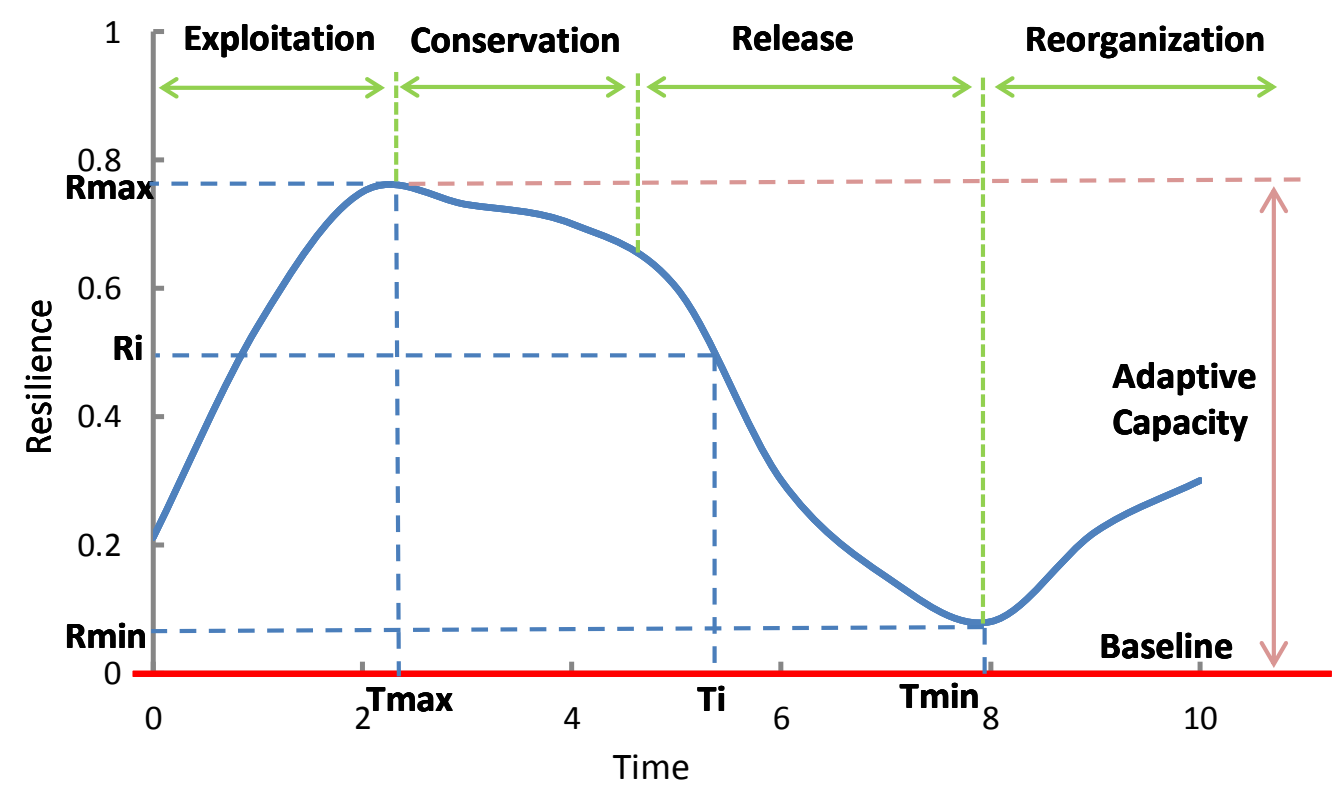

Fig.1.3 Adaptive capacity to disturbances

A response variable can be any variable that is responsive to disturbances. The bottom line (baseline) represents the worst level (threshold), which the system closes to collapse and crosses its threshold. The 
further the resilience value is from the baseline, the better the system is; thus, also representing more adaptive capacity.

\subsubsection{Adaptive cycles}

SESs are never static and they tend to move through four, recurring phases, which is known as the theory of adaptive cycle. Adaptive cycle theory is a conceptual model of the dynamics of coupled systems of people, nature and technology. It describes the progression of socialecological systems through various phases of organization and function as comprising four phases (Fig.1.4): exploitation, conservation, release and reorganization (Gunderson and Holling 2002). Adaptive cycle is one relevant way to understand the processes of selforganizing systems, but the cyclic pattern is not an absolute following the order (Resilience Alliance 2007). A system can just skip one or more phases and turn to another adaptive cycle; this is discussed in Chapter 4 and Chapter 5. More importantly, the adaptive cycle's feedback mechanism helps to represent the system state through a series of causes and processes (diversity, potential for change, level of redundancy and connectedness) (Folke 2006). The adaptive cycle, as an active mechanism, also provides guiding lines for resilience management. It becomes a pathway for achieving the integration of related key concepts into decision making.

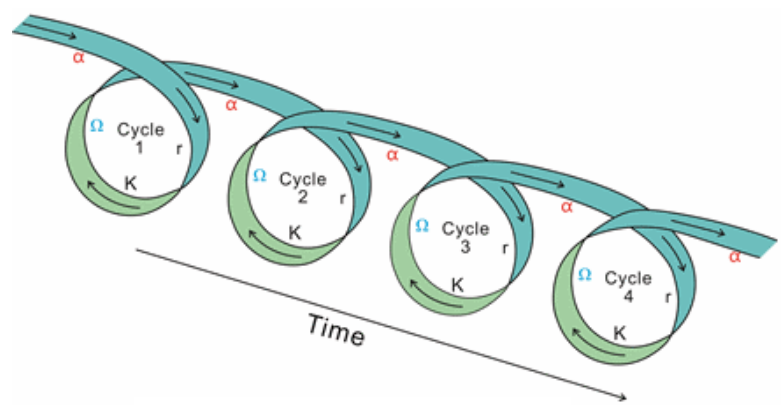

Fig.1.4 Resilience adaptive cycle (Carpenter et al. 2001)

Four phases of adaptive cycle (Carpenter et al. 2001, Liu et al. 2007, Walker and Salt, 2006):

- Exploitation $(r)$ : a phase with rapid growth in which resources are readily available, and entrepreneurial agents exploit niches and opportunities.

- Conservation $(K)$ : leading into a long phase of accumulation, monopolization, and conservation of structure. During this phase, resilience tends to decline, because of the increasingly locked up and unavailable resources in the existing structures and less flexible and responsive to disturbance.

- Release $(\Omega)$ : a very rapid breakdown or release phase (creative destruction). Disturbances cause some chaotic unraveling and release of resources.

- Reorganization $(\alpha)$ : a relatively short phase of renewal and reorganization, and generally transform into a new $r$ phase. New actors and new plans can take hold during this phase.

The transition from exploitation ( $\mathrm{r}$ ) to conservation $(\mathrm{K})$ is referred to as the "fore loop", it constitutes a relatively long developmental period characterized with relative stability, 
predictability and constrained dynamics. Fore loop is essential for accumulation of capitals (i.e. natural, human, social, built and financial) in human systems. The release $(\Omega)$ and reorganization $(\alpha)$ are referred to as the "back loop", it constitutes a rapid, uncertain and novel period, and during which capitals tend to be lost and novelty can succeed (Holling and Gunderson 2002, Resilience Alliance 2007). It's the time of greatest potential for the initiation of either destructive or creative change in the system. It's generally accepted that most systems spend more time in the forward phase, which is relatively slow compared with the back loop. Dynamics of the fore loop and back loop correspond to managing production and sustainability. As a system passes through the different stages of the adaptive cycle, its resilience is subjected to change. More details can be found in Chapter 2 and Chapter 4.

"Panarchy" (Fig.1.5) describes the evolving hierarchical systems with multiple interrelated factors, it is a model of nested and hierarchically arranged adaptive cycles with dynamic interactions and influences across scales and time (Holling et al 2002). As the dynamics of system at that scale are influenced by changes at scales above or below, so it is difficult to manage the system by only focusing on one scale. From the scales above, the interplay can be positive to provide memory and subsidies, also can be negative influences of preventing actions. From the scales below, the degree to which the most critical subsystems stay determines the degree to an overall focal scale change (Gunderson and Holling 2002). The relevant scales can be identified either by their influences on the focal scale, or the influences of the focal scale on related scales.

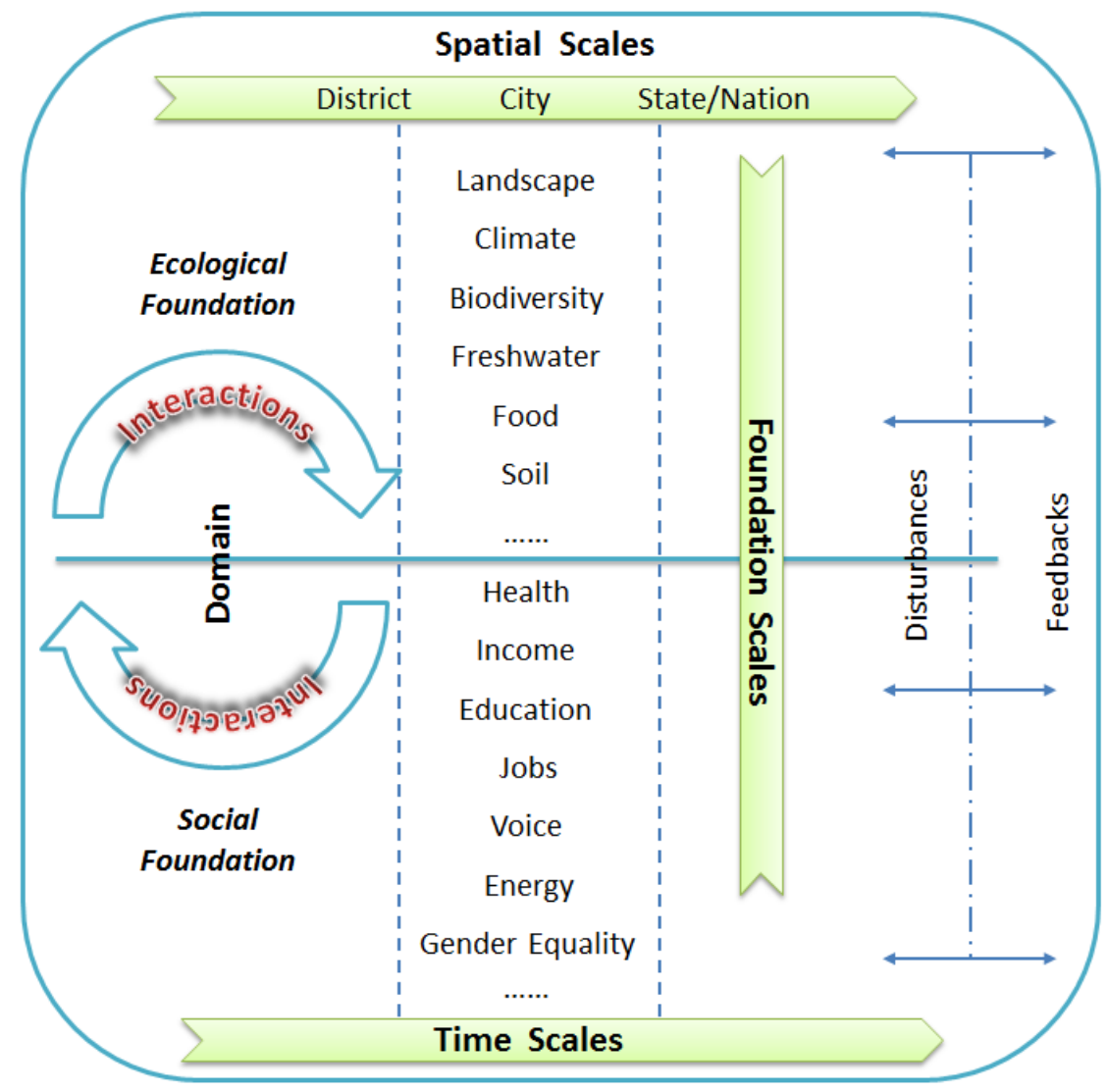

Fig.1.5 Representation of scales in Panarchy 


\subsubsection{Catastrophe theory}

Catastrophe theory (Thorn 1969, Zeeman 1976) was rationally accounted for the phenomenon of discontinuous change in behaviors caused by continuous change in parameters. It can describe the evolution of forms, which is particularly applicable where gradually change leads to abrupt changes in structure or functions. Moreover, it can be used for detecting the feedbacks of environmental stochastic or human disturbances in resilience changes. The unique character of catastrophe theory is that it can capture inherent nonlinearity and complexity behaviors (Oliva et al. 1992, Scheffer et al. 2001, Lin and Petersen 2013). When resilience is lost or significantly decreased, a system is at high risk of shifting into a qualitatively different or undesirable state (Scheffer et al. 2001, Scheffer and Carpenter 2003).

Catastrophe theory has four models: Fold, Cusp, Swallowtail and Butterfly. The type of model used was chosen according to the dimensions (numbers) of control variables of each sub-system (details on Page 22-23 and Page 38-40). Summary descriptions of catastrophe models and their normalization formula are as follows:

- Fold catastrophe-subsystem with only one indicator:

$$
\mathrm{V}=\mathrm{x}^{3}+\mathrm{ax} ; \quad \mathrm{Xa}_{1}=\sqrt{\mathrm{a}_{1}}
$$

- Cusp catastrophe-subsystem with two indicators:

$$
V=x^{4}+a x^{2}+b x ; \quad X a_{1}=\sqrt{a_{1}}, \quad X a_{2}=\sqrt[3]{a_{2}}
$$

- Swallowtail catastrophe-subsystem with three indicators:

$$
V=x^{5}+a x^{3}+b x^{2}+c x ; \quad X a_{1}=\sqrt{a_{1}}, \quad X a_{2}=\sqrt[3]{a_{2}}, \quad X a_{3}=\sqrt[4]{a_{3}}
$$

- Butterfly catastrophe-subsystem with four indicators:

$$
\mathrm{V}=\mathrm{x}^{6}+a \mathrm{x}^{4}+b \mathrm{x}^{3}+c \mathrm{x}^{2}+\mathrm{dx}
$$

$$
X \mathrm{a}_{1}=\sqrt{\mathrm{a}_{1}}, \quad X \mathrm{a}_{2}=\sqrt[3]{\mathrm{a}_{2}}, \quad \mathrm{Xa}_{3}=\sqrt[4]{\mathrm{a}_{3}}, \quad X \mathrm{a}_{4}=\sqrt[5]{\mathrm{a}_{4}}
$$

\subsubsection{Transformation}

Transformation creates a new way of making a living system. It refers to the shifting process, from one resilience state to another that has different controlling components, structure, functions, and feedbacks (O'Connell et al. 2015). Transformation and adaptation are seen as a continuum, transformation occurs when recent system reaches the limits of adaptation and its resilient state can no longer be maintained. When a system shifts into a worse and undesirable regime or state (Fig.1.6), and there is no way out to a desirable regime or state, a transformation will lead system to crossing scale into a different kind of system-Panarchy (Resilience Alliance 2007). Transformational changes happen all the time in SESs, which are normally unplanned and often involve undesirable effects.

Because of non-linear dynamics, a system can shift to alternate stable states. The "Ball and cup" model can be used to represent resilience (Fig.1.6). The ball is the state of the socialecological system. The basin where it can move is the possible set of states which have the same kinds of functions and feedbacks. In the end, a system results in the phase that ball moving 
towards the equilibrium. The dotted line is a threshold separating alternate basins (Walker et al. 2004, Walker and Salt 2006).

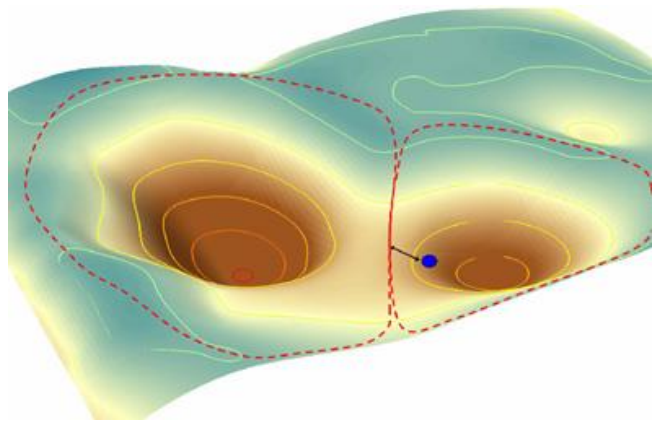

(a)

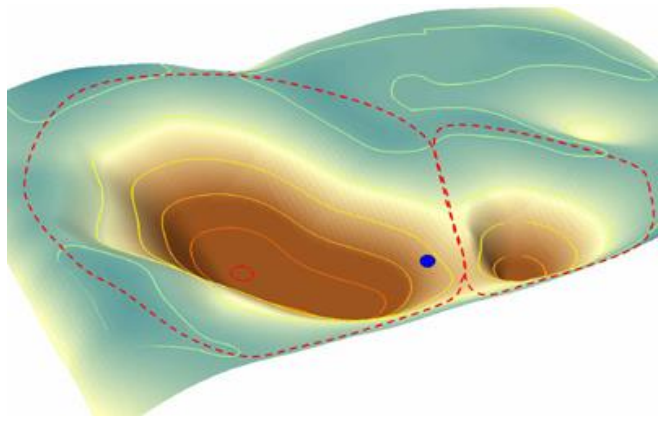

(b)

Fig.1.6 "Ball and cup" model representation of resilience (Walker et al. 2004, Walker and Salt 2006).

It is a three-dimensional stability model of SESs resilience with two basins of attraction (Walker et al. 2004, Walker and Salt 2006). An attractor (the bottom of the basin) is an equilibrium state of a system that does not change unless disturbances and perturbations occur. The basin of attraction constructs with all the stable states that tend to change toward the attractor. The 'ball' shows the current position of the system and how it can shift regimes as the stability system changes. The system can change regimes either by changing the state through two different basins, or through changes in the shape of the basinprocesses and function (Fig.1.6b).

\subsection{Study Area}

This section provides some brief information about Lianyungang, such as location, population, urbanization, etc., as well as the vital city development plan which contributes to its resilience transformation.

\subsubsection{Brief information about study area}

China is urbanizing at an unprecedented increasing urban population, and most city development has been and will be in the eastern part of the country, particularly along the coast. Geographically, Lianyungang has its own advantage. Lianyungang is located on the East Coast of China (a medium-sized coastal city, $7470 \mathrm{~km}^{2}, 5.1$ million people), and forms the south wing of the Yangtze River Delta region which is the largest concentration of economic development in China (Fig.1.7). It is the only coastal port city in Jiangsu Province and an important coastal "open city" (implementing the opening-up policy for Special Economic Cities, the fourteen coastal open cities designated since 1984) in Eastern China. Lianyungang has experienced rapid land use and land cover change characterized by typical extensive urbanization, typical in economically developed areas throughout the coastal cities in China. Table 1.1 summarizes the five subdivisions in Lianyungang: the central district which includes Districts of Xinpu, 
Haizhou and Lianyun, and 4 counties of Ganyu, Donghai, Guannan, and Guanyun.

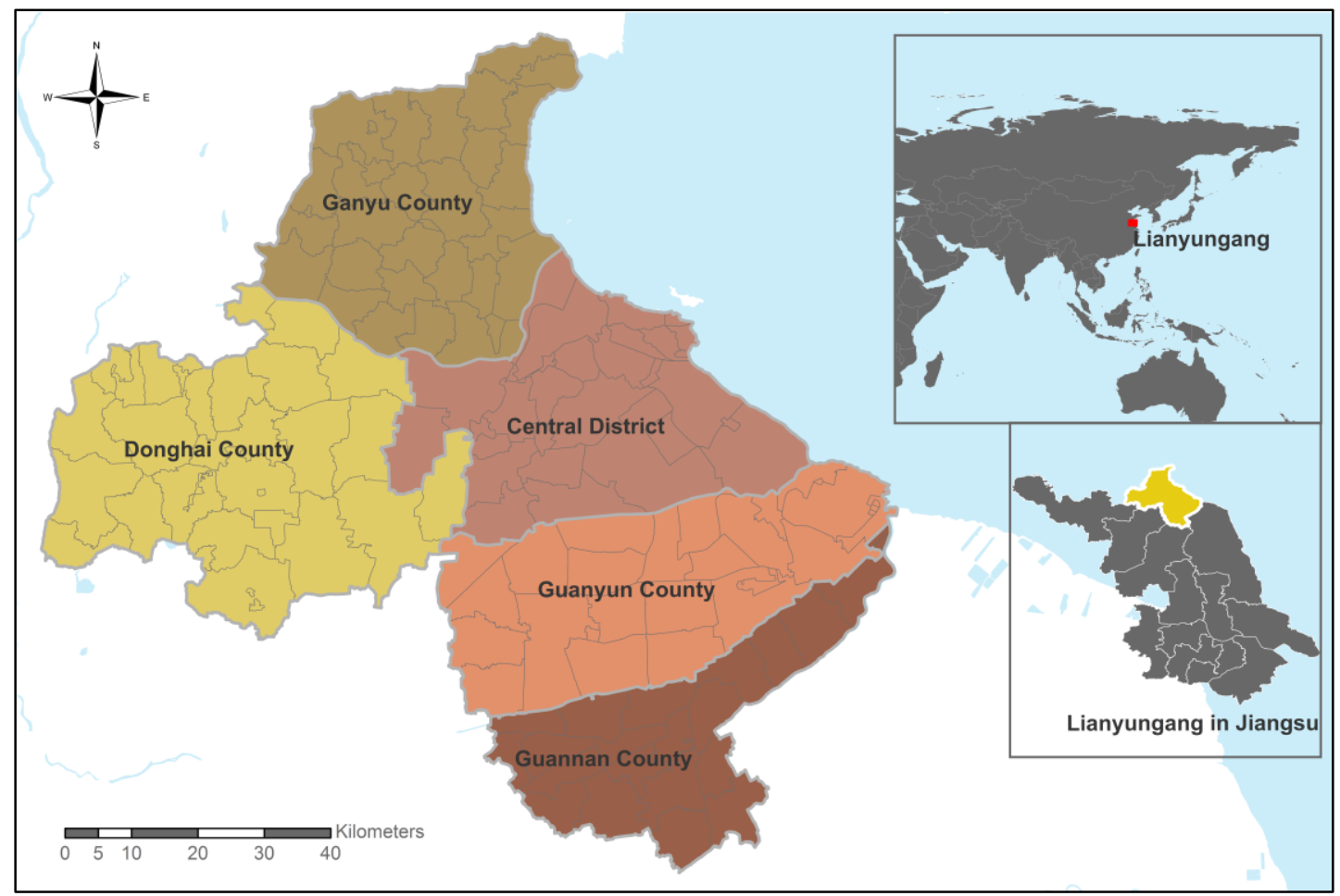

Fig.1.7 Location of Study Area

Table 1.1 Administrations in Lianyungang (2010)

\begin{tabular}{|c|c|c|c|c|c|c|c|c|c|}
\hline \multirow{2}{*}{\multicolumn{2}{|c|}{ Subdivision }} & \multirow{2}{*}{$\begin{array}{l}\text { Area } \\
\left(\mathbf{k m}^{2}\right)\end{array}$} & \multirow{2}{*}{$\begin{array}{c}\text { Population } \\
\left(* 10^{4}\right)\end{array}$} & \multirow{2}{*}{$\begin{array}{l}\text { GDP } \\
\left(* 10^{9}\right)\end{array}$} & \multicolumn{5}{|c|}{ Administrative Subdivisions } \\
\hline & & & & & & & Sub- & & Neighborhood \\
\hline \multirow{3}{*}{$\begin{array}{l}\text { Central } \\
\text { district }\end{array}$} & Xinpu & & & & 2 & 2 & 6 & 38 & 75 \\
\hline & Haizhou & 1156 & 93.59 & 437.29 & 1 & 3 & 4 & 60 & 24 \\
\hline & Lianyun & & & & 3 & 1 & 7 & 39 & 38 \\
\hline \multirow{4}{*}{$\begin{array}{l}\text { Peri- } \\
\text { urban } \\
\text { county }\end{array}$} & Ganyu & 1427 & 112.62 & 223.07 & - & 18 & - & 422 & 33 \\
\hline & Donghai & 2037 & 115.10 & 200.14 & 8 & 13 & - & 346 & 15 \\
\hline & Guannan & 1027 & 76.16 & 140.08 & 5 & 9 & - & 225 & 13 \\
\hline & Guanyun & 1852 & 100.26 & 150.13 & 11 & 7 & - & 302 & 22 \\
\hline
\end{tabular}

The Lianyungang government has established a program of economic reform that accelerates changes to the pattern of economic development and restructuring, which is one of the main factors causing resilience shifts. The gross domestic product (GDP) of Lianyungang rapidly increased to 1402.29 billion Chinese Yuan (CNY) in 2014, which was 249.1 billion in 2000. Following the development of economy, the urbanization rate increased from $28.02 \%$ to $57.13 \%$ in 2010, much higher than the average urbanization rate in China (34.17\%). Given all that, Lianyungang is a typical city in the eastern coastal area with accelerated urbanization along with explosive economic growth. Therefore, it is an appropriate study area for dynamic 
resilience research.

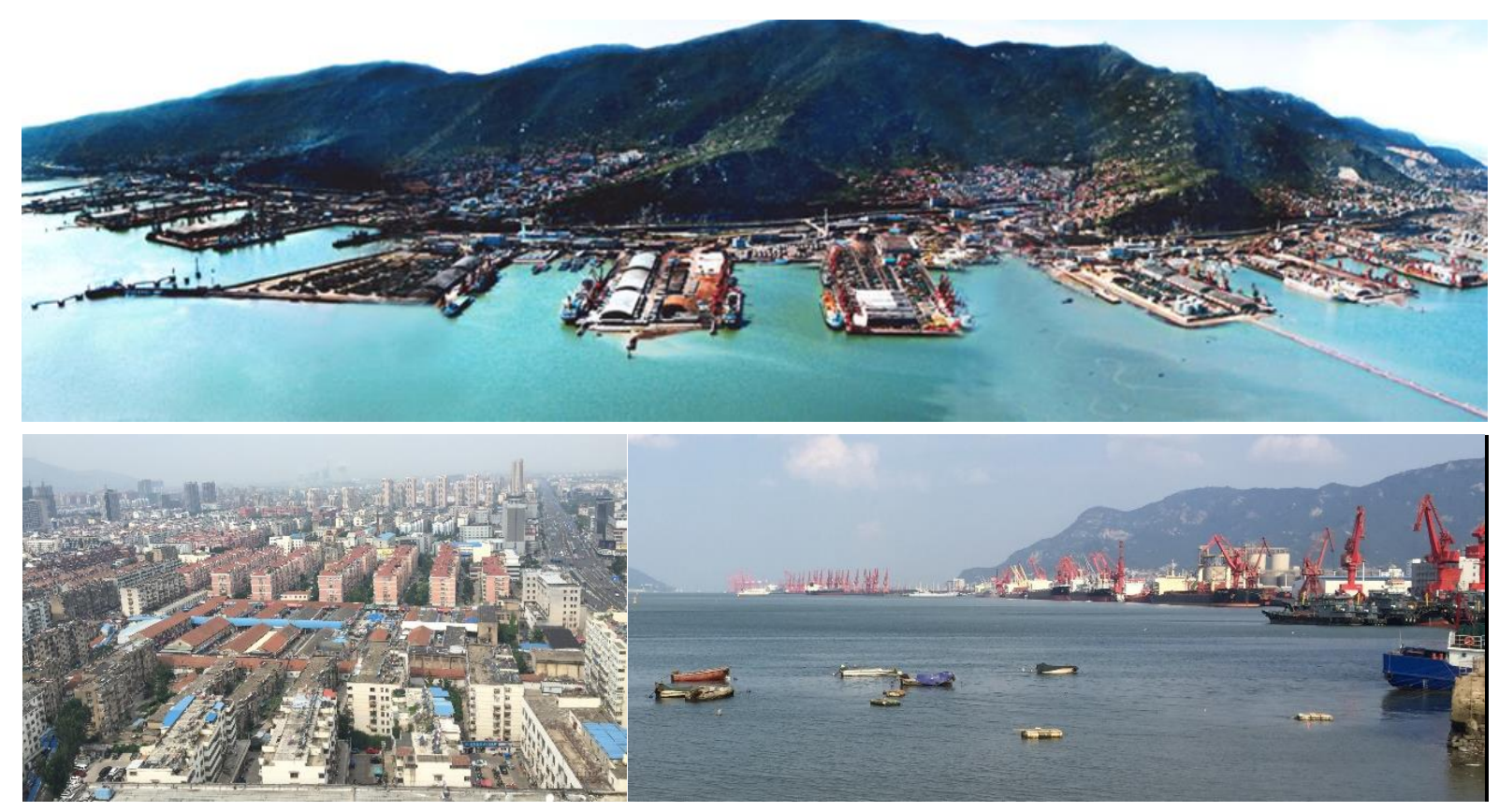

Fig.1.8 Rapid development in Lianyungang

Note: Photo on the top is from the website of Lianyungang government www.lyg.gov.cn.

Photos in below: Yangfan Li.

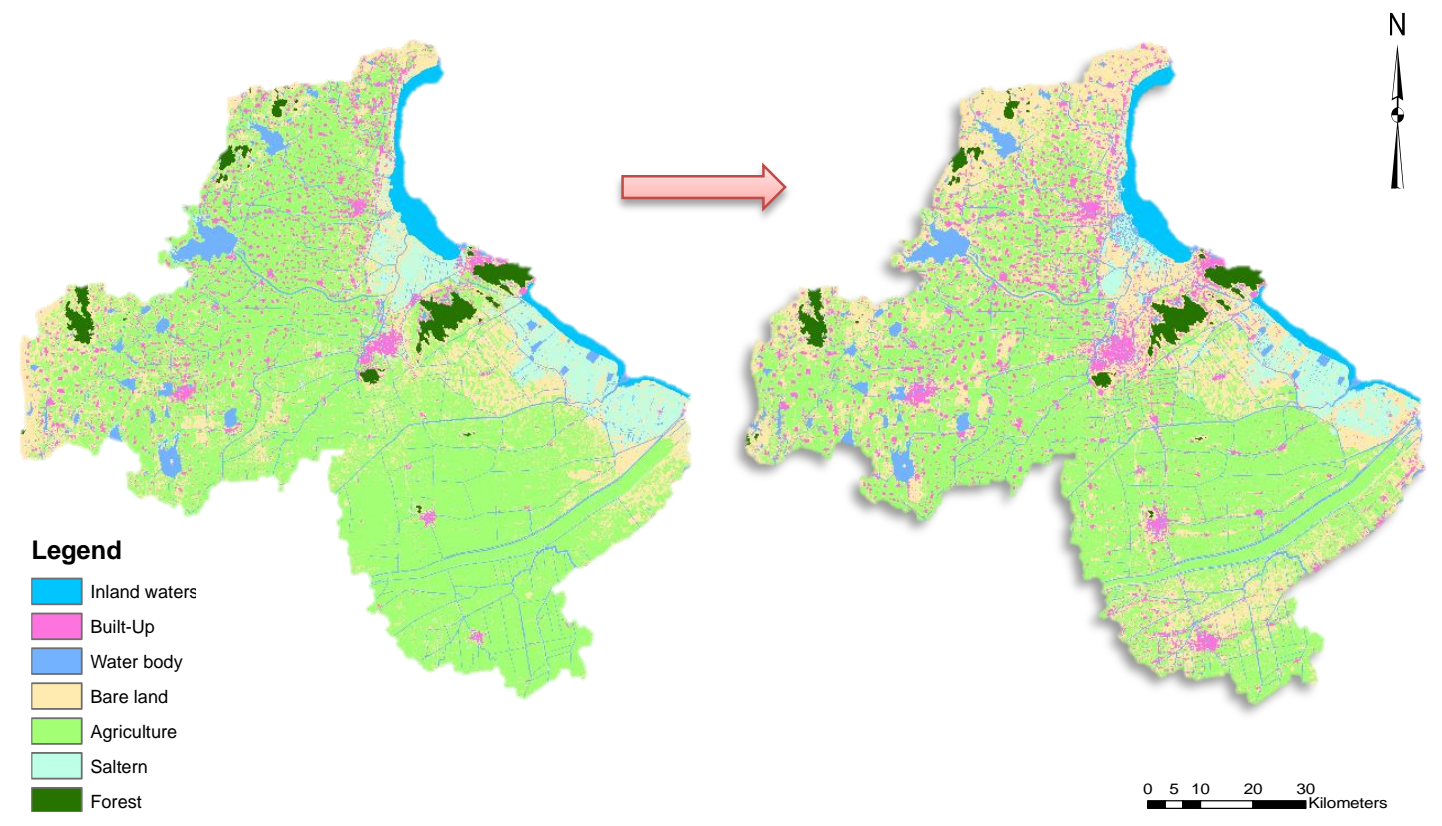

Fig.1.9 Land use mapping of 2000 and 2010

The city is facing a broad range of serious and growing environmental issues due to the rapid urbanization process in the latest decade (Fig.1.8). It makes Lianyungang become the typical developing city case for resilience analysis. Land ecosystems in the region have sustained increasing development pressures and degradation due to rapid population growth, extensive 
urbanization and excessive tourism activity in recent past. The spatial distributions of land use classes in Lianyungang are shown in Fig.1.9 (2000 and 2010). Built-up area, bare land and agricultural land experienced more changes than other land use types during the investigated period, and represented the typical landscape change in Lianyungang. From urban growth, built-up land increased from $441.57 \mathrm{~km}^{2}$ in 2000 to $668.66 \mathrm{~km}^{2}$ in 2010 , an increase of $51.42 \%$. The increased built-up land is mainly distributed in the core zone area, and more fragmented rural sites across the study area. Also, there was more bare land in 2010 with an increase of $54.19 \%$ from $156.43 \mathrm{~km}^{2}$ to $241.19 \mathrm{~km}^{2}$. Most of the bare land was distributed in the coastal saltern/wetland area and north part, those areas were the core zone and wings which are represented in the city plan. The rapid urban sprawl led to more and more exposed land, wetland losses and sea reclamation, due to the new city plan implemented in the coastal area for the expansion of industrial development and transport construction (Li et al. 2014). Large areas of agricultural land were converted into residential lands, which decreased from $453.78 \mathrm{~km}^{2}$ to $359.36 \mathrm{~km}^{2}$. Over $52 \mathrm{~km}^{2}$ of wetland were converted into industrial zones, ports and transportation expansion land (built-up land).

Meanwhile, the amount of waste water discharge of the city increased from 94.7 million tons in 2000 to 144.44 million tons in 2010. The increased wastewater discharges, combined with wetland losses and habitat fragmentation, have resulted in the degradation of coastal water quality in Lianyungang (Sun et al. 2012). The surface water quality below national grade III (IV, V and under V) accounted for 31.6\% of all the surface water bodies in the city in 2010. The Huaishu, Shuxin, and Qiangwei Rivers supply the majority of Lianyungang Municipality's drinking water and are crucial water sources for agriculture and industry. Lianyungang has implemented a series of watershed protection measures and the national standard of surface water in order to facilitate different water uses, including land acquisition, aimed at preserving water quality in the main watersheds. However, some of the rivers and reservoirs have been heavily polluted (water quality degraded to levels IV and V, in environmental quality standards for surface water GB 3838-2002), because of rapid urbanization and increasing share of impervious surfaces.

\subsubsection{City development plans and strategies}

According to our previous research (Li et al. 2010, Li et al. 2015), the period from 2000 to 2010 was the most flexible and dynamic stage in Lianyungang. Except its rapid development, many important policies were implemented during this time, including China's Five-Year-Plan and local development planning which had enormous impacts on resilience change. Nonetheless, Lianyungang's vulnerability has several distinguishable periods during last decade, closely aligning with both nation-wide and local major policy adjustments, which indicates significant impact of national and regional socioeconomic policies on its environmental pressure. The "One Zone and Two Wings" development policy (Fig.1.10) in Lianyungang Coastal Regional Strategic Plan (2005-2030) (Lianyungang Municipal Bureau of Urban Planning 2006) and Urban Master Plan (2008-2030) (Lianyungang Municipal Bureau of Urban Planning 2009) are the main guidelines for city development, where "One ZoneCentral district" refers to the main urban area and the area from Longhai to Donghai, and "Two 
Wings-coastal areas" refer to the Binghai area on two sides of the "One Zone".

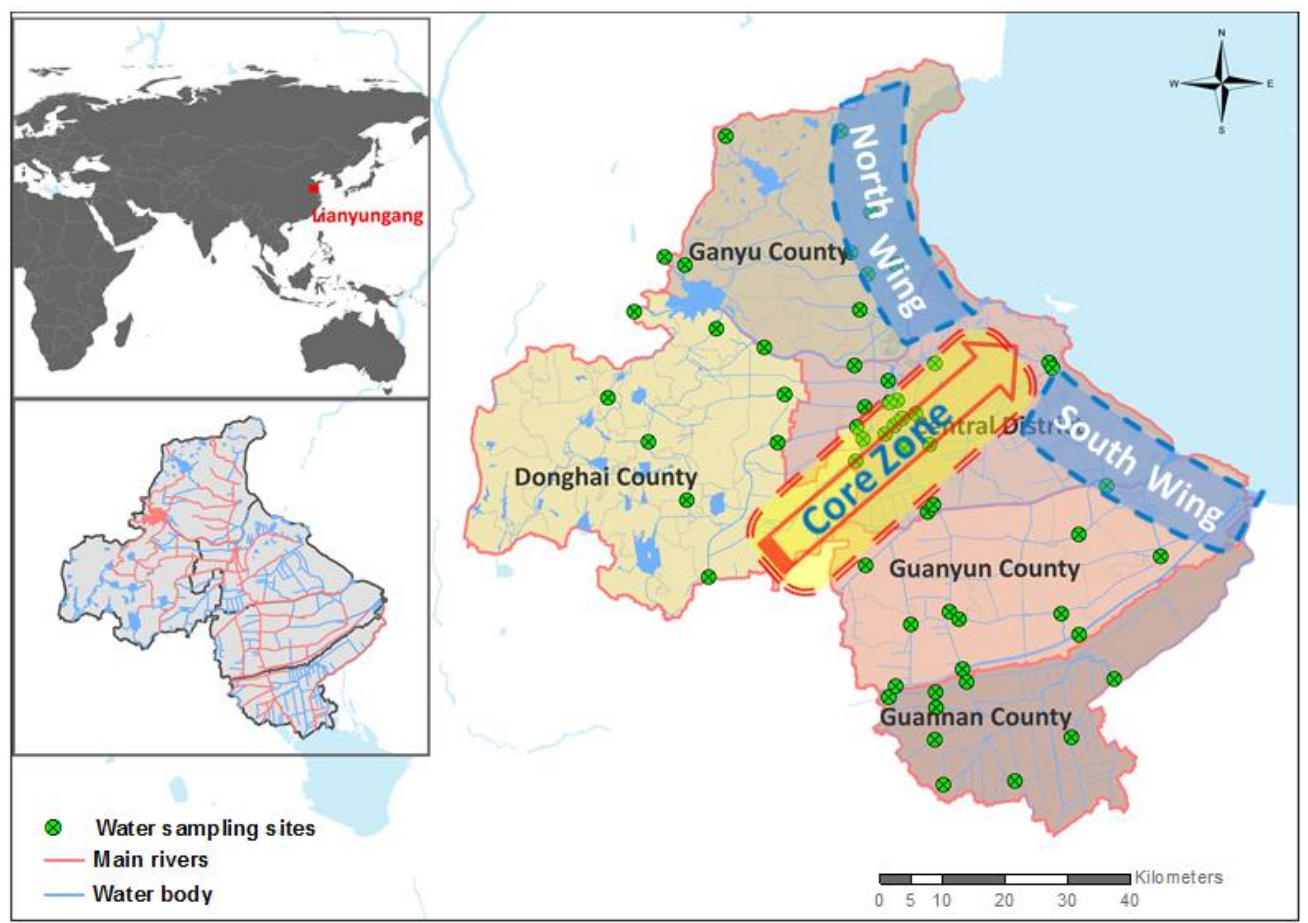

Fig.1.10 Development policy in Lianyungang

With respect to the "One Zone, Two Wings" strategy, the Core Zone in the central district is the "One Zone" area, and "Two Wings" including the North Wing and South Wing along the coast. The "One Zone" area is a new urban-based zone surrounded by three developing districts. The main functions include: administration and business offices, residential buildings, economic development areas and industrial areas, cultural and traveling area etc. The "Two Wings" areas are industrial zones with 6 main ports acting as petrochemical and heavy manufacturing industry centers. The 27 main rivers are where all the 57 water sampling sites are located. A 300 thousand ton harbor infrastructure project in the northern port area will become the largest port in Lianyungang, and the connection between Qingdao and Shanghai.

\section{References}

1. Alberti, M., Marzluff, J. M., Shulenberger, E., Bradley, G., Ryan, C., Zumbrunnen, C. 2003. Integrating humans into ecology: Opportunities and challenges for studying urban ecosystems. Bioscience. 53(12):11691179.

2. Asefa, T., Clayton, J., Adams, A., Anderson, D. 2014. Performance evaluation of a water resources system under varying climatic conditions: Reliability, Resilience, Vulnerability and beyond. Journal of Hydrology. 508:53-65.

3. Carpenter, S. R., Walker, B. H., Anderies, J. M., Abel, N. 2001. From Metaphor to Measurement: Resilience of What to What? Ecosystems. 4:765-781.

4. Colding, J. 2006. Ecological land-use complementation' for building resilience in urban ecosystems. 
Landscape and Urban Planning. 8:46-55.

5. Elmqvist, T. 2012. Cities and Biodiversity Outlook-Unprecedented Opportunities Lie Ahead in Greening Urban Expansion. The Nature of Cities.

6. Folke, C. 2006. Resilience: the emergence of a perspective for social-ecological systems analyses. Global Environmental Change. 16:253-267.

7. Folke, C., Carpenter, S. 2000. Resilience and sustainable development: Building adaptive capacity in a world of transformations. Stockholm: Edita Norstedts Tryckeri Ab.

8. Folke, C., Carpenter, S., Elmqvist, T., Gunderson, L., Holling, C. S., Walker, B. 2002. Resilience and sustainable development: building adaptive capacity in a world of transformations. Ambio. 31:437-440.

9. Folke, C., Carpenter, S., Walker, B., Scheffer, M., Chapin, T., Rockström, J. 2010. Resilience thinking: integrating resilience, adaptability and transformability. Ecology and Society. 15(4):20.

10. Folke, C., Colding, J., Berkes, F. 2002. Building resilience for adaptive capacity in social-ecological systems. In: Berkes F., J. Colding, and C. Folke (eds). Navigating Social-Ecological Systems: Building Resilience for Complexity and Change. Cambridge University Press, Cambridge, UK.

11. Folke, C., Hahn, T., Olsson, P., Norberg, J. 2005. Adaptive Governance of Social-Ecological Systems. Annual Review of Environment and Resources. 30:441-473.

12. Gunderson, L. H. 2000. Ecological resilience-in theory and application. Annual Review of Ecology and Systematics, 31:425-439.

13. Gunderson, L. H., Holling, C. S. (Editors). 2002. Panarchy: understanding transformations in human and natural systems. Island, Washington, D.C., USA.

14. Gunderson, L. H., Holling, C. S., Light, S. S. (Editors). 1995. Barriers and bridges to renewal of ecosystems and institutions. Columbia University Press, New York, New York, USA.

15. Holling, C. S. 1973. Resilience and stability of ecological systems. Annual Review of Ecology, Evolution, and Systematics. 4:1-23.

16. Holling, C. S. 2001. Understanding the complexity of economic, ecological, and social systems. Ecosystems. $4(5): 390-405$.

17. Holling, C. S., Gunderson, L. H. 2002. Resilience and adaptive cycles, Pp 25-62 in Gunderson L. H. and Holling CS (eds). Panarchy: Understanding Transformations in Human and Natural Systems. Island Press, Washington, DC.

18. Holling, C. S., Gunderson, L. H., Peterson, G. D. 2002. Sustainability and Panarchies. In Panarchy: Understanding transformations in Human and Natural Systems. Gunderson, L.H. and Holling, C.S. (Eds.). Island Press. Washington D.C.

19. Hughes, T. P., Rodrigues, M. J., Bellwood, D. R., Ceccarelli, D., Hoegh-Guldberg, O., McCook, L., Moltschaniwskyj, N., Pratchett, M. S., Steneck, R. S., Willis, B. 2007. Phase shifts, herbivory, and the resilience of coral reefs to climate change. Current Biology. 17:360-365.

20. Kinzig, A. P., Ryan, R., Etienne, M., Allison, H., Elmqvist, T., Walker, B. 2006. Resilience and regime shifts: assessing cascading effects. Ecology and Society. 11(1):20.

21. Lenton, T., Held, M. H., Kriegler, E., Hall, J. W., Lucht, W., Rahmstorf, S., Schellnhuber, H. J. 2008. Tipping elements in the Earth's climate system. Proceedings of the National Academy of Sciences of the United States of America. 105:1786-1793.

22. Li, Y. F., Li, Y., Wu, W. 2015. Threshold and resilience management of coupled urbanization and water environmental system in the rapidly changing coastal region. Environmental Pollution. doi: 
10.1016/j.envpol.2015.08.042.

23. Li, Y. F., Zhu, X. D, Sun, X., Wang, F. 2010. Landscape effects of environmental impact on bay-area wetlands under rapid urban expansion and development policy: a case study of Lianyungang, China. Landscape and Urban Planning. 94(3):218-227.

24. Li, Y., Li, Y. F., Qureshi, S., Kappas, M., Hubacek, K. 2015. On the relationship between landscape ecological patterns and water quality across gradient zones of rapid urbanization in coastal China. Ecological Modelling. 318:100-108..

25. Lianyungang Municipal Bureau of Urban Planning. 2009. Urban Comprehensive Plan. http://layout.lyg.gov.cn/ArticleShow.aspx?char=35\&id=2071

26. Lin, B. B., Petersen, B. 2013. Resilience, regime shifts, and guided transition under climate change: examining the practical difficulties of managing continually changing systems. Ecology and Society. 18(1): 28.

27. Liu, J. G., Dietz, T., Carpenter, S. R., Alberti, M., Folke, C., Moran, E., Pell, A. N., Deadman, P., Kratz, T., Lubchenco, J., Ostrom, E., Ouyang, Z. Y., Provencher, W., Redman, C. L., Schneider, S. H., Taylor, W. W. 2007. Coupled Human and Natural Systems. Ambio. 36:639-649.

28. O'Connell, D., Walker, B., Abel, N., Grigg, N., Cowie, A., Durón, G. 2015. An introduction to the Resilience, Adaptation Pathways and Transformation Assessment (RAPTA) Framework.

29. O’Neill, R. V., DeAngelis, D. L., Waide J. B., Allen T. F. H. 1986. A Hierarchical Concept of Ecosystems. Princeton: Princeton University Press.

30. Oliva, T. A., Oliver, R. L., MacMillian, I. C. 1992. A Catastrophe Model for developing service satisfaction strategies. Journal of Marketing. 56(3):83-101.

31. Olsson, P., Galaz, V., Boonstra, W. J. 2014. Sustainability transformations: a resilience perspective. Ecology and Society. 19(4):1.

32. Olsson, P., Gunderson, L. H., Carpenter, S. R., Ryan, P., Lebel, L., Folke, C., Holling, C. S. 2006. Shooting the rapids: navigating transitions to adaptive governance of social-ecological systems. Ecology and Society. 11(1): 18 .

33. Pelling M, High C. 2005. Understanding adaptation: What can social capital offer assessments of adaptive capacity? Global Environmental Change. 15(4):308-319.

34. Pimm, S. L. 1984. The complexity and stability of ecosystems. Nature. 307:321-6.

35. Resilience Alliance. 2007. Assessing resilience in social-ecological systems: A workbook for scientists, version 1.1 [online] URL: http://www.resalliance.org/3871.php.

36. Rockefeller Foundation. 2015. 100 resilient cities. Centennial challenge. Rockefeller Foundation, New York, New York, USA. [online] URL: http://www.100resilientcities.org/\#/__/.

37. Rockström, J., Steffen, W., Noone, K., Persson, Å., Chapin, F. S., Lambin, E., Lenton, T. M., Scheffer, M., Folke, C., Schellnhuber, H., Nykvist, B., De Wit, C. A., Hughes, T., van der Leeuw, S., Rodhe, H., Sörlin, S., Snyder, P. K., Costanza, R., Svedin, U., Falkenmark, M., Karlberg, L., Corell, R. W., Fabry, V. J., Hansen, J., Walker, B., Liverman, D., Richardson, K., Crutzen, P., Foley, J. 2009b. Planetary boundaries: exploring the safe operating space for humanity. Ecology and Society. 14(2): 32.

38. Rockström, J., Steffen, W., Noone, K., Persson, Å., Chapin, F. S., Lambin, E., Lenton, T. M., Scheffer, M., Folke, C., Schellnhuber, H., Nykvist, B., De Wit, C. A., Hughes, T., van der Leeuw, S., Rodhe, H., Sörlin, S., Snyder, P. K., Costanza, R., Svedin, U., Falkenmark, M., Karlberg, L., Corell, R. W., Fabry, V. J., Hansen, J., Walker, B., Liverman, D., Richardson, K., Crutzen, P., Foley, J. 2009a. A safe operating space for humanity. 
Nature. 461:472-475.

39. Salvati, L.; Tombolini, I.; Perini, L.; Ferrara, A. 2013. Landscape changes and environmental quality: the evolution of land vulnerability and potential resilience to degradation in Italy. Reg. Environ. Change. 13:1223-1233.

40. Scheffer, M., Bascompte, J., Brock, W. A., Brovkin, V., Carpenter, S. R., Dakos, V., Held, H., van Nes, E. H., Rietkerk, M., Sugihara, G. 2009. Early-warning signals for critical transitions. Nature. 461:53-59.

41. Scheffer, M., Carpenter, S. R. 2003. Catastrophic regime shifts in ecosystems: linking theory to observation. Trends in Ecology and Evolution. 18(12):648-656.

42. Scheffer, M., Carpenter, S., Foley, J. A., Folke, C., Walker, B. 2001. Catastrophic shifts in ecosystems. Nature. 413:591-596.

43. Sellberg, M. M.; Wilkinson, C., Peterson, G. D. 2015. Resilience assessment: a useful approach to navigate urban sustainability challenges. Ecology and Society. 20(1):43.

44. Smit, B., Wandel, J. 2006. Adaptation, adaptive capacity and vulnerability. Global Environmental Change. 16:282-292.

45. Steffen, W., Broadgate, W., Deutsch, L., Gaffney, O., Ludwig, C. 2015a. The trajectory of the Anthropocene: The Great Acceleration. The Anthropocene Review. 2(1):81-98.

46. Steffen, W., Richardson, K., Rockström, J., Cornell, S. E., Fetzer, I., Bennett, E. M., Biggs, R., Carpenter, S. R., de Vries, W., de Wit, C. A., Folke, C., Gerten, D., Heinke, J., Mace, G.M., Persson, L. M., Ramanathan, V., Reyers, B., Sörlin, S. 2015b. Planetary boundaries: Guiding human development on a changing planet. Science. 347 (6223): 1259855

47. Steffen, W., Sanderson, A., Tyson, P. D., Jäger, J., Matson, P. A., Moore III, B., Oldfield, F., Richardson, K., Schellnhuber, H. J., Turner, B. L., Wasson, R. J. 2004. Global Change and the Earth System: A Planet Under Pressure. Springer.

48. Stockholm Resilience Centre. 2014. What is resilience? An introduction to social-ecological research. Stockholm Resilience Centre, Stockholm, Sweden. [online] URL: http://www.stockholmresilience.org/download/18.10119fc11455d3c557d6d21/1398172490555/SU_SRC_ whatisresilience_sidaApril2014.pdf

49. Thorn, R. 1969. Topological models in biology. Topology. 8:313-33X.

50. Walker, B., Barrett, S., Polasky, S., Galaz, V., Folke, C., Engström, G., Ackerman, F., Arrow, K., Carpenter, S., Chopra, K., Daily, G., Ehrlich, P., Hughes, T., Kautsky, N., Levin, S., Mäler, K. G., Shogren, J., Vincent, J., Xepapadeas, T., de Zeeuw, A. 2009. Looming global-scale failures and missing institutions. Science. 325:1345-1346.

51. Walker, B., Gunderson, L. H., Kinzig, A. P., Folke, C., Carpenter, S. R., Shultz, L. 2006. A handful of heuristics and some propositions for understanding resilience in social ecological systems. Ecology and Society. 11(1):13.

52. Walker, B., Holling, C. S., Carpenter, S. R. Kinzig, A. 2004. Resilience, adaptability and transformability in social-ecological systems. Ecology and Society. 9(2):5.

53. Walker, B., Meyers, J. A. 2004. Thresholds in ecological and social-ecological systems: a developing database. Ecology and Society. 9(2):3.

54. Walker, B., Salt, D. 2006. Resilience Thinking: Sustaining Ecosystems and People in a Changing World. Island Press: Washington, D.C., USA.

55. Walker, B., Salt, D. 2012. Resilience Practice: Building Capacity to Absorb Disturbance and Maintain 
Function. Island Press: Washington, D.C., USA.

56. Wang, S. H., Huang, S. L., Budd, W. W. 2012. Resilience analysis of the interaction of between typhoons and land use change. Landscape and Urban Planning. Landscape Urban Plan. 106:303-315.

57. West, S. P., Schultz, L. 2015. Learning for resilience in the European Court of Human Rights: adjudication as an adaptive governance practice. Ecology and Society. 20(1):31.

58. Westley, F., Carpenter, S. R., Brock, W. A., Holling, C. S., Gunderson, L. 2002. Why systems of people and nature are not just social and ecological systems. Pages 103-119 in L. H. Gunderson and C. S. Holling, editors. Panarchy: understanding transformation of human and natural systems. Island Press, Washington, D.C., USA.

59. Westley, F., Olsson, P., Folke, C., Homer-Dixon, T., Vredenburg, H., Loorbach, D., Thompson, J., Nilsson, M., Lambin, E., Sendzimir, J., Banarjee, B., Galaz, V., van der Leeuw, S. 2011. Tipping toward sustainability: emerging pathways of transformation. Ambio. 40:762-780.

60. Wilkinson, C. 2012. Urban resilience: what does it mean in planning practice? Planning Theory and Practice. 13(2):319-324.

61. World Urbanization Prospects. 2014. United Nations, New York.

62. Yorque, R., Walker, B., Holling, C. S., Gunderson, L. H., Folke, C., Carpenter, S. R., Brock, W. A. 2002. Toward an integrative synthesis. In L. H. Gunderson and C.S. Holling, editors. Panarchy: understanding transformation of human and natural systems. Island Press, Washington, D. C., USA.

63. Zeeman, E. C. 1976. Catastrophe Theory. Scientific American. 234:65-83. 


\title{
Chapter 2 Resilience Assessment of Human-Environment Systems
}

\author{
--Resilience assessment of urban coupled human-environment systems: an \\ integrated approach of catastrophe theory and adaptive cycle
}

\begin{abstract}
Resilience thinking is a rising topic in sustainability discourse and urban social-ecological systems. This research calculated social-ecological resilience according to the modified catastrophe model from an urban human and environmental perspective in Lianyungang, a coastal "open-up" city in China. Adaptive cycle theory was used as a transition theory for detailed analysis of changes in resilience of coupled human and environment systems during this time. This study: (1) calculates results of human and environmental resilience in terms of four catastrophe models (Fold, Cusp, Swallowtail and Butterfly model), where the resilience degree generally showed an upward trend; (2) addresses resilience with the theory of the adaptive cycle which involves the movement of a system through four phases (exploitation- $r$ : 2000-2002; conservation- $K$ : 2002-2008; release- $\Omega$ : 2008-2009 and reorganization- $\alpha$ : 20092010); (3) illustrates how resilience-based environmental management focuses on specific attributes or drivers of complex human-environmental systems. Moreover, the findings of this study conclude that changes of societies and economies increased the natural environmental vulnerability, and we describe regional and national urban development policies and strategies, which enhance the resilience of coupled human and environment systems.
\end{abstract}

Keywords: resilience, catastrophe model, adaptive cycle, urbanization, coupled humanenvironment systems, environmental management 


\subsection{Introduction}

Resilience is increasingly used as an approach for conceptualizing and managing the dynamic of social-ecological systems (SESs) or human-environment systems (Turner et al. 2003, Berkes et al. 2003, Folke 2006, Peterson 2010, Stokols et al. 2013). Definitions of resilience have broadened from the perspective of ecology to SESs after several decades' development (Gunderson and Holling 2002). It is commonly observed that resilience was first introduced in the field of ecology (Holling 1973, Folke 2006, Janssen and Ostrom 2006, Cutter et al. 2008). Resilience is defined in two principal ways in the ecological literature: one focusing on recovery and return time of an ecosystem to return to equilibrium; another perspective recognizes it as the amount of change that a system can undergo and still maintain the same functions and structures (Carpenter et al. 2001, Walker and Salt 2006).

The resilience concept is also viable for the assessment in urban system at different stages of analysis. Human environment interactions are key relationships in linked urban social and ecological systems (Young et al. 2006, Raymond et al. 2013). The feedbacks between human and environment systems can lead to unique system equilibriums because of the adaptation of coupled human and environment systems. Resilience is applied in many fields including urban related research: urban planning and design (Pickett et al. 2004, Ouyang and Duenas-Osorio 2012), energy and environmental security (Coaffee 2008), and urban water management (PahlWostl 2007, Liu et al. 2012).

Human-environment systems are prototypical examples of complex and adaptive systems, characterized by non-linear dynamics, threshold effects and a significant capacity for surprise (Chapin et al. 2009, Thapa et al. 2010, Wang et al. 2012). Catastrophe theory (Thorn 1969, Zeeman 1976) was proposed in an attempt to rationally account for the phenomenon of discontinuous change in behaviors (outputs) resulting from continuous change in parameters (inputs) in a given system. It has internal variables and control variables; the system settles into an equilibrium state/ basin of attraction or internal variables jump suddenly to a different equilibrium/basin (Lin and Petersen 2013).

An emerging definition of resilience, also termed "adaptive capacity" (Peterson et al. 1998), attempts to capture changing systems in the context of internal demands and external forces. The adaptive cycle theory is a conceptual model of the dynamics of coupled systems of people, nature and technology. It describes the general characteristics of dynamic change in ecosystems as comprising four phases: exploitation, conservation, release and reorganization (Gunderson and Holling 2002). Environmental qualities of resilience are evident in the notion of adaptive capacity, which is generally used to analyze how a system does, or does not, respond to endogenous and exogenous changes (Cutter et al. 2008). More importantly, the adaptive cycle's feedback mechanism helps to instantiate the system through a series of cause and effect processes, those processes include diversity, potential for change, level of redundancy and connectedness (feedbacks, flexibility) (Folke 2006). The adaptive cycle describes the interactions between people, institutions and the environment. The adaptive cycle also provides guidance in terms of how to approach adaptive management, becoming the vehicle for achieving the integration of the related concepts into natural resource decision making. 
This paper introduces a new approach to assess the resilience of human-environment systems with social, economic and environmental indicators. This approach combines a modified catastrophe theory and adaptive cycle theory to model the resilience shifts in a particular coastal urban setting during 2000 to 2010. The objectives of this article are: (1) Quantifying socialecological resilience using catastrophe theory based on human and environmental data, and assessing resilience through the adaptive cycle. (2) Describing the key factors leading to human and environmental resilience shifts. (3) Addressing the effects of diversity policies nationally and regionally (e.g. China's Five-Year-Plan, "One Zone and Two Wings" Policy, environmental protection projects), which play important roles in resilience and changes of humanenvironment systems.

\subsection{Methodological Framework for Deriving Resilience Assessments}

With the purpose of illustrating societies' dependence on ecosystem services and the tight coupling between societal development and ecosystem dynamics, we calculated resilience with human and environmental time series indicators (from 2000 to 2010) of Lianyungang, China. Economic, infrastructural, cultural and residential indices represented societal quality; those indices were used for calculation of human resilience. Environmental indices of waste discharge and treatment were calculated for environmental resilience and evaluated the environmental quality. This section provides an overview of the pre-process where available data for Lianyungang were selected and prepared for the assessment process. Figure 2.1 summarized the sequence of the assessment process for resilience starting with a pre-process wherein the main human and environment indicators were identified. After comprehensive data standardization the central resilience calculation process started in consideration of the catastrophe model approach, and its modifications such as "Fold", "Cusp", "Swallowtails" and "Butterfly" (Thorn 1969). In succession of the framework sequence resilience levels were determined and four different phases of adaptive cycle were computed. Finally all results were reviewed concerning the adaptive cycle response to resilience. To manage and enhance the resilience of coupled human and environment systems, it is vital to identify the drivers of resilience shifts. Major issues about future states of the resilient system are of concern to stakeholders, and major uncertainties about how the system will respond to drivers of change.
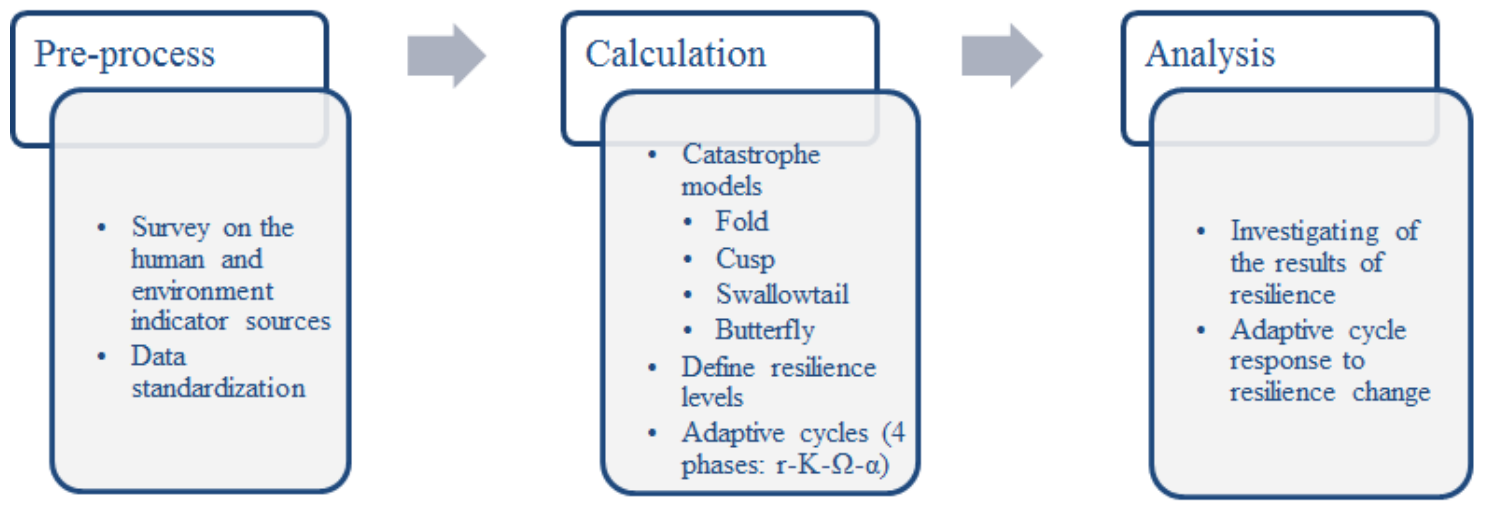

Fig.2.1 Analytical processes for human-environment resilience 


\subsubsection{Available data and development of combined indices for Lianyungang area}

Statistical data are obtained from the Lianyungang Statistical Yearbook 2001-2011 (Lianyungang Bureau of Statistics, 2001-2011). More human data were used for resilience calculation, due to the lack of environmental data. Some indicators (environmental, social, economic and institutional, etc.) for resilience are poverty and deprivation, social capital, quality of life, human development, vulnerability, disaster preparedness, and disaster resilience (Cutter et al. 2008). In total, 74 indices were collected from the Statistical Yearbook (such as financial income, salary, urbanization, energy consumption, fixed assets investment, job condition, numbers of schools and students, etc.).

Indices selection in this study was guided by the principles of integrity, simplicity, dynamic response, geographical accuracy, and data availability based on the importance of every indicator, and most of indicators are commonly used evaluating variables. In the end, we used Principal Component Analysis (PCA) in SPSS Statistics 20 to choose the significant and independent indices from those 74 indices, also in accordance with previously conducted studies ( $\mathrm{Li}$ et al. 2010, Li et al. 2015). Finally, 34 indices were selected that favored the consensus needed to validate our analysis, and divided into two main sub-systems human and environment sub-systems (Table 2.1). Considering that the human sub-system had more indicators than the environment sub-system, we classified all those data into two groups: human-1 and human-2. The human-1 was all economic related indicators from aspects of economy, agriculture and industry, the human-2 includes the situations about other aspects: transport, science, population and resident. Environment sub-system includes: area, treatment and pollution, but some environmental indicators (e.g. soil type and quality, groundwater level and quality, urban air quality and pollution control, surface fragmentation, biodiversity rate etc.) were missing and not available yet.

Table 2.1 Resilience sub-systems and indicators for Lianyungang

\begin{tabular}{lll}
\hline Sub-systems & \multicolumn{1}{c}{ Indicators } & \\
\hline & Economy-1 & Fixed assets investment/GDP \\
& & Average Salary \\
& Proportion of primary industry \\
& & Total income \\
& & Deposit \\
& & GDP \\
& & Retail sales \\
& Agriculture & Agriculture gross product \\
& & Gross product of Farming, Forest, \\
& & Animal husbandry fishing \\
& & Cultivated area \\
& & Crop yield \\
& & Total profit \\
& & Manufactured inventory
\end{tabular}




\begin{tabular}{|c|c|c|}
\hline & & Total assets \\
\hline \multirow{12}{*}{ Human-2 } & Transports & Cargo-handling Capacity of Seaports \\
\hline & & International tourists \\
\hline & & Quantity of possessed motor vehicles \\
\hline & Science Culture & Broadcasting time \\
\hline & & Antiques collection \\
\hline & & Educational institution \\
\hline & Population & Urbanization \\
\hline & & Household population \\
\hline & & Professional workers per 10 thousand \\
\hline & & Employee \\
\hline & Resident & Power consumption \\
\hline & & Total water supply \\
\hline \multirow{8}{*}{ Environment } & Area & Construction scale \\
\hline & & Length of road \\
\hline & Treatment & Decontamination rate of urban refuse \\
\hline & & household garbage \\
\hline & & Industrial solid wastes utilization \\
\hline & & Treated volume of industrial $\mathrm{SO}_{2}$ \\
\hline & Pollution & Volume of Industrial $\mathrm{SO}_{2}$ Emission \\
\hline & & Total discharge of industrial wastewater \\
\hline
\end{tabular}

Given the different dimension and distribution of indices, it was difficult to directly compare or operate among them. Therefore, we standardized the data using formulas (1-2) and eliminated the influence of dimension, magnitude, and positive and negative orientation. For a standardized variable, each case's value on the standardized variable indicated its difference from the mean of the original variable in number of standard deviations (of the original variable), all indicators were transformed to 0 and 1 . The calculation of positive indicators (Average Salary, Agriculture gross product, etc.) should be used when playing a positive role. The greater the index value is, the better the development of the system could be (Formula (1)). The calculation of negative indicators (e.g. Volume of Industrial $\mathrm{SO}_{2}$ Emission, Total discharge of industrial wastewater, etc.) should be used if they play a negative role, the smaller the index value is, the better the development of the system could be (Formula (2)).

Positive indicator: $\quad X_{i j}^{\prime}=\left(X_{i j}-\min \left\{X_{j}\right\}\right) /\left(\max \left\{X_{j}\right\}-\min \left\{X_{j}\right\}\right)$

Negative indicator: $\mathrm{X}_{i j}^{\prime}=\left(\max \left\{X_{j}\right\}-X_{i j}\right) /\left(\max \left\{X_{j}\right\}-\min \left\{X_{j}\right\}\right)$

where $X i j$ represents the value of indicator $j$ in year $i$, and $\max \{X j\}$ and $\min \{X j\}$ indicate the minimum and maximum value of indicator $j$ among all years. 


\subsubsection{Catastrophe models}

\section{Application of catastrophe models}

Environmental resilience Catastrophe models were used for calculating the resilience of human-environment systems based on those 34 indices. Resilience assessment indices and transformed standards are given in Table 2.2. Human-environment systems undergo natural and environmental stochastic or human disturbances and their response indicates the level of resilience. Resilience is particularly characterized by complexity and nonlinear dynamics, and many systems can exist in what are called alternate stable states (Scheffer et al. 2001). Catastrophe theory is a method for describing the evolution of forms, which is particularly applicable where gradually changing forces produce sudden effects, which can be used for detecting the effects of environmental stochastic or human disturbances in resilience changes. Catastrophe theory has four models: Fold, Cusp, Swallowtail and Butterfly, and each of them have their own equilibrium surface. The type of model used was chosen according to the dimensions (numbers) of control variables of each sub-system. Summary descriptions of catastrophe models and their normalization formula are as follows:

(1) Fold catastrophe:

$$
\mathrm{V}=\mathrm{x}^{3}+\mathrm{ax} ; \mathrm{X \textrm {a } _ { 1 }}=\sqrt{\mathrm{a}_{1}}
$$

at negative values of a, the potential has two extrema - one stable, and one unstable. If the parameter a is slowly increased, the system can follow the stable minimum point. The fold catastrophe is used for a sub-system that has only one indicator.

(2) Cusp catastrophe:

$$
V=x^{4}+a x^{2}+b x ; \quad X a_{1}=\sqrt{a_{1}}, \quad X a_{2}=\sqrt[3]{a_{2}}
$$

when one explores what happens to a fold bifurcation if a second parameter, $b$, is added to the control space. The Cusp catastrophe model has two dimensions of control variables, so it can be used for a sub-system that has two indicators.

(3) Swallowtail catastrophe:

$$
\begin{gathered}
V=x^{5}+a x^{3}+b x^{2}+c x \\
X a_{1}=\sqrt{a_{1}}, \quad X a_{2}=\sqrt[3]{\mathrm{a}_{2}}, \quad X a_{3}=\sqrt[4]{\mathrm{a}_{3}}
\end{gathered}
$$

the control parameter space is three dimensional. The bifurcation set in parameter space is made up of three surfaces of fold bifurcations, which meet in two lines of cusp bifurcations, which in turn meet at a single swallowtail bifurcation point. Those sub-systems have three indicators, and they are suitable for this model.

(4) Butterfly catastrophe:

$$
\begin{gathered}
V=x^{6}+a x^{4}+b x^{3}+c x^{2}+d x ; \\
X a_{1}=\sqrt{a_{1}}, \quad X a_{2}=\sqrt[3]{a_{2}}, \quad X a_{3}=\sqrt[4]{a_{3}}, \quad X a_{4}=\sqrt[5]{a_{4}}
\end{gathered}
$$

depending on the parameter values, the potential function may have three, two or one different local minima, separated by the loci of fold bifurcations. At the butterfly point, the different 3 - 
surfaces of fold bifurcations, the 2-surfaces of cusp bifurcations, and the lines of swallowtail bifurcations all meet up and disappear, leaving a single cusp structure remaining when a $>0$. Butterfly catastrophe model has four indicators which is the largest dimension of control variables.

\section{Resilience value transformation}

Since the catastrophe progression is calculated based on the normalization formula, the synthetic values of catastrophe assessment are generally high and the differences are not obvious (Poston and Ian 1978), it is difficult to determine the actual secure level directly using the results obtained by catastrophe assessment. Therefore, the synthetic values of multiattribute assessment were divided into five grades using K-means cluster analysis in SPSS Statistics 20. In data mining, it is a method of cluster analysis which aims to partition $n$ observations into k clusters in which each observation belongs to the cluster with the nearest mean. As a result, each index was classified into 5 grades: non-resilience, lower resilience, middle, resilience and higher resilience (Table 2.2). For instance, the economy in human-1 subsystem, its value ranged from 0.53 in 2000 to 0.94 in 2010, all the resilience values of each indicator were transformed into five grades according to the results of K-means cluster classification, the economy resilience were classified as: non-resilience (Grade 1) that less than 0.54; lower resilience (Grade 2) from 0.54 to 0.68 ; resilience (Grade 3) from 0.68 to 0.78 ; middle resilience (Grade 4) from 0.78 to 0.88 ; and the last one, higher resilience (Grade 5) was more than 0.88. Overall, the resilience results were divided into these five grades as economy. Because different indicators had different resilience values, consequently each indicator had its own grades values. As a result, the results curves were drawn by the grades from 1 to 5 instead of their resilience values.

Table 2.2 Corresponding grade values of catastrophe models

\begin{tabular}{ccccccc}
\hline \multirow{2}{*}{ Grades } & & Non-resilience & $\begin{array}{c}\text { Lower } \\
\text { Resilience }\end{array}$ & $\begin{array}{c}\text { Resilienc } \\
\text { e }\end{array}$ & $\begin{array}{c}\text { Middle } \\
\text { Resilience }\end{array}$ & $\begin{array}{c}\text { Higher } \\
\text { Resilience }\end{array}$ \\
\cline { 3 - 7 } & & 1 & 2 & 3 & 4 & 5 \\
\hline \multirow{2}{*}{ Human-1 } & Economy & $<0.54$ & $0.54-0.68$ & $\begin{array}{c}0.68- \\
0.78\end{array}$ & $0.78-0.88$ & $>0.88$ \\
& Agriculture & $<0.4$ & $0.4-0.5$ & $0.5-0.7$ & $0.7-0.9$ & $>0.9$ \\
& Industry & $<0.2$ & $0.2-0.45$ & $0.45-$ & $0.65-0.8$ & $>0.8$ \\
& & & & 0.65 & & $>0.8$ \\
& Transports & $<0.1$ & $0.1-0.4$ & $0.4-0.6$ & $0.6-0.8$ & $>0.7$ \\
& Science & $<0.4$ & $0.4-0.6$ & $0.6-0.65$ & $0.65-0.7$ & $>0.8$ \\
& Culture & & & & & \\
& Population & $<0.1$ & $0.1-0.4$ & $0.4-0.6$ & $0.6-0.8$ & $>0.9$ \\
& Resident & $<0.15$ & $0.15-0.4$ & $0.4-0.7$ & $0.7-0.9$ & $>0.7$ \\
& Area & $<0.2$ & $0.2-0.4$ & $0.4-0.55$ & $0.55-0.7$ & $>0.8$ \\
& Treatment & $<0.3$ & $0.3-0.5$ & $0.5-0.7$ & $0.7-0.8$ & $>0.8$ \\
\hline
\end{tabular}




\subsubsection{Adaptive cycle}

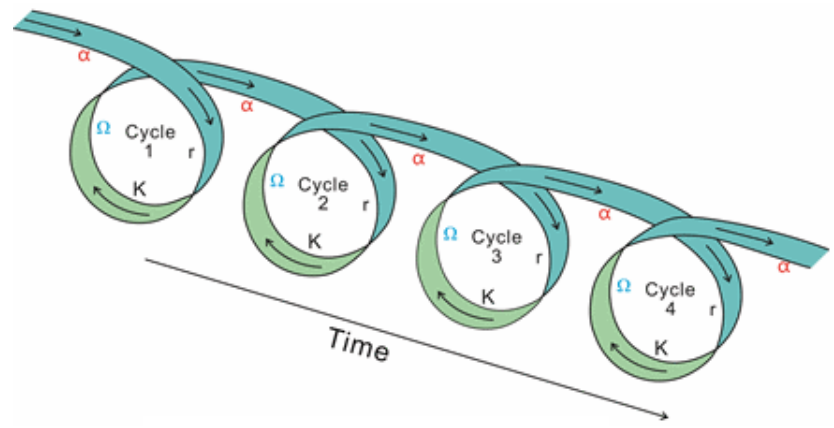

Fig.2.2 Resilience adaptive cycle (Source: Carpenter et al. 2001)

The last section is to evaluate the resilience results derived by catastrophe models. Since the resilience results from catastrophe models were only quantitative values, the theory of adaptive cycle, as a typical theory in resilience, provides a systematic lens to explain and evaluate resilience results from different movement phases. With the dynamic statement of different resilience phases, we can distinguish the positive and negative stage, and stability and redundancy of resilience. Generally, an adaptive cycle involves the movement of a system through four phases (Fig.2.2): (1) rapid growth and exploitation (r); (2) leading into a long phase of accumulation, monopolization, and conservation of structure $(\mathrm{K})$, during which resilience tends to decline; (3) a very rapid breakdown or release phase (creative destruction, $\Omega$ ); (4) a relatively short phase of renewal and reorganization $(\alpha)$ (Carpenter et al. 2001, Liu et al. 2007).

The "forward" (r to K) and "backloop" ( $\Omega$ to $\alpha$ ) dynamics of the adaptive cycle correspond to managing production and managing sustainability. They can be likened, in the area of investment, to the part of the portfolio aimed at maximizing income $(\mathrm{r}-\mathrm{K})$ and the part aimed at maximizing flexibility to cope with, and adapt to, unexpected change in the market ( $\Omega$ to $\alpha)$. The system sufficiently retains previous components, so it can reorganize and remain within the same configuration as before. But it is also a time when novelties can enter-new species, new institutions, ideas, policies, and industries - and the "new", emerging system, whether it is in the same or a different configuration, gains resilience. They have been shown to continually go through dynamic phases of exploitation, conservation, release, and reorganization. As a system passes through the different stages of the adaptive cycle, its resilience is subject to change. Resilience typically declines during long, undisturbed phases of stability (the "front-loop" of the adaptive cycle). During such phases, the tendency of system actors is to promote efficiency by removing redundancies in human resources, natural resources, infrastructure, and operational procedures, and reduce investment in coping and recovery strategies.

\subsection{Results and Discussions}

The resilience shifts are represented by three parts: human sub-system, environmental sub- 
system and the total integrated system.

\subsubsection{Human sub-system}

By using the catastrophe model and adaptive cycle, calculated with the statistical data between 2000 and 2010, we estimated the temporal trend of human resilience values (Fig. 2.32.6).

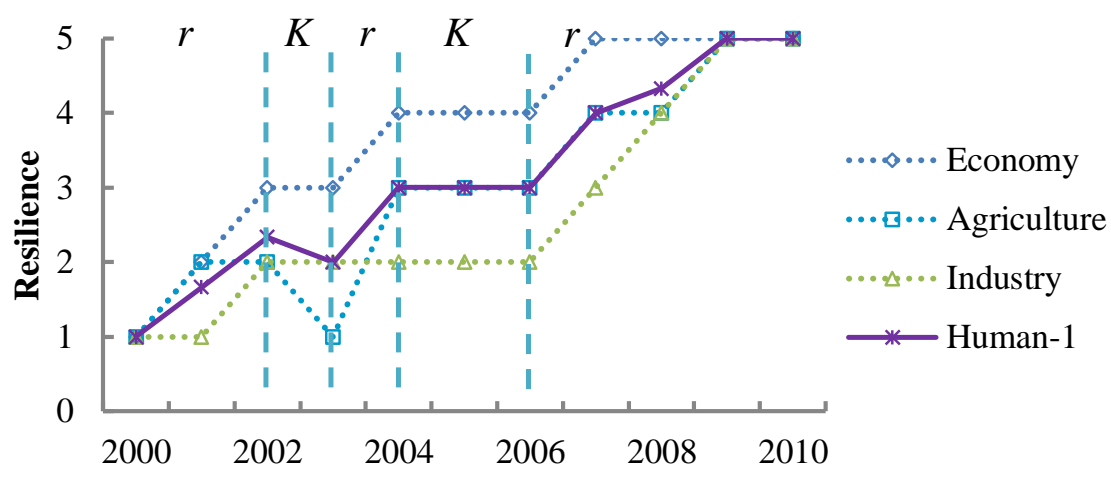

Fig.2.3 Resilience trends of the human-1 sub-system (2000-2010)

As shown in Fig.2.3, the human-1 sub-system changed from low resilience (Grade 1) to the highest resilience (Grade 5). The economy values in Fig.2.3 were the average value of Economy-1 and Economy-2. In 2003, it shows the main factor of this decline was agriculture in 2003, which means agriculture in general was the most effectible index in the human-1 subsystem. However, the main trend of mean value was guided by a combination effect of all three aspects of economy, agriculture and industry. During 2000 to 2010, resilience of human-1 subsystem switched between two phases of the adaptive cycle in human-1 sub-system are: the first state was from 2000 to 2002 as the rapid growth and exploitation (r), during which resilience of human-1 sub-system increased largely to Grade 2; then from 2002 to 2003, it turned into a long phase of accumulation, monopolization, and conservation of structure $(\mathrm{K})$, resilience declined back to the value of 2001; in the year of 2004, it increased to the second peak value of Grade 3; until 2006, it appeared to be a relatively stable conservation phase, which stay at the same grade; after 2006, it ended with a rapid growth and exploitation phase.

Several factors have been adduced to explain the fall in 2003: The natural disasters of floods, longer cloudy and rainy weather, and lodging, lack of sunshine and frequent plant diseases and insect pests. All the agriculture indicators decreased in 2003, and both crop yield and cultivated Area turned to be the lowest values. As agriculture was the principal type of production, the large-scale decrease of crops in Lianyungang became a main pressure. The annual grain yield of Lianyungang in 2003 was 203.5 tons, with $11.8 \%$ decrease compare to annual grain yield in 2002. Crop farming production was 7.0 billion tons, which reduced $9.6 \%$ in 2002; output of cotton, oil crops, and vegetables decreased $26.7 \%, 28.7 \%$ and $7.2 \%$, respectively. Moreover, China began the rapid heavy industrialization process during the 10th Five-Year-Plan (20012005). Heavy manufacturing, as material-intensive manufacturing developed quickly in this period, made the decoupling trends become worse during 2002-2007. The proportion of 
primary industry of Lianyungang in 2003 decreased to $23.6 \%$ from $24.7 \%$ in 2002 . The total profit of secondary industry stayed 1135.6 billion CNY in 2003 that was the same in 2002. However, the GDP contribution from heavy manufacturing industry increased to $56.6 \%$ in 2003. The change of manufacturing industry structure, which started in 2002, was the main driver from the industry perspective, maintaining the same level since 2002.

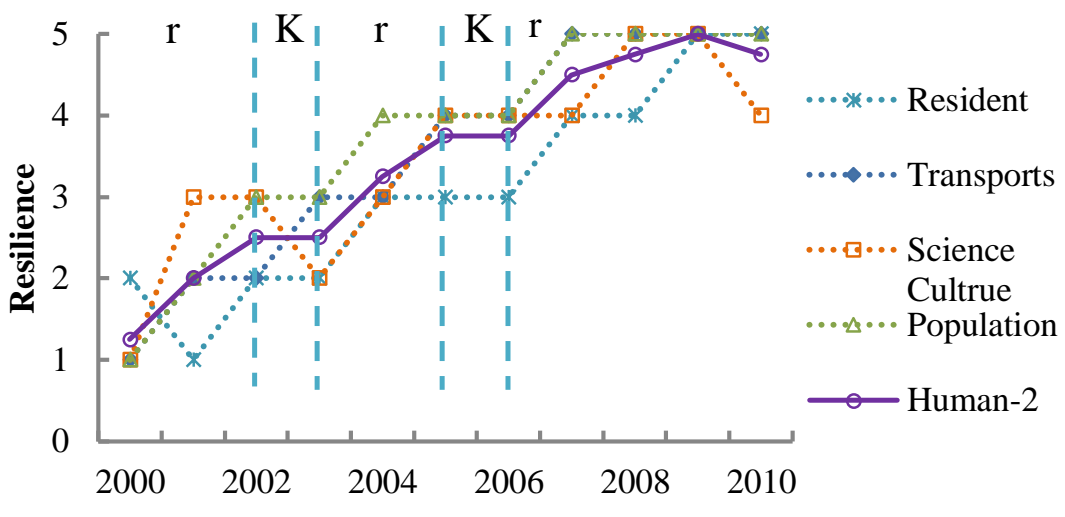

Fig.2.4 Resilience trends of the human-2 sub-system (2000-2010)

In general, the resilience of human-2 sub-system changed from non-resilience (Grade 1) into higher resilience (Grade 5), which is the same with human-1 sub-system. In other words, the whole human sub-system was evaluated as more reliable in the recent decade, and all of these indicators affected the comprehensive value. As displayed in Fig.2.4, the resilience of human2 sub-system presented an increased line curve with several exploitation and conservation phases. The values of resilience degree gradually increased in several exploitation phases: 2000-2002, 2003-2005 and 2006-2010; and during the other time, it maintained temporary balance in conservation phases.

Compared to the downturn resilience of human-1, human-2 sub-system raced up after 2006 which can be seem as $r$ phase; then it slowed down and tended to decrease in 2009, which can be a start of another $\mathrm{K}$ phase. The main drivers for the resilience change of human-2 sub-system (Fig.2.4) are transportation infrastructure and population. Even through compare to other coastal ports like Yantai, Xiamen, etc., Lianyungang has less import and export flows. It still increased dramatically to 0.14 billion tons in 2010. The transportation infrastructure increased each year due to the large increase of Quantity of Possessed Motor Vehicles ( 0.3 in 2000 to 0.6 million in 2010) and Cargo-handling Capacity of Seaports (27.1 in 2000 to 135.1 million tons in 2010). On "China's 21st Century Agenda", Lianyungang is to be developed into an international seaport linking countries in the Pacific Rim with those in Central Asia. It is one of three special development zones in the "National Ocean Development Plan". As a matter of fact, with the proposal of the "One Zone and Two Wings" policy ("One Zone" refers to the main urban area and the area from Longhai to Donghai; "Two Wings" refers to the Binghai area on two sides of the "One Zone") as the vertical strategy in the following interval, the outer zone becomes the most creative and resilient area. Until 2013, it has invested 3.6 billion CNY, which improves the capacity of Lianyungang. 


\subsubsection{Environment sub-system}

Similar to the human sub-system, the resilience of the environmental sub-system also presented an upward trend. However, the mutation point was detected in 2003, 2004, 2007 and 2009 (Fig.2.5). Figure 6 revealed that environmental resilience levels, with regard to the state index, generally remained at a lower level of resilience (Grade 2) to middle resilience (Grade 4) across the period of 2002 to 2010. More specifically, environmental resilience was considered as lower resilience in the beginning year of 2000, while the human resilience started from non-resilience. According to the statistics, from 2000 to 2005, the degree of environmental resilience was influenced by area and treatment. Conversely, even though the value of area and treatment increased during this period, the mean value of environmental resilience stayed at the degree between resilience and middle resilience, because of the abrupt drop in pollution from 2006. The $\mathrm{r}$ phases were 2000-2002 and 2004-2006, during which resilience increased exponentially to Grade 3; followed with two $\mathrm{K}$ phases after each exploitation phase. It first declined and then kept the same value at 2004, and resilience had slow changes each year since 2006 .

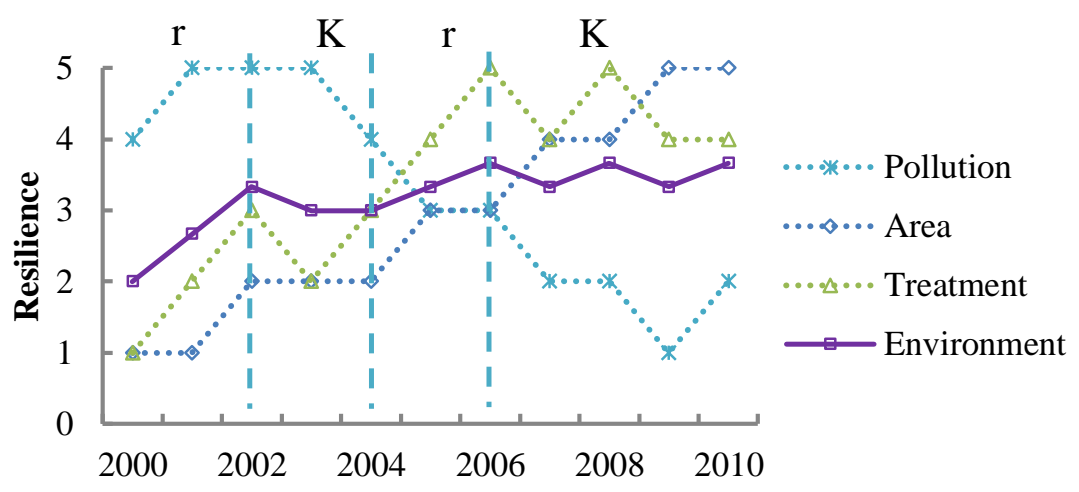

Fig.2.5 Resilience trends of the environment sub-system (2000-2010)

The resilience of environment increased slightly during 2000 to 2010, which was affected by resilience of pollution (Fig.2.5). Even though the Chinese government pursued economic growth to improve life quality, the growth increased at a slower and slower pace. China's population is also expected to grow slowly in the near future. Consumption, in its broadest sense, is a fundamental driver of urban change, the growth of the economy and population will still result in increased environmental pressure, which means the consequence of increase pollution (the decrease of pollution resilience in Fig.2.5). China's economic growth was dominated by light manufacturing industries before 2002 . However, the production structure change induced increasing environmental pollution in 2002-2007 due to the rapid development of heavy manufacturing industries. During 2007-2010, because of the "Industrial Structure Adjustment" policy, China changed the focus into upgrading traditional manufacturing and eliminating outdated technologies. These actions greatly changed the production structure and led to the mitigation of environmental pollution during this period, which caused the decrease of resilience in pollution. 
In addition, due to the environmental protection projects, such as the Urban Human Settlement Construction Project (2006-2010) and the Comprehensive Countermeasures for Basin Ecosystem (2005-2010) that significantly reduced 15878 tons COD and 796 tons $\mathrm{NH}_{3}-$ $\mathrm{N}$ in sewage discharge. The Circular Economy and the Industrial Pollution Treatment Project (2005-2008) reduced 5.3 million tons discharge of waste water, and 1089 tons COD. All these environmental policies improved the resilience of treatment (Fig.2.5), even with more discharge of waste water. As a result of the bankruptcy of a Phosphate company that was one of the major industrial solid wastes producers, $\mathrm{SO}_{2}$ emissions were reduced.

\subsubsection{Social-ecological systems approach}

The resilience of human and environment systems showed an upward trend (Fig.2.6), signifying adaptive and sustainable development during the last decade. As displayed in Fig.7, the total resilience degree presented a wave-liked curve. The resilience degree increased gradually, and reached a peak at 2002 and then went down to a conservation phase of Grade 2 in 2003. The second adaptive cycle started with a rapid exploitation phase until 2005, during which resilience increased to Grade 4. It kept the same level with a stable conservation phase until 2008, and then it shifted to a release phase until 2009, its resilience decreased back to the value of 2003, and started with a rapid exploitation instead of reorganization phase. According to resilience results, overall resilience during the latest decade turned out optimistic results with significant improvement. Rapid urbanization accompanied by resident population growth in recent decades was an important cause for the current environmental problems being experienced in Lianyungang; on the contrary, from the resilience curve of the human subsystem, it increased more rapidly than the resilience of environmental sub-system. It can be seen that the human sub-system was therefore a factor of greatest influence on the comprehensive level of resilience. Referring to the statistical data and government reports, it shows the decrease of resilience in 2003 was caused by agricultural and economic indices, due to extreme weather, natural disasters and government management policies.

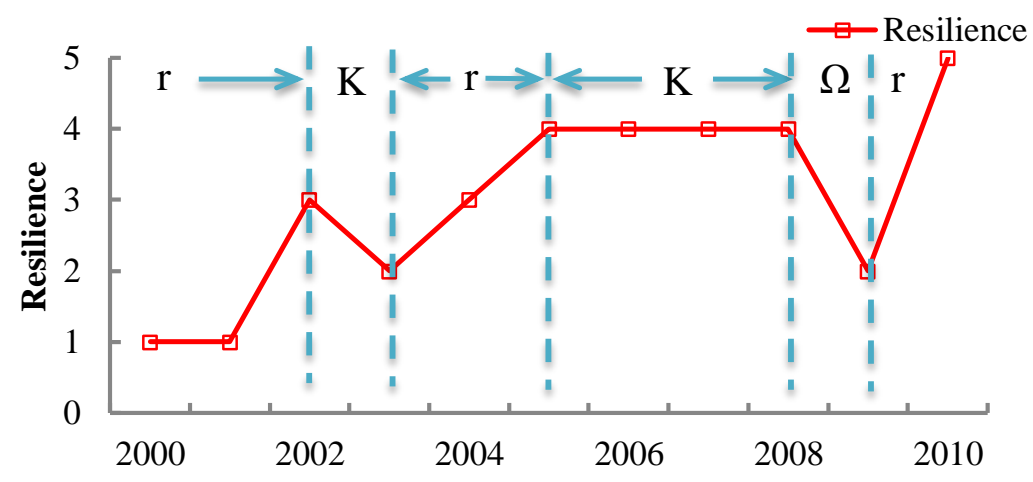

Fig.2.6 Total Resilience Curve (2000-2010)

In the human-1 sub-system, industry and agricultural indices made greater contributions to the coupling system than the other factors. For industry items, urbanization greatly stimulated 
the up scaling and the expansion of total industry assets, increased from 214.4 billion CNY in 2000 to 1584.4 billion CNY in 2010, an increase of 639.9\%; and for the agricultural indices, agriculture crop yields increased from 22.5 million tons in 2000 to 35.1 million tons in 2010, an increase of 56\%. In the human-2 sub-system, transportation infrastructure and resident indices were two of the most effective indicators. For transport indices, the values of quantity of possessed motor vehicles gradually increased from 29.5 million in 2000, reached peak at 60.4 million in 2010; For resident indices, the total water supply increased from 0.8 billion tons in 2000 to 1.4 billion tons in 2010 . Where the high population density and wealth come together, demands for industrial and commercial uses, public infrastructure (e.g. roads, water facilities, and utilities), crops and other agriculture products, housing increase and upcoming construction projects start to appear as "rural sprawl" (Mann 2009). However, it means those will become the influential factors for quick recovery from an environmental perturbation.

In the face of complex domestic/international situations and a series of challenges with comprehensively advancing reforms, those brought about a rapid development in China. Also Lianyungang's productive forces and the overall national strength improved significantly. Progress in all social programs accelerated and livelihoods improved significantly. Comprehensive progress was made in education, science and technology, culture, public health and sports programs. The social security system covering both urban and rural areas was progressively refined. Major progress was made in the reform and opening up policy. New breakthroughs were achieved in crucial areas and key links of reform, and the socialist market economy further improved.

The results implicated that the resilience of coupled human and environment systems increased from 2000 to 2010 in Lianyungang, this result was similar to our previous research (Li et al. 2012) which exhibited that resilience degree generally showed an upward trend. It demonstrated the adaptive and sustainable development of human and environment during the last decade, which showed similar conclusions to other research (Zhang et al. 2015). This situation should also draw the attention of policy makers and public as well. It is true that the government has invested in a number of environmental protection projects and the proportion of scientific research staff was steadily increased. However, the industrial pollution issues have not been effectively tackled which leads to the resilience degrade. Industries are the major sector for the local labor market and also the major financial source for local government. Normally, performance evaluation on local officials is mainly associated with economic growth; environmental protection is not listed as one of the criteria except if serious environmental disasters are made and raises concern ( $\mathrm{Su}$ et al. 2011, Gaudreau 2014). Even though pollution monitoring systems have been introduced, it still tends to lose power in playing an effective role since it is too low to give polluters incentives to reduce their emissions. Water pollution fees are small relative to the marginal costs of pollution control.

\subsection{Conclusion}

This article formulated the resilience of coupled human and environment systems by linking catastrophe theory and adaptive cycle theory, which provides an initial exploration of how these 
two approaches can be combined for social-ecological resilience assessment. The catastrophe theory provides an exercisable method to calculated resilience from the discontinuous changes arose by the dynamic human impacts on environmental system. The accelerating interactions between coupled human-environment systems may lead to degradation and environmental collapse, which in turn compromise the adaptive capacity of coupled human-environment systems. The adaptive cycle highlighted and visualized the characteristic of the dynamic resilience phases derived from the catastrophe theory, especially the adaptive cycle theory as transition theory allows detailed analysis of changes in resilience. Although the adaptive cycle has been addressed in some studies on resilience, this study applied catastrophe theory to resilience for the first time, quantifying and promoting the integration of complexity and nonlinear dynamics of human and environmental resilience.

Additionally, we also explained different phases of adaptive cycle. For all three sub-systems, the transition of resilience states stayed in the fore loop mode with exploitation phases and conservation phases. And the total resilience experienced more integrated and complex transformations: firstly $\mathrm{r}$ phase, resilience increased and reached a peak at 2002, and then decreased in 2003 with a short conservation phase; afterward, it altered to a new adaptive cycle with a exploitation phase-a rapid increase until 2005; and followed with a conservation phase, resilience maintained at the same level until 2008; and transformed to the only one release phase in 2009, resilience decreased back to the value of 2003; the system's resilience bounced up to the highest grade after 2009. Generally, Lianyungang had a rapid resilience transition and oscillation, but ended in a deliberate and positive state.

Each particular driver has different performances for different resilience pressures. For the human sub-system of Lianyungang, the growth of agricultural production and population, and resource demands were the main drivers of resilience change. The environmental pollution change following with the industrial production structure change was the most influential factor in maintaining environmental resilience in Lianyungang. After 2004, because of the environmental protection projects and industrial structure adjustment, the environmental resilience stayed in equilibrium. Therefore, the integration of resilience criteria should be highlighted in policy development. Stricter policies should be implemented in order to keep resilient and sustainable development in the future. Fortunately, after the collapse, environmental management agencies adjusted their mode of independent operation to an integrated loop of involvement with consensus building and decision making, which involved managers and stakeholders. In the "forward" period strong controls existed with slow system changes; regulatory policies and efforts to increase efficiency may be appropriate, although careful experimentation is sometimes critical and application of techniques such as environmental optimal control can be useful. As for the "back loop" period, the system changes rapidly, and is turbulent, with no equilibrium. These two resilience periods will help environmental management agencies to figure out that what is the appropriate approach and potentially resilient new practices.

This paper provided a valuable platform for analyzing resilience based on human and environmental statistical data, but participants in the social and ecological resilience determined that more evaluated data was required for more detail assessment. Moreover, more 
ecological data or more sophisticated models will be used for further regional estimates. For example, land use cover and change data are under preparation.

\section{References}

1. Berkes, F., Colding, J., Folke, C. 2003. Navigating social ecological systems: building resilience for complexity and change. Cambridge University Press, Cambridge, UK.

2. Carpenter, S., Walker, B., Anderies, J. M., Abel, N. 2001. From metaphor to measurement: resilience of what to what? Ecosystem. 4:765-781.

3. Chapin, F. S., Kofinas, G. P., Folke, C. 2009. Principle of ecosystem stewardship: Resilience-based natural resource management in a changing world. New York: Springer.

4. Coaffee, J. 2008. Risk, resilience, and environmentally sustainable cities. Energy Policy. 36:4633-8.

5. Cutter, L. S., Barnes, L., Berry, M., Burton, C., Evans, E., Tate, E., Webb, J. 2008. A place-based model for understanding community resilience to natural disasters. Global Environmental Change. 18:598-606.

6. Folke, C. 2006. Resilience: the emergence of a perspective for social-ecological systems analyses. Global Environmental Change. 16:253-267.

7. Gaudreau, M. 2014. State and Society in China's Environmental Politics. Global Environmental Policy. 14:139-144.

8. Gunderson, L. H., Holling, C. S. 2002. Panarchy: understanding transformations in human and natural systems. Island Press, Washington, D.C., USA.

9. Holling, C. S. 1973. Resilience and stability of ecological systems. Annual Review of Ecology and Systematics. 4:1-23.

10. Janssen, M., Ostrom, E. 2006. Resilience, vulnerability, and adaptation: a cross-cutting theme of International Human Dimension Programme on global Environmental Change. Global Environmental Change. 16:237-239.

11. Li, Y. F., Li, Y., Zhou, Y., Shi, Y. L., Zhu, X. D. 2012. Investigation of a coupling model of coordination between urbanization and the environment. Journal of Environmental Management. 98:127-133.

12. Li, Y. F., Shi, Y. L., Zhu, X. D., Cao, H. H., Yu, T. 2014. Coastal wetland loss and environmental change due to rapid urban expansion in Lianyungang, Jiangsu, China. Regional Environmental Change. 14:11751188.

13. Lin, B. B., Petersen, B. 2013. Resilience, regime shifts, and guided transition under climate change: examining the practical difficulties of managing continually changing systems. Ecology and Society. 18:28.

14. Liu, D. D., Chen, X. H., Nakato, T. 2012. Resilience Assessment of Water Resources System. Water Resource Management. 26:3743-3755.

15. Liu, J. G., Dietz, T., Carpenter, S. R., Alberti, M., Folke, C., Moran, E., Pell, A. N., Deadman, P., Kratz, T., Lubchenco, J., Ostrom, E., Ouyang, Z. Y., Provencher, W., Redman, C. L., Schneider, S. H., Taylor, W. W. 2007. Coupled Human and Natural Systems. Ambio. 36:639-649.

16. Mann, F. 2009. Institutional causes of urban and rural sprawl in Switzerland. Land Use Policy. 26:919-924.

17. Ouyang, M., Duenas-Osorio, L. 2012. Time-dependent Resilience Assessment and Improvement of Urban Infrastructure Systems. CHAOS. 22:033122.

18. Pahl-Wostl, C., Sendzimir, J., Jeffrey, P., Aerts, J., Berkamp, G., Cross, K. 2007. Managing change toward adaptive water management through social learning. Ecology and Society. 12:30-48.

19. Peterson, G. 2010. Expansion of social ecological systems science. Reslilence Science [online] URL: 
http://rs.resalliance.org/2010/04/16/expansion-of-social ecologicalsystems-science/.

20. Peterson, G. D., Allen, C. R., Holling, C. S. 1998. Ecological resilience, biodiversity, and scale. Ecosystems. 1:6-18.

21. Pickett, S. T. A., Cadenasso, M. L., Grove, J. M. 2004. Resilient cities: meaning, models, and metaphor for integrating the ecological, socio-economic, and planning realms. Landscape and Urban Planning. 69:369-84.

22. Poston, T., Ian, S. 1978. Catastrophe theory and application. Lord, Pitman.

23. Raymond, C. M., Singh, G. G., Benessaiah, K., Bernhardt, J. R., Levine, J., Nelson, H., Turner, N. J., Norton, B., Tam, J., Chan, K. M. A. 2013. Ecosystem Services and Beyond: Using Multiple Metaphors to Understand Human-Environment Relationships. BioScience. 63:536-546.

24. Scheffer, M., Carpenter, S., Foley, J. A., Folke, C., Walker, B. 2001. Catastrophic shifts in ecosystems. Nature. 413:591-596.

25. Stokols, D., Perez Lejano, R., Hipp, J. 2013 Enhancing the resilience of human-environment systems: a social-ecological perspective. Ecology and Society.18:7.

26. Su, S. L, Li, D., Yu, X., Zhang, Z. H., Zhang, Q., Xiao, R., Zhi, J. J., Wu, J. P. 2011. Assessing land ecological security in Shanghai (China) based on catastrophe theory. Stoch Env Res Risk A 25:737-746.

27. Thapa, S., Marshall, F., Stagl, S. 2010. Understanding peri-urban sustainability: The role of the resilience approach (STEPS Working Paper 38). Brighton: STEPS Centre.

28. Thorn, R. 1969. Topological models in biology. Topology. 8:313-33X.

29. Turner, B. L., Kasperson, R. E., Maston, P., McCarthy, J. J., Corell, R. W., Christensen, L., Eckley, N., Kasperson, J. X., Luers, A., Martello, M. L., Polsky, C., Pulsipher, A., Schiller, A. 2003. A framework for vulnerability analysis in sustainability science. Proceedings of the National Academy of Sciences of the United States of America. 100:8074-8079.

30. Walker, B., Salt, D. 2006. Resilience thinking: sustaining ecosystems and people in a changing world. Island Press, Washington, DC.

31. Wang, S. H., Huang, S. L., Budd, W. W. 2012. Resilience analysis of the interaction of between typhoons and land use change. Landscape and Urban Planning. 106:303-315.

32. Young, O. R., Lambin, E. F., Alcock, F., Haberl, H., Karlsson, S. I., McConnell, W. J., Myint, T., PahlWostl, C., Polsky, C., Ramakrishnan, P., Schroeder, H., Scouvart, M., Verburg, P. H. 2006. A portfolio approach to analyzing complex human-environment interactions: institutions and land change. Ecology and Society.11:31-35.

33. Zeeman, E. C. 1976. Catastrophe Theory. Scientific American. 234:65-83.

34. Zhang, K., Dearing, J. A., Dawson, T. P., Dong, X. H., Yang, X. D., Zhang, W. G. 2015. Poverty alleviation strategies in eastern China lead to critical ecological dynamics. Science of the Total Environment. 506:164181. 


\title{
Chapter 3 Resilience Assessment of Social-Ecological Systems
}

--A catastrophe-based urban social-ecological resilience assessment and early warning implications

\begin{abstract}
Resilience provides an approach for understanding the dynamic capacity of a system to absorb disturbances in social-ecological systems. With the purpose of assessing social-ecological resilience and its changes, we developed a resilience assessment model based on catastrophe theory with indicators organized around distinct dimensions of each sub-system. We examined the interplay and complementarities of urban resilience in the five administrative areas of Lianyungang city (Central District, Ganyu County, Donghai County, Guannan County, Guanyun County) from 2000 to 2010. Two different resilience states ("Less resilient" or "More resilient") were assessed through the probability distribution equilibrium/equilibria, which provide an integrative method for externalizing resilience trend based on the catastrophe results. The tipping point occurred in "Less resilient" system was the early warning signal of critical resilience transition. We found that economy and transportation were two primary changes of resilience with local development policies and national plans. Therefore, it is forward-looking and helps to explore policy options for navigating resilience change in future development.
\end{abstract}

Keywords: catastrophe model, early warning, probability distribution equilibrium/equilibria (PDE), social-ecological resilience 


\subsection{Introduction}

Resilience provides a suitable lens to evaluate responses to a system's shifts as it interacts with both natural stochastic or human disturbances (Walker and Salt 2012). A wide body of research illustrates the different aspects found in the definitions of general and specific resilience. Social-ecological resilience is a conceptual foundation for natural system management which is integrated with social communities, human activities and market dynamics, as well as a better understanding of complex feedback from other components or ecosystems (Adger et al. 2005, Berkes and Folke 1998, Folke 2006). Ultimately, resilience offers mechanisms for navigating the transformtion of systems in order to adapt to a more stable and sustainable equilibrium (Scheffer et al. 2001, Folke 2006, Sellberg et al. 2015).

Most natural and anthropogenic change follows a common process where factors change continually and then trigger a sudden change in social and ecological system, and some work suggest the existence of generic early-warning signals of tipping point (Scheffer et al. 2001, Young et al. 2006, Lenton et al. 2008, Scheffer et al. 2009). Catastrophe theory, a mathematical model (Thom 1975), was proposed to rationally account for the phenomenon of discontinuous change (outputs) resulting from continuous change in the steady equilibrium state with parameters (inputs) (Thorn 1969, Zeeman 1976, Schreiber et al. 1997). The unique strengths of catastrophe theory can capture inherent nonlinearity and complexity behavior by using fewer nonlinear equilibrium equations than the number of equations needed to describe the same phenomena (Oliva et al. 1992, Scheffer et al. 2001, Lin and Petersen 2013). Moreover, without the requirement of a strict formulation of the mechanistic processes, it is possible to apply the theory to extremely complex systems (Lockwood and Lockwood 1993). These dialectic characteristics and advantages of catastrophe theory make it appropriate for the modeling of complex social-ecological systems, especially with the system whose inner workings may not be known. After several decades of development, catastrophe theory has been applied to multiple objective decision-making and attributes assessment fields including applied mathematics, computer science, engineering, social science, as well as environment and natural resource management (Svorozhtsov et al. 1995, Thomas and Urena 2001, Washington-Allen et al. 2009, Barunik and Vosvrda 2009, Wang et al. 2014).

From the perspective of catastrophe, resilience is a system's capability of adapting to catastrophes as sudden radical changes or the breakdown of certain equilibrium, and navigating change when it approaches system's threshold. Resilience emphasizes alternative stable states or regimes and intervening thresholds that possess great relevance to social and ecological management. Urban resilience as a key concept in urban management and planning, it appears in urban development policy and guidelines in order to adapt to the shifts caused by catastrophes, especially to detect early warning signals when the system approaches tipping point (Resilience Alliance 2007, Scheffer et al. 2009, Sellberg et al. 2015, West and Schultz 2015, Rockefeller Foundation 2015). We therefore propose a new multi-stage framework based on the catastrophe theory to analyze resilience transition of social-ecological systems in Lianyungang, a coastal city in eastern China. Our objectives were to: (1) use catastrophe theory to evaluate resilience by using social-ecological indicators organized according to distinct 
dimensions of each sub-system; (2) analyze the two different resilience states with probability distribution equilibrium (PDE); and (3) address the tipping point of different resilience transition phases as the signal of early warning to generate insights that enhance our understanding of the challenges of interdisciplinary research on resilience.

\subsection{Methods}

Compared to conventional evaluation approaches, resilience assessment simultaneously represents complex adaptive systems, an integrated social-ecological system with long-term sustainability (Gunderson and Holling 2002, Wang et al. 2012). We developed a socialecological resilience assessment model based on catastrophe theory (Fig.3.1). K-means cluster analysis was used to divide the synthetic values from catastrophe models into five resilience grades based on their catastrophe results. Afterwards, the primary drivers were derived from the key system indicators of probability distribution equilibrium/equilibria (PDE), and PDE was used for describing the resilience states with "More resilient" or "Less resilient".

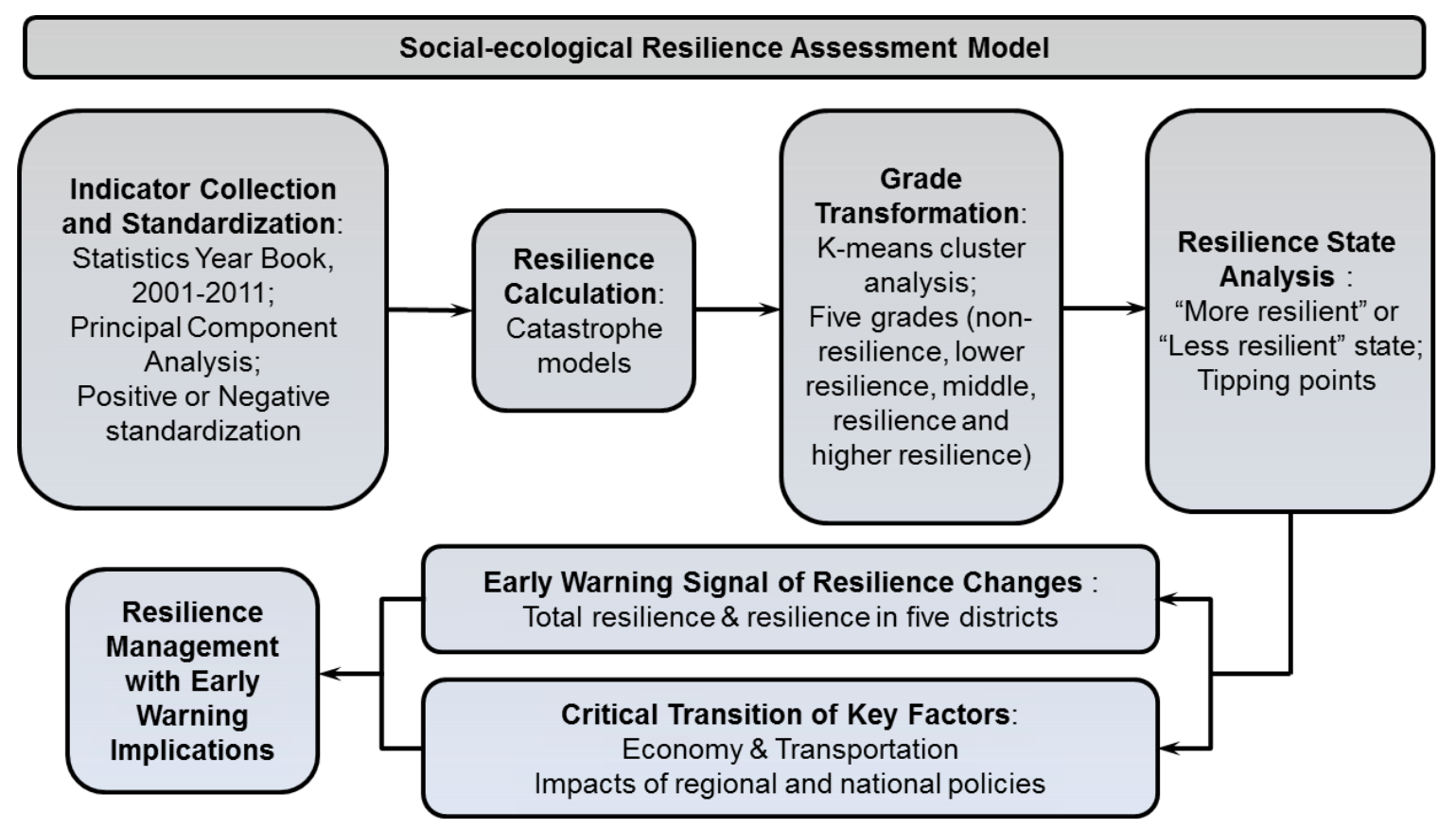

Fig.3.1 Flowchart of social-ecological resilience assessment model

\subsubsection{Data collection and standardization}

According to our previous research in Lianyungang, 2000-2010 was the most flexible and dynamic time period, Lianyungang experienced a vulnerable transition after the year 2005 due to the enforcement of city development plans ( $\mathrm{Li}$ et al. 2012, Li et al. 2015). In addition, China's Five-Year-Plan (FYP: a national development program for spanning five years intervals) and local development plans are the vital policy drivers for the shift of resilience. For the distribution of resilience in Lianyungang, the analysis was conducted in five areas as Central, 
Ganyu, Donghai, Guannan and Guanyun district, each district had its own resilience states. Indicators were selected from Lianyungang Statistics Year Book (2001-2011, Bureau of Statistics in Lianyungang), and indicator selection in this study was guided by the principles of integrity, simplicity, dynamic response, geographical accuracy and data availability based on the weights of every indicator. These indicators are commonly used in related research papers (Zhao et al. 2006, Li et al. 2012), and a set of 72 indicators was developed.

In accordance with previously conducted studies, some vicarious indicators (Quantity of possessed telephone, Total post income, Criminal case, Arable area, etc.) were chosen due to the data integrity for the whole study area. Subsequently, according to the results of Principal Component Analysis (PCA) through SPSS Statistics 20 analysis (Jolliffe 2002), a set of observations of possibly correlated variables were converted into a set of values of linearly uncorrelated variables. In the end, 32 indicators were generated in Table 3.1. Because of the lack of ecological and environmental indicators, more social indicators were chosen for resilience assessment. Additionally, the key drivers in this study were selected through Partial Correlation Analysis in SPSS. It provides a tool for the systematic evaluation of multiple sources of drivers (indicators) in a complex model (Guilford and Fruchter 1973), because it measures the degree of association between two random variables, without the effect of controlling random variables. As catastrophe model is a hierarchical model, all indicators were categorized into two sub-systems: social and ecological with several groups, as listed in Table 3.1 .

Table 3.1 Resilience sub-systems and indicators for Lianyungang

\begin{tabular}{|c|c|c|}
\hline \multicolumn{2}{|c|}{ Sub-systems } & \multirow{2}{*}{$\frac{\text { Indicators }}{\text { Proportion of primary industry }\left(\mathrm{C}_{1}\right)}$} \\
\hline Social-1 $\left(A_{1}\right)$ & Economy- $1\left(\mathrm{~B}_{1}\right)$ & \\
\hline & & Average salary $\left(C_{2}\right)$ \\
\hline & & Fixed assets investment/GDP( $\left.\mathrm{C}_{3}\right)$ \\
\hline & Economy-2( $\left.\mathrm{B}_{2}\right)$ & Retail sales $\left(\mathrm{C}_{4}\right)$ \\
\hline & & Total income $\left(\mathrm{C}_{5}\right)$ \\
\hline & & Total deposits $\left(\mathrm{C}_{6}\right)$ \\
\hline & & $\operatorname{GDP}\left(\mathrm{C}_{7}\right)$ \\
\hline & Agriculture $\left(\mathrm{B}_{3}\right)$ & Agriculture gross product $\left(\mathrm{C}_{8}\right)$ \\
\hline & & Crop yield $\left(\mathrm{C}_{9}\right)$ \\
\hline & & Cultivated area $\left(\mathrm{C}_{10}\right)$ \\
\hline & Industry $\left(B_{4}\right)$ & Total profit $\left(\mathrm{C}_{11}\right)$ \\
\hline & & Manufactured inventory $\left(\mathrm{C}_{12}\right)$ \\
\hline & & Total assets $\left(\mathrm{C}_{13}\right)$ \\
\hline \multirow[t]{6}{*}{ Social-2( $\left.\mathbf{A}_{2}\right)$} & Transports $\left(\mathrm{B}_{5}\right)$ & Total post income $\left(\mathrm{C}_{14}\right)$ \\
\hline & & Quantity of possessed telephone $\left(\mathrm{C}_{15}\right)$ \\
\hline & Science and Culture $\left(\mathrm{B}_{6}\right)$ & Antiques collection $\left(\mathrm{C}_{16}\right)$ \\
\hline & & Educational institution $\left(\mathrm{C}_{17}\right)$ \\
\hline & Population $\left(\mathrm{B}_{7}\right)$ & Urbanization $\left(\mathrm{C}_{18}\right)$ \\
\hline & & Household population $\left(\mathrm{C}_{19}\right)$ \\
\hline
\end{tabular}




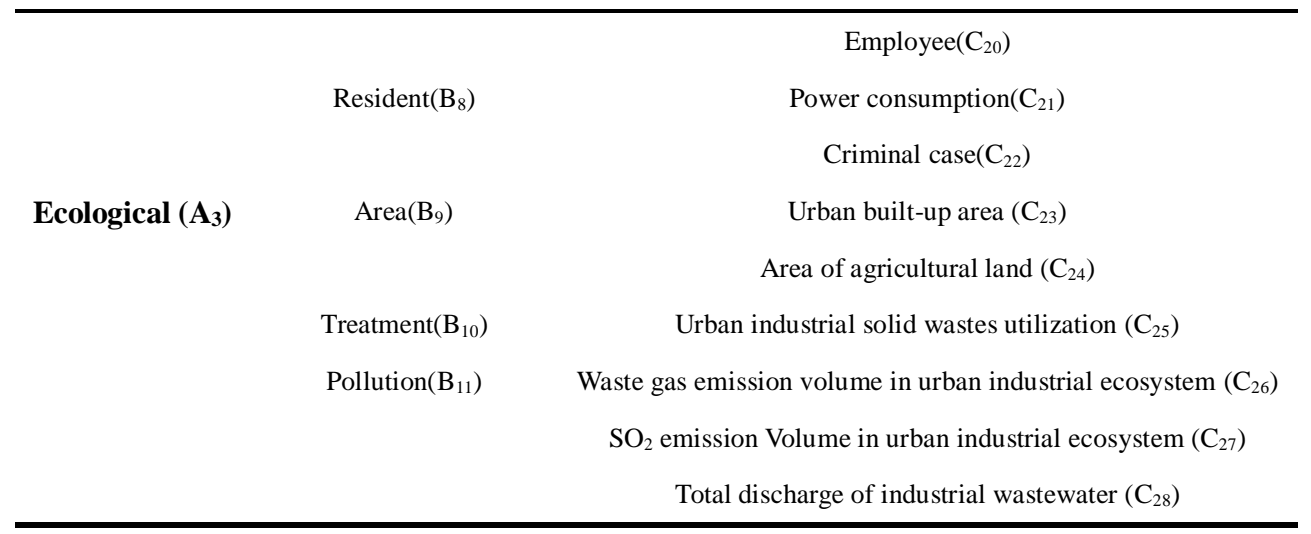

Given the different dimension and distribution of indicators, it is difficult to directly compare or operate among them. Consequently, the original data should be dimensionless through data standardization, which are one of the requirements of catastrophe model. In addition, to correlate with resilience, those indicators can be either negative or positive. A negative indicator is disadvantageous to resilience, which means the higher the values of those indicators are, the less resilient the system is. Conversely, positive correlation is highly advantageous to resilience. The higher the values are, the more resilient the system is. All the indicators were standardized using the following equations:

Positive indicator: $\mathrm{X}_{i j}^{\prime}=\left(\mathrm{X}_{i j}-\min \left\{\mathrm{X}_{j}\right\}\right) /\left(\max \left\{\mathrm{X}_{j}\right\}-\min \left\{\mathrm{X}_{j}\right\}\right)$

Negative indicator: $\mathrm{X}_{i j}^{\prime}=\left(\max \left\{\mathrm{X}_{j}\right\}-\mathrm{X}_{i j}\right) /\left(\max \left\{\mathrm{X}_{j}\right\}-\min \left\{\mathrm{X}_{j}\right\}\right)$

where $X i j$ represents the value of indicator $j$ in year $i$, and $\max \{X j\}$ and $\min \{X j\}$ indicate the minimum and maximum value of indicator $j$ among all years.

\subsubsection{Catastrophe theory}

Scheffer (2009) discussed the use of catastrophe theory as a conceptual framework for understanding gradual and abrupt behavior. Catastrophe theory is used as a method for describing the evolution of a system's forms, which is characterized with the phenomenon of nonlinear changes in the steady equilibrium state in parameters. When resilience is lost or significantly decreased, a system is at high risk of shifting into a qualitatively different or undesirable state (Scheffer et al. 2001, Scheffer and Carpenter 2003). Moreover, catastrophe theory is particularly applicable where gradually changing forces produce sudden effects, which can be used for detecting the effects of environmental stochastic or human disturbances in resilience changes. Social-ecological resilience is particularly characterized by complexity and nonlinear dynamics, which means uncertainty of a system. It can be positive while it recovers after disturbance as maintaining its functions, however, some systems can persist in a state that has negative consequences. Based on these characteristics of catastrophe theory and other research, catastrophe theory is an appropriate method for resilience analysis.

In catastrophe models, the state of a system is described by two kinds of variables: internal 
variables $x=x_{i}(i=1,2 \ldots m)$ and control variables $a=a_{i}(i=1,2 \ldots n)$. These are related by a potential function $f(a, x)$. According to catastrophe theory (Zeeman 1976), the set of critical points of the potential function $f(a, x)$ forms an equilibrium surface. When the control variables $a$ have a fixed value the system settles into an equilibrium state, and its equation is derived from the first derivative of $f(x)$, namely, $f^{\prime}(x)=0$. An associated singularity set is derived from the second derivative of $f(x)$, namely, $f^{\prime \prime}(x)=0$. As the control variables vary, a local minimum can disappear and the internal variables jump suddenly to a different equilibrium. Since the catastrophe model can be divided into hierarchical systems, different sub-system can be assumed as a different catastrophe model according to its variables. Suppose a response variable is one dimension, catastrophe models can be classified into four categories according to the dimension of control variables: Fold, Cusp, Swallowtail and Butterfly, and each of them have their own equilibrium surfaces. The type of model used was chosen according to the dimensions (numbers) of control variables of each sub-system. The descriptions of these models are given in Equation (3)-(6).

(1) Fold catastrophe (for one control variable):

$$
\begin{aligned}
V & =x^{3}+a x ; \\
X a_{1} & =\sqrt{a_{1}}
\end{aligned}
$$

(2) Cusp catastrophe (for two control variables):

$$
\begin{gathered}
V=x^{4}+a x^{2}+b x ; \\
X a_{1}=\sqrt{a_{1}} \quad X a_{2}=\sqrt[3]{a_{2}}
\end{gathered}
$$

(3) Swallowtail catastrophe (for three control variables):

$$
\begin{gathered}
V=x^{5}+a x^{3}+b x^{2}+c x \\
X a_{1}=\sqrt{a_{1}} \quad X a_{2}=\sqrt[3]{a_{2}} \quad X a_{3}=\sqrt[4]{a_{3}}
\end{gathered}
$$

(4) Butterfly catastrophe (for four control variables):

$$
\begin{gathered}
V=x^{6}+a x^{4}+b x^{3}+c x^{2}+d x \\
X a_{1}=\sqrt{a_{1}} \quad X a_{2}=\sqrt[3]{a_{2}} \quad X a_{3}=\sqrt[4]{a_{3}} \quad X a_{4}=\sqrt[5]{a_{4}}
\end{gathered}
$$

\subsubsection{Catastrophe theory application}

\section{Indicator standardization}

The raw data of all control variables were converted to comparable, dimensionless data within the range of $0-1$. This section shows how resilience was demonstrated in terms of a simple example using the central district data in 2002. Normalization was performed according to Equations (1) and (2) (Table 3.2). 
Table 3.2 Statistical data of Social-1 sub-system in central district (central, 2002)

\begin{tabular}{|c|c|c|c|}
\hline Indicators & & Original data & Standardized data \\
\hline \multirow{3}{*}{ Economy-1 $\left(\mathrm{B}_{1}\right)$} & $\mathrm{C}_{1}$ & 0.06 & 0.62 \\
\hline & $\mathrm{C}_{2}$ & 12513 & 0.10 \\
\hline & $\mathrm{C}_{3}$ & 0.89 & 0.85 \\
\hline \multirow{4}{*}{ Economy-2 $\left(\mathrm{B}_{2}\right)$} & $\mathrm{C}_{4}$ & 543986 & 0.08 \\
\hline & $\mathrm{C}_{5}$ & 187591 & 0.05 \\
\hline & $\mathrm{C}_{6}$ & 823091 & 0.16 \\
\hline & $\mathrm{C}_{7}$ & 116.59 & 0.05 \\
\hline \multirow{3}{*}{ Agriculture $\left(\mathrm{B}_{3}\right)$} & $\mathrm{C}_{8}$ & 136474 & 0.03 \\
\hline & $\mathrm{C}_{9}$ & 110635 & 0.05 \\
\hline & $\mathrm{C}_{10}$ & 23.68 & 0.01 \\
\hline \multirow{3}{*}{ Industry $\left(\mathrm{B}_{4}\right)$} & $\mathrm{C}_{11}$ & 0.036 & 0.19 \\
\hline & $\mathrm{C}_{12}$ & 0.02 & 0.27 \\
\hline & $\mathrm{C}_{13}$ & 0.02 & 0.38 \\
\hline
\end{tabular}

\section{Resilience calculation}

Resilience values were calculated with catastrophe theory (Equations 3-6) for variables $\left(B_{i}\right)$ with indicators $\left(C_{i}\right)$. The standardized values were used for resilience calculation instead of original values. The number of control variables in a sub-system decides its catastrophe type, for instance, a fold model is suitable for a sub-system with two control variables, or a swallowtail model for three control variables. An example of the calculation of total catastrophe membership degree was presented below. The rest of the resilience results were deduced using the same processes; as a result, the final resilience value can be calculated with both the value of social and ecological resilience. Each calculating process is shown in Appendix 1.

Swallowtail model for Economy-1 $\left(B_{1}\right)$ :

$$
\mathrm{X}_{B_{1}}=\operatorname{AVERAGE}\left(\sqrt{\mathrm{C}_{1}}+\sqrt[3]{\mathrm{C}_{2}}+\sqrt[4]{\mathrm{C}_{3}}\right)=0.74
$$

Butterfly model for Economy-2 $\left(B_{2}\right)$ :

$$
\mathrm{X}_{B_{2}}=\operatorname{AVERAGE}\left(\sqrt{\mathrm{C}_{4}}+\sqrt[3]{\mathrm{C}_{5}}+\sqrt[4]{\mathrm{C}_{6}}+\sqrt[5]{\mathrm{C}_{7}}\right)=0.45
$$

Because there are two economy sub-systems, we calculate the economy with fold model:

$$
\mathrm{X}_{B_{1-2}}=\operatorname{AVERAGE}\left(\sqrt{B_{1}}+\sqrt[3]{B_{2}}\right)=0.81
$$

Swallowtail model for Agriculture $\left(B_{3}\right)$ :

$$
\mathrm{X}_{B_{3}}=\operatorname{AVERAGE}\left(\sqrt{\mathrm{C}_{8}}+\sqrt[3]{\mathrm{C}_{9}}+\sqrt[4]{\mathrm{C}_{10}}\right)=0.28
$$

Swallowtail model for Industry $\left(B_{4}\right)$ :

$$
\mathrm{X}_{B_{4}}=\operatorname{AVERAGE}\left(\sqrt{\mathrm{C}_{11}}+\sqrt[3]{\mathrm{C}_{12}}+\sqrt[4]{\mathrm{C}_{13}}\right)=0.28
$$


Calculation resilience for variables $\left(A_{l}\right)$ with corresponding items $(B i)$

Butterfly model for Social-1 $\left(A_{l}\right)$ :

$$
\mathrm{X}_{A_{1}}=\operatorname{AVERAGE}\left(\sqrt{B_{1-2}}+\sqrt[3]{B_{4}}+\sqrt[4]{B_{3}}\right)=0.76
$$

\section{Grade transformation}

The synthetic values of catastrophe assessment were generally high and the differences were not obvious, because the catastrophe progression was calculated based on the normalization formula (Poston and Ian 1978). Moreover, different indicators had different resilience values, and it was difficult to determine the actual secure level by directly using the results obtained through catastrophe assessment. In order to make the variation in resilience more visible and to transform data for early warning analysis model, we used K-means cluster analysis in SPSS Statistics 20 to divide the all synthetic values from catastrophe models. The result was categorized into five levels, from 1 to 5 (lowest to highest): non-resilience, lower resilience, middle, resilience and higher resilience. As a result, the curves were drawn with grades from 1 to 5 instead of their resilience values. Consequently, each indicator had its own grade values (Table 3.3).

Table 3.3 Corresponding values between assessment results of catastrophe model and ordinary-used values at different resilience level

\begin{tabular}{lccccc}
\hline \multirow{2}{*}{ Grades } & Non-resilience & Lower Resilience & Resilience & Middle Resilience & Higher Resilience \\
& $\mathbf{1}$ & $\mathbf{2}$ & $\mathbf{3}$ & $\mathbf{4}$ & $\mathbf{5}$ \\
\hline Indicators & $<0.08$ & $0.08-0.32$ & $0.32-0.55$ & $0.55-0.77$ & $>0.77$ \\
\hline
\end{tabular}

\subsection{Resilience Early Warning Analysis}

The key system indicator of social-ecological resilience is probability distribution equilibria (PDE), which provides a quantitative basis for assessing the probability of a nonlinear shift from one dynamic equilibrium to another. It permits observation of the frequencies (or relative probabilities) of observing a modeled system in a specific vulnerable state (Morgan and Henrion 1990, Perz et al. 2013). With this point, it gains insight and can be connected to the catastrophe theory results. More importantly, PDE can be used to observe the ranges of values in one indicator that delineate dynamic behavior of shifts in the SESs over time, also to calculate the proportional areas of the PDE within each phase, which corresponds to the probability of observing SESs. This characteristic describes whether a system is more likely to remain in its present equilibrium or shifts to another phase (PDE), and whether a system can be more or less social-ecologically resilient.

Filled radar graph (Fig.3.2) was used to present the results assessing the resilience level of five areas and total resilience results of Lianyungang. Fig.3.2 showed two types of PDE $(\beta)$ with regard to resilience. The axis indicated a potential phase $(\beta)$ distinct from an initial phase $(\alpha)$, and the areas within curves represented the probability of assessing the SESs in the 
potential phase. Therefore, a larger area of the PDE signifying to a substantial change to higher resilience grade that would suggest better resilience - "More resilient" state (Fig.3.2a); on the other hand, a larger area means that a limited change to lower resilience grade would imply low resilience-"Less resilient" state (Fig.3.2b). Disturbances may prompt a system to shift from one state to another (Gunderson and Pritchard 2002, Cumming et al. 2005, Scheffer et al. 2009), this occurs at "tipping point/period" (TP in Fig.3.2). The TP is where a system stands between two phases and in the sense that perturbations can more easily push them into an alternative state. In other words, the TP is the demarcation point/period of two equilibria. In principle, tipping point can be used to describe a critical transition with irreversible effects resulted in an alternative resilience state; or as a signal of early warning of systems could approach their thresholds, at which the future state of the current resilience system is qualitatively altered (Lenton et al. 2008, Scheffer et al. 2009). More generally, the issue of detecting tipping points and distinguishing environmental fluctuations from the dynamic perturbations under anthropogenic forcing addressed intention of both government and researchers.

\section{More resilient (a)}

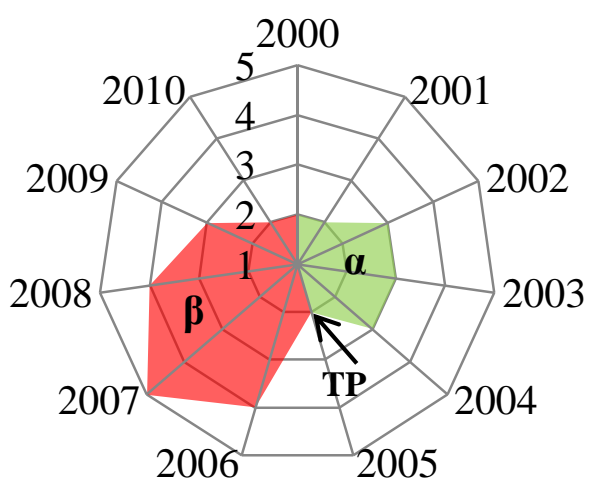

Less resilient (b)

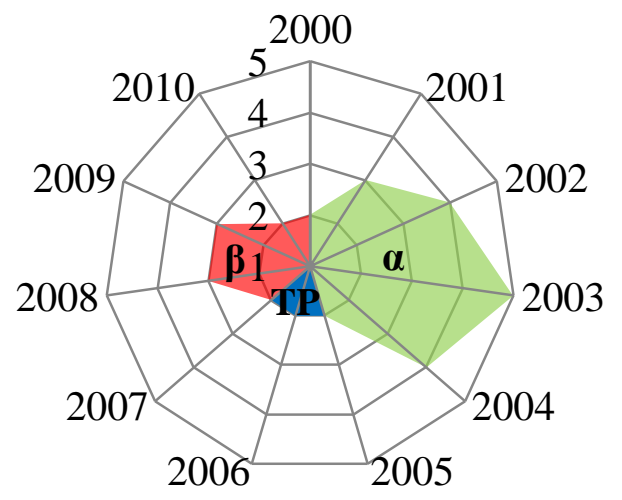

Fig.3.2 Evaluating social-ecological resilience in probability distribution equilibria

Resilience is small and even a moderate perturbation may bring the system into the alternative basin of attraction. It describes a nonlinear shift that SESs will remain in its initial phase $(\alpha)$, or shift to another phase $(\beta)$. The larger the area (with higher resilience grade) around $\beta$, the system is to shift to another more flexible phase, an indication of better resilience (a); the smaller the area (with lower resilience grade) around $\beta$, the system will shift to another vulnerable phase, thus indicating a lack of resilience (b). Each type of resilience has a "tipping point/period" (TP) that divides the contiguous two states, which is vital factor for resilience type analysis. It is difficult for SESs to return to a previous phase due to the loss of pivotal functions or structures, or because of the corresponding TP exhibits a more stable alternative attractor. However, the system could turn to "back loop"-a positive phase of renewal and reorganization that corresponds to managing production and managing sustainability.

\subsection{Results and Discussion}

Based on the theory of catastrophe models and early warning, the resilience transformations in those five areas are different from each other. Some critical triggers of resilience changes are detected. 


\subsubsection{Resilience tipping points of all five areas}

The results of each district were presented by area of PDE. Graphs were used to assess the primary drivers of resilience and resilience level of Lianyungang: total resilience, Central, Ganyu, Donghai, Guanyun, and Guannan district (Fig.3.3).

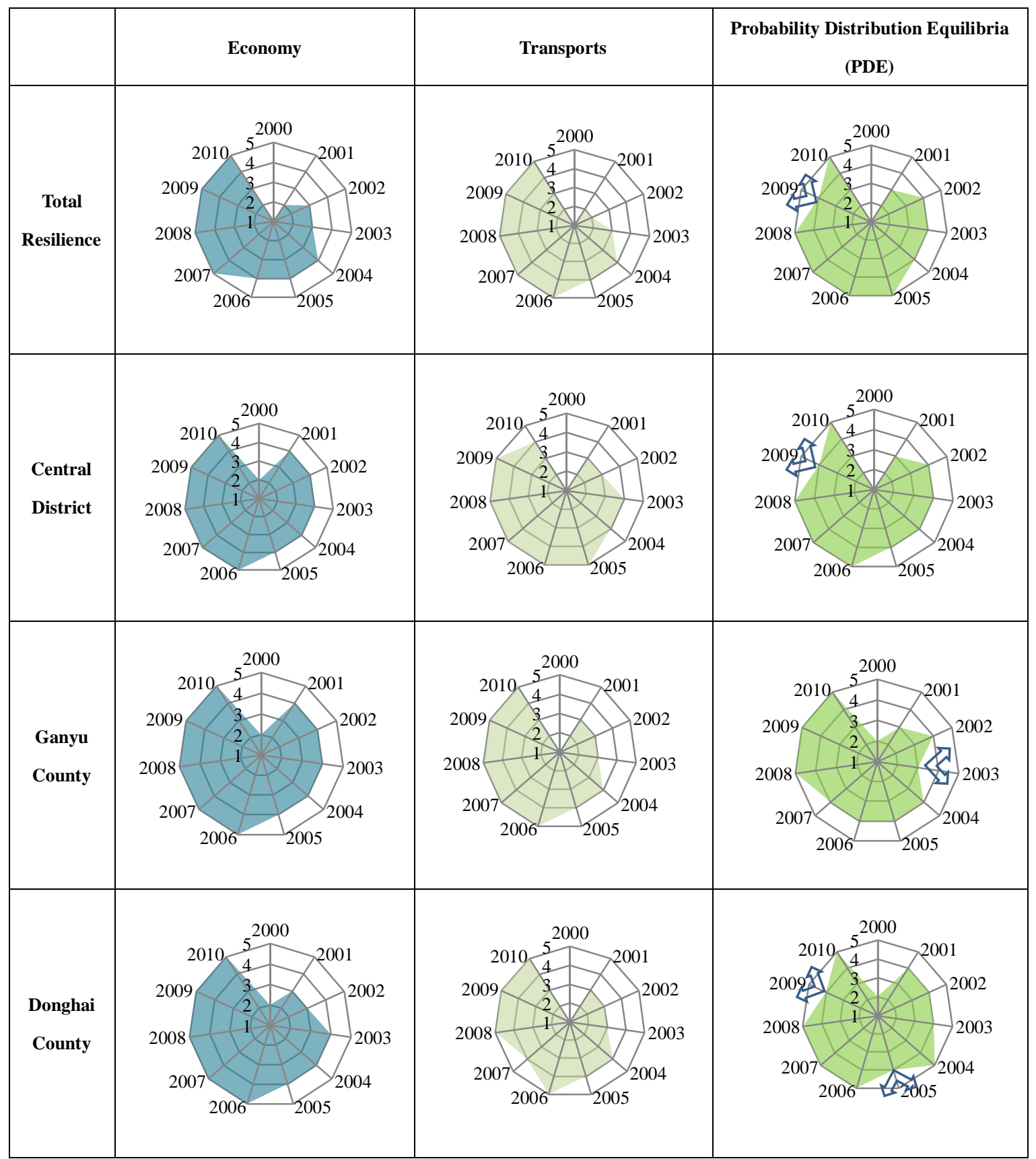




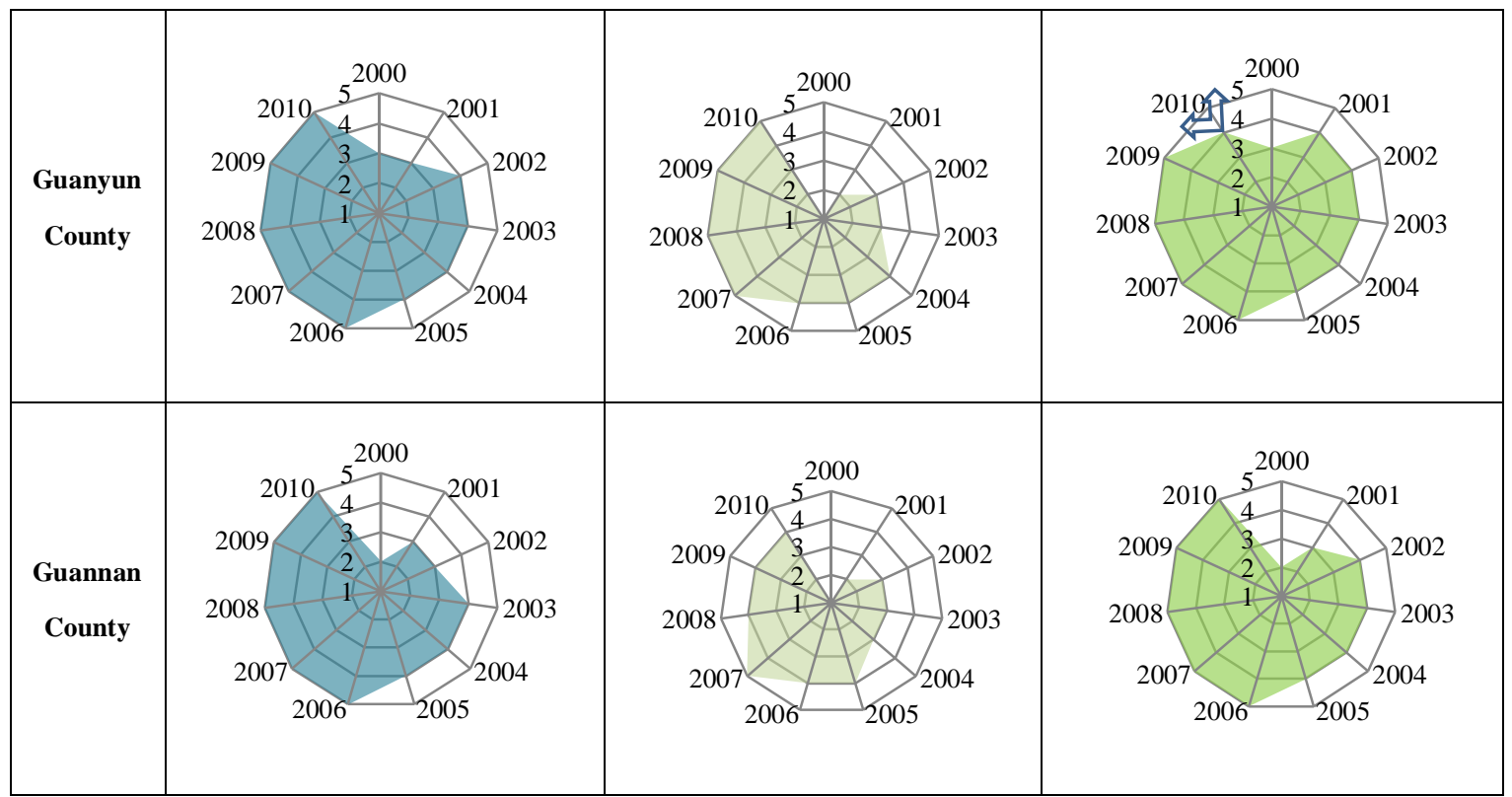

Fig.3.3 Resilience graphs in all five areas

Note: “仓” represents tipping point.

\section{Total resilience and tipping point under "Less resilient" state}

Since the total resilience value had a larger area of $\alpha$ (2000-2009) than the potential state $\beta$ (2009-2010), it implies that the total resilience of Lianyungang was under a "Less resilient" state. However, it kept a relatively positive state with high resilience grades. The resilience PDE increased from Grade 1 to Grade 5 (Fig.3.3), which means the system moved to a better equilibrium resilient state. Firstly, the system's resilience increased after 2000, it reached the peak point in 2006 and kept the value until 2008. But it dropped down to the tipping point (lowest value) in 2009 and increased back to the highest value in 2010. Even though the bifurcation point of total resilience in 2009 did not drive the social-ecological system across the boundary between two equilibria state, but the resilience shift in 2009 caused an uncertainty transition, which can be treated as an early warning signal of resilience collapse. Since resilience returned to Grade 5 in 2010, it showed an alternative equilibrium with high recovery rate. In this case, if the resilience state keeps at higher grades in the next five years, then the area of state $\beta$ will be comparable to the state $\alpha$, which represents a relatively stable phase. In other words, the next five years will be the initial period for resilience state change.

The total result of social-ecological modeling showed that some of the selected indicator sub-systems, such as economy, transports, science and culture, agriculture and pollution, were sensitive to disturbances during 2000 to 2010 (Appendix 2). According to the Partial Correlation Analysis, economy and transports had crucial impacts on system dynamics (Fig.3.3), and they were considered as the main driving forces for the structural shift of socialecological resilience and leading the development of Lianyungang. All those indices showed rising trends since 2000, resulting in larger areas of the original state $\alpha$ until 2009. According to the report of comprehensively improvement of people's well-being from Lianyungang Bureau of Statistics (2011), a more reasonable income distribution pattern was developed in 
both urban and peri-urban areas, as well as the situation of transport, education and culture.

\section{Critical transition states in all five areas}

As the most important district of the city, the central district was the only district under a "Less resilient" phase with high flexibility and low vulnerability to external disturbances. In accordance with the actual situation, because of the rapid development in the core area of "One zone and two wings" development policy, more external disturbances caused the decrease of resilience in 2009. However, with its strong adaptive capacity, it showed more flexibility and low vulnerability. More importantly, the resilience PDE of central district had the same trend as total resilience PDE, which means the central district had decisive impacts on Lianyungang's overall resilience state. When the tipping point in the central district approaches its threshold, it can cause the collapse of the whole system. The proportion of primary industry and fixed assets investment/GDP had the most fluctuation, causing the economic resilience change in the central districts. The population of the central district increased annually but started to slow down in 2009 due to the development of other areas that have gained more resources and support from the government. In 2010, there were 4.98 million people in Lianyungang, with 0.94 million living in the central district. This abrupt change interpreted as an early warning signal of urban resilient critical transition, due to the external regime of perturbations of new city development plan. Since resilience in the central district returned to the highest value in 2010, it implied an exciting opportunity for resulting in a desirable resilience state.

As the north part of the "Two Wings", the resilience in Ganyu showed a "More resilient" phase with a tipping point in 2003. Resilience of the economy and transports had the same TP in 2003, which indicated that they experienced same change in state. From 2000 to 2003, economic resilience practically had the same PDE area with the total resilience PDE in Ganyu, which means that economic resilience caused the main resilience shift in Ganyu. Ganyu is the main fuel manufacturing and processing area, which provides $96 \%$ of the crude oil in Lianyungang. The coastal area of Ganyu becomes the main site of labor demand and coastal industry park of heavy machinery, petrochemical and warehouse logistics. For example, there is one petrochemical heavy industry park in the north coastal area of Ganyu, three marine industry parks along the coastal line, and one provincial economic and technological development zone.

The resilience result of Guanyun as the south part of "Two Wings" area, showed high flexibility and low vulnerability with a tipping point in 2010. This tipping point showed that resilience in Guanyun crossed the border of a basin of attraction, and the stable state was interrupted by a sudden external force. Even though it kept increasing since 2000, it plunged in 2010, reflecting a tipping point. In this circumstance, the resilience type of Guanyun will depend more on the results of changes after the year 2010. The main reasons for the resilience shift were the reduction of household population and employees, industrial solid waste utilization, increased discharge of the volume of industrial $\mathrm{SO}_{2}$ emission and volume of industrial waste gas emissions. Therefore, pollution will be a challenge for further development in Guanyun, policy makers and stakeholders need to formulate more effective environmental protection policies.

Compared to other districts, Donghai had a "More resilient" PDE area that was characterized 
by low flexibility and high vulnerability with less external disturbances. The main reason is that Donghai's main financial drivers are tourism, silicon production and agriculture, and those industries are relatively stable industries that can maintain economic resilience during this period. However, the driving forces of resilience development in Guannan were more complicated, and it had the largest PDE area among all the other areas. While all these parameters had positive resilience effects, it maintained a stable equilibrium system during this period. Guannan was primarily a result of the high flexibility and low vulnerability to external threats and challenges. Also because of the large area of wetland in this district with less threat of urban development, it kept its comparable natural structures.

\subsubsection{Critical resilience changes in Lianyungang}

Resilience issues arising from disturbances in urban and peri-urban areas are complex, due to the multiple interactions between ecological and social-economic systems under human action (Colding 2006, Ludwig and Smith 2005, McDaniels et al. 2008). Given the shifting circumstances experienced by SESs, it is vital to understand the mechanisms in which these localities respond to external factor changes. The graphs of probability distribution equilibria (PDE) pointed out key factors that contributed to the resilience changes during 2000-2010. This analysis proved that economy and transports had vital impacts on the resilience changes in all these five areas, those two sub-system resilience were calculated by fold catastrophe model.

\section{Economic resilience change with related policies}

Economy was one of the primary drivers of human-induced challenge for social-ecological resilience in Lianyungang (Fig.3.3). Specifically, such unstable resilience was tied to multiple stressors including shifts in resource demand resulting from economic changes and industry fluctuations. The GDP target for Lianyungang in 2030 is 5.5 hundred billion Chinese Yuan, a per capita GDP increase to 87700 Chinese Yuan. The ratio of primary, secondary and tertiary industries will be adjusted to 3:56:41, and with the intention of focusing on heavy manufacturing industries and portside industries. UNEP assesses patterns of production and consumption as the main drivers of environmental change (UNEP 2014).

The economic resilience in all five districts had similar changes during 2000-2010. Economic resilience showed stable and increased states, which increased from Grade 1 to Grade 5. However, the decoupling relationship between urban development and environment quality is one of priority issues in Lianyungang, there are more and more serious environmental pollution due to the rapid urbanization ( $\mathrm{Li}$ et al. 2012). From 2000 to 2005, pollution resilience showed a negative and relatively decoupled state with economic resilience, as economic resilience increased while pollution resilience decreased. During 1992-2002, as a transitional strategy of the city plan, Lianyungang's economic growth was dominated by light manufacture, it experienced a rapid heavy industrialization during the $10^{\text {th }}$ Five-Year-Plan (2001 2005). During 2003 to 2004, economic resilience in Central, Ganyu, and Guanyun areas decreased to varying degrees. Moreover, as the primary financial and urbanization area in Lianyungang, the central district faced even more serious challenges to maintain economic stability over time. 
Lianyungang followed the instructions of the city plan and its material-intensive heavy manufacturing developed quickly in this period, leading to the declining pollution resilience.

As mentioned in the city plan (Lianyungang Municipal Bureau of Urban Planning 2009), upgrade to the labor - intensive industries and portside industries became a development guideline in both the central and coastal area. Due to the progress in enhancing conventional industry and industrial upgrading especially since the "One Zone and Two Wings" area, all economic resilience enhanced to a more stable equilibrium with an increased area of equilibrium. A large basin of attraction represents relative high resilience (Scheffer et al. 2009).

China's "Industrial Structure Adjustment" (upgrading traditional manufacturing and eliminating outdated technologies) in the $11^{\text {th }}$ FYP (2006 2010) lowered the share of heavy manufactured goods, and the enforcement of city development plan, which turned the negative trends of economic resilience phase into positive trends. During this time, industrial upgrading and promotion of domestic consumption propelled economic development to a new level. Additionally, the policy accelerated the economic changes according to the pattern of economic development and restructuring, and upgraded the manufacturing industries. Therefore, environmental pressure was also mitigated.

\section{Transportation resilience changes and related policy change}

With more and more resource demands and city development in Lianyungang, increasing demand of roads and transport vehicles became a decisive factor of resilience change; all transport resilience had increasing grades since 2000 (Appendix 2). The accelerating transport resilience interpreted a stable equilibrium without tipping point, and the large area of PDE represented a large basin of attraction. However, its recovery rate from perturbations still unclear until 2010, all the changes maintained in a stable phase. With the construction of industrial parks and harbors in Lianyungang, especially along the seashore strip in Ganyu, Central, and Guanyun, existing transport capacity was no longer meeting the needs of its development. From the perspective of national policy of "China's $21^{\text {st }}$ Century Agenda", Lianyungang intends to be an international seaport linking countries of the Pacific Rim with those in Central Asia. From the city level, in the proposal of the "One Zone and Two Wings" policy in Lianyungang, this leading framework will upgrade regional transport capacity. Moreover, it is recognized as a regional governance guideline for building a harbor-urban integrative traffic network according to the "One Zone and Two Wings" policy. Until 2010, the total area of transportation in Lianyungang was $69.35 \mathrm{~km}^{2}$ compared to $24.41 \mathrm{~km}^{2}$ in 2000 , and 139 million tons of freight amounts in 2010 comparing to 36 million tons in 2000 . Additionally, the quantity of motor vehicles in the city increased to 60000 in 2010 from 30000 million in 2000 .

In order to strengthen the connection between the "One Zone and Two Wings" area, a Tshaped transportation skeleton will be built with an " 11 vertical and 9 horizontal network" and a "16 vertical and 12 horizontal network". The government intends to build an integrated port cluster by increasing collaboration and sharing with other ports. The total port throughput capacity will increase to four hundred million tons in 2030. The new transportation network can have a major influence upon how those regions develop, and strengthen the connection between each district as well as to other cities. According to the positive correlation between 
manufacturing industry/harbor and transport resilience, it implies that the transportation system upgrades will have important impacts for future resilience change. In this circumstance, the local government should consider the voluntary transportation approach in order to keep a more resilient transportation state.

\subsection{Conclusion}

The ability to adapt perturbations without crossing tipping point into an alternative basin of attraction is an important measure of the stability of a system; better resilient management strategies can preserve or improve system's resilience and avoid stochastic events and unwanted shifts with alternative basins of attraction. As shown in our research, human-related changes and cascading effects in the SESs can be captured by combining the concepts of resilience with the catastrophe theory. Catastrophe theory provided a precise and categorical method for resilience calculation with different nonlinearity and complexity disturbances, which is based on the dimensions (numbers) of control variables of each sub-system. According to the results of catastrophe theory, the resilience correlation analysis in the results of the PDE and simulation herein reflected the effects of external disturbances in different districts.

Tipping point occurs when a system approaches its threshold, and early warning signals tend to arise in a "Less resilient" system with critical resilience transition. The total resilience in Lianyungang appeared to be under a "Less resilient" phase with a tipping point in 2009, which can be an early warning signal of critical resilience transition. However, the resilience values after 2010 will have important impacts for defining the resilience phase, and can decide whether it turns into a "Less resilient" or "More resilient" phase. Resilience in the central districts, Ganyu and Donghai revealed their thresholds, and the central district leaded the city's resilience development. Those three areas are the main planning zones with rapid exploration and expanding development. As systems close to a critical threshold of losing resilience, catastrophic regime shifts may be announced in advance by statistical early warning signals with tipping points.

Additionally, the integrated framework links with the main systems of governance to emphasize the main driving incentives required for implementing and supporting effective and sustainable social-ecological resilience. The resilience changes of economy and transports were two of the closely correlated indicators with resilience change among other factors. Two indicators were connected to the geographical location, national and local policies and strategies (Lianyungang Urban Comprehensive Plan, China's $21^{\text {st }}$ Century Agenda, the $10^{\text {th }}$ and $11^{\text {th }}$ Five Year Plan). More importantly, the impacts of economy and transport are becoming increasingly important strategically in the "One Zone and Two Wings" policy. The city strategies related to economy and transports need to be careful guided and detected before a critical transition occurs.

There are a number of hurdles for resilience-building strategies. Integrating the resilience related factors into decision making is a difficult proposition. It still remains an open question as to how to manage changes, and how urban and peri-urban areas can adapt to altered stable 
conditions. Such questions of management change necessarily deal with the connection of governance. Therefore we are preparing further research within the "One Zone and Two Wings" development strategy with city's transport system maps from 2000 to 2030, with the purpose of finding out its spatial resilience changes and predicting the urban resilience with land use models. Another drawback in our study is that most of the indicators were in social sub-system, and as such the social sub-system had more weight in resilience system. Therefore, future research will be focus on the ecological and environmental changes caused by social and economic motivated development, for instance land use change and coastal wetland sea reclamation, water quality degradation.

\section{References}

1. Adger, W. N., Hughes, T., Folke, C., Carpenter, R., Rockström, J. 2005. Social ecological resilience to coastal disasters. Science. 309:1036-1039.

2. Barunik, J., Vosvrda, M. 2009. Can a stochastic cusp catastrophe model explain stock market crashes? Journal of Economic Dynamics and Control. 33:1824-1836.

3. Berkes, F., Folke, C. 1998. Linking Social and Ecological Systems: Management Practices and Social Mechanisms for Building Resilience. Cambridge: Cambridge University Press.

4. Colding, J. 2006. Ecological land-use complementation' for building resilience in urban ecosystems. Landscape and Urban Planning. 81:46-55.

5. Cumming, G. S., Barnes, G., Perz, S. G., Schmink, M., Seiving, K. E., Southworth, J., Bin-ford, M., Holt, R. D., Stickler, C., Van Holt, T. 2005. An exploratory framework forthe empirical measurement of resilience. Ecosystems. 8:975-987.

6. Folke, C. 2006. Resilience: the emergence of a perspective for social-ecological systems analyses. Global Environmental Change. 16:253-67.

7. Guilford, J. P., Fruchter, B. 1973. Fundamental statistics in psychology and education. Tokyo: McGraw-Hill Kogakusha, LTD.

8. Gunderson, L., Holling, C. S. 2002. Panarchy: understanding transformations in human and natural systems. Island Press, Washington, D. C., USA.

9. Gunderson, L. H., Pritchard, L. (Editors). 2002. Resilience and the Behavior of Large-scale Systems. Island Press, Washington, DC.

10. Jolliffe, I. T. 2002. Principal Component Analysis. Second Edition. New York: Springer-Verlag.

11. Lenton, T. M., Held, H., Kriegler, E., Hall, J. W., Lucht, W., Rahmstorf, S., Schellnhuber, H. J. 2008. Tipping elements in the Earth's climate system. Proceedings of the National Academy of Sciences of the United States of America. 105:1786-1793.

12. Li, Y., Li, Y. F., Qureshi, S., Kappas, M., Hubacek, K. 2015. On the relationship between landscape ecological patterns and water quality across gradient zones of rapid urbanization in coastal China. Ecological Modelling. 318:100-108.

13. Li, Y. F., Li, Y., Zhou, Y., Shi, Y. L., Zhu, X. D. 2012. Investigation of a coupling model of coordination between urbanization and the environment. Journal of Environmental Management. 98(15):127-133.

14. Lianyungang Municipal Bureau of Urban Planning. 2009. Urban Comprehensive Plan. http://layout.lyg.gov.cn/ArticleShow.aspx?char=35\&id=2071

15. Lin, B. B., Petersen, B. 2013. Resilience, regime shifts, and guided transition under climate change: 
examining the practical difficulties of managing continually changing systems. Ecology and Society. 18(1):28.

16. Lockwood, J. A. Lockwood, D. R. 1993. Catastrophe Theory: A Unified Paradigm for Rangeland Ecosystem Dynamics Source: Journal of Range Management. 46(4):282-288.

17. Ludwig, A. A., Smith, M. D. S. 2005. Interpreting and correcting cross-scale mismatched in resilience analysis: A procedure and examples from Australia's rangelands. Ecology and Society. 10(2):20.

18. McDaniels, T., Chang, S., Cole, D., Mikawoz, J., Longstaff, H. 2008. Fostering resilience to extreme events within infrastructure systems: Characterizing decision contexts for mitigation and adaptation. Global Environmental Change. 18:310-318.

19. Morgan, M. G., Henrion, M. 1990. Uncertainty: A Guide to Dealing with Uncertainty in Quantitative Risk and Policy Analysis. Cambridge University Press, Cambridge.

20. Oliva, T. A., Oliver, R. L., MacMillian, I. C. 1992. A Catastrophe Model for developing service satisfaction strategies. Journal of Marketing. 56(3):83-101.

21. Perz, S. G., Mũnoz-Carpena, R., Kiker, G., Holt, R. D. 2013. Evaluating ecological resilience with global sensitivity and uncertainty analysis. Ecological Modelling. 263:174-186.

22. Poston, T., Ian, S. 1978. Catastrophe theory and application. Lord, Pitman.

23. Resilience Alliance. 2007. Assessing resilience in social-ecological systems: A workbook for scientists, version 1.1. [online] URL: http://www.resalliance.org/3871.php.

24. Rockefeller Foundation. 2015. 100 resilient cities. Centennial challenge. Rockefeller Foundation, New York, New York, USA. [online] URL: http://www.100resilientcities.org/\#/-_/

25. Scheffer, M. 2009. Critical transitions in nature and society. Princeton University Press, Cambridge, UK.

26. Scheffer, M., Bascompte, J., Brock, W. A., Brovkin, V., Carpenter, S. R., Dakos, V., Held, H., van Nes, E. H., Rietkerk, M., Sugihara, G. 2009. Early-warning signals for critical transitions. Nature. 461:53-59.

27. Scheffer, M., Carpenter, S., Foley, J. A., Folke, C., Walker, B. 2001. Catastrophic shifts in ecosystems. Nature. 413:591-596.

28. Scheffer, M., Carpenter, S. R. 2003. Catastrophic regime shifts in ecosystems: linking theory to observation. Trends in Ecology and Evolution. 18(12):648-656.

29. Schreiber, F. A., Baiguera, M., Bortolotto, G., Caglioti, V. 1997. A study of the dynamic behavior of some workload allocation algorithms by means of catastrophe theory. Journal of Systems Architecture. 43:605624.

30. Sellberg, M. M., Wilkinson, C., Peterson, G. D. 2015. Resilience assessment: a useful approach to navigate urban sustainability challenges. Ecology and Society. 20(1):43.

31. Svorozhtsov, E. V., Scobeiev, B. Y., Ganzha, V. G. 1995. Symbolic-numerical method for the stability analysis of difference schemes on the basis of the catastrophe theory. Journal of Computational Physics. 116(1):26-38.

32. Thom, R. 1975. Structural stability and morphogenesis. W.A. Benjamin Inc, Reading, MA.

33. Thomas, D. M., Urena, B. 2001. A mathematical model describing the evolution of West Nile-like encephalitis in New York City. Mathematical Computational Modelling. 34(7):771-781.

34. Thorn, R. 1969. Topological models in biology. Topology. 8:313-33X.

35. UNEP. 2014. Assessing Global Land Use: Balancing Consumption with Sustainable Supply. A Report of the Working Group on Land and Soils of the International Resource Panel. Bringezu S., H. Schütz, W. Pengue, M. O’Brien, F. Garcia, R. Sims, R. Howarth, L.Kauppi, M. Swilling, and Herrick J. 
36. Walker, B., Salt, D. 2012. Resilience Practice: Building Capacity to Absorb Disturbance and Maintain Function. Island Press: Washington, DC.

37. Wang, S. H., Huang, S. L., Budd, W. W. 2012. Resilience analysis of the interaction of between typhoons and land use change. Landscape and Urban Planning. 106:303-315.

38. Wang, X. J., Zhang, J. Y., Shamsuddin, S., Xia, X. H., He, R. M., Shang, M. T. 2014. Catastrophe theory to assess water security and adaptation strategy in the context of environmental change. Mitigation and Adaptation Strategies for Global Change. 19:463-477.

39. Washington-Allen, R. A., Briske, D. D., Shugart, H. H., Salo, L. F. 2009. Introduction to special feature on catastrophic thresholds, perspectives, definitions, and applications. Ecology and Society. 15(3):38.

40. West, S. P., Schultz, L. 2015. Learning for resilience in the European Court of Human Rights: adjudication as an adaptive governance practice. Ecology and Society. 20(1):31.

41. Young, O. R, Lambin, E. F., Alcock, F., Haberl, H., Karlsson, S. I., McConnell, W. J., Myint, T., Pahl-Wostl, C., Polsky, C., Ramakrishnan, P., Schroeder, H., Scouvart, M., Verburg, P. H. 2006. A portfolio approach to analyzing complex human-environment interactions: institutions and land change. Ecology and Society. 11:31-35.

42. Zeeman, E. C. 1976. Catastrophe Theory. Scientific American. 234(4):65-83.

43. Zhao, Y., Zou, X., Cheng, H., Jia, H. K., Wu, Y. Q., Wang, G. Y., Zhang, C. L., Gao, S. Y. 2006. Assessing the ecological security of the Tibetan plateau: methodology and a case study for Lhaze County. Journal of Environmental management. 80:120-131. 


\title{
Chapter 4 Ecological Resilience Assessment
}

\section{--Adaptive capacity based water quality resilience transition and policy implications in}

rapidly urbanizing landscapes

\begin{abstract}
Resilience-based management focuses on specific attributes or drivers of complex socialecological systems, in order to operationalize and promote guiding principles for water quality management, and predict potential threats and vulnerabilities of the urban system. Therefore this chapter represents a resilience lens drawing on adaptive capacity theory to evaluate the urban resilience between water quality and land use type in relation to urban development plans from 2000 to 2010 in Lianyungang, a coastal city in China. The findings show that: (1) The resilience of water quality variables, which were calculated based on their adaptive capacities, showed positive trends with dramatic fluctuation; (2) $\mathrm{NH}_{3}-\mathrm{N}$, Cadmium and Total Phosphorus experienced the most resilient shifts in the built-up area under rapid urbanization; (3) Analogous resilient transition states occurred in the agricultural and bare land; (4) National and regional planning practices (City Development Plan and China's Five-Year-Plan) contribute to ongoing shifts (Ammoniacal Nitrogen, Cadmium, Total Phosphorus and Oil) in different resilient transition states. Ultimately, we pointed to political underpinnings for building and managing resilient urban system in a particular coastal urban setting.
\end{abstract}

Keywords: adaptive capacity; land use; urban resilience; urban planning; water quality 


\subsection{Introduction}

Urban areas are hot and vulnerable spots that generate environmental impacts at multiple scales and time (Qureshi et al. 2014), the integrated urban social-ecological systems are special ecosystems that demonstrate both the challenges and solutions of rapidly urbanization for sustainable development in relation to resilient city. The drastic changes of land use, industrial pollution in catchments are the main reasons of water quality degradation (Foley et al. 2005, Park et al. 2014). Chapter 4 is an integration of several research studies, including two published papers (Li et al. 2015a, Li et al. 2015b) and one manuscript. The purpose of this manuscript is to apply a resilience lens to the urban environment from different perspectives, in order to explain the changes between urban water quality and land uses, particularly in relation to the adaptive capacity of local government policy.

\subsubsection{Urban resilience theory}

Urban resilience is a key concept in urban management and planning, appearing in urban development policy and guidelines as operationalizing and promoting a city's sustainability and flexibility and seeking to apply these principles for resilient cities (Colding 2006, Resilience Alliance 2007, Sellberg et al. 2015, West and Schultz 2015). Intense human pressures characterize the rapidly urbanizing landscape, which makes urban resilience evaluation even more difficult than resilience in natural systems. On the other hand, there is a particular need for understanding urban sustainable management in order to manage the changes that come with urbanization. To put it differently, as urbanization continues, new ways of organizing human-environmental activities (regimes) can lead to different stable outcomes (attractors) (Alberti and Marzluff 2004). Urban resilience considers not just preventing disturbances in existing planning systems, but also concerns strengthening government abilities in terms of building structures of land distribution and functions in order to increase its adaptive capacity to disturbances (Ayda and Tuna 2013).

Adaptive capacity refers to the ability of a system to deal with ecological and social disturbances in order to maintain resilience (Holling et al. 2002, Folke et al. 2002, Smit and Wandel 2006). Systems with high adaptive capacity are able to re-organize and renew themselves against disturbances without significant structure changes. The loss of adaptive capacity is the loss of opportunity for resilience, and "gaining from the disturbances" became a new path of perceiving resilience. Recent studies identify and quantify adaptive capacity in social-ecological resilience at different scales, which are based on the quantitative assessment of focal control variables within a certain safe space (Pelling and High 2005, Rockström et al. 2014, Steffen et al. 2015). Specifically, in order to identify a safe operating space for humanity on Earth, different studies present a set of indicators of capacity to adapt to variability and resilience about climate change (Brooks et al. 2005, Engle and Lemos 2010, Hobson and Niemeyer 2011, García-López et al. 2011, Kuruppu and Liverman 2011), coastal communities (Maldonado and Moreno-Sánchez 2014, Aguilera et al. 2015), water resource system (Eakin et al. 2010, Rockström et al. 2014) etc.

Acknowledging that local actions on water management continue to trigger global-scale syndromes is a necessary first step toward effective governance (Vörösmarty et al. 2015). Of particular importance are the agents within a given system who are able to respond to 
disturbances in various ways. For example, individuals, government institutions, and private actors and organizations are all involved in responding to disturbances. In the case of urban water quality, local governments play significant roles in urban planning, water/sanitation, and public policy, with a key role in setting up a legal environment that responds to and alleviates pressures. It not only emphasizes the adaptive capacity of urban-environmental systems, but also recognizes the role of human agency in fostering water quality change (Gunderson 2000). Together, the capacity among social-ecological agents to respond to disturbances lead to transitions within the adaptive cycle to more and less resilient states. The adaptive cycle is one relevant way to understand the transitions of self-organizing systems, but the cyclic pattern is not an absolute following the order (Resilience Alliance 2007). The adaptive cycle also provides guiding lines of adaptive management, becoming the pathway for achieving the integration of the related key concepts into decision making.

Landscape pattern change is one of the major anthropogenic impacts on the environment, significant landscape pattern change occurs in the process of urbanization, industrialization and agricultural development. Land use change can modify watershed cover characteristics and can cause water quality deterioration (Bhat et al. 2006). Numerous studies analyze the relationships between land use and water quality through different methods (Tong and Chen 2002, Su et al. 2011, Gilfedder et al. 2012, Dodder et al. 2014), though rarely adapting the perspective of resilience. As one of the key elements of urban ecological systems and key functions of local government, water quality has significant impacts on urban environment, and it demands that cities be more resilient.

In this study, urban resilience refers to the ability of the urban system to establish and increase its adaptive capacity and provide particular guiding principles or sustainability strategies for policy makers and urban planners. Resilience issues between water quality and the landscape change are the main concern for growth management in Lianyungang ( $\mathrm{Li}$ et al. 2015). The way in which urban water quality resilience responds to land use change can be identified as a controller for redundancy and learning management, as well as a predictor for potential threats and vulnerabilities of the urban system. Therefore, temporal and spatial resilience are quantified and visualized between water quality variables and different land use types in Lianyungang, and the complex feedbacks and strategies for resilience changes of water quality. The main objectives are to: (1) explore the characteristics and resilience states of surface water quality variables, based on the theory of adaptive capacity, in both urban and peri-urban areas during rapid urbanization (2000-2010); (2) evaluate probability functions of the key social, economic and political regimes and policies for resilience shifts between different transition states; and (3) highlight applications and suggestions for urban resilience management under urban agglomeration and city structure updating.

\subsubsection{Brief background information}

The first paper (Li et al. 2015a) aims to detect the linkage between landscape ecological changes and water quality under rapid urbanization, and assesses it in three spatial urban development zones, i.e. center, inner peri-urban and outer peri-urban of the eastern coastal municipality of Lianyungang, China. Particularly the loss of arable land and saltern cover in the center and inner part of watershed caused by urbanization development was analyzed. The increasing influences on water quality will be a challenge for future development. The 
government needs to adjust and maintain sufficient green spaces, especially in the rapidly developing urban areas. Another focal factor affecting water quality is the increasing built-up driven land fragmentation, it indicates that the key points of river restoration and management are: stricter regulations about built-up land expansion, decrease urbanization-related pollution and develop sustainable urban landscapes. One of the main issues in peri-urban area is agricultural land management.

The second paper ( $\mathrm{Li}$ et al. 2015b) identifies the threshold and addresses resilience management to inform land-water management. The fitted regression models reveal the dynamic linkages between landscape metrics and water quality variables in Lianyungang. The threshold offers a window to analyze land-water coping management, and it informs the potential adaptive management of resilient systems to maintain the configuration and function in such system, due to the excessive disturbance and degradation in ecosystems. The knowledge of thresholds assists managers to adjust city plans for future environmental conservation and restoration. The safe operating spaces within thresholds are critical support information for resilience management.

More detail information is provided in Appendix 3 (Box 1 and Box 2).

\subsection{Methods}

According to our previous research, Lianyungang has undergone a complex period of multiple-policy implementations ( $\mathrm{Li}$ et al. 2012, Li et al. 2015a). Following resilience theory for urban planning, this section proposes a systematic methodology to investigate and quantify the resilience of water quality in conjunction with different land use types. Land use maps were derived from Landsat TM/ETM+ images with 7 different land use types. Water quality was calculated by the Water Comprehensive Pollution Index (WCPI) based on the water quality assessment in the Environmental Quality Standards for Surface Water (GB 3838-2002). All the water monitoring sites are located along the 27 main rivers (Fig.4.1). Since water quality variables have different units, we used the Min-Max Normalization to categorize them into values between $0 \sim 1$. Afterwards, a series of statistical methods were applied for further distribution testing. In the end, resilience values of water quality with corresponding land use type were calculated with the measurement of adaptive capacity based on the instantaneous and maximal disturbance, which was derived from the basic definition of resilience. 


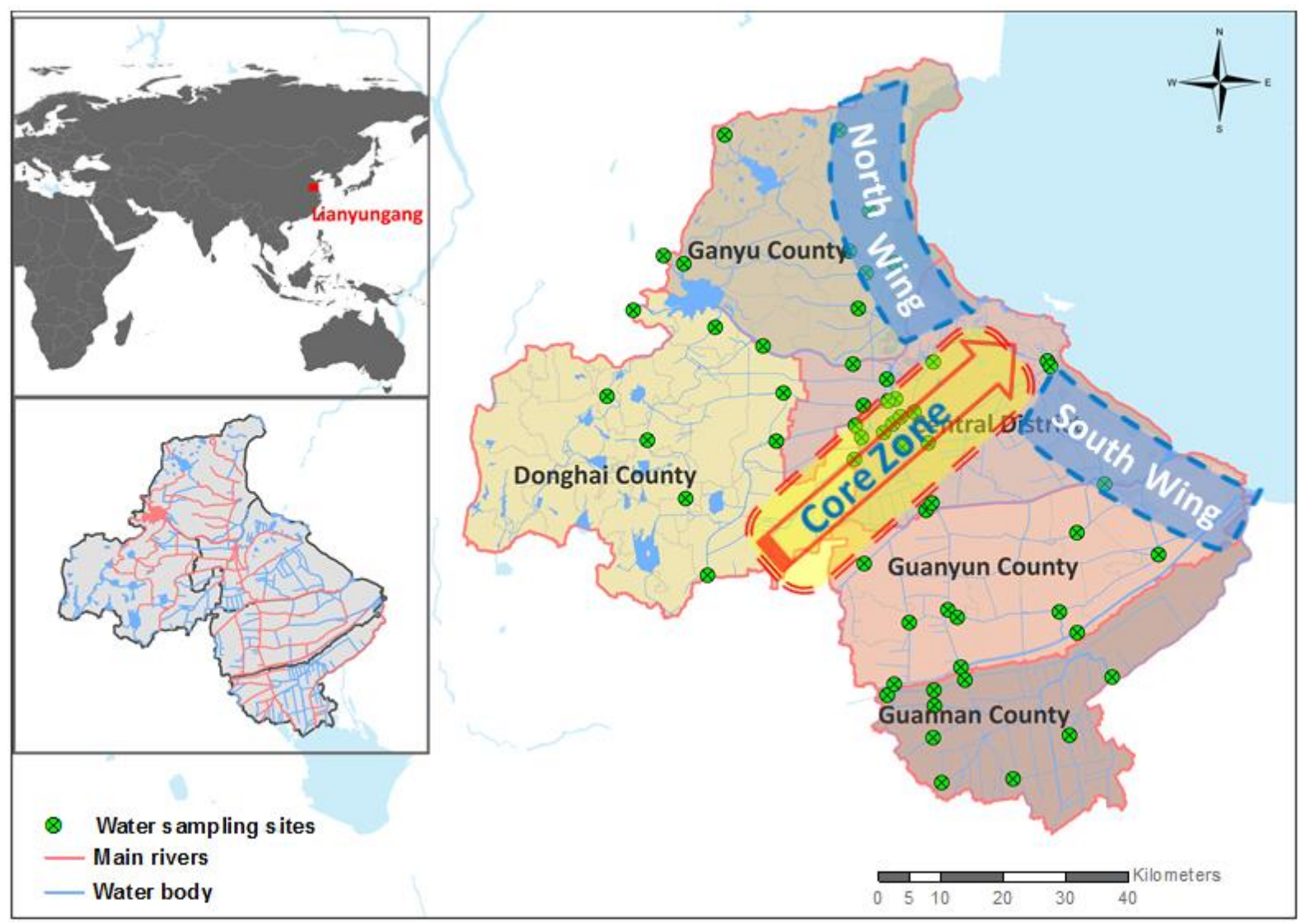

Fig.4.1 Development policy in Lianyungang

\subsubsection{Image preprocessing}

Eleven sets of Landsat 7 ETM+ (2000-2003) and Landsat 5 TM (2004-2010) images were obtained from the United States Geological Survey (USGS) with 30*30 meter resolution. Acquisition dates of all these images were from December to February, each Landsat scene was corrected and georeferenced to the coordinate system of WGS 1984 UTM Zone 50 North. In the end, seven land use types were derived by the Maximum Likelihood Classification. Land use types are: ocean, built-up, water body, bare land, agriculture, saltern land and forest.

In order to get the specific land use type near the water monitoring sites, we created $5 \mathrm{~km}$ buffer zones for each water sampling site in ArcGIS based on the regulation in the Environmental Quality Standards for Surface Water (GB 3838-2002). This buffer was chosen because the water quality monitoring sections in Lianyungang belong to the Surface Water Grade II, III, IV and V, with the largest protection area of $5 \mathrm{~km}$ for Standard II. The majority values of land use type were selected as the value of land use type in each buffer zone.

\subsubsection{Water quality variables}

In Lianyungang, 10 rivers flow through urban areas. Our water quality monitoring dataset included 57 samples (Fig.4.1) of both urban and peri-urban sub-catchments from 2000 to 2010. The time period was designed according to the duration of the Chinese Five-Year-Plan. The year 2000 was chosen as a reference value, because it was the last year of the $9^{\text {th }}$ Five-Year- 
Plan. The $10^{\text {th }}$ Five-Year-Plan was from 2001 to 2005 , and the $11^{\text {th }}$ from 2006 to 2010 . According to the requirements of water quality assessment in the Environmental Quality Standards for Surface Water (GB 3838-2002), 12 water quality variables were collected from the Lianyungang Environmental Quality Bulletin (2001-2011). Annual mean values were used for water quality evaluation, and those values were calculated as the mean of 12 monthly values at each monitoring site. Water quality variables included $\mathrm{pH}, \mathrm{KMnO}_{4}$ (Potassium Permanganate), BOD (Biochemical Oxygen Demand), $\mathrm{NH}_{3}-\mathrm{N}$ (Ammoniacal Nitrogen), VP (Volatile Phenol), As (Arsenic), $\mathrm{Cr}^{6+}$ (Chromium), Pb (Lead), Cd (Cadmium), Oil, TP (Total Phosphorus), F (Fluoride).

Considering the different units of those variables, the Water Comprehensive Pollution Index (WCPI) was used to analyze and monitor water quality for resilience assessment (Wang et al. 2008, Liu et al. 2011, Wang et al. 2015), which was calculated according to the Environmental Quality Standards for Surface Water (GB 3838-2002) as:

$$
\begin{gathered}
P_{i j}=\frac{C_{i j}}{C_{i 0}} ; \\
P_{j}=\sum_{i=1}^{n} P_{i j}(n=1,2, \ldots 12)
\end{gathered}
$$

where $C_{i j}$ is the mean value of variable $i$ in river $j, C_{i 0}$ is the standard value from the Environmental Quality Standards for Surface Water; $P_{i j}$ is the pollution index of variable $i$ in river $j, P_{j}$ is the total pollution index of river $j$. Standard values of water monitoring sites are based on river function zoning in the Environmental Quality Standards for Surface Water (GB 3838-2002), the water variable in each zone has a national standard value. River function zones are categorized and regionalized based on the river's natural properties and social standards, such as resource status, geographic location, utilization level of water resources, demand of social advancement on water quality and quantity of water resources. There are five standard water grades from Grade I to Grade V. Grade I is the best water quality for drinking water, while Grade $V$ is the worst quality that can only be used for agriculture and landscaping purpose. Being a negative indicator, the higher the WCPI, the worse the water quality is.

This work is an integrated and further research about water quality status in Lianyungang. This paper addressed resilience theory into a quantitative method for resilience calculation of water quality with different land use types, which was based on the adaptive capacities of different water quality variables. According to accepted research about water quality changes and thresholds of different water quality variables (Li et al. 2015a, Li et al. 2015b), the fitted regressions in the research showed the nonlinear relation between landscape metrics and water quality variables in Lianyungang, landscape thresholds showed variability depending on the landscape metrics used and water quality variables studied (see Appendix 3). There are two different types of threshold. The possible turning points on the curves within the range of landscape metrics and water quality were considered as Type- 1 landscape thresholds. Type- 2 landscape thresholds were calculated by the landscape metrics and water quality standards of surface water (GB3838-2002, GB standards are the Chinese National Standards issued by the Standardization Administration of China), which were based on the regression relations.

From the Environmental Quality Standards for Surface Water, the standard of surface water quality can be classified into five grades (Table 4.1), which are based on the functions of surface 
water and the regulations of protected area:

Standard I: applicable to water source and water in the national natural protected area;

Standard II: applicable to the first grade protected area of centralized drinking water source, habitat of rare and endangered Aquatic species, spawning places, feeding ground, etc.;

Standard III: applicable to the second grade protected area of centralized drinking water source, habitat of Aquatic species in winter, aquatic migration pathway, fishing area and swimming area;

Standard IV: applicable to industrial water and non-directive contact water area;

Standard V: applicable to agricultural water and landscape water area.

Table 4.1 Environmental Quality Standard value for Surface Water

\begin{tabular}{cccccc}
\hline Standards (mg/L) & I & II & III & IV & V \\
\hline $\mathrm{pH}$ & $6-9$ & $6-9$ & $6-9$ & $6-9$ & $6-9$ \\
$\mathrm{KMnO}_{4}$ (Potassium Permanganate) & 2 & 4 & 6 & 10 & 15 \\
$\mathrm{BOD}$ (Biochemical Oxygen Demand) & 3 & 3 & 4 & 6 & 10 \\
& & & & & \\
$\mathrm{NH}_{3}-\mathrm{N}$ (Ammoniacal Nitrogen) & 0.15 & 0.5 & 1 & 1.5 & 2 \\
Oil & 0.05 & 0.05 & 0.05 & 0.5 & 1 \\
$\mathrm{VP}$ (Volatile Phenol) & 0.002 & 0.002 & 0.005 & 0.01 & 0.1 \\
$\mathrm{TP}$ (Total Phosphorus) & 0.02 & 0.1 & 0.2 & 0.3 & 0.4 \\
F (Fluoride) & 1 & 1 & 1 & 1.5 & 1.5 \\
Pb (Lead) & 0.01 & 0.01 & 0.05 & 0.05 & 0.1 \\
As (Arsenic) & 0.05 & 0.05 & 0.05 & 0.1 & 0.1 \\
Cd (Cadmium) & 0.001 & 0.005 & 0.005 & 0.005 & 0.01 \\
$\mathrm{Cr}{ }^{6+}$ (Chromium) & 0.01 & 0.05 & 0.05 & 0.05 & 0.1 \\
\hline
\end{tabular}

\subsubsection{Normalization}

As one of the most used normalization methods, Min-Max Normalization is the process of transforming WCPI values into standardized values by scaling between 0 and 1 . The lowest $\left(E_{\min }\right)$ value is set to 0 and the highest $\left(E_{\max }\right)$ value is set to 1.0 , if $E_{\max }$ is equal to $E_{\min }$ then Normalized $\left(e_{i}\right)$ is set to 0.5 . Therefore we can compare different water quality variables that were measured using different scales or different units. The normalized value $\left(E_{i}^{\prime}\right)$ was calculated as:

$$
\mathrm{E}_{i}^{\prime}=\left(E_{i}-E_{\text {min }}\right) /\left(E_{\max }-E_{\text {min }}\right)
$$

Where: $E_{i}{ }^{\prime}$ is the normalized value; $E_{\min }$ is the minimum value for each Water Comprehensive Pollution Index (WCPI $) ; E_{\max }$ is the maximum value for WCPI. In this case, the $E_{i}^{\prime}$ of 1 being the worst rank, it means that this water monitoring site has the worst water quality or is heavily polluted over the water quality standard; and $E_{i}^{\prime}$ of 0 being the best with the least pollution or 
meets its water quality standard.

After normalization, a series of statistical methods was applied for further testing. Firstly, we checked whether all the data are normally distributed. This was done by using the Kolmogorov-Smirnov test (K-S test), Lilliefors test and Shapiro-Wilk test (Lilliefors 1967, Stephens 1974, Press 1992). Because the dataset included only 57 monitoring sites, considering the statistical reliability of dataset, all the results were based on these three tests. All the water quality variables used in this study need to pass at least two of those tests, and five water quality variables $\left(\mathrm{NH}_{3}-\mathrm{N}, \mathrm{Pb}, \mathrm{Cd}\right.$, Oil, $\left.\mathrm{TP}\right)$ were chose for further processing. Afterwards, ANOVA for normally distributed data and the associated nonparametric method, and the Kruskall-Wallis ANOVA were used to test the influence of the different indicators on the land use type. In both cases, we tested the null hypothesis of the water quality variables being equal in all the different land use types, versus the alternative hypothesis of at least one land use type being different. We used the Mann Whitney U Test to identify all land use types significantly different from at least one other. After all these processes, the most significant water variables and land use types were generated for resilience evaluation.

\subsubsection{Adaptive capacity based resilience evaluation}

A resilient system has the qualities of monitoring its performance, and responding to the multiple pollutant resources without significant declines in system's functions and capacity to respond to environmental change. Resilience is thus related to social relationships, economic prosperity and productivity, and ecological cycles. Orwin and Wardle (2004) have linked resilience with the measurement of the instantaneous and maximal disturbance, and here we calculated the resilience of water quality according to its Water Comprehensive Pollution Index (WCPI) and adaptive capacity. The ability to self-organize is particularly important in adaptive capacity for dealing with disturbances and how city sustainability planning enhances a system's adaptive capacity. The higher adaptive capacity represents higher resilience (Fig.4.2), which means the system has a better chance to recover and maintain its structure after disturbances.

Adaptive capacity can affect the system state as much as changes in key water quality variables, and even result in an alternative desirable phase of urban resilient system. There are four phases in the adaptive cycle (Carpenter et al. 2001): "Exploitation" (with rapid resilience growth); "Conservation" (accumulation, monopolization, and conservation of structure, during which resilience tends to decline); "Release" (rapid breakdown or release phase of creative destruction); "Reorganization" (renewal and reorganization phase, during which resilience tends to increase). Adaptive capacity is lost when a water system fails to address the "backloop" phases (Release and Reorganization), and it can cause the collapse of resilience or shift to a new regime. The "forward" phases (Exploitation and Conservation) are the time for developing new policies and action plans, and changes of management practices in order to maintain desired water quality (Walker and Salt 2012). These four quantitative phases of the adaptive cycle are tied to the adaptive capacity of the social agents involved in urban planning, which will be discussed in full in the Section 4.3.

$$
\operatorname{Resilience}_{i}\left(\mathrm{R}_{i}\right)=\left(2 \times\left|E_{\text {max }}\right| /\left|E_{\text {max }}\right|+\left|E_{i}\right|\right)-1
$$




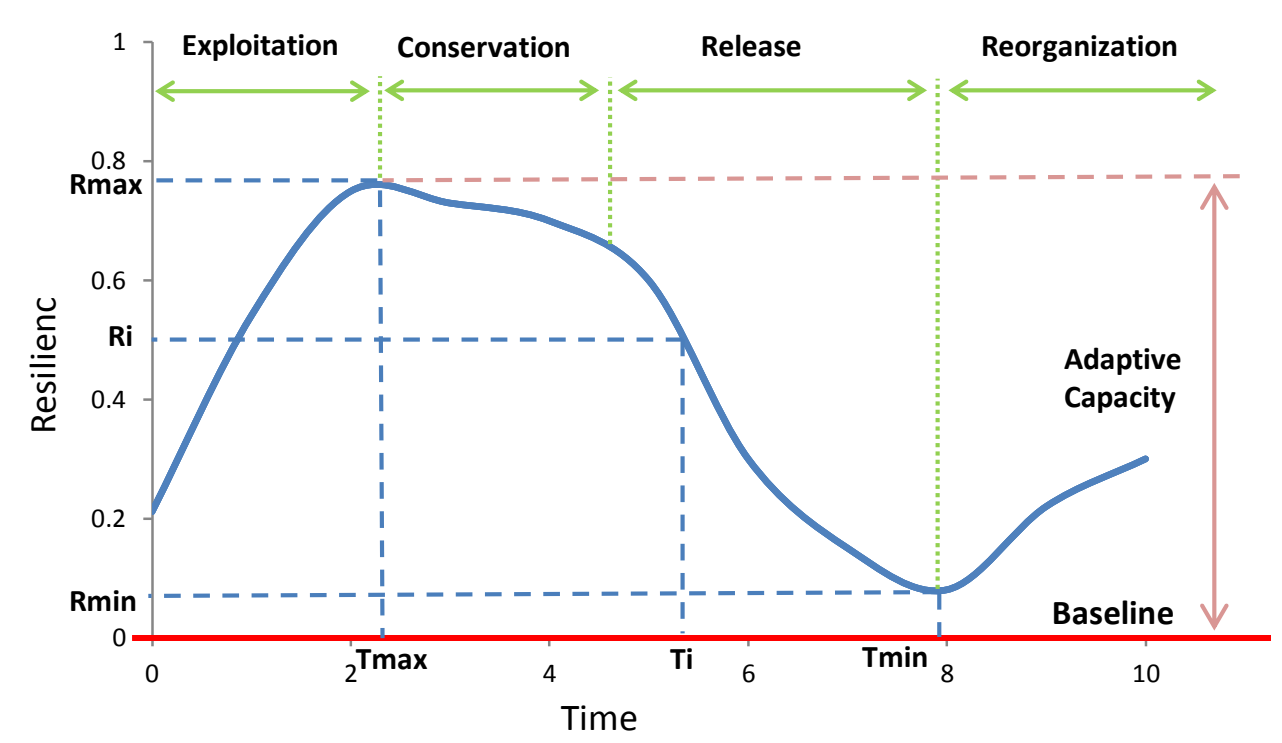

Fig.4.2 Typical resilience performance to disturbances and resilience measurement

A response variable can be any water quality variable that is responsive to disturbances. The bottom line (baseline) represents the worst water quality, or the system close to collapse and cross its threshold. The further the resilience value is from the baseline, the better the water quality is; thus, also representing more adaptive capacity.

where $E_{\max }$ is the maximum Water Comprehensive Pollution Index (WCPI), $E_{i}$ is the WCPI at the time point $T_{i} . R_{\max }$ is the maximum resilience value, $R_{i}$ is the resilience at the time $T_{i}$ (Fig.4.2). The baseline indicates the lowest resilient system. This index of resilience is also bounded by 0 and 1 . A value of 1 at the time of measurement indicates full adaptive capacity (maximal resilience), and lower values indicate a lower adaptive capacity.

\subsection{Results and Discussion}

As a developing city, Lianyungang experiences the intense pressure of water pollution due to its rapid urbanization. The resilience results between different land use types and water quality variables are analyzed in this section.

\subsubsection{Water quality of different landscapes}

According to the Lianyungang Environmental Quality Bulletin, during the period 2006-2010 the total sewage discharge was 684.68 million tons, with an increase of $10 \%$ compared to the five years prior. The proportion of industrial sewage discharge decreased to $25.11 \%$, but the high concentration of pollutant from industrial pollution, it was still one of the main sources of pollution. Sanitary waste water from the citizens increased to $74.88 \%$ which was another main pollution resource. Furthermore, only $38.85 \%$ of sewage was from the central urban area. Agricultural pollution was also a main pollution source of $\mathrm{NH}_{3}-\mathrm{N}$ and TP. Therefore, most 
pollution was sourced from the citizens of the peri-urban area, industrial point pollution and agricultural non-point pollution.

During this time, the vulnerability and shifts of water quality continued to be a challenge for city's development. Eight of the water quality variables $\left(\mathrm{pH}, \mathrm{KMnO}_{4}, \mathrm{BOD}, \mathrm{VP}, \mathrm{As}, \mathrm{Cr}^{6+}\right.$ and F) had slight shifts, while the stable variables still changed within current resilient capacity above the base line. On the other hand, the results for $\mathrm{NH}_{3}-\mathrm{N}, \mathrm{Pb}, \mathrm{Cd}$, Oil and TP expressed at different resilient adaptive capacity. Water quality change results of these three land use types were relatively stable, WCPI ranged between 0.2-0.35 (Fig.4.3 in supporting information). Water quality values were calculated by the mean value of the all water quality variables. In built-up areas, the total water quality decreased slightly from 0.32 to 0.24 , which means that water quality improved at the end of 2010. Agricultural land and bare land area increased in WCPI level as a resulted of more water pollution. It implies that both bare land and agricultural land were interrelated and interacted with each other.

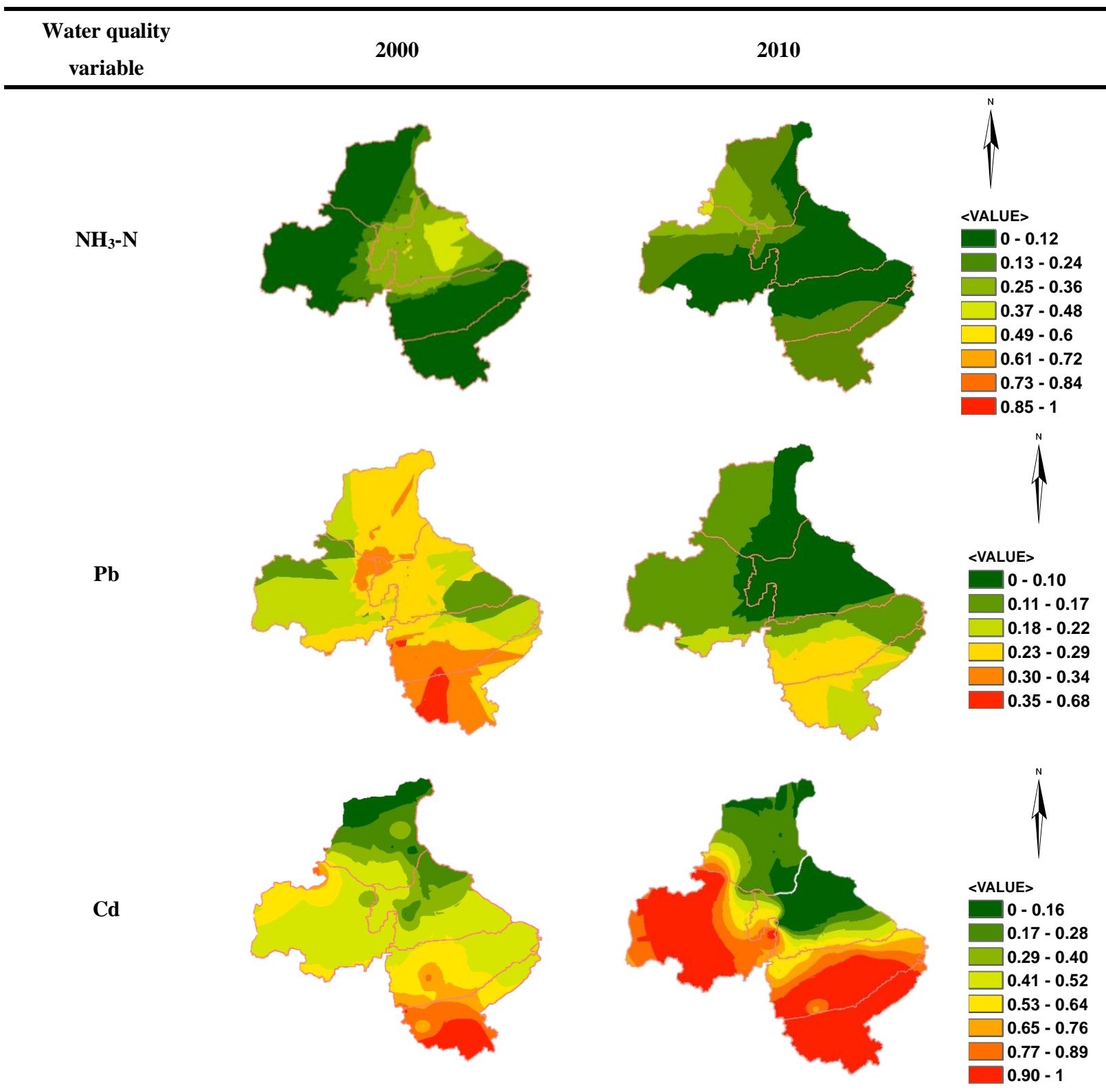


Oil
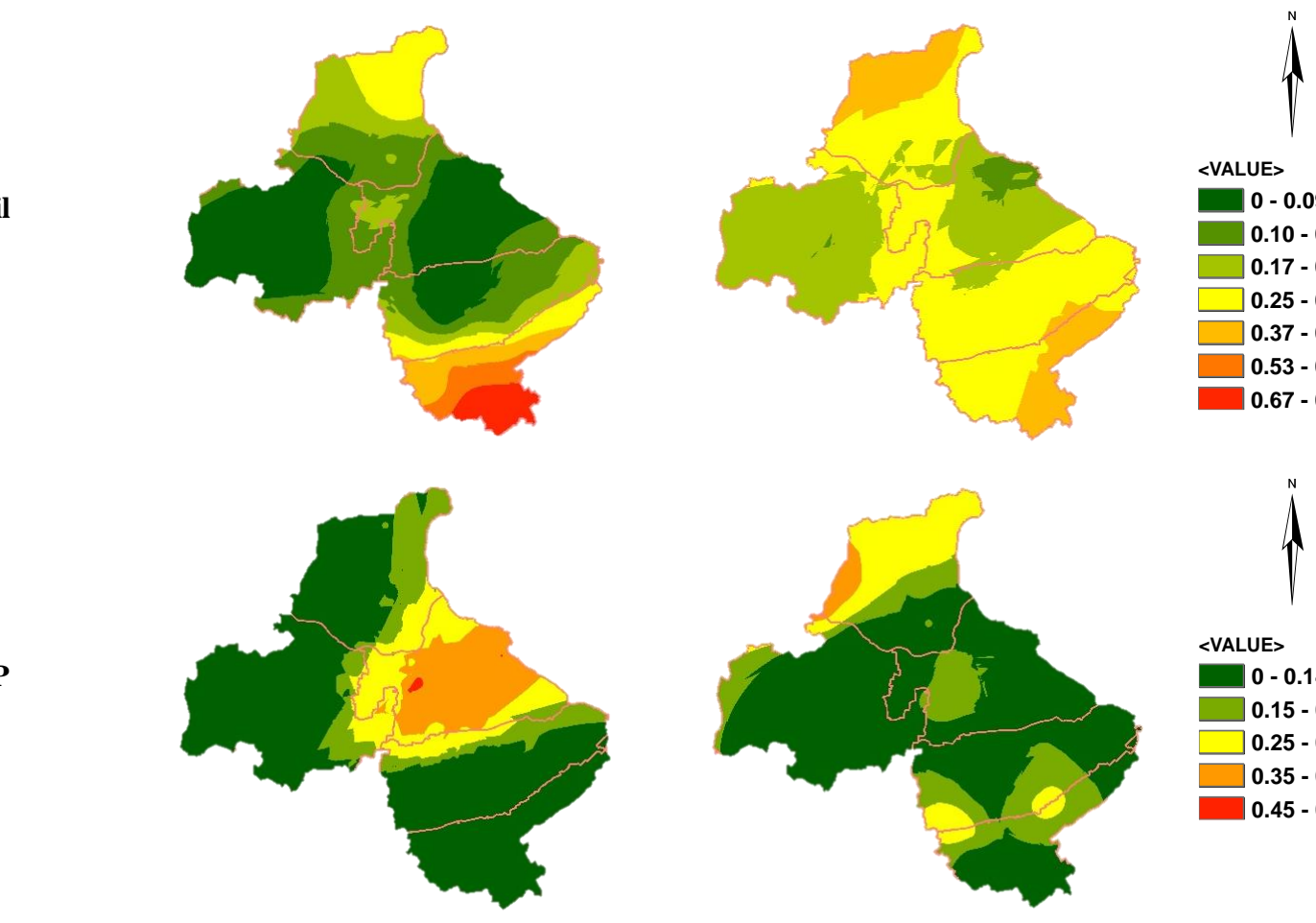

$<$ VALUE $>$

$0-0.09$

$0.10-0.16$

$0.17-0.24$

$0.25-0.36$

$0.37-0.52$

$0.53-0.67$

$0.67-0.82$

TP

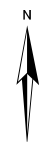

<VALUE>

Fig.4.3 Spatial distribution of Water Comprehensive Pollution Index (2000 and 2010)

Water Comprehensive Pollution Index was graded from the lowest (green) to highest (red). Darker green represents less pollution, darker red represents heavier pollution. All the water quality variables had different index ranges. Each variable is shown in the same scale.

The WCPI distributions of five significant water quality variables $\left(\mathrm{NH}_{3}-\mathrm{N}, \mathrm{Pb}, \mathrm{Cd}, \mathrm{Oil}, \mathrm{TP}\right)$ were different from 2000 to 2010 (Fig.4.3). According to the changes of WCPI during 2000 to 2010, the higher polluted areas sprawled to other peri-urban area. Since urbanization and industrialization spread to other peri-urban districts, mostly in Donghai, Guanyun and Guannan districts, WCPI of all those five water variables turned into higher pollution values. Cd had relative serious change with a larger heavy polluted area during this time. In 2000, the higher values were in the middle of central urban area and southwest of Guannan district. It had a large area with higher values, but most of those were among the medium value, only Guannan had a higher value. $\mathrm{NH}_{3}-\mathrm{N}, \mathrm{Pb}$ and $\mathrm{TP}$ had positive changes in 2010 compared to 2000. In general, more areas had lower WCPI values especially the central urban area. For example, the higher value of $\mathrm{NH}_{3}-\mathrm{N}$ and TP appeared in Ganyu district instead of the urban center. Both variables showed a similar increase along the boundary between Guanyun and Guannan.

According to the city plan's water quality component, water quality should improve to Grade III in 2012, and reach to Grade II in 2030, which is the standard water quality of drinking water; other rivers should improve to Grade III in 2030. Based on those expected goals, $\mathrm{NH}_{3}-\mathrm{N}, \mathrm{Pb}$, $\mathrm{Cd}$, Oil, TP will be the priority monitoring indicators. Agricultural pollution is the main source of $\mathrm{NH}_{3}-\mathrm{N}$ and $\mathrm{TP}$, with a smaller proportion coming from domestic sewage and industrial pollution. For instance, in the Qiangwei River (one of the main rivers), $71.2 \%$ of total $\mathrm{NH}_{3}-\mathrm{N}$ pollution was agricultural pollution, $28.6 \%$ was from domestic pollution, and $0.2 \%$ from industrial pollution. TP pollution from those three sources was $81.8 \%, 17.2 \%$ and $1 \%$, 
respectively. In order to recover the water quality in the Qiangwei River, 214.8 tons of $\mathrm{NH}_{3}-\mathrm{N}$ and 202.7 tons of TP need to be decreased per year. In response, the Lianyungang government has set new regulations for water quality control, and approximately 20 hundred million yuan will be used for 40 water quality improvement projects.

\subsubsection{Resilience results between different land use types and water quality variables}

\section{Resilience transition in built-up area}

The resilience of five water quality variables $\left(\mathrm{NH}_{3}-\mathrm{N}, \mathrm{Pb}, \mathrm{Cd}\right.$, Oil and $\left.\mathrm{TP}\right)$ experienced transition states from 2000 to 2010 (Fig.4.4). Generally, the resilience in the built-up area had a positive trend that resulted in a more resilient state than 2000. The higher resilience represented a higher adaptive capacity in built-up area after the abrupt change of resilience collapse. With the start of first planning period (2005-2010) in the city plan, more and more industrial zones show up in the new urban-based area and eastern coastal area. All the five water quality variables showed certain resilience transitions after 2005, which triggered from perturbations of city development. Until 2030, the area of planned built-up land will increase to $240 \mathrm{Km}^{2}$, with an increase of $5.87 \mathrm{Km}^{2}$ per year. In this case, more and more perturbations may accelerate resilience changes in built-up land.

For the built-up area, $\mathrm{NH}_{3}-\mathrm{N}, \mathrm{Cd}$ and $\mathrm{TP}$ showed increased vulnerability and less resilience with damage propagation that was classified as release phase with low-resilience in this period: release phases of Cd from 2001 to 2003 and 2005 to 2006, release phase of TP from 2004 to 2005. During this time, the adaptive capacity of $\mathrm{Cd}$ dropped to baseline, and TP decreased to its lowest value. Even though, the system's adaptive capacity recovered and resulted in a more resilient state during exploitation phase, the fluctuation from the worst to the best value in such a short time reveals that there were some unconditional or intense disturbances triggered abrupt collapses during this time. On the other hand, $\mathrm{Pb}$ and Oil appeared to be in a more flexible and conservation resilient phase.
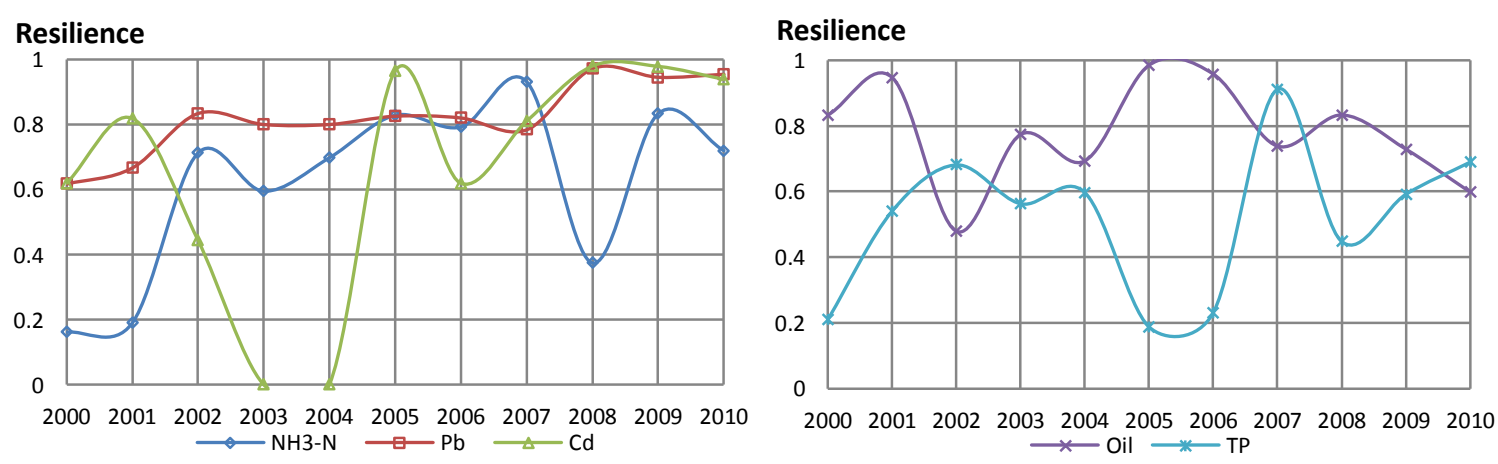

Fig.4.4 Resilience value of five significant water quality variables in built-up land from 2000 to 2010

$\mathrm{X}$ axis is the resilience base line, the closer resilience value to base line, the worse resilience it has, and worse adaptive capacity it has. 


\section{Resilience transition in bare land}

As expected with safer levels (lower WCPI value), the water quality in the bare land areas experienced a more resilient state than the built-up area (Fig.4.5). Resilience of Cd was the only variable that had tremendous shifts during 2000 to 2010, while the others were almost interpreted in terms of equilibrium states. The conservation phase started from 2000 to 2002, resilience stayed at the same level; then followed with a release phase, during which resilience dropped in 2003; and a reorganization phase until 2006 with the lowest adaptive capacity that approached its base line; in the end, resilience recovered during exploration phase. But from 2009 to 2010, Cd resilience appeared to decrease in conservation phase, following with the decrease of adaptive capacity. The transition state of bare land was even longer than that in the built-up area, the resilience of $\mathrm{Cd}$ almost exceeded the adaptive capacity. Furthermore, other variables had more stable resilience with slight degradation in conservation phase. Without doubt, the existence of water pollution and the potential for property damage were all realities that have serious negative implications for water quality.
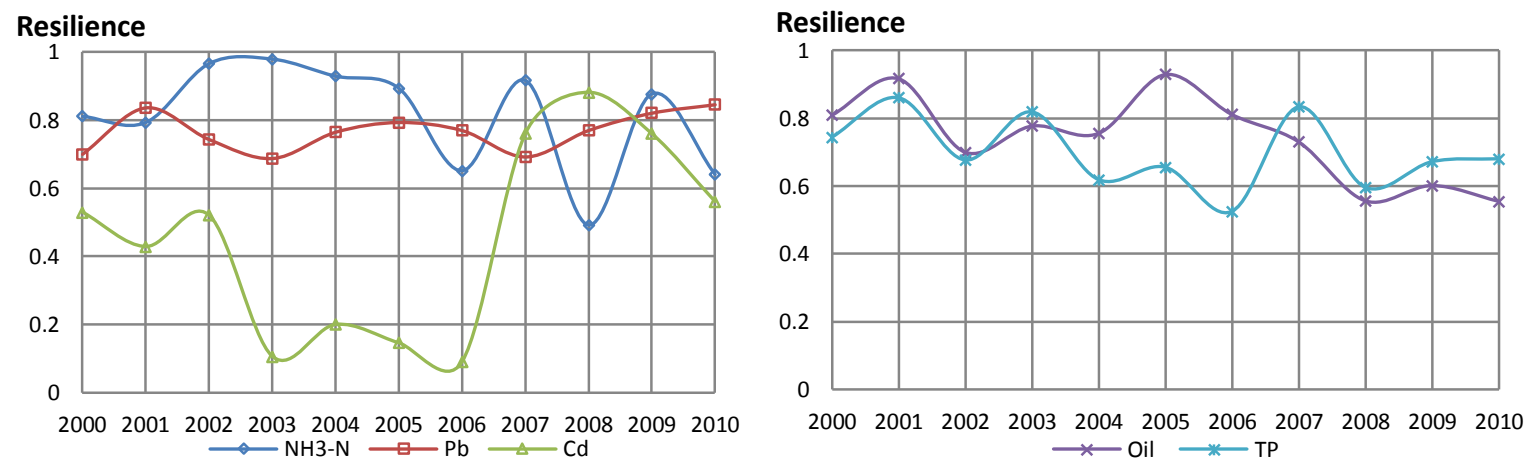

Fig.4.5 Resilience value of five significant water quality variables in bare land from 2000 to

2010

\section{Resilience transition in agricultural land}

As the largest land use type in Lianyungang, agricultural land experienced periodic and compounding disturbances to water quality (Fig.4.6). Between 2000 and 2002, it was in the conservation phase with relatively stable adaptive capacity. The resilience of $\mathrm{Cd}$ reflected a more complex and uncontrollable transition state. There was a dramatic shift of $\mathrm{Cd}$ resilience from 2002 to 2003 and 2009-2010, in the release phase, the proximity to the bottom line exacerbated the balance of water quality and landscape in the later four years. However, after a relatively short phase of exploitation and conservation, its capacity recovered and created a two-year safety resilient state. From 2009 to 2010, with a very rapid breakdown phase, the adaptive capacity of $\mathrm{Cd}$ fell to another low resilient state close to the baseline. The trend of $\mathrm{Cd}$ resilience demonstrates that the $\mathrm{Cd}$ resilience was nearly beyond adaptive capacity, after withstanding unexpected disturbances. Other variables were almost maintained around the same resilience level, except short durations of instability.

In the City Comprehensive Plan, the total agricultural land should be maintained at 689.89 $\mathrm{km}^{2}$, and in order to be protected without any disturbances $432.7 \mathrm{~km}^{2}(29.1 \%$ of the total 
planning area) are needed. The government will control the built-up land in peri-urban area by moving and combining nearby districts or counties, optimizing the management of agricultural land to avoid urban sprawling and encroaching upon the surrounding fields. The final goal is to control the total built-up land so as to be less than $34.43 \mathrm{~km}^{2}(2.3 \%$ of the whole planning area).
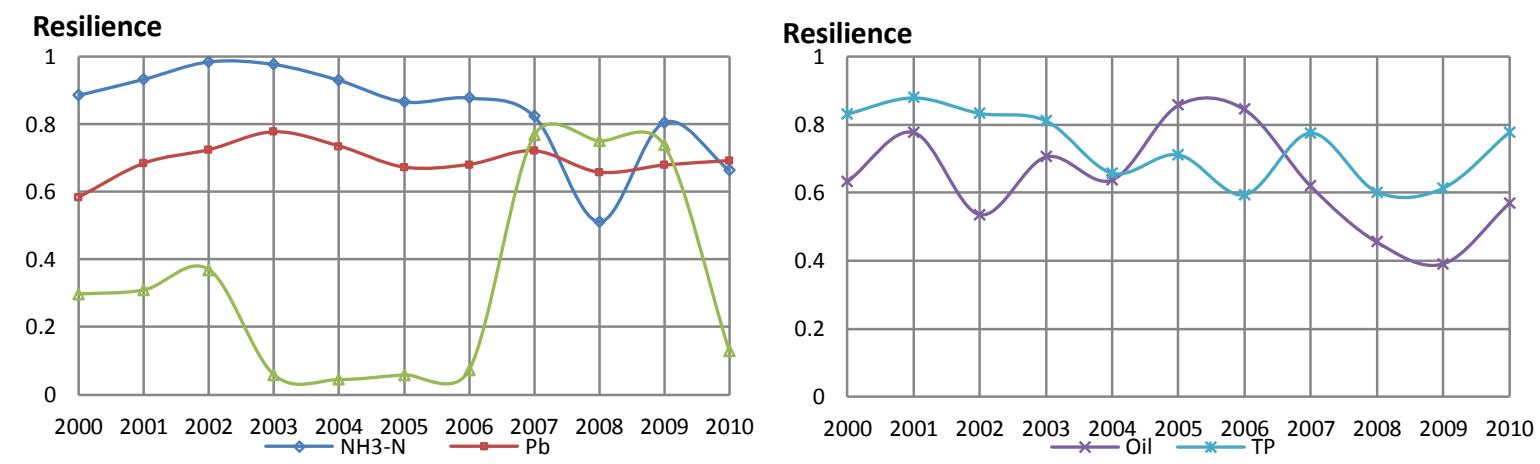

Fig.4.6 Resilience value of five significant water quality variables in agricultural land from 2000 to 2010

\subsubsection{Discussion}

Degraded adaptive capacity of water quality in the built-up area

Our results revealed that the built-up area had the most vulnerable transition state compared to others during 2000 to 2010 . Resilience of water quality degraded to release phase during 2003-2006, the main pollutants were $\mathrm{NH}_{3}-\mathrm{N}, \mathrm{Cd}$ and TP. Cd and TP were two of the most vulnerable water quality variables during the study period, indicating high levels of chemical industrial pollution and other mineral pollution (Mulholland et al. 2008, Silva et al. 2011). Even though industry represented a small proportion of the source of sewage, it still had an important effect on water quality. It is evidenced by the fact that Lianyungang experienced rapid urbanization and industrialization since 2003. The majority of those pollutants were from the domestic sewage and industrial waste water. From the spatial distribution of the Water Comprehensive Pollution Index (WCPI) of 2000, the most polluted rivers are in the central urban area. Distribution of WCPI transferred to the newly developing built-up areas in other peri-urban areas, due to the increased demands for food, transport equipment, construction and other services dominate the increasing environmental pressure in the area of "One Zone, Two Wings" policy. Domestic sewage was the main form of pollution in Yan, Paidan, Qingkou, Longwei and Qiangwei rivers, some of which were heavy polluted during 2003-2006.

Manufacturing industry was another direct contributor to the degraded water quality, primarily due to increased production of chemical products, nonferrous metal ores, ferrous metals, electric and heat power (Liang 2014). Most of the pollutants were produced by manufacturing industry, Paidan, Xiyandapu and Yudai River loaded the main industrial pollution, which caused the degradation of water quality beyond the acceptable pollution capacity. In the city plan, the ratio of primary, secondary and tertiary industries will be adjusted 
to 3:56:41, and intend to focus on heavy manufactural industries and portside industries in the area of "One Zone and Two Wings".

When the city government of Lianyungang began observing increased water pollution after the turn of the century, a primary form of response to combat further water degradation was to implement modern wastewater infrastructure. Before 2005, the height of overall water pollution in the city, only one wastewater treatment plant existed in the city. The capacity of this single plant was only 0.1 million tons/day during a period of intensified water usage. As a result of the city development plan, 9 additional waste water treatment facilities were constructed by 2010, increasing treatment capacity threefold from 0.1 million tons/day to 0.31 million tons/day. Further the local urban development plans targeted other urban management practices related to water quality, including the enforcement of water quality regulation by local authorities and the renovation of the wastewater network system and replenishment of clean upper-stream water. These new investments, policies, and concerted policy enforcement allowed most of the rivers to maintain their standard water quality levels. In keeping with water quality regulations, all the residence buildings and industries in the first or second protected areas for drinking water sources were either moved out or shut down, the waste water discharge pipes nearby were closed, and automatic monitoring system and up-to-date waste water treatment technologies were used in newly built treatment plants.

As the resilience increased after 2006, urban resilience was improved by cooperation between each district, and effective alternatives and recycling of industrial land from local policies in Lianyungang. Furthermore, local government now optimizes land use structures according to the implementation of city development plans, in order to minimize the disturbances from city development, especially in the area of "One Zone and Two Wings". Whereas industrial activity was previously scattered throughout the city, making industrial wastewater control difficult and leading to more water pollution, it has now been concentrated into specific areas with better monitoring and treatment. Within the four new districts and three development axes each now has its own functional ability. Sophisticated, intensive, and clustering industrial development will also be helpful for land use management, updating the structure in former urban area, trying to keep new industry within the south industry park as directed by the City Plan.

\section{Analogous resilience shifts of water quality in agricultural and bare land}

Our study showed that agricultural and bare land had closely analogous trends with extreme shifts from the lowest to the highest resilience state. Affected by non-point source pollution, the high input of phosphorus and nitrogen into the river from fertilizers in farmland affects water quality. The result can be identified as a property of systems approaching adaptive capacity limitation upon the system's dynamics during 2003-2006. On the other hand, resilience recovered and reorganized in a short time after 2006, which maintained the temporary flexibility of the system before it crossed the limits to adaptive capacity. Another degradation of resilience in both agricultural and bare land from 2008 may be seen as a basin of attraction of resilience (Walker et al. 2004), it was an early warning signal of resilience and sustainability loss. It means that if the local government postpones intervention, the system's adaptive capacity will collapse.

As the special urban development zone in east coastal area, where most of agricultural and bare land exists, those areas are experiencing grand challenges and intensive disturbances. Oil 
was also a vulnerable variable in agricultural land and bare land due to the pollutants from shipping and industrial waste along the coastal developing area. Future river monitoring and management plans must consider the related pollution, especially those that are correlated with $\mathrm{Cd}$ and TP. As an increasing number of new ports and transport shipping lines connect to other cities, more and more Oil pollution spread in both Ganyu and Guanyun districts. In order to control non-point pollution, a series of pollution controlling measures are the sluices in tributary can help to control and store the pollution in dry seasons, especially where has the serious pollution on the map of spatial distribution of the Water Comprehensive Pollution Index. More importantly, the government encourages the upgraded agricultural economic structure, builds ecological and organic agricultural area to reduce the usage of fertilizers. Previously, agriculture has contributed to water pollution through the use of multiple fertilizers to enrich soil, as well as chemical herbicides and pesticides, all of which run-off into water systems. Through encouraging ecological and organic agriculture, there are more and more ecological plantations with precise amount of fertilizers which supported by local government. The government aims to continue food production in the area while reducing chemical inputs that negatively affect water quality. For instants, the local governments will reduce $30 \%$ of the consumption of fertilizers and pesticides in the basin of Qiangwei River in 2015.

\section{Resilience timeline analysis with regional and national policies}

The coordinative changes and tipping points between the resilience of water quality and regional/national policies demonstrated the significant relationship between resilience states and policies (Fig.4.7). The future ambitions in terms of land development plan for the urban agglomeration of Lianyungang can be easily read from Lianyungang Coastal Regional Strategic Plan (2005-2030) and Urban Master Plan (2008-2030). The credo of the Lianyungang Coastal Regional Strategic Plan is how to further increase the density of the urban landscape with the consideration of sustainable and resilient systems, specifically employing the language of resilience (弹性, tanxing) in the local planning documents. The majority of land use changes happened in the core zone and the two wing areas, and dispersive built infrastructure in all periurban areas. As it is written in city plans, the primary regulations are territorial conservation and reorganization for built-up and agricultural land, improving its land use function and efficiency, therefore create a healthy and sustainable urban development circumstance. Since 2003, the interplay between the enlarge industry zones, export port and labor market and the improvement of the regional transport system are the most central issues in the regional planning discourse. However, from our results, the water quality degraded to the lowest level during 2003 to 2006 that caused the disorder of resilience and was operating close to its adaptive capacity. Because of the intensive transformability of the changes in economic structure and pressures within a growing urban agglomeration around the central urban area, more unexpected water pollution and incomplete water treatment plants lead to the abrupt resilience degradation. 


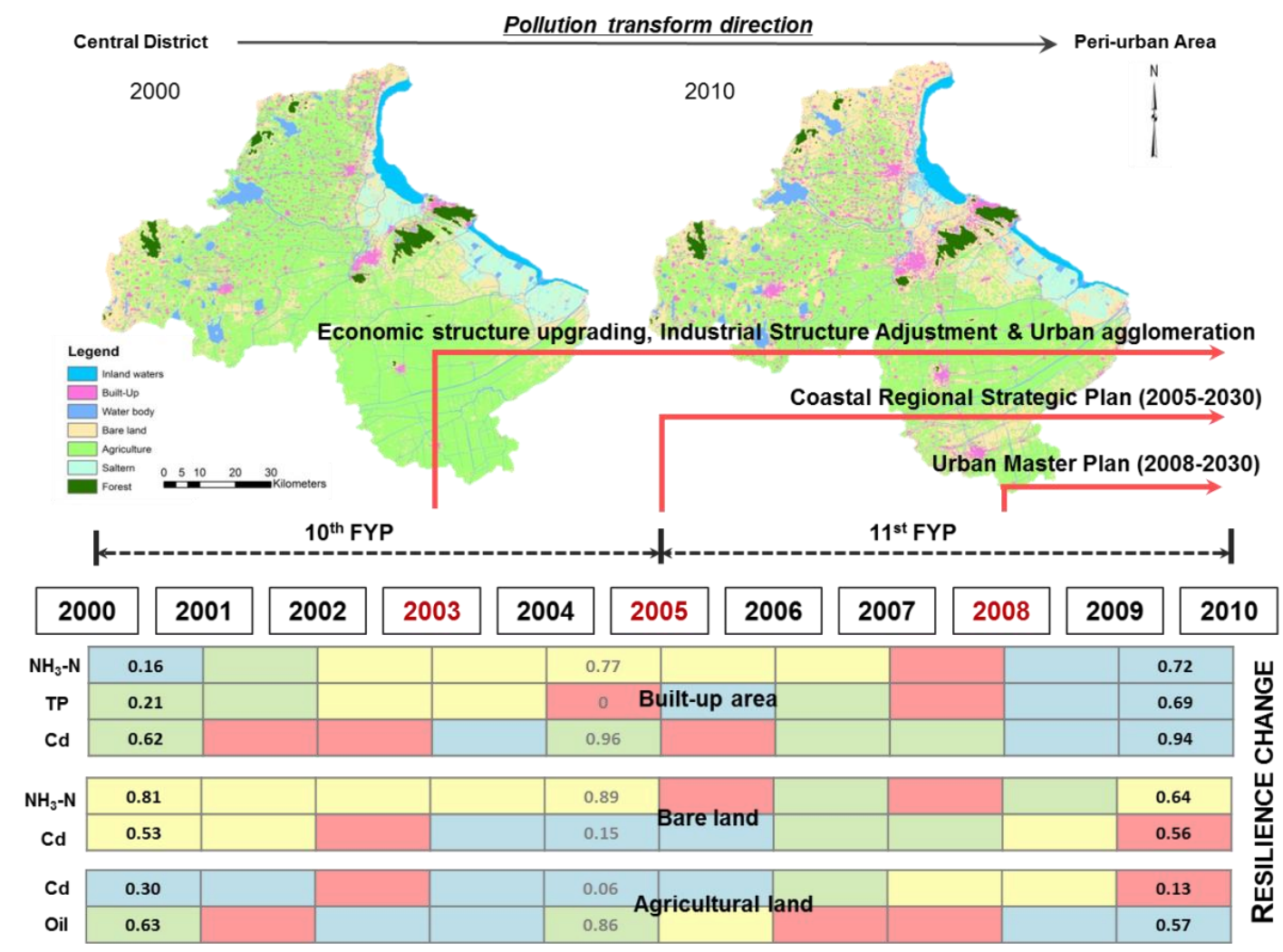

\begin{tabular}{ll|l|l|l|} 
The box in different color represents different phase of adaptive cycle: Exploitation & Conservation & Release Reorganization \\
\cline { 2 - 4 }
\end{tabular}

Fig.4.7 Resilience timeline with regional and national policies

The values in the boxes of resilience change were the start and end resilience values of each variables.

In the central urban area, the mixed distribution and fragmentation of all three different land use types (built-up, agricultural and bare land) intensifies the conflicts between land use and water quality, which is consistent with other research. The main exploitation phase happened during 2006-2007, this was the best time for enforcing new policies and management practices. Therefore, in the later regional plan after 2006, the normative principle has been renewed to follow up the intended gradual transformation of a rather monocentric urban configuration into a polycentric one, which is more focused on both central urban and east coastal line (Ganyu and Guanyun district). The emerging polycentric shape is to be structured by two regional axes located across the central core. The core zone serves as "territorial anchors" to concentrate land developments, as well as to accommodate distinct urban functions. The "One Zone and Two Wings" development policy, in certain cases, created a coastal development zone from north to south and west to east, effectively releasing the pressure from the central urban area.

Another direct contributor is the "top-down" policy restructuring in China. The notable variation of decoupling resilience of water pollution and land use type closely corresponds with the nation-wide major policy adjustments every five years, indicating significant impact of China's national social and economic policies on its environmental pressure. UNEP and EEA assesses patterns of production and consumption as the main drivers of environmental and landuse change (UNEP 2014, EEA 2015). For the decreased water pollutant discharge into rivers, industrial structure formation is the largest contributor to mitigate ammonia $\mathrm{NH}_{3}-\mathrm{N}, \mathrm{Cd}$ and $\mathrm{TP}$ emissions. In comparison to the period of the $10^{\text {th }}$ Five-Year-Plan, the resilience of water 
quality increased in the $11^{\text {th }}$ Five-Year-Plan. During 1992-2002, China's economic growth was dominated by light manufacture. In the course of the $10^{\text {th }}$ Five-Year-Plan (FYP, 2001-2005), the economic structure significantly shifted from labor-intensive manufactured goods to heavy industrial products with higher material intensity. Lianyungang's government followed the change of industrial instructions, leading to the declining resilience of water quality. In the $11^{\text {th }}$ FYP (2006-2010), the "Industrial Structure Adjustment" (upgrading traditional manufacturing and eliminating outdated technologies) lowered the share of heavy manufactured goods. With the decreasing share of heavy manufactured goods, resilience of water quality was also mitigated. The structural promotion turned the negative trends of resilience into positive trends during 2007-2010.

\subsection{Resilience-based Management Implications}

This paper addressed resilience theory into a quantitative method for resilience calculation of water quality with different land use types, which was based on the adaptive capacities of different water quality variables. The higher polluted areas sprawled to other peri-urban area due to the rapid urban agglomeration and the manufacturing structural adjustment in the area of "One Zone and Two Wings" policy. Stricter policies are needed to control the $\mathrm{NH}_{3}-\mathrm{N}, \mathrm{TP}$ and $\mathrm{Cd}$ in the built-up area, as well as the Oil and organic pollutants in agricultural and bare land. The main contributor to those resilient state change were domestic sewage in built-up area and non-point waste water in agricultural and bare land.

The resilience of water quality in Lianyungang underwent a more complex and uncontrollable degraded state during 2003-2006 in reorganization phase; the adaptive cycles of some water quality variables approached the baseline after release phase. As a medium sized developing city, Lianyungang needs to balance its economy and environmental protection, in order to maintain the adaptive capacity to address water quality before the system collapses. Especially during the exploitation phase (2006-2007), this was the best time for consolidation and making rapid progress and growth. Therefore, enforcing new policies and management practices enables and navigates the system resilience, as the Coastal Regional Strategic Plan. This was proved in Lianyungang, after the enforcement of the reformed city plans, resilience turned into a relatively short transition conservation phase, and then resulted in a more resilient state. Based on resilience results of water quality, we proposed resilience-based water quality and land use management suggestions in accordance with city development guidelines. It will be interesting in the next step to understand how Lianyungang's Coastal Regional Strategic Plan is carried out in practice after 2010 and whether urban resilience changed into a desirable state with city development strategies. It remains to be seen if such a planning direction helps to combat urban sprawl, or whether it has influence on intensification of land-use development and water quality protection.

\section{References}

1. Aguilera, S.E., Cole, J., Finkbeiner, E.M., Le Cornu, E., Ban, N.C., Carr, M.H., Cinner, J. E., Crowder, L. B., Gelcich, S., Hicks, C. C., Kittinger, J. N., Martone, R., Malone, D., Pomeroy, C., Starr, R. M., Seram, S., Zuercher, R., Broad, K. 2015. Managing Small-Scale Commercial Fisheries for Adaptive Capacity: 
Insights from Dynamic Social-Ecological Drivers of Change in Monterey Bay. PLoS ONE 10(3):e0118992.

2. Alberti, M., Marzluff, J. M. 2004. Ecological resilience in urban ecosystems: linking urban patterns to human and ecological functions. Urban ecosystems. 7(3):241-265.

3. Alberti, M., Marzluff, J. M., Shulenberger, E., Bradley, G., Ryan, C., Zumbrunnen, C. 2003. Integrating humans into ecology: Opportunities and challenges for studying urban ecosystems. Bioscience. 53 (12):1169-1179.

4. Ayda, E., Tuna, T. 2013. Resilience Thinking in Urban Planning-Springer Netherlands. Springer.

5. Bhat, S., Jacobs, J. M., Hatfield, K., Prenger, J. 2006. Relationships between stream water chemistry and military land use in forested watersheds in Fort Benning, Georgia. Ecological Indicator. 6:458-466.

6. Brooks, N., Adger W. N., Kelly, P. M. 2005. The determinants of vulnerability and adaptive capacity at the national level and the implications for adaptation. Global Environmental Change. 15(2):151-163

7. Carpenter, S., Walker, B., Anderies, J. M., Abel, N. 2001. From metaphor to measurement: resilience of what to what? Ecosystem. 4:765-781.

8. Colding, J. 2006. Ecological land-use complementation' for building resilience in urban ecosystems. Landscape Urban Plan. 8:46-55.

9. Dodder, N. G., Maruya, K. A., Ferguson, P. L., Grace, R., Kiosterhaus, S., La Guardia, M. J., Lauenstein, G. G., Ramirez, J. 2014. Occurrence of contaminants of emerging concern in mussels (Mytilus spp.) along the California coast and the influence of land use, storm water discharge, and treated wastewater effluent. Marine Pollution Bulletin. 81(2):340-346.

10. Eakin, H., Lerner, A. M., Murtinho, F. 2010. Adaptive capacity in evolving peri-urban spaces: Responses to flood risk in the Upper Lerma River Valley, Mexico. Global Environmental Change. 20:14-22.

11. Engle, N. L, Lemos, M. C. 2010. Unpacking governance: Building adaptive capacity to climate change of river basins in Brazil. Global Environmental Change. 20(1):4-13.

12. European environment-state and outlook 2015: Assessment of global megatrends. European Environment Agency (EEA), Copenhagen. 2015. http://www.eea.europa.eu/soer-2015/synthesis/report/action-downloadpdf.

13. Falkenmark, M. 1989. The massive water scarcity threatening Africa-why isn't it being addressed. Ambio. 18(2):112-118.

14. Foley, J. A., DeFries, R., Asner, G. P., Barford, C., Bonan, G., Carpenter, S. R., Stuart Chapin, F, Coe M. T., Daily, G. C., Gibbs, H. K., Helkowski, J. H., Holloway, T., Howard, E. A., Kucharik, C. J., Monfreda, C., Patz, J. A., Colin Prentice, I., Ramankutty, N., Snyder, P. K. 2005. Global consequences of land use. Science. 309:570-574.

15. Folke C., Colding, J., Berkes, F. 2002. Building resilience for adaptive capacity in social-ecological systems. In: Berkes F., J. Colding, and C. Folke (eds). Navigating Social-Ecological Systems: Building Resilience for Complexity and Change. Cambridge University Press, Cambridge, UK.

16. García-López, J. M., Allué, C. 2011. Modelling phytoclimatic versatility as a large scale indicator of adaptive capacity to climate change in forest ecosystems. Ecological Modelling. 222:1436-1447.

17. Gaudreau, M., Cao, H. H. 2015. Political Constraints on Adaptive Governance: Environmental NGO Networks in Nanjing, China. Journal of Environment Development. DOI: 10.1177/1070496515602044.

18. Gilfedder, M., Rassam, D. W., Stenson, M. P., Jolly, I. D., Walker, G. R., Littleboy, M. 2012. Incorporating land-use changes and surface-groundwater interactions in a simple catchment water yield model. Environmental Modelling and Software. 38:62-73. 
19. Gunderson, L. H. 2000. Ecological resilience-in theory and application. Annual Review of Ecology and Systematics. 31:425-439.

20. Hobson K., Niemeyer, S. 2011. Public responses to climate change: The role of deliberation in building capacity for adaptive action. Global Environmental Change. 21:957-971.

21. Holling, C. S. 1973. Resilience and stability of ecological systems. Annual Review of Ecology and Systematics. 4:1-23.

22. Holling, C. S., Gunderson, L., Ludwig, D. 2002. In Quest of a Theory of Adaptive Change.In: Panarchy: Understanding Transformations in Human and Natural Systems. Gunderson, L. H., Holling, C. S., Eds., Island Press, Washington, D.C.

23. Kuruppu, N., Liverman, D. 2011. Mental preparation for climate adaptation: The role of cognition and culture in enhancing adaptive capacity of water management in Kiribati. Global Environmental Change. 21:657-669.

24. Li, Y. F., Li, Y., Wu, W. 2015b. Threshold and resilience management of coupled urbanization and water environmental system in the rapidly changing coastal region. Environmental Pollution. doi: 10.1016/j.envpol.2015.08.042.

25. Li, Y. F., Li, Y., Zhou, Y., Shi, Y. Q., Zhu, X. D. 2012. Investigation of a coupling model of coordination between urbanization and the environment. Journal of Environmental Management. (98):127-133.

26. Li, Y., Li, Y. F., Qureshi, S., Kappas, M., Hubacek, K. 2015a. On the relationship between landscape ecological patterns and water quality across gradient zones of rapid urbanization in coastal China. Ecological Modelling. 318:100-108.

27. Liang, S., Liu, Z., Crawford-Brown, D., Wang, Y. F., Xu, M. 2014. Decoupling Analysis and Socioeconomic Drivers of Environmental Pressure in China. Environmental Science and Technology. 48(2):1103-1113.

28. Lilliefors, H. 1967. On the Kolmogorov-Smirnov test for normality with mean and variance unknown. Journal of the American Statistical Association. 62:399-402.

29. Liu, S. G., Lou, S., Kuang, C. P., Huang, W. R., Chen, W. J., Zhang, J. L., Zhong, G. H. 2011. Water quality assessment by pollution-index method in the coastal waters of Hebei Province in western Bohai Sea, China. Marine Pollution Bulletin. 62:2220-2229.

30. Ludwig, A. A., Smith, M. D. S. 2005. Interpreting and correcting cross-scale mismatched in resilience analysis: A procedure and examples from Australia's rangelands. Ecology and Society. 10(2):20.

31. Maldonado, J. H., Moreno-Sánchez, R. 2014. Estimating the adaptive capacity of local communities at marine protected areas in Latin America: a practical approach. Ecology and Society. 19(1):16.

32. Mulholland, P. J., Helton, A. M., Poole, G. C., Hall, R. O., Hamilton, S. K., Peterson, B. J., Tank, J. L., Ashkenas, L. R., Cooper, L. W., Dahm, C. N., Dodds, W. K., Findlay, S. E. G., Gregory, S. V., Grimm, N. B., Johnson, S. L., McDowell, W. H., Meyer, J. L., Valett, H. M., Webster, J. R., Arango, C. P., Beaulieu, J. J., Bernot, M. J., Burgin, A. J., Crenshaw, C. L., Johnson, L. T., Niederlehner, B. R., O’Brien, J. M., Potter, J. D., Sheibley, R. W., Sobota, D. J., Thomas, S. M. 2008. Stream denitrification across biomes and its response to anthropogenic nitrate loading. Nature. 452:202-205.

33. Orwin, K. H., Wardle, D. A. 2004. New indices for quantifying the resistance and resilience of soil biota to exogenous disturbances. Soil Biol. Biochem. 36:1907-1912.

34. Park, Y. S., Kwon, Y. S., Hwang, S. J., Park, S. 2014. Characterizing effects of landscape and morphometric factors on water quality of reservoirs using a self-organizing map. Environmental Modelling \&Software. 55:214-221. 
35. Pelling M, High C. 2005. Understanding adaptation: What can social capital offer assessments of adaptive capacity? Global Environmental Change. 15(4):308-319.

36. Pimm, S. L. 1984. The complexity and stability of ecosystems. Nature. 307:321-326.

37. Press, W. H., Flannery, B. P., Teukolsky, S. A., Vetterling, W. T. 1992. Kolmogorov-Smirnov Test. In Numerical Recipes in FORTRAN: The Art of Scientific Computing, 2nd ed. Cambridge, England: Cambridge University Press.

38. Qureshi, S., Haase, D., Coles, R. 2014. The Theorized Urban Gradient (TUG) method - a conceptual framework for socio-ecological sampling in complex urban agglomerations. Ecological Indicators. 36:100110.

39. Resilience Alliance. 2007. Assessing resilience in social-ecological systems: A workbook for scientists, version 1.1 - Draft for testing and evaluation. http://www.resalliance.org/3871.php.

40. Rockström, J., Falkenmark, M., Folke,C. Lannerstad, M., Barron, J., Enfors, E., Gordon, L., Heinke, J., Hoff, H., Pahl-Wostl, C. 2014. Water Resilience for Human Prosperity. Cambridge University Press.

41. Salvati, L., Tombolini, I., Perini, L., Ferrara, A. 2013. Landscape changes and environmental quality: the evolution of land vulnerability and potential resilience to degradation in Italy. Reginal Environment Change. 13:1223-1233.

42. Sellberg, M. M., Wilkinson, C., Peterson, G. D. 2015. Resilience assessment: a useful approach to navigate urban sustainability challenges. Ecology and Society. 20(1):43.

43. Silva, J., da Cunha Bustamante, M., Markewitz, D., Krusche, A., Ferreira, L. 2011. Effects of land cover on chemical characteristics of streams in the Cerrado region of Brazil. Biogeochemistry. 105:75-88.

44. Smit, B., Wandel, J. 2006. Adaptation, adaptive capacity and vulnerability. Global Environmental Change. 16:282-292.

45. Steffen, W., Richardson, K., Rockström, J., Cornell, S. E., Fetzer, I., Bennett, E. M., Biggs, R., Carpenter, S. R., de Vries, W., de Wit, C.A., Folke, C., Gerten, D., Heinke, J., Mace, G.M., Persson, L.M., Ramanathan, V., Reyers, B., Sörlin, S. 2015. Planetary boundaries: Guiding human development on a changing planet. Science. 347(6223):1259855.

46. Stephens, M. A. 1974. EDF Statistics for Goodness of Fit and Some Comparisons. Journal of the American Statistical Association. 69(347):730-737.

47. Su, S. L., Li, D., Zhang, Q., Xiao, R., Huang, F., Wu, J. P. 2011. Temporal trend and source apportionment of water pollution in different functional zones of Qiantang River, China. Water Research. 45:1781-1795.

48. Tong, S. T. Y., Chen, W. 2002. Modeling the relationship between land use and surface water quality. Journal of Environmental Management. 66:377-393.

49. UNEP. 2014. Assessing Global Land Use: Balancing Consumption with Sustainable Supply. A Report of the Working Group on Land and Soils of the International Resource Panel. Bringezu S., Schütz H., Pengue W., O’Brien M., Garcia F., Sims R., Howarth R., Kauppi L., Swilling M., Herrick J. http://www.unep.org/resourcepanel-old/Portals/24102/PDFs//Full_ReportAssessing_Global_Land_UseEnglish_(PDF).pdf.

50. Vörösmarty, C. J., Hoekstra, A. Y., Bunn, S. E., Conway, D., Gupta, J. 2015. What scale for water governance? Fresh water goes global. Science. 349(6247):478-480.

51. Walker, B., Holling, C. S., Carpenter, S. R., Kinzig, A. P. 2004. Resilience, adaptability and transformability in social-ecological systems. Ecology and Society. 9(2):5.

52. Walker, B., Salt, D. 2012. Resilience Practice: Building Capacity to Absorb Disturbance and Maintain Function. Island Press: Washington, D. C. 
53. Wang, J. Y., Da, L. J., Song, K., Li, B. L. 2008. Temporal variations of surface water quality in urban, suburban and rural areas during rapid urbanization in Shanghai, China. Environmental Pollution. 152:387393.

54. Wang, Q., Wu, X. H., Zhao, B., Qin, J., Peng, T. C. 2015. Combined Multivariate Statistical Techniques, Water Pollution Index (WPI) and Daniel Trend Test Methods to Evaluate Temporal and Spatial Variations and Trends of Water Quality at Shanchong River in the Northwest Basin of Lake Fuxian, China. PLoS ONE. 10(4):0118590.

55. Wang, S. H., Huang, S. L., Budd, W. W. 2012. Resilience analysis of the interaction of between typhoons and land use change. Landscape and Urban Planning. 106:303-315.

56. West, S. P., Schultz, L. 2015. Learning for resilience in the European Court of Human Rights: adjudication as an adaptive governance practice. Ecology and Society. 20(1):31. 


\section{Chapter 5 Synthesis}

\subsection{Summary of Resilience Methods}

With the purpose of assessing social-ecological resilience and its changes, this thesis develops integrated approaches for resilience transformation based on different theories and models. The catastrophe models (model information on Page 9) and adaptive capacity theory (see Page 6) are used to calculate resilience. They interpret resilience from different characteristics of system change. With the values derived from these two methods, resilience transitions are demonstrated by the mechanism of early warning model (see Page 5 and Page 41) and adaptive cycles (see Page 7).

\subsubsection{Catastrophe models \& Adaptive capacity model}

The main calculation methods for resilience in this thesis are catastrophe models and adaptive capacity theory (Table 5.1). Catastrophe theory provides a conceptual framework for understanding and describing gradual and abrupt system behavior. Adaptive capacity is the system's capacity to manage resilience in relation to alternate regimes.

Table 5.1 Comparison of catastrophe models and adaptive capacity

\begin{tabular}{|c|c|c|c|}
\hline & Methods & Catastrophe models & Adaptive capacity \\
\hline 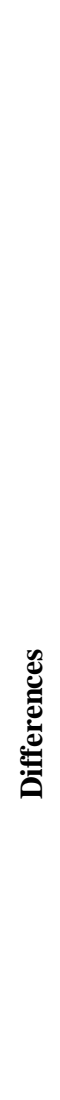 & Dynamics & $\begin{array}{l}\text { Reference: Scheffer et al. } 2009 \\
\text { Non-linear dynamics: } \\
\text { Gradual and abrupt changes } \\
\text { Hierarchical sub-systems: } \\
\text { Indicators in different sub-systems. } \\
\text { The type of model that should be used is } \\
\text { chosen by the dimension (number) of } \\
\text { indicators of each sub-system. } \\
\text { Transformability: } \\
\text { How a system transforms into or creates } \\
\text { a fundamentally new state. } \\
\text { Focusing on system's changes and } \\
\text { vulnerabilities. }\end{array}$ & $\begin{array}{l}\text { Linear and non-linear dynamics: } \\
\text { Specified and detective changes } \\
\text { Parallel indicators: } \\
\text { Without category, all indicators are } \\
\text { equal and independent. } \\
\text { The maximum value of the input data } \\
\text { represents the highest capacity of a } \\
\text { system. } \\
\text { Adaptability: } \\
\text { The capacity of a system to manage } \\
\text { resilience in relation to alternate } \\
\text { regimes. } \\
\text { Focusing on system's adaptation and } \\
\text { self-organization. }\end{array}$ \\
\hline
\end{tabular}




\begin{tabular}{c|c|l}
\hline Theory & $\begin{array}{l}\text { Value range } \\
\text { Visible and numeric results of resilience: ranged from } 0 \text { to } 1.0 . \\
\text { or transformations caused by disturbances; and they embrace changes instead of } \\
\text { avoiding changes. }\end{array}$ \\
\hline
\end{tabular}

\section{Different types of dynamics}

Since the effects and feedbacks of human disturbances or environmental stochastic events are complexity and nonlinear dynamics, catastrophe theory provides a conceptual framework for the calculation of the resilience transformations, calculating by gradual and abrupt dynamics. Especially for the complex social-ecological systems whose inner workings may not be known or are integrated among different scales. In this case, catastrophe theory is appropriate for detecting the dynamics in such system without considering the intermediate interactions.

The theory of adaptive capacity can be used for both linear and non-linear dynamics. As a specific environmental quality assessment, for instance, water quality, air quality and biodiversity loss etc., these can be either linear or non-linear. Another point of adaptive capacity is that the dynamics in such a system are specified and detectives of changes. Like the examples in Chapter 4, water quality indicators are more detectable and easier to trace the pollutant resources than the integrated social-ecological systems. Furthermore, in this thesis, every water quality indicator has standard values of different water quality grades (from the Environmental Quality Standards for Surface Water, GB 3838-2002). So it is possible to analyze the change of adaptive capacity according to the standard grades of water quality indicators.

\section{Different indicator status}

The second difference between catastrophe model and adaptive cycle is the status of inputs (indicators). Catastrophe theory is an external and hierarchical mechanism, and adaptive capacity is an internal and self-organizing mechanism. The inputs of the catastrophe model are indicators from different hierarchical sub-systems. The dimension (number) of indicators in each sub-system decides which type of model should be used (see examples in Section 3.3.3 on Page 39-40). In the end, there is only one final output value for each sub-system in the catastrophe model. The details of intermediate processes are not the main concerns of the outputs. Also it is difficult to trace the details of resilience transformation without time series data.

For resilience analysis based on the theory of adaptive capacity, all indicators can be parallel indicators without categories, and they are in one equal level. Considering the water quality variables used in Chapter 4, all those indicators were calculated in their own scales (e.g., in Section 4.3.2 on Page 63-65). So the results of each indicator are independent from other indicators, which provide individual outputs for system resilience assessment. The maximum value of each data input represents the highest capacity of a system, and all other values of the same indicator are calculated based on the maximum value.

\section{Different focal points}

The critical difference of these two methods is that they are focusing on different aspects of resilience phase change-transformation and adaptation. Catastrophe theory addresses the 
system's transformability, and its focal point is how a system transforms into or creates fundamentally new states. A system's dynamics and vulnerabilities are the key aspects of resilience in respect to catastrophe theory, and transformational changes in SESs are unplanned and involve undesirable effects. The changing components or configurations can lead to a new basin of attraction, or cause the collapse of SESs, which can cross the uncertainty zone or the safe boundaries of some sub-systems. Another possibility of transformation is that it can develop a deliberate and positive way of sustaining a life if the system has the necessary amount of capacity. For example, the social sub-system developed into a more resilient state with higher resilience (see Fig.2.3 on Page 25, and Fig.2.4 on Page 26).

In comparison to the catastrophe model, the key character of the adaptive capacity model is a system's adaptability (see Fig.4.2, Page 60). It allows the system to adopt external disturbances without changing its function. In this thesis, the adaptive capacities of different water quality variables maintain their resilience above the baseline. The central point of adaptive capacity is how the capacity of a system manages resilience in relation to alternative regimes, and it focuses on the system's adaptation and self-organization. Adaptive capacity determines the trajectory of the system state, whether it moves to another position or maintains its original position. From the results of the water quality indicators, most of these indicators still maintained a certain stable position after abrupt resilience shifts. Another possibility is that adaption can also alter the shape of the basins, making the system more or less resistant to perturbations. Adaptation of each water quality indicator avoids the system crossing its threshold or turning into an undesirable system regime. This was achieved by shifting resilience states within the safe zones of standard water quality.

\section{Similarity of catastrophe models and adaptive capacity}

The output ranges of the catastrophe models and the theory of adaptive capacity are both from 0 to 1.0. It helps to understand and compare resilience results in the same scale, and omits the distraction of difference units or sub-systems. Additionally, they have the same back ground theory in resilience. They are both focusing on how to detect and trace a system's resilience transitions or transformations during the time. The complex and integrated dynamics of a system are the basic components of resilience, and the theory of catastrophe models and adaptive capacity both accept the system's dynamics instead of avoiding them.

\subsubsection{Early warning model \& Adaptive cycles}

The theory of early warning and adaptive cycles are two different analytical methods for resilience results, both operating on a different system (Table 5.2). An early waning state contains two equilibria: a potential equilibrium $(\beta)$ distinct from an initial equilibrium $(\alpha)$ with regard to resilience (more description on Page 41-42). Adaptive cycles describe the progression of social-ecological systems through various phases of organization and function as comprising four phases (this is illustrated in the figure on Page 7). 
Table 5.2 Comparison of early warning model and adaptive cycles

\begin{tabular}{|c|c|c|c|}
\hline & Methods & Early warning model & Adaptive cycles \\
\hline 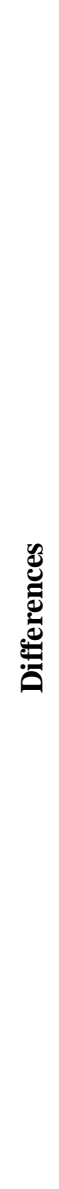 & $\begin{array}{l}\text { Operating } \\
\text { Scale }\end{array}$ & $\begin{array}{l}\text { Two transition modes: } \\
\text { "More resilient" or "Less resilient" } \\
\text { state. } \\
\text { Including two different equilibria, the } \\
\text { second one is related to the first. } \\
\text { One focal scale: } \\
\text { Without crossing scales. } \\
\text { State changes: } \\
\text { The key point of resilience is about the } \\
\text { changes of state in a system: positive or } \\
\text { negative change. } \\
\text { Feedbacks/responses: } \\
\text { System's feedbacks and responses to } \\
\text { disturbances. } \\
\text { Consequences: } \\
\text { Gaining from disturbances or resilience } \\
\text { changes, and providing guidelines from } \\
\text { experiences. }\end{array}$ & $\begin{array}{l}\text { Reference: Carpenter et al. } 2001 \\
\text { Four phases, two modes: } \\
\text { The cyclic pattern is not an absolute, not } \\
\text { all } 4 \text { phases appear together each time. } \\
\text { A development loop (fore loop) and a } \\
\text { release and reorganization loop (back } \\
\text { loop). } \\
\text { Crossing scales: } \\
\text { "Panarchy": self-organizing systems } \\
\text { operate over a range of different scales. } \\
\text { Trajectory: } \\
\text { Tracing the critical resilience transitions } \\
\text { based on } 4 \text { possible phases and } 2 \text { modes. } \\
\text { Interventions/actions: } \\
\text { Intervening new policies, changing } \\
\text { management practices and developing } \\
\text { action plans in the fore loop. } \\
\text { Pre-operating strategies: } \\
\text { Providing adaptive management } \\
\text { strategies or guidelines before resilience } \\
\text { collapse. }\end{array}$ \\
\hline 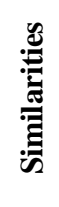 & Symptom & \multicolumn{2}{|c|}{$\begin{array}{l}\text { Interacting process: states and loops are correlated and complemented, the } \\
\text { integrated resilience including two parts of states/loops. } \\
\text { Threshold/tipping points: a certain zone to maintain system's resilience, and intend } \\
\text { to avoid system's collapse. }\end{array}$} \\
\hline
\end{tabular}

\section{Different resilience transition modes}

The first difference between early warning model and adaptive cycles is the transforming structure of resilience. The early warning method has two modes: "More resilient" or "Less resilient". A "more resilient" transition (descriptions in Fig.3.2a, Page 42) is when a system shifts into equilibrium with a larger area of resilience state, which represents a more stable state after its transition. The "Less resilient" state has a larger area of the original equilibrium which implies low resilience (Fig.3.2b, Page 42). The resilience transition mode reveals the changes of those two equilibria based on time, so it is a relative comparable resilience transition.

The adaptive cycle is a valuable way to understand self-organizing systems with four phases, 
and it includes two loops (Page 7-8): the fore loop with the exploitation and conservation phase, back loop with the release and reorganization phase. It is usually a useful thought to conceive of a system moves through four phases, but not always in that sequence. The cyclic pattern is not an absolute mode, because there are many variations in human and natural systems. A rapid exploitation phase usually moves at some point into a conservation phase, but it can (through small perturbations) move directly toward a release phase. Take the water quality variable $\mathrm{Cd}$ for example (as discussed in section 4.3.2, Page 63-65 and Fig.4.7, Page 68), it skipped a conservation and reorganization phase in the built-up area for the first five years, and only showed the exploitation and release phase. A reorganization phase usually proceeds into a new exploitation phase, but it can also go back into a release phase. An example is the water quality variable $\mathrm{Cd}$ on the agricultural land, it started with a reorganization phase then turned into a release phase and a long-term reorganization phase.

\section{Different operating scales}

The second difference of these two methods is the observation scale. The theory of adaptive cycles is known for its crossing scales of self-organizing systems, while the early warning model focuses on one focal scale. The characteristic property of early warning model is that it describes whether a system is more likely to remain in its original equilibrium or shifts to another potential phase (discussed in section 3.3, Page 41-42), and its main point is about detecting a system's probability of changing direction. So the two resilience states are parallel with each other in a single scale.

The adaptive cycle is also a useful concept for understanding a system's behavior and trajectory in a certain way. From the perspective of self-organizing systems, it operates over a range of different scales (i.e., "Panarchy" on Page 8), but only one focal scale can have tremendous and critical influences on the other scales above it or on the embedded scales. The study area of Lianyungang is more or less a regional scale, but also with five different local districts. Moreover, the focal scale is not fixed, because different stakeholders have particular interest in one scale in the system. For example, the local Environmental Protection Agency would be most concerned with what is happening at the scale of environment quality, and a citizen might focus on the scale of drinking water quality. Still, as an integrated and selforganizing system, it is critical to observe a system with the focal scale and also the influences from the scales above and below.

\section{Different focal points}

The representing forms of resilience outcome are also different: the method of early warning illustrates resilience change with positive or negative states ("More resilient" or "Less resilient"); adaptive cycles show the self-organizing processes and transitions among different phases. The early warning model addresses resilience states that are separated by tipping points, the "More resilient" or "Less resilient" mode is decided by the area of a system's original state and the potential state. However, there are some cases without tipping points; therefore, the resilience mode depends on the trend of the original state. Like the total resilience in Guannan district, it didn't have a tipping point during 2000-2010, but it showed a high resilience level (Fig.3.3, Page 43-44). Adaptive cycles can trace the trajectories of a system's resilience change at different time points, the four phases and two transition modes are explicit statements of resilience changes. Cd was the most vulnerable water quality variable; it experienced abrupt 
and drastic changes in the release phase, which nearly crossed its threshold value (in Section 4.3.2, Page 63-65). Also in the release phase, the locked-up resources suddenly released to support the next re-organization phase, therefore, the capacity of $\mathrm{Cd}$ in the built-up area bounced back to its highest level. The trajectories of resilience changed within four phases in the adaptive cycle, which can provide a clear transition process and scientific suggestions for management.

The functions of early warning model and adaptive cycles are also different. While the early warning model focus is on the system's feedbacks and responses to disturbances, and adaptive cycles' focus on interventions or actions before a system shows its threshold. When the capacity of a system is able to absorb external shocks or disturbances and reorganize to retain essentially the same identity (functions, structure and feedbacks), the system's resilience can maintain within a safe zone; but sometimes the effects of extreme shocks or disturbances are beyond a system's capacity to cope, then a tipping point will be an early warning signal, which exhibits quite a lot of variation or changing of identity. As it is shown in the whole study area with the tipping point in 2009 (Fig.2.6 on Page 28; Section 3.4.1 on Page 42-45), it can be seen as an early warning signal of resilience change. The adaptive capacity of the urban system was under threat.

The theory of adaptive cycle is characterized by its stability, reorganizing ability and potential of creativity, which can be seen from the two modes of adaptive cycle. The fore loop (exploitation and conservation phase) represents a system's stability, relative predictability and conservation. Because the exploitation phase is the time for consolidation and making rapid progress and growth, it enables the intervention of new policy development and changes in management practices. As for the conservation phase, where things are in gridlock, it is the most difficult time to change. However, it is an important time for developing action plans when the gridlock is ended by some crisis. The Coastal Regional Strategic Plan and Urban Master Plan (see Fig.4.7, Page 68), two of the most important city development plans, started in the conservation phase. Even though, compare to the exploitation phase, it was not the best timing of interventions, still these plans helped most of the water quality variables to maintain a safe level. The back loop, by contrast, is a mode with novelty and experimentation. During the back loop (release and reorganization phase), the system is in an uncertain state with greatest potential for the initiation of either destructive or creative change. According to the water quality change in Lianyungang, it was in a relatively vulnerable state.

The way that early warning model and adaptive cycle operate and cope with disturbances is different. The early warning model gains experiences from disturbances or resilience changes after a system's tipping point show up, and provides guidelines for future city development. Early warning signals can help to avoid the collapse of a system, and keep a system in a safe operating zone. An adaptive cycle is a pre-operating theory, and it focuses on active and passive adaptive management in certain phases before its resilience release, so it is able to avoid crossing the system's threshold. The fore loop is an active phase for implementing and developing new plans, the back loop is a passive phase for responses and feedbacks.

\section{Similarities of early warning model and adaptive cycles}

Even though there are many differences between the theories of early warning and adaptive cycle, they still have some similarities. They are both interacting processes with equilibria or loops, which are correlated and complemented. The integrated systems contain both of two 
states or loops, the interacting connections constitute and navigate a system of resilience transformation. A tipping point connects the potential equilibrium and original equilibrium, the area of original equilibrium is the background value of the system's resilience, therefore, and the area of the potential equilibrium is based on this background value. For adaptive cycles, the fore loop and back loop represent two connected resilience states with complementary functions. They also establish a certain zone to maintain the system's resilience, either tipping points of early warning signals or thresholds can enable and navigate the system's capacity to cope with external disturbances, and avoid undesirable and unplanned resilience transformations.

\subsection{Resilience Transition in Lianyungang}

The purpose of this study is to apply a resilience lens to the urban system in order to explain the changes between social and ecological systems in Lianyungang, particularly the coordinative changes and thresholds/tipping points in relation to local development policies.

\subsubsection{Total resilience transition in Lianyungang}

This study reveals a range of social and ecological indicators that deal with change and uncertainty, during which the integrated systems adapted to external disturbances while reorganizing and nurturing sources for system renewal. The resilience of social-ecological systems showed an upward trend represented by adaptive cycle, which signifies the adaptive and sustainable development during the last decade. From the results of catastrophe models and early warning model, the SESs sequenced interventions in adaptive cycles and adapted perturbations without shifting into an alternative basin of attraction. It is an important aspect of the stability and adaptability of a system, which represented the high adaptive capacity in Lianyungang to maintain its resilience in a relative stable and desirable regime.

From the results of catastrophe models, the resilience of Lianyungang increased with an exploitation phase until 2002, and a conservation phase from 2002 to 2003. Instead of transitioning to a release phase, its resilience shifted to a new adaptive cycle with an exploitation phase until 2005, during which resilience enhanced to its higher level; the SESs maintained a long phase of conservation until 2008, followed with a release phase of an abrupt resilience drop in 2009, which was the only one tipping point. It showed an early warning signal of resilience collapse. However, it didn't cross the threshold of the system's adaptive capacity during the release phase; its resilience bounced back and increased to the highest level within a short exploitation phase.

As well as the early warning model assessment in section 3.4 (Page 42-45), the total resilience value had a larger area of the original state before the tipping point (2000-2009) than the potential state (2009-2010), which implied that the total resilience of Lianyungang was under a "Less resilient" state. However, it ended with a relatively positive state with high resilience grades. Since there was only one year from the potential equilibrium, the resilience trajectory of the next several years could address its final transition. 

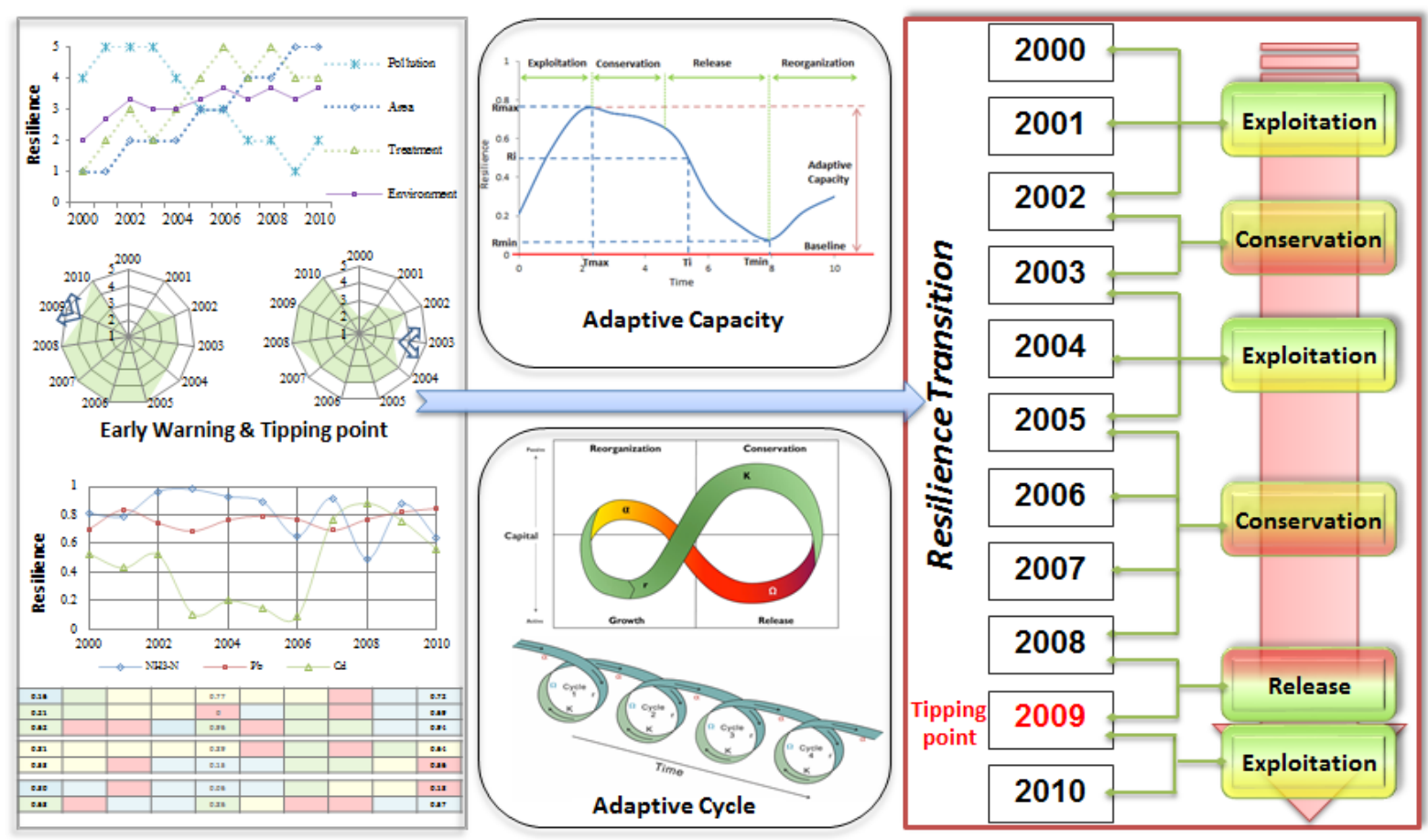

Fig.5.1 Resilience transition phases during 2000-2010

The changes of resilience transition phases during 2000-2010 reveals the adaptive trajectory in Lianyungang (Fig.5.1). Despite the consistent results of total resilience in Lianyungang, it experienced more complexity and undesired resilience changes in both social/human and ecological/environmental sub-systems, also it had different resilience shifts in the five districts of Lianyungang. In the social sub-system, all seven different aspects (economy, agriculture, industry, resident, transports, science and culture and population) oscillated between the phases of exploitation and conservation. In general, as the results showed in Chapter 2 and Chapter 3, three exploitation phases were seen from 2000 to 2002, 2003 to 2005 and 2006 to 2010, and two conservation phases from 2002 to 2003 and 2005 to 2006. The same pattern was seen in the environment sub-system, its resilience states changed between those two phases, exploitation in 2000 to 2002 and 2004 to 2006, and conservation in 2002 to 2004 and 2006 to 2010. Because both sub-systems were in the same phases coincidently from 2000 to 2003, the whole system went through an exploitation and conservation phase. Because the two subsystems shifted between exploitation and conservation phases after 2003 differently, its resilience states moved through an integrated adaptive cycle from 2003 to 2010.

One of the critical city development plans, Coastal Regional Strategic Plan (2005-2030), is a special development strategy for different districts in Lianyungang. Different development directions determined the variable resilience transformations in those five districts. The central and Guanyun districts were under "Less resilient" states, Ganyu and Donghai districts were under "More resilient" states, and Guannan had only one resilience state, its resilience state was not clear until 2010. The core zone, central district, had the same trend as the total change of resilience in Lianyungang, with the tipping point also occurring in 2009. The resilience changes in the central district addressed the critical effects of central district in resilience transition of the overall resilience trend in Lianyungang. 


\subsubsection{Water quality}

After detecting the resilience change of social-ecological systems as an integrated system, most of the main findings are about social sub-system. Therefore, it is necessary to understand more about ecological sub-system. Based on the results of previous research ( $\mathrm{Li}$ et al. 2015a, Li et al. 2015b), there are clear thresholds between the landscape pattern change and water quality degradation (more details in the next sections). It provides the basic and critical supporting information for further research about resilience change. As one of the main components of environmental system, the water quality in Lianyungang underwent a tremendous change during 2000 to 2010 .

\section{Water quality changes}

Most water quality variables of concern can be predicted reasonably well by using landscape metrics, especially for urban areas. The water quality variables that could be best predicted by landscape metrics were $\mathrm{COD}_{\mathrm{Mn}}, \mathrm{P}, \mathrm{BOD}, \mathrm{NH}_{3}-\mathrm{N}$, Oils, and $\mathrm{DO}$, these variables had different thresholds (see Appendix 3). Since there are certain theoretical threshold between landscape types and water quality variables in the urban area, it is critical to detect what the system's resilience transitions in Lianyungang are and how to best sequence and manage interventions. This process can help for operationalizing and promoting guiding principles for water quality management, and predicting potential threats and vulnerabilities of the urban system.

Due to rapid urbanization and development, Lianyungang experiences the intense pressure of water pollution. From the report of Lianyungang Environmental Quality Bulletin, most pollution was sourced from the citizens of the peri-urban area, industrial point pollution and agricultural non-point pollution. During the first decade, the vulnerability and shifts of water quality was still a challenge for city development (see Appendix 3). Eight water quality variables $\left(\mathrm{pH}, \mathrm{KMnO}_{4}, \mathrm{BOD}, \mathrm{VP}, \mathrm{As}, \mathrm{Cr}^{6+}\right.$ and $\left.\mathrm{F}\right)$ experienced slight shifts, while the stable variables still maintained a safe operating space within their respective thresholds. However, resilience of $\mathrm{NH}_{3}-\mathrm{N}, \mathrm{Pb}, \mathrm{Cd}$, Oil and $\mathrm{TP}$ expressed different adaptive capacities with tremendous resilience changes.

From the results of Water Comprehensive Pollution Index (WCPI) maps during 2000 to 2010 (Fig.4.3, Page 61-62), the areas with heavier pollution spread to other peri-urban areas, with less pollution in the central district. As can be seen from Fig.4.3, large areas with higher values (heavier pollution) exist in the middle of central urban area and southwest of Guannan district in 2000. With the enforcement of city development plans, the government decided to manage urbanization and industrialization, and moved the most pollutant contributors to newly planned industrial zones in other peri-urban districts, which are mostly located in Ganyu and Guanyun districts. Conversely, $\mathrm{NH}_{3}-\mathrm{N}, \mathrm{Pb}$ and $\mathrm{TP}$ showed positive changes with less pollution in 2010 than that of 2000. Generally, Lianyungang had a larger area with lower WCPI values, especially in the central urban area. The orientation of pollutant change illustrates the potential resilience transitions in the peri-urban area, which provides a direction for related policy makers and environmental agencies.

More specifically, in built-up areas, the total WCPI had a slight decrease, which represents an improvement of water quality during this time. WCPI levels in agricultural land and bare land area increased as a result of more water pollution. It also implies that bare land and 
agricultural land had analogous changes, the resilience transitions in these two landscape types were interrelated and interacted with each other.

Resilience transitions in different land use types and water quality variables

The results of resilience transition can be explained with four different phases of adaptive cycles, which reveals the trajectory of the system's resilience (representing results in Chapter 4 and Appendix 3). Resilience in the built-up area showed a positive trend with a more resilient state in 2010 than that in 2000. However, the increased vulnerability and lower resilience of $\mathrm{NH}_{3}-\mathrm{N}, \mathrm{Cd}$ and $\mathrm{TP}$ altered the resilience state into the release phase resulting in abrupt resilience changes. During the release phase, the adaptive capacity of $\mathrm{Cd}$ dropped to the baseline of its standard value, and TP approached its lowest value. After the abrupt change of resilience, the exploitation phase with higher resilience represents higher adaptive capacity in the built-up area.

In the bare land area, Cd was the only variable that had tremendous shifts during 2000 to 2010, while the others water quality variables could almost be interpreted as being in a state of equilibrium. Its adaptive cycle started with a conservation phase; then followed by a short release phase, during which resilience dropped to its lowest value; and a reorganization phase with the lowest adaptive capacity that approached its baseline; in the end, resilience recovered during an exploitation phase. Conversely, from 2009 to 2010, Cd resilience appeared to decrease in a conservation phase with decreasing adaptive capacity.

As the largest land use type in Lianyungang, the transition state of agricultural land experienced periodic and compounding disturbances. The resilience of $\mathrm{Cd}$ reflects more complex and uncontrollable transition states: a conservation phase with relatively stable adaptive capacity; a dramatic shift in the release phase, during which the proximity to the bottom line exacerbated the balance of water quality and landscape. However, after a relatively short phase of exploitation and conservation, its capacity recovered and created a two-year safety resilient state from 2009 to 2010 . With a very rapid breakdown phase, the adaptive capacity of $\mathrm{Cd}$ fell to another low resilient state close to the baseline.

\subsection{Resilience Implications for City Development}

Resilience-based management strategies can enhance system's sustainability and adaptability. A more resilient management plan can navigate system's resilience changes, in order to avoid stochastic and undesired shifts to alternative configuration and function. The resilience implications for future city development in Lianyungang are is discussed in more detail in this section.

\subsubsection{General trajectory of resilience transitions}

\section{The total resilience transition in Lianyungang}

This section is based on material from Chapter 2 and Chapter 3. Resilience issues arising from external perturbations or interventions in urban and peri-urban areas are complex, due to the multiple and integrated interactions between ecological and social-economic systems under the continued development of human societies. Given the shifting circumstances experienced by SESs, there is an urgent need for a new paradigm that understands the mechanisms through 
which these localities respond to external factor changes. The main purposes of this thesis are to address how the SESs resilience responds to changes and pressures, and point to policy management underpinnings for building and managing resilient urban system in a particular coastal urban setting. Ultimately, this thesis provides guidelines for the government or management organizations about how to reorganize resilience changes or impending changes, and to persist or improve adaptive capacity of SESs.

According to resilience results, overall resilience turned out optimistic results with significant improvement. Rapid urbanization accompanied by residential population growth in recent decades was an important cause for the current environmental problems being experienced in Lianyungang. In the integrated SESs, the human/social sub-system was therefore a factor of greatest influence on the comprehensive level of resilience. Industry and transportation made greater contributions to the coupling system than the other factors. Industries are the major sector for the local labor market and also the major financial source for local government. However, the accelerating interactions between coupled SESs may lead to degradation and environmental collapse, which in turn compromise the adaptive capacity of SESs. Government has invested in a number of environmental protection projects and the proportion of scientific research staff was steadily increased. However, the industrial pollution issues have not been effectively tackled which leads to the resilience degrade. Also the conflicting incentives that local tax base and environmental funding depend mostly on local industry, and historical promotion of officials has been tied to GDP performance. Even though pollution monitoring systems have been introduced, it still tends to lose power in playing an effective role since it is too low to give polluters incentives to reduce their emissions. For example, water pollution fees are small relative to the marginal costs of pollution control.

\section{Thresholds/tipping points}

Most importantly, there is a clear threshold or tipping point to support that the external disturbances in SESs altered its resilience into a danger zone, which can cause the collapse of a system's resilience. Adaptive cycle theory and the early warning model highlighted and visualized the characteristic of the dynamic resilience phases derived from the catastrophe theory. Especially the adaptive cycle theory as a transition theory allows detailed analysis of changes in resilience. The resilience adaptive cycles in Lianyungang included predictable development loops (fore loop) with exploitation and conservation phases from 2000 to 2008, and a novel renewal loop (or back loop) with a release and reorganization phase in 2009 and 2010. As the fore loop is the best time for intervening new policies, changes in management practices and developing action plans, this means the time from 2000 until 2008 was the appropriate period for new city development plans. In certain cases, adaptive cycle is not an absolute cyclic pattern, due to the variations in human and natural systems. The main resilience phases of SESs were exploitation and conservation phases, which maintained resilience above the threshold instead of irreversible resilience collapse.

The same can be said for the trajectory of the early warning signal with a tipping point. In this work, it assumes that the tipping point occurs when a system approaches its threshold, and early warning signals tend to arise in a "Less resilient" system with critical resilience transition. As a system closes to a critical threshold of losing resilience, catastrophic regime shifts may be announced in advance by statistical early warning signals of a tipping point. The total resilience in Lianyungang appeared to be under a "Less resilient" phase with a tipping point in 
2009, which can be an early warning signal of critical resilience transition. However, resilience value bounced to its highest level in 2010, which was the same as the change detected with adaptive cycle. Resilience in the central districts, Ganyu and Donghai revealed their thresholds, and the central district led the city's resilience development. Since the central and Ganyu district are the main planning zones with rapid urbanization and expanding development in the next two decades, therefore, managers need to pay more attention to those external disturbances and uncertainties, which are mentioned in the next sections. Those factors or drivers might trigger tremendous resilience changes.

\subsubsection{Decoupling resilience between urban development and environment quality}

The critical drivers of resilience change are showed in Chapter 4 and Appendix 3. Economy and transport were two of the primary drivers of human-induced challenge for social-ecological resilience in Lianyungang. Specifically, such unstable resilience was tied to multiple stressors including shifts in resource demand resulting from economic changes and industry fluctuations. More importantly, the decoupling relationship between urban development and environment quality is one of priority issues in Lianyungang. There is more and more environmental pollution due to its rapid urbanization. Because of the progress in enhancing conventional industry and industrial upgrading, especially in the "One Zone and Two Wings" area, all economic resilience enhanced to a more stable state with an increased area of equilibrium. The accelerating transport resilience interpreted a stable equilibrium without tipping point, and the large area of PDE represented a large basin of attraction.

Conversely, the environmental pollution change following with the industrial production structure change was the most influential factor in maintaining environmental resilience in Lianyungang. Stricter policies should be implemented in order to keep resilient and sustainable development in the future. Fortunately, after the degradation of water quality, environmental management agencies adjusted their mode of independent operation to an integrated loop of involvement with consensus building and decision making, which involved managers and stakeholders. One principle of proceeding new development strategies is the timing of two loops of adaptive cycle. In the "fore loop" period, strong controls exist with slow system changes. Regulatory policies and efforts to increase efficiency may be appropriate, although careful experimentation is sometimes critical and application of techniques, such as environmental optimal control, can be useful. As for the "back loop" period, the system changes rapidly, and is turbulent, without equilibrium. The reorganization phase is the only possible phase for innovations, because of the tenuous system boundaries and renewal in this phase. These two resilience loops will help environmental management agencies to figure out what is the appropriate approach and potentially resilient new practices.

In general, the resilience results illustrate that an opportunity enabled managers to navigate SESs from an undesirable state to a stable one that developed into a deliberate and adaptive management system. The analyzing results demonstrate that multiple-actor systems have the ability of self-organizing, learning from the regime shifts, and actively adapting to and shaping change. The development of ecosystem management can create and widen the scope of resilience management from water quality to a broad set of issues in relation to ecosystems processes. The findings of resilience transition indicate that the adaptive co-management approach has the potential to build and enhance resilience capacity of SESs, and navigate 
toward a more active and positive regime.

\subsubsection{Resilience-based management and policy intervention}

Resilience-based management provides a suitable lens to evaluate responses to a system's shifts (threshold/tipping point), and navigates resilience change by providing adaptive management strategies or guidelines (new policies, management practices and developing action plans, etc.) before resilience collapse. The safe operating space is one of the focal factors for designing of sustainable management and governance. Urban planners and managers are interested in identifying thresholds to keep a system's sustainability, which can help prioritize and optimize identifiable configuration of a system, as well as detect the operating safe zone before a system crosses its turning point or threshold. Adaptive cycle concretizes the time of appropriate actions or policies, the four phases of adaptive cycle decide when and how can intervention be implemented in an adaptive framework.

\section{Operating direction of adaptive resilience}

This section is based on the previous research ( $\mathrm{Li}$ et al. 2015a, Li et al. 2015b), which is provided in Appendix 3 (Box 1 and Box 2). In these two studies, the city is presented as a part of the integrated dynamic landscapes and regional ecosystems, threshold values of water quality in relation to landscape patterns are the key information for maintaining water quality of the integrated system under rapid urbanization (Fig.5.2).

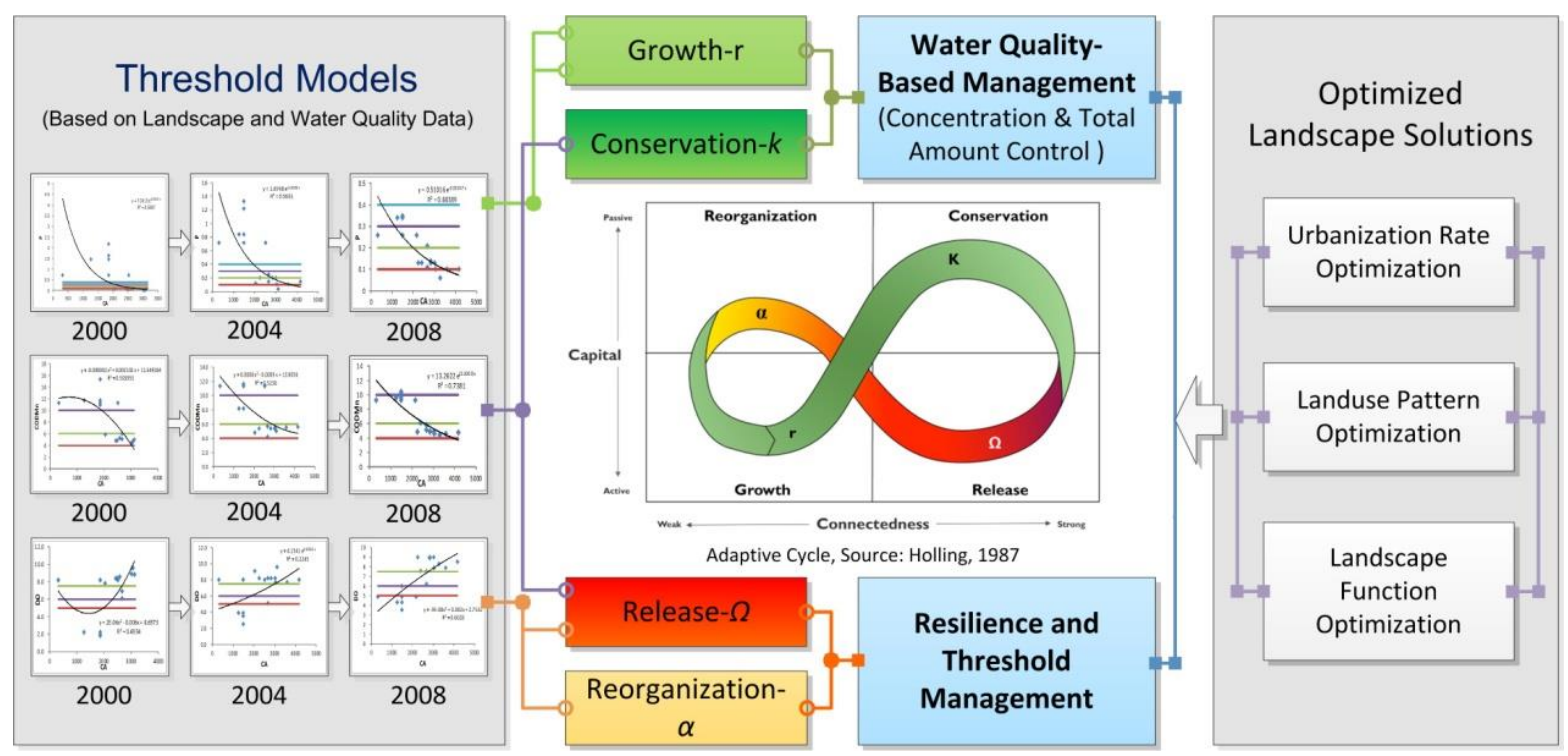

Fig.5.2 Landscape and water quality management with threshold models (Li et al. 2015b)

As the main conclusions from the second paper state ( $\mathrm{Li}$ et al. 2015b): "Management strategies for one scale (for example, landscape, water, human, or urban planning) often rely on the functionality of other scales (above or embedded scale, larger or finer scale). For instance, focusing on improving one water quality variable that requires urgent control may lead to landscape conservation target on one metric, which likely affect the other metrics, causing possibly unexpected changes in the other water quality variables. Therefore, we recommend the regression models for all the water quality variables studied altogether and the 
tradeoff of targeting on different landscape metrics examined comprehensively, e.g. how one landscape metric affects multiple water quality variables, and how one water quality variable is affected by different landscape metrics."

\section{Details of system's resilience transformability}

More specifically, the previous work provided a possible operating direction of the resilience management between land use change and water quality. Based on this evidence, the theory of adaptive capacity and adaptive cycles provide a critical framework for detecting further details of system's resilience transitions and transformability. Adaptive capacity represents the system's capacity to manage resilience in relation to alternate regimes, which makes the system more or less resistant to perturbations. Adaptive cycle, as a heuristic model, portrays an endogenously driven four-phase cycle, which provides guidelines for adaptive management in different states. The resilience of five water quality variables $\left(\mathrm{NH}_{3}-\mathrm{N}, \mathrm{Pb}, \mathrm{Cd}\right.$, Oil and $\left.\mathrm{TP}\right)$ experienced most oscillation and transition states from 2000 to 2010. In other words, those variables were the focal indicators for resilience management.

(1) Resilience management strategies in the built-up area:

Lianyungang has been experiencing rapid urbanization and industrialization since 2003. The majority of those pollutants were from the domestic sewage and industrial waste water, manufacturing industry was another direct contributor to the degraded water quality. When the city government of Lianyungang began observing increased water pollution after the turn of the century, some new investments, policies, and concerted policy enforcement allowed most of the rivers to maintain their standard water quality levels. The local urban development plans targeted other urban management practices related to water quality, including:

- Enforcement of water quality regulation by local authorities and the renovation of the wastewater network system, and the government implementation of modern wastewater infrastructure.

- Replenishment of clean upper-stream water.

- All the residence buildings and industries in the first Grade or second Grade protected areas for drinking water sources were either moved out to industrial zones or shut down, the waste water discharge pipes nearby were closed, and automatic monitoring system and up-to-date waste water treatment technologies were used in newly built treatment plants.

- Whereas industrial activity was previously scattered throughout the city, making industrial wastewater control difficult and leading to more water pollution, it has now been concentrated into specific areas with better monitoring and treatment.

(2) Resilience management strategies in agricultural and bare land

As the special urban development zone in east coastal area, where most of agricultural and bare land exists, those areas are experiencing grand challenges and intensive disturbances. The non-point source pollution from agricultural land and the construction pollution from bare land were the main pollutant sources for the high input of phosphorus and nitrogen into the river. Oil was also a vulnerable variable in agricultural land and bare land due to the pollutants from shipping and industrial waste along the coastal developing area. Future river monitoring and management plans must consider the related pollution, especially those that are correlated with $\mathrm{Cd}$ and TP. Through encouraging ecological and organic agriculture there are more and more 
ecological plantations with precise amount of fertilizers, a move supported by local government. The government aims to continue food production in the area while reducing chemical inputs that negatively affect water quality.

\section{Management framework based on resilience trajectory of different adaptive phases}

The coordinative changes and tipping points between the resilience of water quality and regional/national policies demonstrated the significant relationship between resilience states and policies. Lianyungang Coastal Regional Strategic Plan (2005-2030) and Urban Master Plan (2008-2030) are two of the vital city development policies that implements during the time of fore loop state. Lianyungang Coastal Regional Strategic Plan highlights the issue of how to further increase the density of the urban landscape with the consideration of sustainable and resilient systems, specifically employing the language of resilience (弹性, tanxing) in the local planning documents.

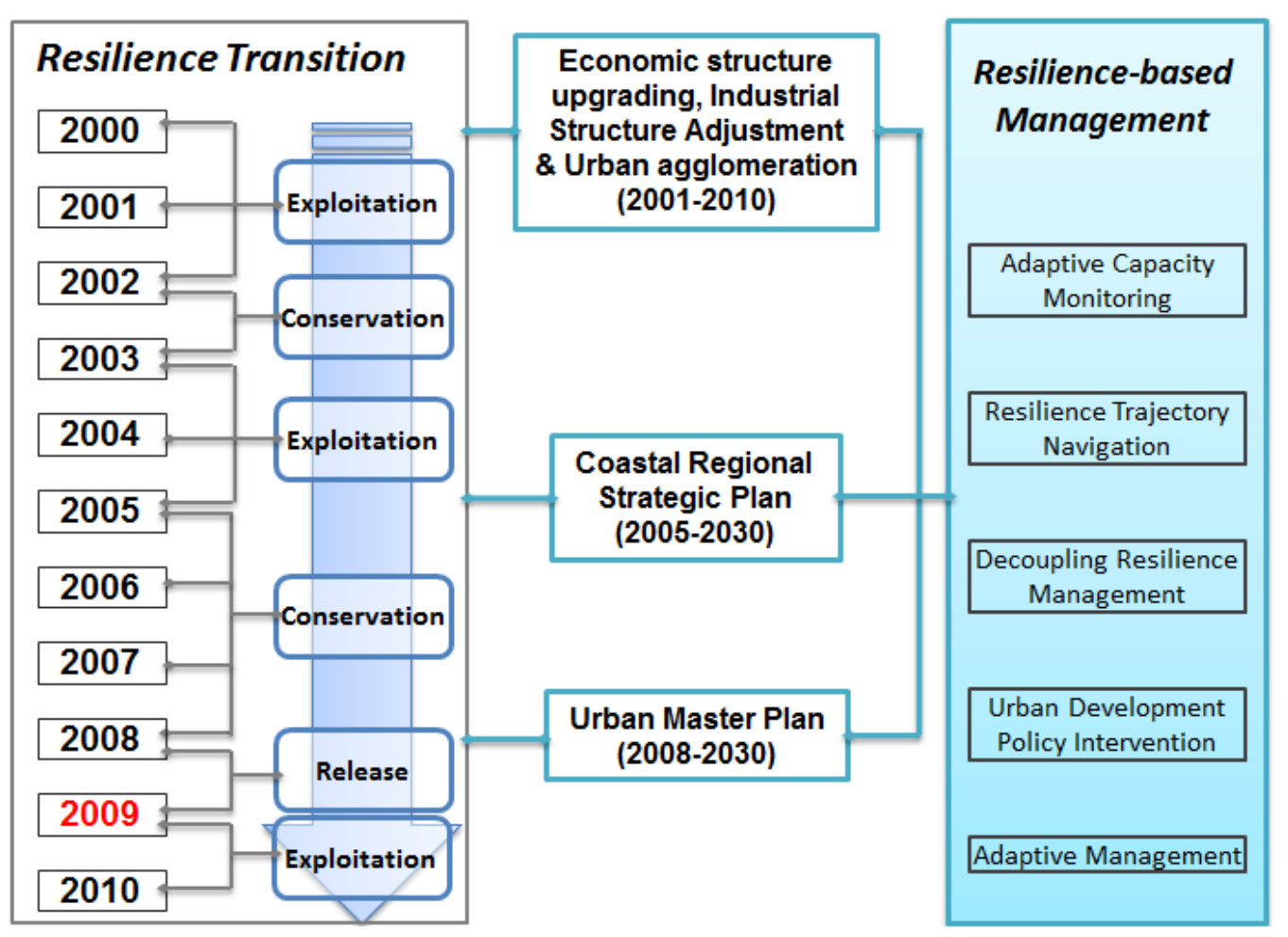

Fig.5.3 Resilience-based management framework

The majority of land use changes happened in the core zone and the two wing areas, and dispersive built infrastructure in all peri-urban areas. As the primary regulations in city plans are to create a healthy and sustainable urban development circumstance, the territorial conservation and reorganization for built-up and agricultural land improved its land use function and efficiency. However, because of the intensive transformation of the changes in economic structure and pressures within a growing urban agglomeration around the central urban area, more unexpected water pollution and incomplete water treatment plants lead to the abrupt resilience degradation during 2001 to 2003. The resilience of water quality in Lianyungang underwent a more complex and uncontrollable degraded state in the release phase; the adaptive cycles of some water quality variables approached its adaptive capacity. 
As a medium sized developing city, Lianyungang needs to balance and maintain the adaptive capacity to address environment quality before the system collapses. A release phase usually moves at some point into a reorganization phase, but it can (through small perturbations) move toward an exploitation phase. The main exploitation phase happened during 2006-2007, this was the best time for enforcing new policies and management practices. Therefore, enforcing new policies and management practices enables and navigates the system resilience, as seen in the Coastal Regional Strategic Plan. In the later regional plan after 2006, the normative principle has been renewed to follow up the intended gradual transformation of a rather monocentric urban configuration into a polycentric one, which is more focused on both central urban and east coastal line (Ganyu and Guanyun district). The new polycentric structure of the "One Zone and Two Wings" development policy effectively releases the pressure from the central urban area. As can be seen from the resilience trajectory in Lianyungang, after the enforcement of the reformed city plans, resilience turned into a relatively short to a transition conservation phase. More importantly, government or managers should often monitor the change in the exploitation phase, which is a better way to prevent a large collapse in the late conservation phase.

Because the conservation phase is a locked-up phase with slow change, it is an important time for developing action plans. Generally, it was a short conservation phase for most of water quality variables during 2007-2008, and another critical city plan-Urban Master Plan was developed at this time. A conservation phase usually transforms into a release phase, but it can also move back toward a growth phase, like the sub-systems' resilience changes mentioned in Chapter 2. That is, theoretically, a conservation phase is another operating phase for managers or planners to avoid a release phase at one focal scale by generating release and reorganization phases at other focal scales. But in reality, some water quality variables continued with release phases, during which resilience reduced. The optimal way is to manage system's resilience during the conservation phase, in order to avoid or reduce the pressure in the next release phase. This finding can be a potential guideline for future city development planning to maintain system's resilience by avoiding collapse.

\subsubsection{Adaptive management-learning and creating opportunity}

With the purpose of developing a program of interventions to address resilience issues, an adaptive-management framework can help to conceive systems and assets in order to withstand shocks and stresses. Adaptive management is a resilience-based approach combined with both passive and active parts, which represents the focal point of adaptive cycles. The essence of resilience management is treating management as a hypothesis coupled to an experiment, and to test system's responses to this hypothesis. Because the threshold/tipping point appears as the system's feedbacks, this can provide valuable information for future management, but it can also cause system's collapse. On the other hand, managers can implement and develop new acting plans or policies during the fore loop of adaptive cycle, which can avoid tremendous resilience shifts to maintain a system's resilience in a safe zone. Resilience management also requires the explicit statement of expected response to disturbances or policy intervention. For example, after the enforcement of the Coastal Regional Strategic Plan, if the system's responses are different, managers need to adjust and develop the model of the system structure and function. The principle is that the adjustment of management practices and processes should 
be guided by monitoring the feedbacks of the social-ecological change. By monitoring and managing feedbacks of system's change, rather than blocking them out, adaptive management has the potential to avoid the collapse of SESs, and enable the system to learn and build adaptive capacity through reorganization.

Furthermore, adaptive management often shifts the status quo, which is not easy to detect by stakeholders in research and management. Adaptive policy might be perceived as a threat to existing research programs and management regimes. In this case, government needs to address the issue in the latter development plan, and it should be considered as part of the framework for implementing the potential interventions that arise out of a resilience assessment. An active adaptive management strategy plays an important role in putting resilience thinking into practice. It simultaneously allows for tests of different management policies and emphasizes learning to live with change and uncertainty, and creating opportunity for selforganization during the latter policy discourse.

\subsection{Outlook}

Resilience transition assessments in this thesis are based on data from 2000 to 2010 in Lianyungang. Even though the detected resilience transitions provided implications for city development, it still a limited case study within a short time scale of 11 years. So it will be interesting in the next step to demonstrate resilience change in a longer time or a larger space. There is possibility that some characters of the resilience transformations during these 11 years will be disappear, and new trajectory may lead the whole resilience to different basins of attraction. In order to understand a long term resilience transformation, more basic theories and state models are need, as well as scenario analysis models. Continuing with the study area in Lianyungang, it will be better to understand how Lianyungang's Coastal Regional Strategic Plan is carried out in practice after 2010, and see whether urban resilience changes into a desirable state. It remains to be seen if the planning direction and plans help to combat urban sprawl, or whether they have an influence on resilience adaptation and transformation.

Additionally, further research will be needed to explore the interconnections of adaptive cycles across scales, and each scale is going through its own adaptive cycle. The connection plays an important role in detecting the dynamics of the whole set. "Panarchy" operates over many different scales of time and space, the way in which they are linked across scales are more complex. The critical point of using the Panarchy theory is to find the focal scale among a range of different scales, while self-organizing systems operate over all related scales, including different space and time.

Furthermore, urban development had vital impacts on resilience changes and the transport network has been changing due to the rapid urbanization in Lianyungang. Further research will focus on discovering how the changes of transport system affect resilience. SLEUTH model (Clarke et al. 1997, Clarke and Gaydos 1998, US Geological Survey 2003) and State-andtransition (S\&T) model (Westoby et al. 1989, Briske et al. 2008, Bestlemeyer et al. 2009, Suding and Hobbs 2009) will be used for transports resilience identification and scenario analysis. 


\section{References}

1. Bestelmeyer, B. T., Tugel, A. J., Peacock, G. L., Robinett, D. G., Shaver, P. L., Brown, J. R., Herrick, J. E., Sanchez, H., Havstad, K. M. 2009. Stateand-transition models for heterogeneous landscapes: A strategy for development and application. Rangeland Ecology and Management. 62:1-15.

2. Briske, D. D., Bestelmeyer, B. T., Stringham, T. K., Shaver, P. L. 2008. Recommendations for development of resilience-based state-and-transition models. Rangeland Ecology and Management. 61:359-367.

3. Carpenter, S. R., Walker, B. H., Anderies, J. M., Abel, N. 2001. From Metaphor to Measurement: Resilience of What to What? Ecosystems. 4:765-781.

4. Clark, K. C., Hoppen, S., Gaydos, L. 1997. A self-modifying cellular automaton model of historical urbanization in the San Francisco Bay area. Environment and Planning B: Planning and Design. 24:247-261.

5. Clarke, K. C., Gaydos, L. J. 1998. Loose-coupling a cellular automaton model and GIS: long-term urban growth prediction for San Francisco and Washington/Baltimore. International Journal of Geographical Information Science. 12:699-714.

6. Environmental Quality Standards for Surface Water (GB 3838-2002). 2002. Ministry of Environmental Protection of the People's Republic of China. http://bz.mep.gov.cn/bzwb/shjbh/shjzlbz/200206/W020061027509896672057.pdf.

7. Li, Y. F., Li, Y., Wu, W. 2015b. Threshold and resilience management of coupled urbanization and water environmental system in the rapidly changing coastal region. Environmental Pollution. doi: 10.1016/j.envpol.2015.08.042.

8. Li, Y., Li, Y. F., Qureshi, S., Kappas, M., Hubacek, K. 2015a. On the relationship between landscape ecological patterns and water quality across gradient zones of rapid urbanization in coastal China. Ecological Modelling. 318:100-108.

9. Scheffer, M., Bascompte, J., Brock, W. A., Brovkin, V., Carpenter, S. R., Dakos, V., Held, H., van Nes, E. H., Rietkerk, M., Sugihara, G. 2009. Early-warning signals for critical transitions. Nature. 461:53-59.

10. Suding, K. N., Hobbs, R. J. 2009. Threshold models in restoration and conservation: A developing framework. Trends in Ecology \& Evolution 24:271-279.

11. US Geological Survey, 2003, Project Gigalopolis. http://www.ncgia.ucsb.edu/projects/gig/.

12. Westoby, M., Walker, B., Noy-Meir, I. 1989. Opportunistic management for rangelands not at equilibrium. Journal of Range Management 42:266-274. 


\section{Appendices}

\section{Appendix 1}

Fig.S1 Catastrophe progression model for the Social-Ecological System

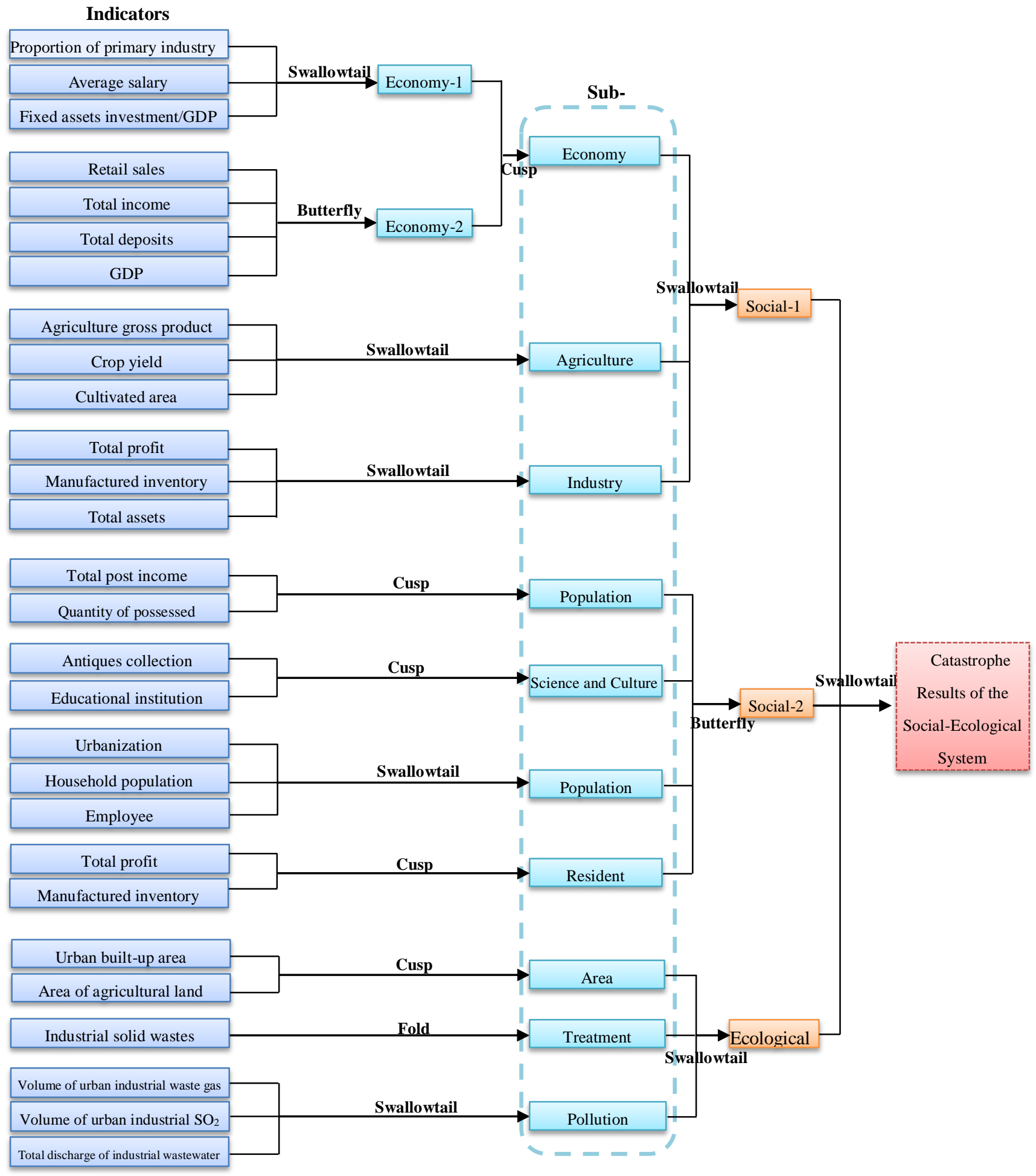




\section{Appendix 2}

Fig.S2 Resilience graphs in all five areas

\begin{tabular}{|c|c|c|c|}
\hline & Science \& Culture & Agriculture & Population \\
\hline $\begin{array}{c}\text { Total } \\
\text { resilience }\end{array}$ & $10 \frac{5}{4}$ & & \\
\hline $\begin{array}{l}\text { Central } \\
\text { District }\end{array}$ & $\begin{array}{ll} & 2006 \\
- & \text { Science Culture-1 }\end{array}$ & & Population \\
\hline $\begin{array}{c}\text { Guannan } \\
\text { County }\end{array}$ & $\begin{array}{l}20062005 \\
\text { Science Culture-5 }\end{array}$ & Agriculture- & $\begin{array}{l}06 \\
\text { Pollution-5 }\end{array}$ \\
\hline
\end{tabular}




\section{Appendix 3}

\section{Supporting Information}

Box 1

All the text, tables and figures are from the published paper:

Li, Y., Li, Y. F., Qureshi, S., Kappas, M., Hubacek, K. 2015a. On the relationship between landscape ecological patterns and water quality across gradient zones of rapid urbanization in coastal China. Ecological Modelling. 318:100-108.

DOI: 10.1016/j.ecolmodel.2015.01.028.

\section{Introduction}

The paper analyzes the relationship between urban landscape ecological pattern and water quality in three landscape zones. The study explores this relationship and its policy implications. The results of our analysis are as follow: (1) In the center zone, the landscape pattern metrics, Largest Patch Index (LPI) and Total Class Area (CA) were strongly correlated with water quality parameters, such as $\mathrm{COD}_{\mathrm{Mn}}$ and $\mathrm{NH}_{3}-\mathrm{N}$; (2) In the inner periurban zone, the number of significant relations of land use pattern metrics and water quality parameters in 2008 was greater than that in 2000 and 2004; (3) land use pattern metrics in the outer peri-urban were less correlated to water quality than in the other zones; (4) the degree of correlation in different spatial zones was in following order: center $(2008>2000>2004)$, inner peri-urban $(2008>2000>2004)$, outer peri-urban $(2004>2000=2008)$. Thus, the relationships between landscape and water quality varies significantly over space due to varying watershed characteristics and pollution sources across space.

\section{Methods \& Results}

\section{- Water quality data:}

Water quality data for the years 2000, 2004, and 2008 were obtained from the Lianyungang Environmental Quality Bulletin. The water quality indicators include $\mathrm{pH}$, dissolved oxygen (DO), permanganate $\left(\mathrm{COD}_{\mathrm{Mn}}\right)$, biochemical oxygen demand (BOD), ammonium $\left(\mathrm{NH}_{3}-\mathrm{N}\right)$, Oil (petroleum), volatile phenol (VP), phosphorus (P), fluoride $(\mathrm{F})$, mercury $(\mathrm{Hg})$, lead $(\mathrm{Pb})$, arsenic $(\mathrm{As})$, cadmium $(\mathrm{Cd})$, hexavalent chrome $\left(\mathrm{Gr}^{6+}\right)$, and cyanide $(\mathrm{CN})$.

\section{- Landscape pattern metrics derived from the software FRAGSTATS:}

total class area (CA), percentage of landscape (PLAND), patch density (PD), largest patch index (LPI), edge density (ED), area-weighted mean shape index (SHAPE_AM), cohesion index (COHESION) 

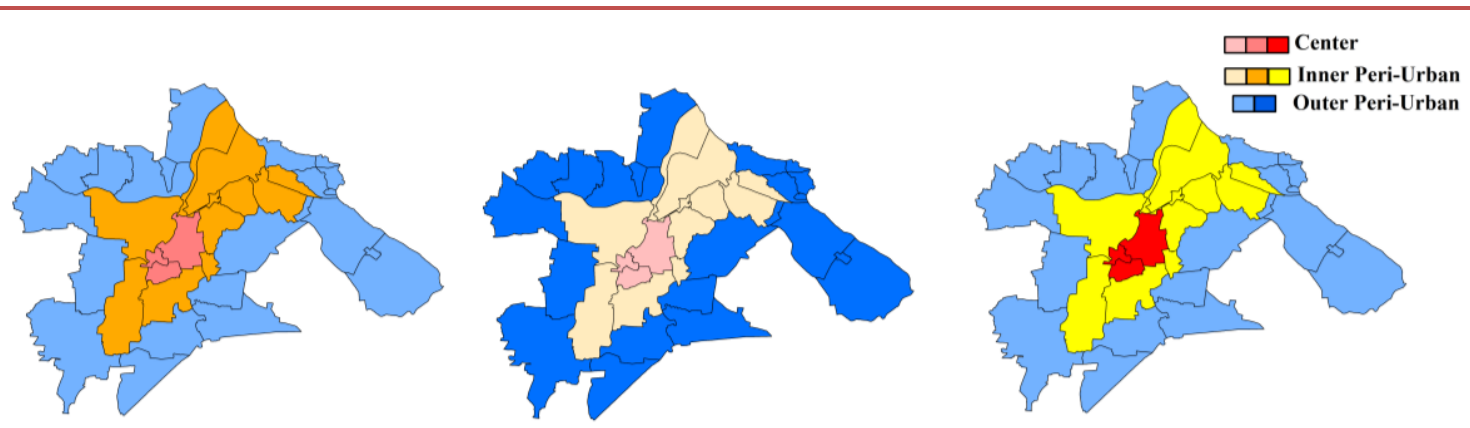

Fig.S3 Mapping correlation analysis of landscape metrics and water quality parameters at the $0.01 \mathrm{p}$ level

Note: This figure is interpreted based on the correlation analysis in Tables S1-S3. The greater the correlation at the $0.01 \mathrm{p}$ level was, the deeper the color for the zone became. In other words, the shade of color indicates the degree of correlation.

\section{Conclusions}

This study investigates the relationship between selected urban landscapes and water quality parameters, the main drivers for the water quality degradation. Evaluating the linkage between landscape ecological changes and water quality plays a pivotal role for regional water pollution management and land use planning. Especially, in the center and inner part of watershed where arable land and saltern cover were being lost to urban development, the potential impacts to water quality may expected to increase without domestic and industry sewage. Offsetting the impacts of future land use change will require maintaining sufficient green spaces, especially in the rapidly developing urban areas.

We also explore the relationship and its policy implications in three distinct urban development zones. It shows that urbanization as the increase of built-up driven land fragmentation is the main factor affecting water quality, indicating that river restoration and management should focus on restricting urban built-up land expansion, reducing urbanization-related pollution, and on planning more sustainable urban landscapes. But for the peri-urban area, the agricultural land use management is the major factor for water quality. 
Table S1 Pearson correlation coefficients between landscape metrics and water quality in the center, inner, and outer peri-urban layers for 2000

\begin{tabular}{|c|c|c|c|c|c|c|c|c|c|c|c|c|c|}
\hline & & pH & DO & $\operatorname{COD}_{M n}$ & BOD & $\mathbf{N H}_{3}-\mathbf{N}$ & Oil & VP & $\mathbf{P}$ & $\mathbf{F}$ & $\mathbf{P b}$ & As & $\mathrm{CN}$ \\
\hline \multirow{3}{*}{ CA } & Urban & 0.628 & $0.762 b$ & $-0.940 \mathrm{a}$ & -0.753 & $-0.853 b$ & $-0.926 a$ & -0.743 & $-0.869 b$ & -0.544 & 0.547 & $-0.934 a$ & $0.998 \mathrm{a}$ \\
\hline & Inner & 0.630 & $0.964 \mathrm{a}$ & -0.811 & $-0.889 b$ & $-0.959 a$ & -0.797 & $-0.926 a$ & $-0.940 a$ & -0.638 & -0.661 & 0.499 & $-0.871 b$ \\
\hline & Outer & -0.650 & -0.080 & $-0.974 a$ & $-0.949 b$ & $-0.934 b$ & $-0.978 \mathrm{a}$ & -0.393 & $-0.950 b$ & 0.043 & -0.463 & 0.576 & -0.813 \\
\hline \multirow{3}{*}{ PLAND } & Urban & 0.296 & 0.360 & -0.444 & -0.356 & -0.403 & -0.437 & -0.351 & -0.410 & -0.257 & 0.258 & -0.441 & 0.471 \\
\hline & Inner & 0.038 & 0.502 & $-0.877 b$ & -0.799 & -0.600 & $-0.859 b$ & -0.385 & -0.711 & -0.720 & -0.703 & 0.414 & -0.511 \\
\hline & Outer & -0.745 & -0.219 & $-0.906 b$ & $-0.882 b$ & -0.846 & $-0.939 b$ & -0.408 & -0.865 & -0.139 & -0.375 & 0.453 & $-0.919 b$ \\
\hline \multirow{3}{*}{ PD } & Urban & -0.570 & -0.691 & $0.853 b$ & 0.683 & $0.774 b$ & $0.840 \mathrm{~b}$ & 0.674 & $0.789 b$ & 0.493 & -0.496 & $0.847 b$ & $-0.906 a$ \\
\hline & Inner & 0.410 & 0.571 & $-0.816 b$ & $-0.826 b$ & -0.711 & -0.797 & -0.611 & -0.777 & -0.202 & -0.274 & 0.356 & -0.491 \\
\hline & Outer & 0.000 & -0.692 & -0.668 & -0.780 & -0.755 & -0.750 & $-0.968 a$ & -0.719 & 0.530 & 0.395 & -0.220 & -0.323 \\
\hline \multirow{3}{*}{ LPI } & Urban & -0.066 & -0.080 & 0.099 & 0.079 & 0.090 & 0.098 & 0.078 & 0.092 & 0.057 & -0.058 & 0.099 & -0.105 \\
\hline & Inner & 0.118 & 0.385 & -0.552 & -0.510 & -0.424 & -0.500 & -0.277 & -0.475 & $-0.869 b$ & -0.439 & 0.009 & -0.512 \\
\hline & Outer & -0.847 & -0.114 & -0.838 & -0.785 & -0.746 & -0.861 & -0.234 & -0.776 & -0.315 & -0.488 & 0.527 & $-0.968 a$ \\
\hline \multirow{3}{*}{ ED } & Urban & -0.597 & -0.724 & $0.893 a$ & 0.716 & $0.811 b$ & $0.880 \mathrm{a}$ & 0.706 & $0.826 b$ & 0.516 & -0.520 & $0.887 \mathrm{a}$ & $-0.949 \mathrm{a}$ \\
\hline & Inner & 0.438 & 0.484 & -0.652 & -0.679 & -0.601 & -0.661 & -0.536 & -0.650 & 0.080 & -0.159 & 0.375 & -0.415 \\
\hline & Outer & 0.054 & -0.658 & -0.663 & -0.778 & -0.759 & -0.738 & $-0.965 \mathrm{a}$ & -0.721 & 0.593 & 0.393 & -0.208 & -0.265 \\
\hline \multirow{3}{*}{ SHAPE_AM } & Urban & -0.628 & $-0.762 b$ & $0.941 \mathrm{a}$ & 0.754 & $0.854 b$ & $0.927 \mathrm{a}$ & 0.743 & $0.870 \mathrm{~b}$ & 0.544 & -0.547 & $0.935 \mathrm{a}$ & $-0.999 a$ \\
\hline & Inner & $0.944 \mathrm{a}$ & 0.557 & -0.079 & -0.256 & -0.519 & -0.024 & -0.665 & -0.396 & -0.207 & 0.338 & -0.335 & -0.670 \\
\hline & Outer & 0.010 & -0.304 & -0.822 & $-0.899 b$ & $-0.911 b$ & -0.837 & -0.779 & $-0.883 b$ & 0.698 & 0.046 & 0.165 & -0.249 \\
\hline \multirow{3}{*}{ COHESION } & Urban & -0.503 & -0.611 & 0.754 & 0.604 & 0.684 & 0.742 & 0.595 & 0.697 & 0.436 & -0.439 & 0.749 & $-0.801 b$ \\
\hline & Inner & -0.071 & -0.365 & 0.600 & 0.579 & 0.451 & 0.648 & 0.369 & 0.522 & -0.197 & 0.438 & -0.680 & 0.162 \\
\hline & Outer & 0.000 & 0.431 & -0.696 & -0.681 & -0.746 & -0.602 & -0.130 & -0.742 & 0.624 & -0.524 & 0.694 & -0.043 \\
\hline
\end{tabular}

From Table S1 to Table S3: a Correlation is significant at the 0.01 level (2-tailed)

b Correlation is significant at the 0.05 level (2-tailed) 
Table S2 Pearson correlation coefficients between landscape metrics and water quality in the center, inner, and outer peri-urban layers for 2004

\begin{tabular}{|c|c|c|c|c|c|c|c|c|c|c|c|c|c|}
\hline & & pH & DO & $\operatorname{COD}_{M n}$ & BOD & $\mathbf{N H}_{3}-\mathbf{N}$ & Oil & VP & $\mathbf{P}$ & $\mathbf{F}$ & $\mathbf{P b}$ & As & $\mathrm{CN}$ \\
\hline & Urban & 0.635 & 0.723 & $-0.883 a$ & $-0.842 b$ & $-0.850 \mathrm{~b}$ & -0.522 & -0.337 & $-0.864 b$ & $-0.772 b$ & $0.947 \mathrm{a}$ & -0.745 & 0.716 \\
\hline \multirow[t]{3}{*}{$\mathbf{C A}$} & Inner & -0.076 & -0.226 & -0.633 & -0.670 & -0.640 & -0.645 & -0.749 & -0.646 & 0.694 & -0.335 & 0.810 & -0.675 \\
\hline & Outer & -0.153 & -0.273 & $-0.897 b$ & $-0.961 \mathrm{a}$ & $-0.933 b$ & -0.376 & -0.049 & $-0.917 b$ & 0.561 & -0.463 & 0.763 & 0.243 \\
\hline & Urban & 0.665 & $0.758 b$ & $-0.925 a$ & $-0.882 \mathrm{a}$ & $-0.891 \mathrm{a}$ & -0.547 & -0.354 & $-0.905 a$ & $-0.809 b$ & $0.992 \mathrm{a}$ & $-0.781 b$ & 0.750 \\
\hline \multirow[t]{3}{*}{ PLAND } & Inner & -0.419 & -0.019 & $-0.944 b$ & $-0.982 \mathrm{a}$ & $-0.954 b$ & $-0.972 \mathrm{a}$ & -0.527 & $-0.901 b$ & 0.258 & 0.236 & 0.407 & -0.484 \\
\hline & Outer & 0.061 & -0.417 & -0.831 & $-0.900 b$ & -0.850 & -0.203 & 0.086 & -0.814 & 0.354 & -0.375 & 0.586 & 0.354 \\
\hline & Urban & 0.441 & 0.502 & -0.613 & -0.584 & -0.590 & -0.362 & -0.234 & -0.600 & -0.536 & 0.657 & -0.517 & 0.497 \\
\hline \multirow[t]{3}{*}{ PD } & Inner & -0.594 & 0.255 & $-0.922 b$ & $-0.901 b$ & $-0.918 b$ & $-0.900 \mathrm{~b}$ & -0.825 & $-0.946 b$ & 0.217 & -0.149 & 0.690 & -0.450 \\
\hline & Outer & -0.575 & -0.060 & $-0.966 a$ & $-0.933 b$ & $-0.965 \mathrm{a}$ & -0.432 & -0.070 & $-0.933 b$ & 0.509 & -0.014 & 0.842 & 0.250 \\
\hline & Urban & 0.017 & 0.020 & -0.024 & -0.023 & -0.023 & -0.014 & -0.009 & -0.024 & -0.021 & 0.026 & -0.020 & 0.020 \\
\hline \multirow[t]{3}{*}{ LPI } & Inner & 0.166 & -0.390 & -0.170 & -0.271 & -0.194 & -0.259 & 0.553 & -0.037 & -0.067 & 0.840 & -0.592 & -0.010 \\
\hline & Outer & 0.567 & -0.655 & -0.348 & -0.364 & -0.288 & 0.418 & 0.495 & -0.188 & -0.484 & 0.242 & -0.174 & 0.599 \\
\hline & Urban & 0.594 & 0.677 & $-0.826 b$ & $-0.788 b$ & $-0.796 b$ & -0.488 & -0.316 & $-0.809 b$ & -0.723 & $0.886 \mathrm{a}$ & -0.697 & 0.670 \\
\hline \multirow[t]{3}{*}{ ED } & Inner & -0.587 & 0.259 & $-0.905 b$ & $-0.881 b$ & $-0.901 b$ & $-0.880 b$ & -0.842 & $-0.934 b$ & 0.229 & -0.187 & 0.714 & -0.452 \\
\hline & Outer & -0.325 & -0.251 & $-0.953 b$ & $-0.935 b$ & $-0.938 b$ & -0.266 & 0.076 & $-0.883 b$ & 0.325 & 0.020 & 0.697 & 0.388 \\
\hline & Urban & 0.479 & 0.546 & -0.667 & -0.635 & -0.642 & -0.394 & -0.255 & -0.652 & -0.583 & 0.715 & -0.562 & 0.540 \\
\hline \multirow[t]{3}{*}{ SHAPE_AM } & Inner & -0.204 & 0.425 & 0.146 & 0.252 & 0.172 & 0.238 & -0.563 & 0.013 & 0.036 & -0.830 & 0.589 & 0.023 \\
\hline & Outer & -0.231 & -0.315 & $-0.918 b$ & $-0.899 b$ & $-0.894 b$ & -0.179 & 0.144 & -0.827 & 0.215 & 0.083 & 0.607 & 0.443 \\
\hline & Urban & 0.654 & 0.745 & $-0.910 \mathrm{a}$ & $-0.867 b$ & $-0.876 a$ & -0.538 & -0.348 & $-0.890 \mathrm{a}$ & $-0.796 b$ & $0.976 \mathrm{a}$ & $-0.768 b$ & 0.738 \\
\hline \multirow[t]{2}{*}{ COHESION } & Inner & 0.218 & 0.186 & 0.706 & 0.782 & 0.725 & 0.772 & -0.013 & 0.600 & -0.049 & -0.679 & 0.135 & 0.265 \\
\hline & Outer & -0.639 & 0.013 & $-0.960 \mathrm{a}$ & $-0.940 b$ & $-0.977 \mathrm{a}$ & -0.528 & -0.159 & $-0.963 a$ & 0.642 & -0.143 & $0.919 b$ & 0.159 \\
\hline
\end{tabular}


Table S3 Pearson correlation coefficients between landscape metrics and water quality in the center, inner, and outer peri-urban layers for 2008

\begin{tabular}{|c|c|c|c|c|c|c|c|c|c|c|c|c|c|}
\hline & & pH & DO & $\operatorname{COD}_{M n}$ & BOD & $\mathbf{N H}_{3}-\mathbf{N}$ & Oil & VP & $\mathbf{P}$ & $\mathbf{F}$ & $\mathbf{P b}$ & As & $\mathrm{CN}$ \\
\hline \multirow{3}{*}{ CA } & Urban & -0.393 & $0.906 a$ & $-0.944 a$ & $-0.887 \mathrm{a}$ & $-0.908 \mathrm{a}$ & -0.740 & $-0.893 a$ & $-0.911 \mathrm{a}$ & $-0.795 b$ & $-0.818 b$ & -0.697 & $-0.947 \mathrm{a}$ \\
\hline & Inner & -0.703 & 0.740 & -0.809 & -0.741 & -0.646 & -0.715 & -0.816 & -0.798 & -0.400 & 0.142 & 0.506 & -0.442 \\
\hline & Outer & -0.133 & 0.863 & $-0.984 a$ & -0.861 & -0.848 & -0.521 & $-0.939 b$ & -0.808 & -0.773 & 0.236 & 0.770 & -0.541 \\
\hline \multirow{3}{*}{ PLAND } & Urban & -0.418 & $0.951 \mathrm{a}$ & $-0.991 \mathrm{a}$ & $-0.947 \mathrm{a}$ & $-0.961 \mathrm{a}$ & $-0.803 b$ & $-0.935 \mathrm{a}$ & $-0.959 a$ & $-0.851 b$ & $-0.881 \mathrm{a}$ & -0.730 & $-0.992 \mathrm{a}$ \\
\hline & Inner & -0.827 & $0.969 \mathrm{a}$ & $-0.982 \mathrm{a}$ & $-0.979 a$ & $-0.891 b$ & $-0.979 a$ & $-0.995 \mathrm{a}$ & $-0.912 b$ & -0.572 & 0.131 & 0.405 & -0.729 \\
\hline & Outer & 0.019 & 0.797 & $-0.967 \mathrm{a}$ & -0.816 & -0.763 & -0.414 & $-0.883 b$ & -0.747 & -0.769 & 0.125 & 0.843 & -0.521 \\
\hline \multirow{3}{*}{ PD } & Urban & -0.145 & 0.364 & -0.380 & -0.315 & -0.345 & -0.230 & -0.364 & -0.359 & -0.277 & -0.274 & -0.285 & -0.387 \\
\hline & Inner & $-0.966 a$ & 0.876 & $-0.960 \mathrm{a}$ & -0.810 & $-0.939 b$ & -0.875 & $-0.941 b$ & $-0.991 \mathrm{a}$ & -0.797 & 0.000 & 0.730 & -0.402 \\
\hline & Outer & -0.488 & 0.526 & -0.376 & -0.046 & -0.628 & -0.299 & -0.643 & -0.425 & $-0.901 b$ & -0.480 & 0.656 & 0.490 \\
\hline \multirow{3}{*}{ LPI } & Urban & 0.107 & -0.279 & 0.292 & 0.229 & 0.259 & 0.156 & 0.281 & 0.273 & 0.199 & 0.193 & 0.219 & 0.298 \\
\hline & Inner & -0.611 & $0.904 b$ & -0.845 & $-0.959 a$ & -0.773 & $-0.936 b$ & -0.874 & -0.702 & -0.396 & 0.168 & 0.067 & $-0.887 b$ \\
\hline & Outer & 0.194 & 0.505 & -0.735 & $-0.889 b$ & -0.413 & -0.350 & -0.485 & -0.528 & -0.075 & 0.692 & 0.239 & $-0.981 \mathrm{a}$ \\
\hline \multirow{3}{*}{ ED } & Urban & -0.381 & $0.881 \mathrm{a}$ & $-0.918 \mathrm{a}$ & $-0.858 \mathrm{~b}$ & $-0.881 \mathrm{a}$ & -0.712 & $-0.869 b$ & $-0.885 a$ & $-0.768 b$ & $-0.790 \mathrm{~b}$ & -0.678 & $-0.921 \mathrm{a}$ \\
\hline & Inner & $-0.951 b$ & 0.857 & $-0.945 b$ & -0.792 & $-0.912 b$ & -0.851 & $-0.927 b$ & $-0.981 \mathrm{a}$ & -0.770 & 0.008 & 0.736 & -0.381 \\
\hline & Outer & -0.119 & 0.715 & -0.781 & -0.476 & -0.735 & -0.317 & -0.842 & -0.634 & $-0.969 a$ & -0.301 & $0.949 \mathrm{~b}$ & -0.019 \\
\hline \multirow{3}{*}{ SHAPE_AM } & Urban & -0.218 & 0.528 & -0.550 & -0.483 & -0.513 & -0.376 & -0.524 & -0.525 & -0.428 & -0.432 & -0.409 & -0.556 \\
\hline & Inner & $-0.901 b$ & 0.692 & -0.818 & -0.600 & -0.795 & -0.673 & -0.788 & $-0.908 b$ & -0.754 & -0.042 & 0.839 & -0.143 \\
\hline & Outer & 0.021 & 0.788 & $-0.955 b$ & -0.779 & -0.759 & -0.394 & $-0.882 b$ & -0.735 & -0.803 & 0.060 & 0.876 & -0.464 \\
\hline \multirow{3}{*}{ COHESION } & Urban & -0.360 & $0.836 \mathrm{~b}$ & $-0.872 b$ & $-0.809 b$ & $-0.834 b$ & -0.667 & $-0.826 b$ & $-0.839 b$ & -0.724 & -0.742 & -0.645 & $-0.876 a$ \\
\hline & Inner & $-0.935 b$ & $0.942 b$ & $-0.994 a$ & $-0.904 b$ & $-0.953 b$ & $-0.948 b$ & $-0.988 \mathrm{a}$ & $-0.982 \mathrm{a}$ & -0.736 & 0.049 & 0.606 & -0.556 \\
\hline & Outer & -0.480 & 0.777 & -0.697 & -0.421 & -0.853 & -0.488 & $-0.889 b$ & -0.678 & $-0.978 \mathrm{a}$ & -0.190 & 0.764 & 0.111 \\
\hline
\end{tabular}




\section{Box 2}

All the text, tables and figures are from the published paper"

$\mathrm{Li}, \quad \mathrm{Y} . \mathrm{F} ., \mathrm{Li}, \mathrm{Y} ., \mathrm{Wu}, \mathrm{W} .2015 \mathrm{~b}$. Threshold and resilience management of coupled urbanization and water environmental system in the rapidly changing coastal region. Environmental Pollution. DOI: 10.1016/j.envpol.2015.08.042

\section{Introduction}

Here we studied how commonly used regression models can be applied in the analysis of environmental thresholds. The change of landscape patterns from 2000 to 2008 were analyzed and derived potential landscape thresholds which indicated abrupt changes in water quality or the dividing point between exceeding and failing to meet national surface water quality standards for a rapidly coastal urbanizing city. The analysis of landscape thresholds was based on regression models linking each of the seven water quality variables to each of the six landscape patterns for this coupled land-water system. We found substantial and accelerating urban sprawl at the suburban areas during the eight years, and detected significant nonlinear relations and thresholds between water quality and landscape pattern. It demonstrated that a simple modeling technique could be effectively used to provide insights on environmental thresholds to support more-informed decision making in land use, water environmental and resilience management.

\section{Methods \& Results}

- 15 standard water quality variables: data source-Lianyungang Environmental Quality Bulletin, Lianyungang Environmental Protection Agency). The water quality variables include $\mathrm{pH}$, dissolved oxygen (DO), $\mathrm{COD}_{\mathrm{Mn}}$ (Permanganate), Biochemical Oxygen Demand (BOD), Ammonium nitrogen $\left(\mathrm{NH}_{3}-\mathrm{N}\right)$, Oils (Petroleum), Volatile Phenol (VP), Total Phosphorus (P), Fluoride ( $\left.\mathrm{F}^{-}\right)$, Total Mercury (Hg,), Lead ( $\mathrm{Pb}$ ), Arsenic (As), Cadmium (Cd), Hexavalent Chrome $\left.\left(\mathrm{Gr}^{6+}\right)\right)$, Cyanide $(\mathrm{CN})$.

- Landscape pattern metrics derived from the software FRAGSTATS: total class area (CA), percentage of landscape (PLAND), patch density (PD), edge density (ED), area-weighted mean shape index (SHAPE_AM), cohesion index (COHESION).

\section{- Threshold models:}

Power model: $\quad Y=A_{1} x^{B_{1}}+\varepsilon_{1}$

Exponential model: $\quad Y=A_{2} \mathrm{e}^{B_{2} x}+\varepsilon_{2}$

Quadratic model: $Y=A_{3} x^{2}+B_{3} x+\varepsilon_{3}$

\section{Conclusions}

Identifying thresholds provides potential targets for environmental management so it will facilitate more-informed decision making in order to achieve sustainable urbanization and water environmental functions. We performed statistical analyses to link water quality 
variables to landscape patterns at a rapid urbanization region in China, from which, we attempted threshold analyses to inform land-water management. The fitted regressions in the research showed the dynamic linkage between landscape metrics and water quality variables in Lianyungang. ED and COHESION are two landscape metrics that could best predict water quality variables, and the landscape thresholds showed variability depending on the landscape metrics used and water quality variables studied.

Due to rapid change of urban and water environment, it might be difficult for many managed systems to keep a steady state. An understanding of threshold offers new insights into land-water coping management because it is based on knowledge of how natural systems work and it informs us about precautions that can take to prevent excessive disturbance and degradation in ecosystems. The 'safe range of values' of landscape metrics before the change of each turning point or standard threshold are valuable information for sustainable management and environmental governance. The knowledge of thresholds can potentially assist land and conservation managers set targets for environmental conservation and restoration and, where possible, landscape and water recovery. In human dominated landscapes, these indicators can help to identify the best water quality management and water usage guide.

In this research, we checked one-to-one relation between landscape pattern and water quality without considering their interactions. The landscape for each water quality sampling site is not the site's upper watershed area due to the sites were chosen in three urban and peri-urban zones with the consideration of the development mode, which sprawl from center to surround counties and along the coastal area ( $\mathrm{Li}$ et al., 2015). In addition to landscape pattern, the water quality is affected by other environmental factors (climate, topography, sewage treatment plants etc.). These landscapes for different water quality are similar in climate, topography, sewage treatment, wetland areas in this case. Studying temporal water quality over time at each water quality site can help decision making and resilience management. Therefore, further studies that address the long-term temporal and spatial variation of the relationships and interactions between water qualtiy and the corresponding land use features are necessary. 

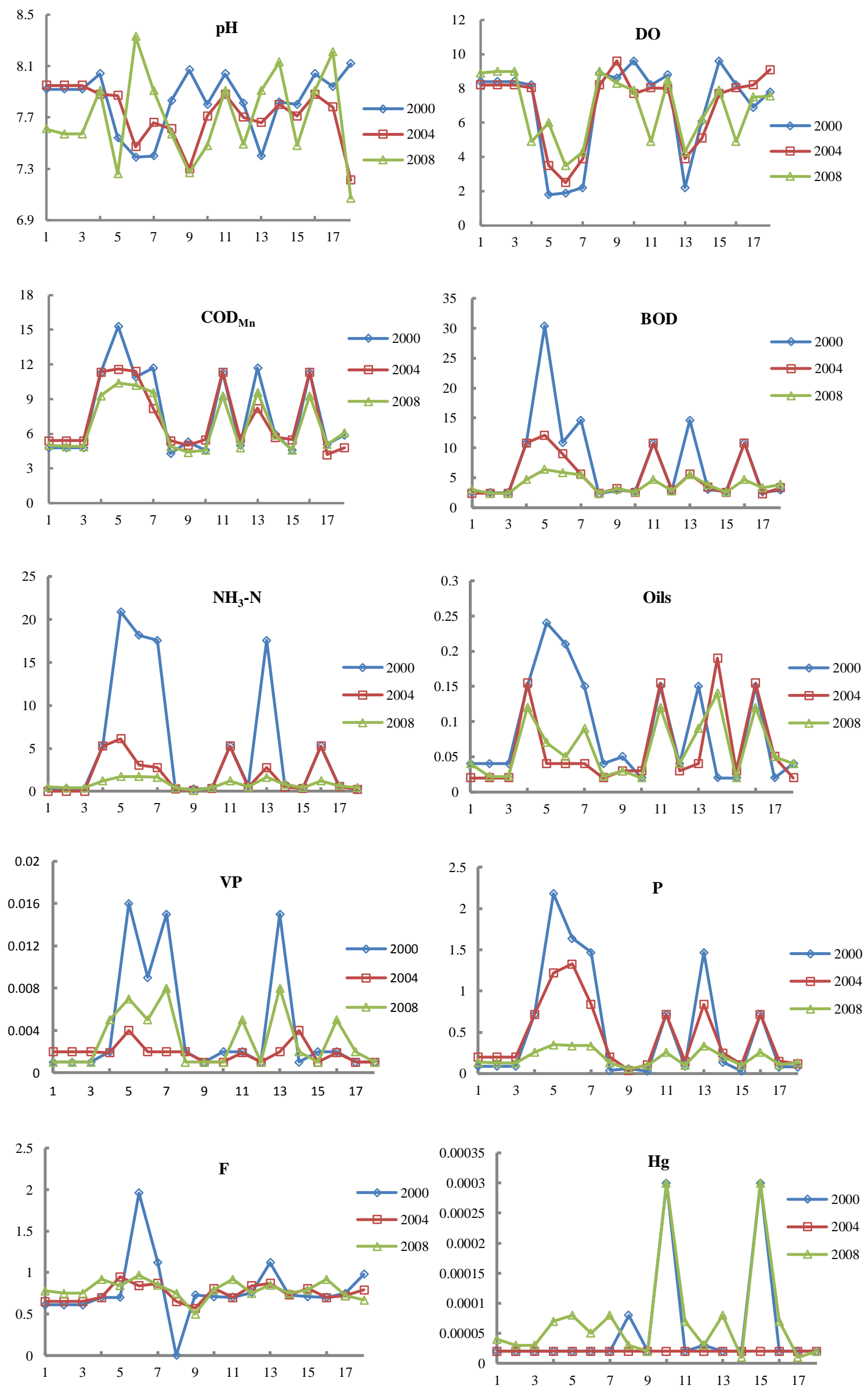


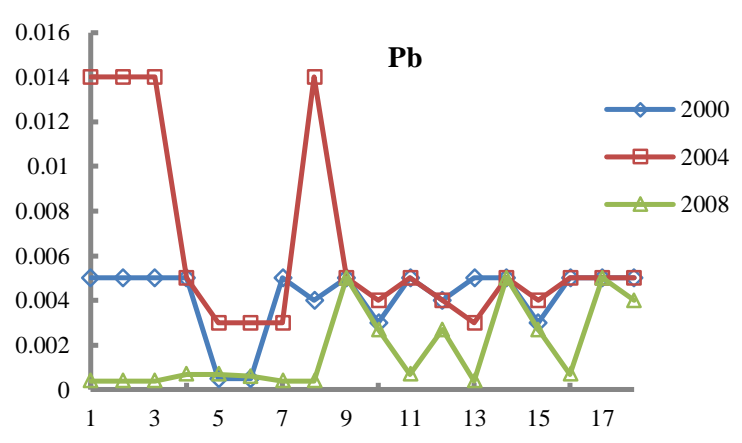

Fig.S4 Change in water quality variables in 2000, 2004 and 2008
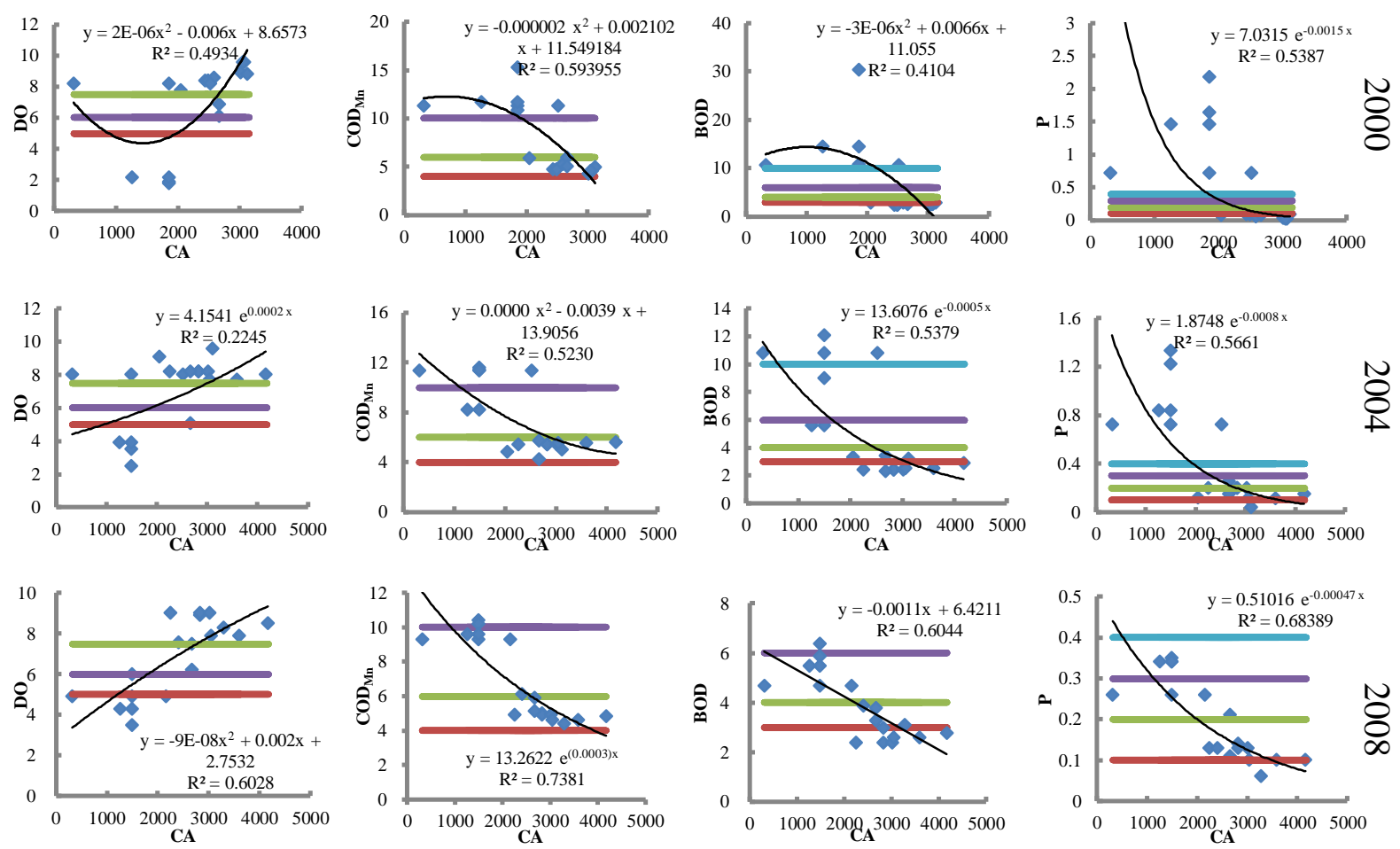

Fig.S5 Scatter plot and regression lines between CA and water quality variables

Note: Red transverse line represents water quality standard of I; Green transverse line represents water quality standard of II; Purple transverse line represents water quality standard of III ; Blue transverse line represents water quality standard of IV. More figures are available online. 
Table S4 Fitting Model and Threshold of PLAND and Water Quality Variables

\begin{tabular}{|c|c|c|c|c|c|c|c|c|c|c|}
\hline \multirow{2}{*}{$\begin{array}{c}\text { Landscape } \\
\text { metrics }\end{array}$} & \multirow{2}{*}{$\begin{array}{c}\text { Water } \\
\text { quality } \\
\text { variable }\end{array}$} & \multirow{2}{*}{ Year } & \multirow{2}{*}{ Fitting model } & \multirow{2}{*}{$\mathbf{R}^{2}$} & \multicolumn{6}{|c|}{ Threshold } \\
\hline & & & & & Turning point & Standard I & Standard II & Standard III & Standard IV & Standard V \\
\hline \multirow{12}{*}{ PLAND } & \multirow{3}{*}{$\mathrm{COD}_{\mathrm{Mn}}$} & 2000 & $\mathrm{y}=29.975 \mathrm{e}^{(0.056) \mathrm{x}}$ & 0.417 & --- & --- & --- & $28.72 / 6$ & $19.60 / 10$ & --- \\
\hline & & 2004 & $\begin{array}{c}y=0.0353 x^{2}-2.1915 x \\
+39.0774\end{array}$ & 0.834 & $31.3 / 4.78$ & --- & --- & $\begin{array}{l}25.89 / 6 \\
36.19 / 6\end{array}$ & $\begin{array}{l}19.22 / 10 \\
42.87 / 10\end{array}$ & --- \\
\hline & & 2008 & $\begin{array}{c}y=0.0042 x^{2}-0.5303 x \\
+17.6263\end{array}$ & 0.794 & $63.13 / 0.89$ & --- & --- & $\begin{array}{l}28.24 / 6 \\
98.02 / 6\end{array}$ & $\begin{array}{l}16.55 / 10 \\
109.71 / 10\end{array}$ & --- \\
\hline & \multirow{3}{*}{ BOD } & 2000 & $y=67.509 e^{-0.099 x}$ & 0.364 & --- & \multicolumn{2}{|c|}{$31.45 / 3$} & $28.55 / 4$ & $24.45 / 6$ & $19.29 / 10$ \\
\hline & & 2004 & $\begin{array}{c}y=0.046 x^{2}-2.854 x+ \\
46.53\end{array}$ & 0.808 & $31.02 / 2.26$ & \multicolumn{2}{|c|}{$27.02 / 3$} & $\begin{array}{l}24.88 / 4 \\
37.17 / 4\end{array}$ & $\begin{array}{l}22.01 / 6 \\
40.04 / 6\end{array}$ & $\begin{array}{l}18.05 / 10 \\
43.99 / 10\end{array}$ \\
\hline & & 2008 & $\mathrm{y}=10.12 \mathrm{e}^{-0.03 \mathrm{x}}$ & 0.584 & --- & \multicolumn{2}{|c|}{$40.53 / 3$} & $30.94 / 4$ & --- & --- \\
\hline & \multirow{3}{*}{ Oils } & 2000 & $y=1.626 e^{-0.12 x}$ & 0.532 & --- & \multicolumn{3}{|c|}{$29.02 / 0.05$} & --- & --- \\
\hline & & 2004 & $\begin{array}{c}y=0.0012 x^{2}-0.0646 x \\
+0.8867\end{array}$ & 0.424 & $26.92 / 0.02$ & \multicolumn{3}{|c|}{$\begin{array}{l}21.70 / 0.05 \\
32.14 / 0.05\end{array}$} & --- & --- \\
\hline & & 2008 & $\begin{array}{c}y=0.0005 x^{2}-0.0274 x \\
+0.4362\end{array}$ & 0.477 & $27.4 / 0.05$ & \multicolumn{3}{|c|}{$27.40 / 0.05$ (turning point) } & --- & --- \\
\hline & \multirow{3}{*}{$\mathrm{P}$} & 2000 & $y=23.73 e^{-0.18 x}$ & 0.390 & --- & --- & $30.39 / 0.1$ & $26.53 / 0.2$ & $24.28 / 0.3$ & $22.68 / 0.4$ \\
\hline & & 2004 & $\begin{array}{c}y=0.0024 x^{2}-0.1775 x \\
+3.3184\end{array}$ & 0.660 & $36.98 / 0.04$ & --- & $\begin{array}{l}31.84 / 0.1 \\
42.12 / 0.1\end{array}$ & $\begin{array}{l}28.73 / 0.2 \\
45.23 / 0.2\end{array}$ & $\begin{array}{l}26.50 / 0.3 \\
47.46 / 0.3\end{array}$ & $\begin{array}{l}24.67 / 0.4 \\
49.29 / 0.4\end{array}$ \\
\hline & & 2008 & $\mathrm{y}=0.951 \mathrm{e}^{-0.06 \mathrm{x}}$ & 0.666 & --- & --- & $37.54 / 0.1$ & $25.99 / 0.2$ & $19.23 / 0.3$ & $14.45 / 0.4$ \\
\hline
\end{tabular}


Table S5 Fitting Model and Threshold of PD and Water Quality Variables

\begin{tabular}{|c|c|c|c|c|c|c|c|c|c|c|}
\hline \multirow{2}{*}{$\begin{array}{c}\text { Landscape } \\
\text { metrics }\end{array}$} & \multirow{2}{*}{$\begin{array}{l}\text { Water } \\
\text { quality } \\
\text { variable }\end{array}$} & \multirow{2}{*}{ Year } & \multirow{2}{*}{ Fitting model } & \multirow{2}{*}{$\mathbf{R}^{2}$} & \multicolumn{6}{|c|}{ Threshold } \\
\hline & & & & & $\begin{array}{c}\text { Turning } \\
\text { point }\end{array}$ & Standard I & Standard II & Standard III & Standard IV & Standard V \\
\hline \multirow{9}{*}{ PD } & \multirow{3}{*}{ DO } & 2000 & $\begin{array}{c}y=-27.41 x^{2}+22.61 x+ \\
3.604\end{array}$ & 0.355 & $0.41 / 8.27$ & $\begin{array}{l}0.25 / 7.5 \\
0.58 / 7.5\end{array}$ & $\begin{array}{l}0.70 / 6 \\
0.13 / 6\end{array}$ & $\begin{array}{l}0.07 / 5 \\
0.76 / 5\end{array}$ & --- & --- \\
\hline & & 2004 & $\begin{array}{c}y=6.816 x^{2}-14.49 x \\
+13.49\end{array}$ & 0.216 & $1.06 / 5.79$ & $\begin{array}{l}0.56 / 7.5 \\
1.57 / 7.5\end{array}$ & $\begin{array}{l}0.74 / 6 \\
1.39 / 6\end{array}$ & --- & --- & --- \\
\hline & & 2008 & $\begin{array}{c}y=0.536 x^{2}+2.390 x \\
+3.589\end{array}$ & 0.20 & --- & $1.27 / 7.5$ & $0.85 / 6$ & $0.53 / 5$ & --- & --- \\
\hline & \multirow{3}{*}{$\mathrm{NH}_{3}-\mathrm{N}$} & 2000 & $\begin{array}{c}y=121.7 x^{2}-114 x+ \\
27.04\end{array}$ & 0.532 & $0.47 / 0.34$ & --- & $\begin{array}{l}0.43 / 0.5 \\
0.51 / 0.5\end{array}$ & $\begin{array}{l}0.40 / 1 \\
0.54 / 1\end{array}$ & $\begin{array}{l}0.37 / 1.5 \\
0.57 / 1.5\end{array}$ & $\begin{array}{l}0.35 / 2 \\
0.59 / 2\end{array}$ \\
\hline & & 2004 & $y=-4.101 x+7.263$ & 0.399 & --- & --- & $1.65 / 0.5$ & $1.53 / 1$ & $1.41 / 1.5$ & $1.28 / 2$ \\
\hline & & 2008 & $y=3.001 e^{-1.36 x}$ & 0.226 & --- & --- & $1.32 / 0.5$ & $0.81 / 1$ & $0.51 / 1.5$ & $0.30 / 2$ \\
\hline & \multirow{3}{*}{ Oils } & 2000 & $\begin{array}{c}y=1.55 x^{2}-1.526 x+ \\
0.404\end{array}$ & 0.737 & $0.49 / 0.03$ & \multicolumn{3}{|c|}{$\begin{array}{l}0.38 / 0.05 \\
0.61 / 0.05\end{array}$} & --- & --- \\
\hline & & 2004 & $\begin{array}{c}y=0.052 x^{2}-0.212 x \\
+0.243\end{array}$ & 0.333 & $2.04 / 0.03$ & \multicolumn{3}{|c|}{$\begin{array}{l}1.37 / 0.05 \\
2.71 / 0.05\end{array}$} & --- & --- \\
\hline & & 2008 & $\begin{array}{c}y=0.024 x^{2}-0.127 x \\
+0.168\end{array}$ & 0.252 & $2.65 / 0$ & \multicolumn{3}{|c|}{$\begin{array}{l}1.20 / 0.05 \\
4.09 / 0.05\end{array}$} & --- & --- \\
\hline
\end{tabular}


Table S6 Fitting Model and Threshold of ED and Water Quality Variables

\begin{tabular}{|c|c|c|c|c|c|c|c|c|c|c|}
\hline \multirow{2}{*}{$\begin{array}{c}\text { Landscape } \\
\text { metrics }\end{array}$} & \multirow{2}{*}{$\begin{array}{c}\text { Water } \\
\text { quality } \\
\text { variable }\end{array}$} & \multirow{2}{*}{ Year } & \multirow{2}{*}{ Fitting model } & \multirow{2}{*}{$\mathbf{R}^{2}$} & \multicolumn{6}{|c|}{ Threshold } \\
\hline & & & & & $\begin{array}{c}\text { Turning } \\
\text { point }\end{array}$ & Standard I & $\begin{array}{c}\text { Standard } \\
\text { II }\end{array}$ & Standard III & Standard IV & $\begin{array}{c}\text { Standard } \\
\text { V }\end{array}$ \\
\hline \multirow{15}{*}{ ED } & \multirow{3}{*}{ CODMn } & 2000 & $y=0.065 x^{2}-2.436 x+27.46$ & 0.579 & $18.74 / 4.64$ & --- & --- & $\begin{array}{l}14.16 / 6 \\
23.32 / 6\end{array}$ & $\begin{array}{l}9.66 / 10 \\
27.82 / 10\end{array}$ & --- \\
\hline & & 2004 & $\begin{array}{c}y=0.003 x^{2}-0.421 x+ \\
16.058\end{array}$ & 0.706 & $70.17 / 1.28$ & --- & $\begin{array}{l}40.10 / 4 \\
100.23 / 4\end{array}$ & $\begin{array}{l}30.54 / 6 \\
109.80 / 6\end{array}$ & $\begin{array}{l}16.28 / 10 \\
124.06 / 10\end{array}$ & --- \\
\hline & & 2008 & $\begin{array}{c}y=0.004 x^{2}-0.392 x+ \\
13.93\end{array}$ & 0.605 & $49 / 4.33$ & --- & --- & $\begin{array}{l}28.54 / 6 \\
69.46 / 6\end{array}$ & $\begin{array}{l}11.34 / 10 \\
86.66 / 10\end{array}$ & --- \\
\hline & \multirow{3}{*}{ BOD } & 2000 & $\begin{array}{c}y=0.115 x^{2}-4.132 x+ \\
39.42\end{array}$ & 0.459 & $17.97 / 2.30$ & \multicolumn{2}{|c|}{$\begin{array}{l}15.51 / 3 \\
20.43 / 3\end{array}$} & $\begin{array}{l}14.13 / 4 \\
21.81 / 4\end{array}$ & $\begin{array}{l}12.30 / 6 \\
23.64 / 6\end{array}$ & $\begin{array}{l}9.79 / 10 \\
26.15 / 10\end{array}$ \\
\hline & & 2004 & $\begin{array}{c}y=0.007 x^{2}-0.712 x+ \\
18.11\end{array}$ & 0.651 & $50.86 / 0.005$ & \multicolumn{2}{|c|}{$30.17 / 3$} & $\begin{array}{l}26.97 / 4 \\
74.75 / 4\end{array}$ & $\begin{array}{l}21.59 / 6 \\
80.12 / 6\end{array}$ & $\begin{array}{l}13.07 / 10 \\
88.65 / 10\end{array}$ \\
\hline & & 2008 & $\begin{array}{c}y=0.003 x^{2}-0.212 x+ \\
7.368\end{array}$ & 0.363 & $35.33 / 3.62$ & \multicolumn{2}{|c|}{$40.67 / 3$} & $\begin{array}{l}24.12 / 4 \\
46.55 / 4\end{array}$ & --- & --- \\
\hline & \multirow{3}{*}{$\mathrm{NH}_{3}-\mathrm{N}$} & 2000 & $\begin{array}{c}y=0.109 x^{2}-3.818 x+ \\
33.51\end{array}$ & 0.444 & $17.51 / 0.08$ & --- & $\begin{array}{l}15.54 / 0.5 \\
19.49 / 0.5\end{array}$ & $\begin{array}{l}14.60 / 1 \\
20.43 / 1\end{array}$ & $\begin{array}{l}13.90 / 1.5 \\
21.13 / 1.5\end{array}$ & $\begin{array}{l}13.31 / 2 \\
21.72 / 2\end{array}$ \\
\hline & & 2004 & $\begin{array}{c}y=0.004 x^{2}-0.433 x+ \\
9.755\end{array}$ & 0.675 & --- & --- & $\begin{array}{l}29.31 / 0.5 \\
78.94 / 0.5\end{array}$ & $\begin{array}{l}26.91 / 1 \\
81.34 / 1\end{array}$ & $\begin{array}{l}24.70 / 1.5 \\
83.55 / 1.5\end{array}$ & $\begin{array}{l}22.65 / 2 \\
85.60 / 2\end{array}$ \\
\hline & & 2008 & $y=-0.041 x+1.907$ & 0.479 & --- & --- & $34.31 / 0.5$ & $22.12 / 1$ & $9.93 / 1.5$ & --- \\
\hline & \multirow{3}{*}{ Oils } & 2000 & $\begin{array}{c}y=0.0014 x^{2}-0.0495 x+ \\
0.4796\end{array}$ & 0.622 & $17.68 / 0.04$ & \multicolumn{3}{|c|}{$\begin{array}{l}15.30 / 0.05 \\
20.06 / 0.05\end{array}$} & --- & --- \\
\hline & & 2004 & $\begin{array}{c}y=0.0004 x^{2}-0.0218 x+ \\
0.3319\end{array}$ & 0.398 & $27.25 / 0.04$ & \multicolumn{3}{|c|}{$\begin{array}{l}21.10 / 0.05 \\
33.10 / 0.05\end{array}$} & --- & --- \\
\hline & & 2008 & $\begin{array}{c}y=0.0002 x^{2}-0.0137 x+ \\
0.2388\end{array}$ & 0.429 & $28.58 / 0.04$ & \multicolumn{3}{|c|}{$\begin{array}{l}23.08 / 0.05 \\
34.08 / 0.05\end{array}$} & --- & --- \\
\hline & \multirow{3}{*}{$\mathrm{P}$} & 2000 & $\begin{array}{c}y=0.011 x^{2}-0.390 x+ \\
3.485\end{array}$ & 0.515 & $17.73 / 0.03$ & --- & $\begin{array}{l}15.17 / 0.1 \\
20.28 / 0.1\end{array}$ & $\begin{array}{l}13.78 / 0.2 \\
21.68 / 0.2\end{array}$ & $\begin{array}{l}12.76 / 0.3 \\
22.70 / 0.3\end{array}$ & $\begin{array}{l}11.91 / 0.4 \\
23.54 / 0.4\end{array}$ \\
\hline & & 2004 & $\begin{array}{c}y=-0.0009 x^{2}+0.0053 x+ \\
0.9351\end{array}$ & 0.536 & $2.95 / 0.94$ & --- & $33.55 / 0.1$ & $31.68 / 0.2$ & $29.67 / 0.3$ & $27.51 / 0.4$ \\
\hline & & 2008 & $y=0.510 e^{-0.043 x}$ & 0.546 & --- & --- & $37.89 / 0.1$ & $21.77 / 0.2$ & $12.34 / 0.3$ & --- \\
\hline
\end{tabular}


Table S7 Fitting Model and Threshold of COHESION and Water Quality Variables

\begin{tabular}{|c|c|c|c|c|c|c|c|c|c|c|}
\hline \multirow{2}{*}{$\begin{array}{c}\text { Landscape } \\
\text { metrics }\end{array}$} & \multirow{2}{*}{$\begin{array}{c}\text { Water } \\
\text { quality } \\
\text { variable }\end{array}$} & \multirow{2}{*}{ Year } & \multirow{2}{*}{ Fit model } & \multirow{2}{*}{$\mathbf{R}^{2}$} & \multicolumn{6}{|c|}{ Threshold } \\
\hline & & & & & $\begin{array}{c}\text { Turning } \\
\text { point }\end{array}$ & $\begin{array}{c}\text { Standard } \\
\text { I }\end{array}$ & $\begin{array}{c}\text { Standard } \\
\text { II }\end{array}$ & $\begin{array}{c}\text { Standard } \\
\text { III }\end{array}$ & $\begin{array}{c}\text { Standard } \\
\text { IV }\end{array}$ & $\begin{array}{c}\text { Standard } \\
\text { V }\end{array}$ \\
\hline \multirow{12}{*}{ COHESION } & \multirow{3}{*}{ DO } & 2000 & $\begin{array}{c}y=-0.0196 x^{2}+ \\
3.2914 x- \\
129.4025\end{array}$ & 0.250 & $83.97 / 8.78$ & $\begin{array}{l}92.04 / 7.5 \\
75.89 / 7.5\end{array}$ & $\begin{array}{l}95.87 / 6 \\
72.06 / 6\end{array}$ & $\begin{array}{l}70.08 / 5 \\
97.85 / 5\end{array}$ & --- & --- \\
\hline & & 2004 & $\begin{array}{c}y=-0.1038 x^{2}+ \\
20.1488 x- \\
969.8409\end{array}$ & 0.370 & $97.06 / 7.94$ & $\begin{array}{l}95.00 / 7.5 \\
99.11 / 7.5\end{array}$ & $\begin{array}{l}92.74 / 6 \\
101.38 / 6\end{array}$ & $\begin{array}{l}91.74 / 5 \\
102.38 / 5\end{array}$ & --- & --- \\
\hline & & 2008 & $\begin{array}{c}y=0.0982 x^{2}- \\
17.9365 x+ \\
822.8967\end{array}$ & 0.310 & $91.33 / 3.86$ & $\begin{array}{l}97.42 / 7.5 \\
85.24 / 7.5\end{array}$ & $\begin{array}{l}96.00 / 6 \\
86.66 / 6\end{array}$ & $\begin{array}{l}94.74 / 5 \\
87.92 / 5\end{array}$ & --- & --- \\
\hline & \multirow{3}{*}{$\mathrm{COD}_{\mathrm{Mn}}$} & 2000 & $\begin{array}{c}y=0.0347 x^{2}- \\
5.9198 x+ \\
256.9296\end{array}$ & 0.352 & $85.30 / 4.45$ & --- & --- & $\begin{array}{l}91.98 / 6 \\
78.62 / 6\end{array}$ & $\begin{array}{l}72.65 / 10 \\
97.95 / 10\end{array}$ & --- \\
\hline & & 2004 & $\begin{array}{c}y=0.2797 x^{2}- \\
53.5199 x+ \\
2,565.5990\end{array}$ & 0.470 & $95.67 / 5.38$ & --- & --- & $\begin{array}{l}94.18 / 6 \\
97.17 / 6\end{array}$ & $\begin{array}{l}91.61 / 10 \\
99.74 / 10\end{array}$ & --- \\
\hline & & 2008 & $\begin{array}{c}y=-0.1495 x^{2}+ \\
27.3647 x- \\
1,241.4196\end{array}$ & 0.409 & $91.52 / 10.80$ & --- & $\begin{array}{l}98.27 / 4 \\
84.78 / 4\end{array}$ & $\begin{array}{l}97.19 / 6 \\
85.86 / 6\end{array}$ & $\begin{array}{l}89.21 / 10 \\
93.83 / 10\end{array}$ & --- \\
\hline & \multirow{3}{*}{ BOD } & 2000 & $\begin{array}{c}y=0.0727 x^{2}- \\
12.5159 x+ \\
539.9416\end{array}$ & 0.296 & $85.73 / 3.47$ & \multicolumn{2}{|c|}{$\begin{array}{l}81.19 / 3 \\
90.97 / 3\end{array}$} & $\begin{array}{l}79.94 / 4 \\
92.25 / 4\end{array}$ & $\begin{array}{l}94.15 / 6 \\
78.01 / 6\end{array}$ & $\begin{array}{l}97.04 / 10 \\
75.12 / 10\end{array}$ \\
\hline & & 2004 & $\begin{array}{c}y=0.4215 x^{2}- \\
80.3769 x+ \\
3,835.2014\end{array}$ & 0.448 & $95.35 / 3.38$ & \multicolumn{2}{|c|}{$95.35 / 3$} & $\begin{array}{l}94.14 / 4 \\
96.56 / 4\end{array}$ & $\begin{array}{l}92.86 / 6 \\
97.84 / 6\end{array}$ & $\begin{array}{l}91.39 / 10 \\
99.31 / 10\end{array}$ \\
\hline & & 2008 & $\begin{array}{l}y=-0.063 x^{2}+ \\
11.61 x-527.1\end{array}$ & 0.204 & $91.72 / 5.36$ & \multicolumn{2}{|c|}{$\begin{array}{l}97.83 / 3 \\
85.62 / 3\end{array}$} & $\begin{array}{l}96.36 / 4 \\
87.09 / 4\end{array}$ & --- & --- \\
\hline & \multirow{3}{*}{$\mathrm{NH}_{3}-\mathrm{N}$} & 2000 & $\begin{array}{c}y=0.0770 x^{2}- \\
13.2506 x+ \\
568.8163\end{array}$ & 0.320 & --- & --- & $\begin{array}{l}81.29 / 0.5 \\
90.80 / 0.5\end{array}$ & $\begin{array}{l}80.65 / 1 \\
91.44 / 1\end{array}$ & $\begin{array}{l}80.07 / 1.5 \\
92.01 / 1.5\end{array}$ & $\begin{array}{l}79.55 / 2 \\
92.53 / 2\end{array}$ \\
\hline & & 2004 & $\begin{array}{c}y=0.2351 x^{2}- \\
44.8634 x+ \\
2,141.1582\end{array}$ & 0.404 & $95.41 / 0.87$ & --- & --- & $\begin{array}{l}94.68 / 1 \\
96.15 / 1\end{array}$ & $\begin{array}{l}93.78 / 1.5 \\
97.05 / 1.5\end{array}$ & $\begin{array}{l}93.22 / 2 \\
97.60 / 2\end{array}$ \\
\hline & & 2008 & $\begin{array}{c}y=-0.0427 x^{2}+ \\
7.8664 x-\end{array}$ & 0.417 & $92.11 / 5.36$ & --- & $\begin{array}{l}97.08 / 0.5 \\
87.15 / 0.5\end{array}$ & $\begin{array}{l}96.26 / 1 \\
88.05 / 1\end{array}$ & $\begin{array}{l}89.89 / 1.5 \\
94.42 / 1.5\end{array}$ & --- \\
\hline
\end{tabular}


Appendices

\begin{tabular}{|c|c|c|c|c|c|c|c|c|c|c|}
\hline \multirow{6}{*}{$\begin{array}{c}\text { Landscape } \\
\text { metrics }\end{array}$} & \multirow{3}{*}{$\begin{array}{c}\text { Water } \\
\text { quality } \\
\text { variable }\end{array}$} & \multirow{2}{*}{ Year } & \multirow{2}{*}{ Fit model } & \multirow{2}{*}{$\mathbf{R}^{2}$} & \multicolumn{6}{|c|}{ Threshold } \\
\hline & & & & & $\begin{array}{c}\text { Turning } \\
\text { point }\end{array}$ & $\begin{array}{c}\text { Standard } \\
\text { I }\end{array}$ & $\begin{array}{c}\text { Standard } \\
\text { II }\end{array}$ & $\begin{array}{c}\text { Standard } \\
\text { III }\end{array}$ & $\begin{array}{c}\text { Standard } \\
\text { IV }\end{array}$ & $\begin{array}{c}\text { Standard } \\
\text { V }\end{array}$ \\
\hline & & & 360.7442 & & & & & & & \\
\hline & \multirow{3}{*}{$\mathrm{P}$} & 2000 & $\begin{array}{c}y=0.0073 x^{2}- \\
1.2557 x+ \\
53.9204\end{array}$ & 0.348 & --- & --- & $\begin{array}{l}81.06 / 0.1 \\
90.96 / 0.1\end{array}$ & $\begin{array}{l}79.83 / 0.2 \\
92.19 / 0.2\end{array}$ & $\begin{array}{l}93.21 / 0.3 \\
78.80 / 0.3\end{array}$ & $\begin{array}{l}94.11 / 0.4 \\
77.91 / 0.4\end{array}$ \\
\hline & & 2004 & $\begin{array}{c}y=0.0367 x^{2}- \\
7.0476 x+ \\
338.9668\end{array}$ & 0.605 & $96.12 / 0.26$ & --- & --- & --- & $\begin{array}{l}95.05 / 0.3 \\
97.19 / 0.3\end{array}$ & $\begin{array}{l}94.15 / 0.4 \\
98.09 / 0.4\end{array}$ \\
\hline & & 2008 & $\begin{array}{c}y=-0.0079 x^{2}+ \\
1.4477 x- \\
66.3458\end{array}$ & 0.421 & $91.63 / 0.31$ & --- & $\begin{array}{l}97.30 / 0.1 \\
86.89 / 0.1\end{array}$ & $\begin{array}{l}95.88 / 0.2 \\
88.30 / 0.2\end{array}$ & $\begin{array}{l}90.81 / 0.3 \\
93.37 / 0.3\end{array}$ & --- \\
\hline
\end{tabular}


Table S8 Fitting Model and Threshold of SHAPE_AM and Water Quality Variables

\begin{tabular}{|c|c|c|c|c|c|c|c|c|c|c|}
\hline \multirow{2}{*}{$\begin{array}{c}\text { Landscape } \\
\text { metrics }\end{array}$} & \multirow{2}{*}{$\begin{array}{l}\text { Water } \\
\text { quality } \\
\text { variable }\end{array}$} & \multirow{2}{*}{ Year } & \multirow{2}{*}{ Fitting model } & \multirow{2}{*}{$\mathbf{R}^{2}$} & \multicolumn{6}{|c|}{ Threshold } \\
\hline & & & & & $\left|\begin{array}{c}\text { Turning } \\
\text { point }\end{array}\right|$ & Standard I & Standard II & StandardIII & Standard IV & Standard V \\
\hline \multirow{9}{*}{ SHAPE_AM } & \multirow{3}{*}{$\mathrm{COD}_{\mathrm{Mn}}$} & 2000 & $\begin{array}{c}y=2.23 x^{2}-19.09 \\
x+46.32\end{array}$ & 0.435 & $4.28 / 5.47$ & --- & --- & $\begin{array}{l}3.79 / 6 \\
4.77 / 6\end{array}$ & $\begin{array}{l}2.86 / 10 \\
5.71 / 10\end{array}$ & --- \\
\hline & & 2004 & $\begin{array}{c}y=0.246 x^{2}- \\
3.969 x+20.03\end{array}$ & 0.371 & $8.07 / 4.02$ & --- & --- & $\begin{array}{l}5.23 / 6 \\
10.90 / 6\end{array}$ & $\begin{array}{l}3.14 / 10 \\
13.00 / 10\end{array}$ & --- \\
\hline & & 2008 & $\begin{array}{c}y=-0.106 x^{2}- \\
0.342 x+11.15\end{array}$ & 0.312 & --- & --- & $6.76 / 4$ & $5.54 / 6$ & $2.06 / 10$ & --- \\
\hline & \multirow{3}{*}{ Oils } & 2000 & $\begin{array}{c}y=0.043 x^{2}- \\
0.366 x+0.820\end{array}$ & 0.408 & $4.256 / 0.04$ & \multicolumn{3}{|c|}{$\begin{array}{l}3.80 / 0.05 \\
4.71 / 0.05\end{array}$} & --- & --- \\
\hline & & 2004 & $\begin{array}{l}y=0.024 x^{2}- \\
0.222 x+0.55\end{array}$ & 0.323 & $4.63 / 0.04$ & \multicolumn{3}{|c|}{$\begin{array}{l}3.88 / 0.05 \\
5.37 / 0.05\end{array}$} & --- & --- \\
\hline & & 2008 & $\begin{array}{c}y=0.010 x^{2}- \\
0.113 x+0.345\end{array}$ & 0.249 & $5.65 / 0.03$ & \multicolumn{3}{|c|}{$\begin{array}{l}4.09 / 0.05 \\
7.21 / 0.05\end{array}$} & --- & --- \\
\hline & \multirow{3}{*}{$\mathrm{P}$} & 2000 & $\begin{array}{c}y=0.353 x^{2}- \\
2.954 x+6.318\end{array}$ & 0.332 & $4.19 / 0.14$ & --- & --- & $\begin{array}{l}3.77 / 0.2 \\
4.60 / 0.2\end{array}$ & $\begin{array}{l}3.51 / 0.3 \\
4.86 / 0.3\end{array}$ & $\begin{array}{l}3.32 / 0.4 \\
5.05 / 0.4\end{array}$ \\
\hline & & 2004 & $\begin{array}{c}y=0.0139 x^{2}- \\
0.3533 x+ \\
1.7579\end{array}$ & 0.295 & --- & --- & $\begin{array}{l}6.21 / 0.1 \\
19.21 / 0.1\end{array}$ & $\begin{array}{c}5.68 / 0.2 \\
19.74 / 0.2\end{array}$ & $\begin{array}{c}5.18 / 0.3 \\
20.23 / 0.3\end{array}$ & $\begin{array}{c}4.72 / 0.4 \\
20.70 / 0.4\end{array}$ \\
\hline & & 2008 & $y=0.623 e^{-0.26 x}$ & 0.240 & --- & --- & $7.04 / 0.1$ & $4.37 / 0.2$ & $2.81 / 0.3$ & --- \\
\hline
\end{tabular}




\section{Curriculum Vitae}

\section{PERSONAL DATA}

Name: Yi Li

Date of Birth: $23^{\text {th } J u n e, ~} 1987$

Place of Birth: Changsha, P. R. China
Gender: Female

Marital Status: Single

\section{EDUCATION}

Ph.D. Oct. 2012--Feb. 2016 Cartography, GIS and Remote Sensing Department, Institute of Geography, Georg-August University of Goettingen, Germany

M.S. Sept. 2010--June 2012 School of the Environment, Nanjing University, China

B.A. Sept. 2005--Aug. 2009 College of Environmental Science and Engineering, Guilin University of Technology, China

\section{PUBLICATIONS \& PREPARING MANUSCRIPTS}

2016 Li, Y. F., Li, Y., Wu, W. Threshold and resilience management of coupled urbanization and water environmental system in the rapidly changing coastal region. Environmental Pollution. (Accepted, Online available) doi:10.1016/j.envpol.2015.08.042

2015 Li, Y., Li, Y. F., Qureshi, S., Kappas, M., Hubacek, K. On the relationship between landscape ecological patterns and water quality across gradient zones of rapid urbanization in coastal China. Ecological Modelling. 318:100-108.

2015 Li, Y., Li, Y. F., Kappas, M. Resilience assessment of urban coupled humanenvironment systems: an integrated approach of catastrophe theory and adaptive cycle. (Under review: Regional Environmental Change)

2016 Li, Y., Fan, P. L., Kappas, M. Urban social-ecological resilience assessment: a catastrophe-based framework with political underpinnings. (Preparing to submit)

2016 Li, Y., Degener, J., Li, Y. F., Gaudreau, M., Kappas, M. Resilience under rapid urbanization: surface water quality and adaptive capacity in the urban development policy of Lianyungang, China. (Preparing to submit) 